\title{
Transition towards a renewable European electricity system
}

Citation for published version (APA):

Falcan, I. E. (2021). Transition towards a renewable European electricity system. [Doctoral Thesis, Maastricht University]. ProefschriftMaken. https://doi.org/10.26481/dis.20210831if

Document status and date:

Published: 01/01/2021

DOI:

10.26481/dis.20210831if

Document Version:

Publisher's PDF, also known as Version of record

\section{Please check the document version of this publication:}

- A submitted manuscript is the version of the article upon submission and before peer-review. There can be important differences between the submitted version and the official published version of record.

People interested in the research are advised to contact the author for the final version of the publication, or visit the DOI to the publisher's website.

- The final author version and the galley proof are versions of the publication after peer review.

- The final published version features the final layout of the paper including the volume, issue and page numbers.

Link to publication

\footnotetext{
General rights rights.

- You may freely distribute the URL identifying the publication in the public portal. please follow below link for the End User Agreement:

www.umlib.nl/taverne-license

Take down policy

If you believe that this document breaches copyright please contact us at:

repository@maastrichtuniversity.nl

providing details and we will investigate your claim.
}

Copyright and moral rights for the publications made accessible in the public portal are retained by the authors and/or other copyright owners and it is a condition of accessing publications that users recognise and abide by the legal requirements associated with these

- Users may download and print one copy of any publication from the public portal for the purpose of private study or research.

- You may not further distribute the material or use it for any profit-making activity or commercial gain

If the publication is distributed under the terms of Article $25 \mathrm{fa}$ of the Dutch Copyright Act, indicated by the "Taverne" license above, 


\section{Transition towards a renewable European electricity system}

\section{DISSERTATION}

to obtain the degree of Doctor at Maastricht University, on the authority of the Rector Magnificus Prof. Dr. Rianne M. Letschert, in accordance with the decision of the Board of Deans, to be defended in public on Tuesday, 31st August 2021, at 13:00 hours

by

\section{Iulia Elena Falcan}


Copyright @Iulia Elena Falcan, 2021

ISBN: 978-94-6423-340-7

Cover Design: Bregje Jaspers

Publisher: ProefschriftMaken, Vianen, the Netherlands 


\section{Supervisors:}

Dr. Thomas Ziesemer, Maastricht University

Dr. Adriaan van Zon, Maastricht University

\section{Assessment Committee:}

Prof. Dr. Pierre Mohnen (Chairman)

Prof. Dr. Sabine Fuss, Humboldt University of Berlin

Prof. Dr. Kornelis Blok, Technical University of Delft

Prof. Dr. Olaf Sleijpen 


\section{Acknowledgments}

There are as many ways of pursuing a phd degree as there are doctoral candidates. Despite the common experiences of naïve enthusiasm, humility and self-doubt, each phd journey faces unique ups and downs. In the case of the work that led to this book, there is a wealth of individuals who helped me navigate the difficult parts and provided me with encouragement, support and trust in reaching this final moment of my phd journey. In the following pages, I would like to take the opportunity to show them my gratitude, as much as words allow.

First and certainly foremost, I would like to thank my supervisors: Adriaan van Zon and Thomas Ziesemer. Thomas Ziesemer provided me with much-needed cautious enthusiasm in my early days of research idea development, by steering me towards research topics that are both academically interesting and socially relevant. Both my work and myself have benefitted tremendously from his econometrics rigor and expertise on energy economics. Adriaan van Zon was very generous in sharing his modelling wisdom and reflections on the bigger picture of my research. Beyond this, I am extremely grateful for his persistent dedication to helping me bring much more clarity to my thinking and writing. If the reader takes any pleasure in the clarity of the following pages, it is in very large part due to him. More importantly, I will forever be thankful to both of them for giving me the intellectual freedom to pursue my research interests, for their scrutiny and sharp eye for detail and for their superhuman amount of patience. I would particularly like to thank them for their generous availability and consistently fast responsiveness to all my questions, and above all, for the unrestricted kindness and encouragements they showed in guiding me towards this final output of my work.

I would also like to show my deepest appreciation for the members of my assessment committee: Prof. Sabine Fuss, Prof. Olaf Sleijpen, Prof. Kornelis Blok, and Prof. Pierre Mohnen, who chaired the committee. I feel genuinely fortunate to have someone with their scientific expertise and achievements providing me with valuable feedback. As someone who wishes to continue her career in an environment that is closer to informing energy policy-making, I am deeply inspired by their achievements both in academia and 
in distinguished policy research institutions. Considering their multiple affiliations and correspondingly busy schedules, I am very grateful for the time they took to discuss my thesis.

It takes a village to raise a child - and a whole institute to see a phd student through to defense day! I would like to thank Robin, Mindel and Tatiana for always showing me genuine care and giving me much-needed constructive directions in the early days of the phd program and anytime else I needed it. I am very thankful to Ad, Herman, Mourik-Jan and Marc for consistently getting back to me seconds after I reached out for help with library access, technical or finance related issues. I would like to thank Serdar Türkeli and René Kemp for their generosity in sharing their expertise on sustainability topics, every time I reached out to them.

In parallel to my phd research, I was very fortunate to be involved in several teaching and project activities. All these experiences made my time as a phd student much more exciting and richer than I could have imagined. I am very grateful to Howard, Lutz and Diego for giving me the opportunity to be involved in several science communication projects. I have thoroughly enjoyed working with and learning from you. Sueli, thank you for the occasional French chats and the many impromptu environment-related discussions. I am also very thankful to Lutz and Denis de Crombrugghe for the many teaching opportunities in the MPP program. These experiences opened up a completely new world for me that I hope I will continue to be involved in.

Eveline: you are not only the backbone of the institute - you are its heart. Thank you for always having an open door, a kind word or a healthy hug, even for the most minor situations. I've often wondered where you take the energy and emotional strength from to be so present and active, whenever anyone has a serious issue - issue that generally goes very, very far beyond your official jurisdiction. Thank you for always being available for any question, no matter how minor, and especially for your sixth sense of knowing to say the right thing at the right time.

Thinking back at my early phd days, I realize how very lucky I was to be part of a particularly tight and socially active cohort. Especially during the first year, the atmosphere that developed from our regular interactions in-class - and out - is something that I will forever think about very fondly. Thank you to Alison, Ayla, Charlotte, Elisa, Elise, Elvis, Hassen, Jenny, Mary, Mira, Mueid, Tamer and Youssef.

With time, I met more and more people that made my years in Maastricht memorable: I had the best office mates anyone could wish for - Eva, Juan-Carlos, Sheng, Raquel, Nga, Davina, Tamara and Cheng. It was a great joy to spend my time at the different offices with you all. Thank you to Francesca, Iman, Ortrun, Andrea, Bea, Michelle, Paula, Danilo, Tobias and Giacomo for all the moments in - and outside the institute. I feel very proud that, even as we are all gradually leaving Maastricht, a small number of 
us can relocate the MERIT mojo in different parts of the world - or of the Netherlands.

A special mention goes to the WLC - the initially ad-hoc lunch group now transformed into instant world news platform/personalized economics search engine/real-time photo album. Thank you for keeping the MERIT spirit on, I'm always looking forward to the topic of the week!

A paraphrased quote attributed to Maya Angelou says that you don't remember people by what they said, or did - but by how they made you feel. Sadly, I think the meaning of this is only truly understood after someone's passing. To me, there are two people in connection to whom this quote strikes deep chords. The dedication on the first page of this book is inspired in large part by them. I am grateful to Ibrahima for his contagious love of life - shown in everything from political debates, deep work focus, dancing and greeting everyone with indiscriminate big smiles. I am very thankful to Eddy for greeting students - especially confused first-year ones - with understanding and encouraging smiles, for his patience in constructively challenging less-than-fullybaked arguments and for his always making time for a quick impromptu chat. Some of my first interactions at the UNU-MERIT were with him and made a big difference in how I approached my $\mathrm{PhD}$ experience.

This final section is dedicated to my family. I am very thankful to my parents for instilling in me and my sister a deep appreciation for learning, at a very young age. I grew up knowing for a fact that, with hard work and strong commitment, I could build whatever life I chose to. This may sound like an empty statement now but, growing up in an Eastern European country, in its early days of transitioning from a communist regime to ad-hoc capitalism, individual self-determination was more of an abstract idea than a default reality. I am grateful to my father for showing me the power of perseverance and hard work and I am grateful to my mother for her patient encouragement and support for my academic interests. I would like to thank my parents for all their hard work and sacrifices, so that their children can have an easier, happier and fulfilled life. Vã mulţumesc si vã iubesc.

The second most important person in my life is my sister. Ana, I have been looking up to you for as long as I can remember. I became excited about school years before attending, because I'd see you coming home with high grades and big smiles. You are the best big sister anyone could wish for. Thank you also for the new extended family and for your unconditional love and encouragements.

I do not think there was an exact moment when I became interested in environmental sustainability. It happened as a gradual realization of the fact that I was naturally drawn to this topic in different circumstances. Growing up, I always thought I had many strong academic interests, but no particular passion (anecdotal evidence suggests this is not uncommon among Economics graduates). However, in my university years 
I was finding myself spending more time on news on this topic than on other topics, looking up international policy developments and the main institutional actors in this area. Gradually, by the time I applied to the UNU-MERIT phd program, my interest in environmental sustainability - and particularly in the transition to a less polluting energy system - had eclipsed all other options for future careers and I was experiencing it as part of my identity. I now cannot see my professional life in any other field. Thinking back to my early and confused university years, I feel very fortunate to have found this much clarity in my professional ambitions. This was a gradual but very organic process that made me see the answers to some of my life's big decisions very plainly.

My coming to Maastricht made another life's big decision very clear to me. In the early days of my phd, I met the person who would become my life partner. Just like above, I do not remember the exact moment this decision became clear to me - life just began to be easier and more fun with every moment we spent together. Iman, I want to thank you for everything you've put up with me in these past years, for believing in me more than I sometimes believed in myself, for pushing me to always aim higher. With you, the occasional low moments seemed half as low, and the highs - way higher than I could've celebrated on my own. Thank you for everything!

For me, this is the end of a long, winding and beyond-enriching journey. Thinking back to my teenage self, I could not have dreamt of having the opportunity to grow academically and especially personally in a similar environment. I hope that these pages managed to do even a slight bit of justice to everyone who has contributed to my reaching this step in my career and personal journey. 
To anyone who inspires those around them to want to do and be better 


\section{Summary}

The research presented in this dissertation identifies and addresses part of the challenges ahead of the energy transition in the European Union. More specifically, it looks at how the increasing share of power generated by variable renewable energy (VRE) technologies affects the existing power system and the electricity markets, and discusses the technological and economic implications of a fully renewable European power system.

Chapter Two puts forward an analytical framework to understand how different energy generation and balancing technologies can contribute to a $100 \%$ renewable European power system. The first part investigates whether different power technologies -of generation, storage and transmission - behave as either complements or substitutes in a decarbonized European power system. Having a clear understanding of how each energy technology can contribute to a clean power system and how its contribution impacts the contribution of other technologies - by either displacing or supporting it - is crucial to the design of a cost-optimal, clean European power system. The second part zooms in on how these technology and cost interactions change across five scenarios of power trade integration.

This framework emphasizes the importance of policy coordination among member states. As countries increase their reliance on power trade, their optimal energy mixes change - as does the aggregate European optimal energy mix. The findings of this chapter suggests that a cost-optimal European energy system in which power trade is restricted to $25 \%$ of an individual country's demand has a very different energy technology mix than a European power system where trade among member states is unrestricted. Understanding the cost and technology implications of these different scenarios provides a starting point for discussing the importance of energy policy coordination among EU member states.

Chapters Three and Four focus on the effects of electricity from VRE on the electricity market. The current electricity markets of most developed countries have been designed decades ago for entirely different energy technology portfolios and market structures. The recent upsurge of intermittent power from VRE technologies has challenged 
the appropriateness of the current electricity market design for a VRE-intensive power system.

One of the challenges which VRE raises for the electricity market refers to its effect on the electricity price and its volatility. More specifically, liberalized power systems function on the microeconomics principle whereby the price is determined by the marginal cost which, in turn, for conventional power technologies, is determined by the fuel price. Since VRE and in particular wind and solar power technologies have zero fuel cost, they have a downward effect on electricity prices, during periods of high wind speed or high solar radiation. In the current design of electricity markets, this makes it difficult for conventional power technologies to remain competitive, even though they are important for the stability of the power grid. On this background, Chapter Three looks at the effects of power generated by VRE on the main variables of interest of the electricity market - i.e. the electricity price and its volatility. The research findings discussed in this Chapter suggest that the volatility of electricity prices is expected to increase, as VRE take up a higher share in the energy mix. However, this effect is mainly due to power generated by wind power plants alone.

Chapter Four looks at the relation between the increasing share of electricity from VRE technologies and the process of integration of the different national power systems into a pan-European system. Over the past few decades, the European agenda of energy policy has been dominated by two main items: the integration of the electricity systems of individual countries into a pan-European electricity system, and the transition to a power system that is less reliant on fossil fuels and more intensive in cleaner, renewable energy resources. These two ambitions have historically been addressed individually, at both national and supra-national European levels - as is also reflected in two separate strands of literature - with different results. Indeed, the literature on the effect of VRE on electricity markets is unambiguous in its findings that an increase in VRE has a downward effect on electricity prices. On the other hand, the literature looking at power trade integration between different national power systems reports mixed results in terms of the effect of increased levels of power trade on electricity prices, finding both positive and negative relations between VRE and electricity price convergence. In Chapter Four it is argued that the two ambitions overlap in many respects and that a clear understanding of the relation between intermittent power generation from VRE and electricity market integration can reveal more efficient ways of pursuing this dual goal. As electricity markets become more integrated and electricity is freely traded among more countries, the price differential between these countries decreases. To this end, Chapter Four develops a framework that looks at these two issues jointly and tackles the following question: what is the effect of intermittent power, generated by VRE, on the process of electricity price convergence? Using data for eight European, the research 
finds that there is an inverted U-shaped relation between VRE and electricity prices convergence, i.e. for very low and very high levels of VRE, the price differential is large, whereas for intermediate levels of VRE, prices tend to converge, thus reducing the price differential. The results point to the fact that an acceleration of interconnector capacity developments is required in order to benefit from the price-reduction effect of VRE, at the European level. Furthermore, increased policy coordination in different countries would mitigate the short-term negative effects of price divergence, e.g. the difference in consumer welfare in different countries, in the context of a pan-European energy system, following from unilateral decision making.

Finally, Chapter Five summarizes the main findings of the research presented in this dissertation and discusses several concluding remarks and implications for European energy policy-making. It also highlights some limitations of the research and points to key areas for future research into the process of the transition towards a clean European power system.

Taken together, the research results presented in this dissertation shed light on several economic and political challenges that the transition to a low-carbon electricity system in Europe is expected to face. These findings aim to contribute to an informed discussion on weighing the different economic, social and environmental implications of the ambitious task ahead of decarbonizing the European power sector. 


\section{Contents}

1 Introduction 1

1.1 Towards a renewable energy future . . . . . . . . . . . . . 1

1.2 Challenges ahead of the energy transition in the EU . . . . . . . 3

1.3 Contribution to existing research and reading guide . . . . . . . . . 5

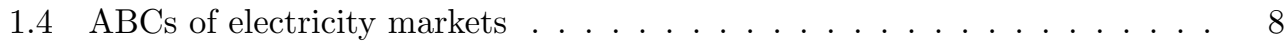

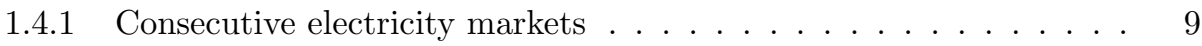

1.4.2 Determinants of the day-ahead electricity price . . . . . . . . 11

1.4.3 Merit-order effect (MoE) . . . . . . . . . . . . . . . . . . 12

1.4.4 Negative day-ahead electricity prices . . . . . . . . . . . 13

2 What are the effects of power trade integration on the energy mixes of different European countries? 15

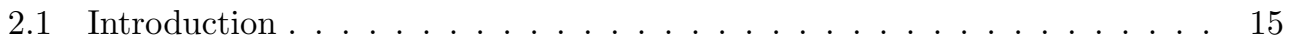

2.2 Overview of options to overcome fluctuating power supply . . . . . . . 19

2.3 Application of optimization in the energy economics literature . . . . . . 24

2.4 Data . . . . . . . . . . . . . . . . . . . 26

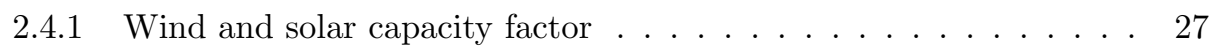

2.4.2 Power demand per country . . . . . . . . . . . . . . . . 32

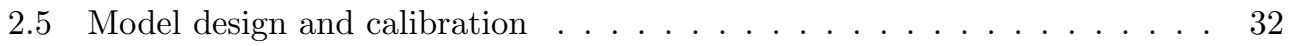

2.5 .1 Model design . . . . . . . . . . . . . . . . 36

2.5.2 Model calibration . . . . . . . . . . . . . . . . . . 37

2.6 Results . . . . . . . . . . . . . . . . . . . . . . . 39

2.6.1 The cost-optimal energy technology portfolio at the aggregate level 40

2.6.2 The energy technology portfolios for individual countries . . . . . . 44

2.7 Aggregate cost and country-level technology mix across integration thresholds 49

2.7.1 The aggregate investment requirements for a European power system across integration thresholds . . . . . . . . . . . . 51

2.7.2 Energy technologies across different integration thresholds . . . . . 52 


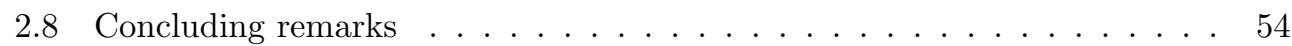

Appendix 2.A Simulation results . . . . . . . . . . . . . 57

3 Effects of renewable energy on electricity price level and variance $\quad 59$

3.1 Introduction . . . . . . . . . . . . . . . . . . . . . 59

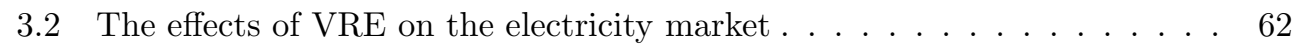

3.3 Data . . . . . . . . . . . . . . . . . . . . . . . . 69

3.4 Model . . . . . . . . . . . . . . . . . . . . . . . . . . 71

3.5 Model results and discussion . . . . . . . . . . . . . . . . 74

3.5.1 Effects of solar and wind power on the level of electricity price . . 74

3.5.2 Effects of solar and wind power on electricity price variance . . . 77

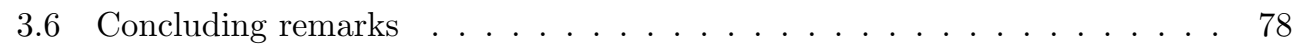

Appendix 3.A Summary statistics of the main variables . . . . . . . . 80

4 Understanding the relation between VRE and electricity price convergence $\quad 83$

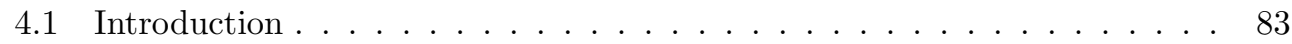

4.2 Literature review . . . . . . . . . . . . . . . . . . . . . 85

4.3 Theoretical model . . . . . . . . . . . . . . . . . . . . . 90

4.3 .1 Case one: single country . . . . . . . . . . . . . . . . 90

4.3 .2 Case Two: two countries . . . . . . . . . . . . . . . . . . 92

4.4 Data . . . . . . . . . . . . . . . . . . . . . . . . 98

4.5 Empirical model . . . . . . . . . . . . . . . . . . . . . . . . . . 101

4.6 Results . . . . . . . . . . . . . . . . . . . . . . 105

4.7 Concluding remarks . . . . . . . . . . . . . . . . . . 110

Appendix 4.A Descriptive statistics of all variables of interest $\ldots \ldots \ldots 112$

Appendix 4.B Results for hour, day-of-the week and month dummies . . . . . 114

Appendix 4.C Robustness test: Instrumental variable regression and Durbin-

Wu-Hausman test for endogeneity . . . . . . . . . . . 116

Appendix 4.D Data coverage in the whole range of the U-shaped relationships 118

5 Conclusions

5.1 Key findings and concluding remarks . . . . . . . . . . . . . . . . . . . 121

5.2 Future research . . . . . . . . . . . . . . . . . . . . . . . . . . . . 124 


\section{List of Tables}

2.1 Summary statistics of hourly capacity factors $(1985-2016) \ldots \ldots$. . . 31

2.2 Summary statistics of hourly electricity demand in 2017 (MWh) . . . . 34

2.3 Summary statistics of the 100 simulations results $\ldots \ldots \ldots \ldots$

3.1 Statistics based on daily data $\ldots \ldots \ldots \ldots \ldots \ldots 71$

3.2 Regression results . . . . . . . . . . . . . . . . . . . 75

3.3 Mean of all variables per bidding zone $\ldots \ldots \ldots \ldots \ldots$

3.4 Number of observations per bidding zone $\ldots \ldots \ldots \ldots$

4.1 Granger-Engle Augmented Dickey Fuller . . . . . . . . . . . . . . . . . . . 104

4.2 Regressions results: cross-sectional coefficient of variation of price as dependent variable $\ldots \ldots \ldots \ldots \ldots \ldots \ldots \ldots$

4.3 Hourly electricity prices per bidding zone (in Euro/MWh) . . . . . . . . 112

4.4 Hourly load distribution per bidding zone (in MW) . . . . . . . . . . . 112

4.5 Distribution of the share of wind power in hourly consumption (in \%) . . 113

4.6 Distribution of the share of solar power in hourly consumption (in \%) . . 113

4.7 Distribution of power trade, as a share in hourly load (in\%) . . . . . 113

4.8 Robustness test: regression with two-stage least squares technique $\ldots . .117$ 


\section{List of Figures}

1.1 Transition towards wind and solar electricity $\ldots \ldots \ldots \ldots$

1.2 The consecutive electricity markets . . . . . . . . . . . . . 10

1.3 Merit order effect . . . . . . . . . . . . . . . . . . . . . . 12

1.4 Merit order effect of wind power on the electricity price $\ldots \ldots \ldots 13$

2.1 Transition towards wind and solar electricity $\ldots \ldots \ldots \ldots$

2.2 Average of hourly capacity factors, per year . . . . . . . . . . . 28

2.3 Average of hourly capacity factors, per calendar month . . . . . . . . . . 29

2.4 Average of hourly capacity factors, per calendar day . . . . . . . . . . 29

2.5 Average of hourly capacity factors, per hour of a day . . . . . . . . 30

2.6 Electricity demand in Spain, Finland, Greece and Germany in year 2017 . 33

2.7 Cost of $100 \%$ renewable European power system _ . . . . . . . . . 41

2.8 European energy technology $\operatorname{mix} \ldots \ldots \ldots \ldots \ldots$

2.9 Wind installed capacity across countries . . . . . . . . . . . 46

2.10 Solar installed capacity across countries . . . . . . . . . . . . 47

2.11 Cost of a fully renewable European power system . . . . . . . . . . . 51

2.12 Country distribution of installed capacity of wind power . . . . . . . . 52

2.13 Country distribution of installed capacity of solar power . . . . . . . . 54

2.14 EST capacity requirements, in gigawatt-hours . . . . . . . . . . . 55

3.1 Global installed capacity of renewable power . . . . . . . . . . . 60

3.2 The effect of residual demand on electricity price variance: the case of a

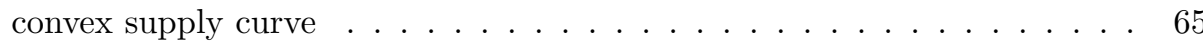

3.3 The effect of residual demand on electricity price variance: the case of a concave-convex supply curve . . . . . . . . . . . . . . 65

3.4 Partial autocorrelation of the electricity price return for different lags . . 72

3.5 Average monthly price per bidding zone in Euros/MWh . . . . . . . . 81

3.6 Average monthly share of electricity generated by wind per bidding zone . 81 
3.7 Average monthly share of electricity generated by solar per bidding zone . 82

3.8 Average monthly demand for electricity per bidding zone in MW . . . . 82

4.1 Cumulative global installed capacity of wind and solar power technologies.

RoW stands for "rest of the world". . . . . . . . . . . . . . . . 84

4.2 The price function $\ldots \ldots \ldots \ldots \ldots$

4.3 The electricity prices of countries A and B . . . . . . . . . . 94

4.4 Price difference between countries A and B . . . . . . . . . . 95

4.5 Price difference of country A and B when trade is restricted . . . . . . 98

4.6 Estimated coefficients for hour dummies in regression 4 of table 4.2. . . . 114

4.7 Estimated coefficients for day-of-week dummies in regression 4 of table 4.2.114

4.8 Estimated coefficients for month dummies in regression 4 of table 4.2. . . 115

4.9 Fitted U-shaped relationships, with multivariate approach . . . . . . . 119

4.10 Fitted U-shaped relationships, with univariate approach . . . . . . . . 119 


\section{Chapter 1}

\section{Introduction}

\subsection{Towards a renewable energy future}

In 2007, the United Nations' Intergovernmental Panel on Climate Change and the American politician and environmentalist Al Gore were awarded the Nobel Peace Prize "for their efforts to build up and disseminate greater knowledge about man-made climate change, and to lay the foundations for the measures that are needed to counteract such change" (Nobel Media (2007)). Eleven years later, William Nordhaus would be awarded the 2018 Nobel Prize in Economics, for "integrating climate change into long-run macroeconomic analysis" (Nobel Media (2019)). ${ }^{1}$

Both developed and developing countries have made great progress in mitigating human-driven climate change between these dates, and continue to do so. Indeed, all signatory countries of the 2015 Paris Agreement - the objective of which is to limit the global temperature increase by the end of this century to well below 2, and closer to 1.5 , degrees Celsius above pre-industrial levels - have committed to become net-zero emitters by 2050. Bhutan and Surinam have already become negative emitters, i.e. they absorb more greenhouse gases (hereafter GHG) than they emit. Sweden has passed laws to become carbon neutral by 2045 and six other countries have announced similar legally binding net-zero targets for 2050.

Most of this progress has been due to the decarbonisation of the electricity sector. Indeed, globally installed capacity of solar and wind power plants has increased more than six times over the 2008 - 2018 period and reached a combined installed capacity of over $1000 \mathrm{GW}$. This corresponds to an increase from $15 \%$ to $45 \%$ in total installed

\footnotetext{
${ }^{1}$ Nordhaus shared the 2018 Nobel Prize in Economics with Paul Romer who was awarded the prize for his work on "integrating technological innovations into long-run macroeconomic analysis" (Nobel Media (2019)).
} 
capacity of renewable energy technologies, over the same period (IRENA (2019b)). In 2018 , solar and wind power technologies accounted for over $50 \%$ of the global increase in installed capacity of all - renewable and non-renewable - power generation technologies (IEA (2019)).

Economic development and emissions of greenhouse gases (GHG) have gone hand in hand since the inception of national power systems. However, the past decade has witnessed a decoupling of the two: GHG emissions have increased at a slower rate than economic growth. This has been driven mainly by gains in energy efficiency and fast drops in the costs of wind and solar power technologies - both forces benefiting from increasing political support. Even so, the electricity sector still accounts for $40 \%$ of energy-related CO2 emissions - and more than a quarter of GHG emissions (Pavarini and Mattion (2019)). At the same time, it is the fastest sector to decrease its reliance on carbon-intensive fossil fuels.

The European Union (EU) aims to reduce GHG emissions by $45 \%$, by 2030, compared to the 1990 level, and to reach net-zero GHG emissions by 2050. These ambitious targets are the guiding principles behind the European Green Deal, revealed by the European Commission in December 2019 (European Commission (2019a)). One intermediary step to achieve this is to increase the reliance on clean energy technologies to $32 \%$ by 2030 (European Commission (2019b) $)^{2}$ According to the latest available official data, $18.9 \%$ of all energy consumption was met by renewable energy, in 2018 (Eurostat, 2020), almost double the share in 2010 (Eurostat (2010)). This corresponds to a level of installed capacity that increased almost 2.5 times over the same period (Figure 1.1). ${ }^{3}$ These developments of renewable energy present an important, but limited picture of the EU's goals. Indeed, the 2030 targets for renewable energy and GHG emissions are part of a more ambitious plan for an Energy Union - i.e. a pan-European electricity system where low-carbon electricity flows unrestrictedly between member states. Achieving the targets associated with the Energy Union relies on a clear understanding of the challenges ahead.

The process of energy transition - i.e. a move away from a carbon-intensive energy system to a cleaner one - has been the subject of increasing academic interest in the past two decades. The case of the EU differs from the usual national approach of the energy transition literature in that all national-level political agendas of the EU member states need to be coordinated both with each-other and with the supra-national EU agenda. Indeed, the transition away from fossil-fuel power technologies and towards cleaner power technologies is supplemented by the transition to a more integrated European power sys-

\footnotetext{
${ }^{2}$ The terms "clean energy" and "renewable energy" are used interchangeably in the terminology of EU institutions. Consistent with EU's energy policies and ambitions, these terms exclude nuclear energy. This is the main reason why we do not consider this option in the research presented in the following chapters.

3 "ET" is an acronym for "energy technologies".
} 


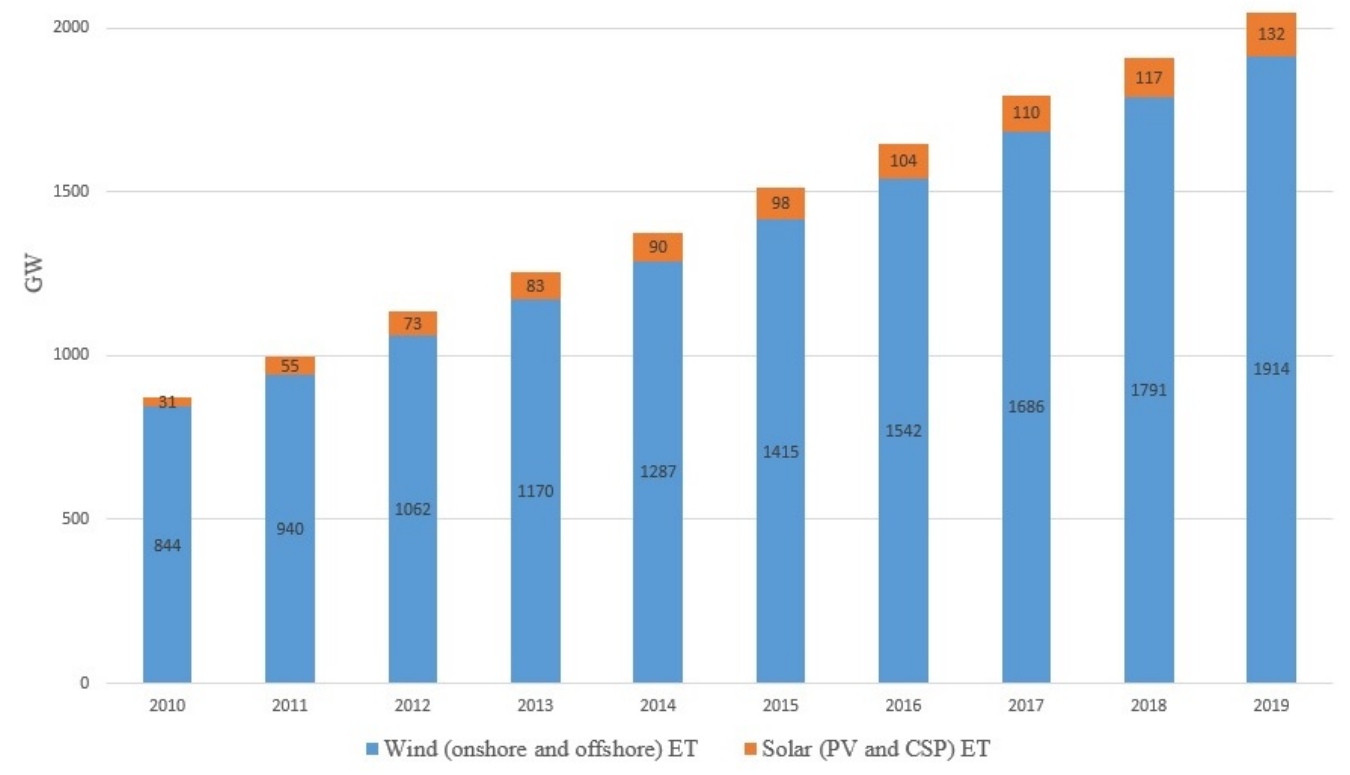

Figure 1.1: Transition towards wind and solar electricity

Growth in cumulative installed capacity of wind and solar energy technologies in the $\mathrm{EU}(28)$, over the 2010 - 2019 period. "ET" is an acronym for "energy technologies".

Source: Own computation, based on IRENA data (Source: IRENA (2019b))

tem. Therefore, the process of energy transition in the EU faces a unique combination of challenges, when compared to single-country energy transitions The aim of this dissertation is to shed light on these challenges and to provide insights that could inform the process of the European electricity system transition.

\subsection{Challenges ahead of the energy transition in the EU}

The urgency of the energy transition has drawn increasing academic interest over the past two decades. The various theoretical frameworks designed to address this process generally span several disciplines, of which environmental economics, energy systems analysis, innovation studies and political science are at the core. In a meta-theoretical study, Cherp, Vinichenko, Jewell, Brutschin and Sovacool (2018) argue that, while insights from various disciplines and theoretical approaches may be useful for addressing different national energy transitions, this does not mean that the exact same configuration of concepts can be applied to all individual - i.e. national - cases. Instead, they suggest "a meta-theoretical framework as a nested conceptual map of variables and the- 
ories from different social science disciplines which we believe are necessary for explaining specific cases and broader classes of national energy transitions. In this regard, the exact boundaries between the perspectives are less important than their ability to identify critical variables and theories which explain their interaction and behavior" (p.187). In a review of the recent theoretical and empirical literature on policy mixes in the energy transitions, Rogge, Kern and Howlett (2017) argue that, while the various disciplines that are jointly used to address this process are unquestionably useful, the resulting language can be ambiguous, as each discipline comes with a different understanding for a given term, which can render the interdisciplinary dialogue more difficult. Rogge, Kern and Howlett (2017) thus suggest the need for increased awareness of this issue. Similarly, they point out that the majority of the literature has focused on a single - usually European country and argue for an extended geographical scope for the study of energy transitions.

The interdisciplinary approach to the study of the energy transition process is justified by the diverse set of challenges ahead of it, which span political, technological and socioeconomic aspects. More specifically, the political challenges lie in the systematic inertia due to the political power that actors representing incumbent energy technologies have secured, since the inception of national energy systems. In the case of the EU, an additional political challenge lies in the integration of national electricity systems into a pan-European system, where power would flow freely among member states. ${ }^{4}$

The technological challenges mainly refer to the integration of variable renewable energy technologies (VRE) - namely wind and solar power - into the electricity system. Indeed, since wind and solar power plants can only generate power when the wind is blowing or the sun is shining - and power supply needs to match demand at all times a balanced power system would need to rely on a number of other energy - storage and generation - technologies. The current low share of wind and solar power does not pose a threat to the stability of the power grid due to two main reasons: the high share of flexible and dispatchable conventional power plants that can generate power on demand, and the low energy storage capacity currently required for the excess power generation from wind and solar plants. However, as clean power technologies are expected to meet the bulk of power demand in the coming decades, they are predicted to bring about significant transformations to the current mix of energy technologies.

Third, the socio-economic challenges facing the energy transition have traditionally referred to the social acceptance of new, clean energy technologies and resistance to change. However, the increasing awareness among the wider public of the urgency to reduce the level of GHG emissions by switching from fossil fuels to renewable energy, as well

\footnotetext{
${ }^{4}$ Achieving a pan-European energy system requires a partial shift of decision power from the national level to the European level. The research presented in the following chapter looks at how both aggregate and country-level investment requirements change, as power trade among EU member states increases, i.e. the European power system becomes more integrated.
} 
as the continuously decreasing costs of clean power technologies, have mobilized social acceptance and support for the energy transition, especially in the developed countries.

The research presented in this dissertation addresses these challenges, in the context of the EU, and aims to provide insights for an appropriate design of a low-carbon European power system.

\subsection{Contribution to existing research and reading guide}

The research presented in this dissertation identifies and addresses part of the challenges ahead of the energy transition in the EU. More specifically, it looks at how the increasing share of power generated by VRE technologies affects the existing power system and the electricity markets, and discusses the technological and economic implications of a fully renewable European power system. It does so by raising the following questions: 1a. How do different desired technological configurations of a fully renewable European power sector affect the investment requirements for such a sector? 1b. How does the process of the integration of different European countries' national power systems into a single, pan-European power system, affect the energy mix? 2. What is the effect of the increasing contribution of VRE-generated electricity on the electricity market - more specifically, on the level and volatility of electricity prices? 3. How does the growing share of renewable power in the electricity mix affect the process of integration of the different national electricity markets, as reflected in the convergence of electricity prices? The following chapters of this dissertation address these questions.

In chapter 2, I develop an analytical framework to understand how different energy generation and balancing technologies can contribute to a $100 \%$ renewable European power system. In the first part, I investigate whether different power technologies - of generation, storage and transmission - behave as either complements or substitutes in a decarbonised European power system. Having a clear understanding of how each energy technology can contribute to a clean power system and how its contribution impacts the contribution of other technologies - by either displacing or supporting it - is crucial to the design of a cost-optimal, clean European power system. ${ }^{5}$ Therefore, I address the following research questions: 1 . What is the contribution of each energy power generation, storage and transmission technology, in a clean European power system, from the point of view of investment requirements? and 2. How does the integration process of different national power systems into a single, supranational power system,

\footnotetext{
${ }^{5}$ As will be discussed in detail in the following chapter, the objective function of the optimisation model is to minimise the investment required for a $100 \%$ clean power system. This cost corresponds to a static image of the final power system, as opposed to a dymanic investment process. Therefore, the phrase "cost-optimal" refers to the financial investment requirements associated with the final technology portfolio that corresponds to the output of the model.
} 
affect this distribution, for different levels of power trade integration?

To answer these questions, I develop a portfolio optimisation model that covers the technology distribution per type, i.e. power generation, storage and transmission, and per country. I look at these distributions across four scenarios: 1. power demand is met entirely by solar and wind power generation for each individual country; 2. energy storage technologies can help smooth the intermittent supply of wind and solar power; 3. instead of energy storage technology, the cross-border transmission infrastructure can help smooth power supply geographically; and 4. both energy storage and transmission technologies are part of the energy mix. For simplicity, I limit my analysis to four European countries with four different weather patterns, representative of different European regions, i.e. Spain, Germany, Finland and Greece.

To address the second question, I include thresholds for the process of power trade, i.e. each country is increasingly allowed to rely on imports to meet up to $25 \%, 50 \%$, $75 \%$ and $100 \%$ of its power needs. This framework emphasises the importance of policy coordination among member states. As countries increase their reliance on power trade, their optimal energy mixes change - as does the aggregate European optimal energy mix. A cost-optimal European energy system in which power trade is restricted to $25 \%$ of an individual country's demand has a very different energy technology mix than a European power system where trade among member states is unrestricted. Understanding the cost and technology implications of these different scenarios provides a starting point for discussing the importance of energy policy coordination among EU member states.

The research in Chapter 2 contributes to an established energy modelling literature by addressing explicitly the issue of European power trade integration as a gradual process. This approach raises the issue of an optimal level of power trade integration and how the ensuing cost savings can be equitably distributed among member states. So far, the energy modelling literature has focused only on the financial and technological implications of different designs of energy systems. The research presented here argues that the political dimension - captured in the model developed in Chapter 2 as thresholds of reliance on electricity imports - is crucial to achieving a cost-optimal pan-European power system.

In Chapters 3 and 4, I focus on the effects of electricity from VRE on the electricity market. The current electricity markets of most developed countries have been designed decades ago for entirely different energy technology portfolios and market structures. The recent upsurge of intermittent power from VRE technologies has challenged the appropriateness of the current electricity market design for a VRE-intensive power system. One of the challenges which VRE raises for the electricity market refers to its effect on the electricity price and its volatility. More specifically, liberalized power systems function on the microeconomics principle whereby the price is determined by the marginal cost 
- which, in turn, for conventional power technologies, is determined by the fuel price. Since VRE and in particular wind and solar power technologies have zero fuel cost, they have a downward effect on electricity prices, during periods of high wind speed or high solar radiation. In the current design of electricity markets, this makes it difficult for conventional power technologies to remain competitive, even though they are important for the stability of the power grid.

In Chapter 3, I look at the effects of power generated by VRE on the main variables of interest of the electricity market - i.e. the electricity price and its volatility. Despite the rapidly increasing literature on the effects of VRE-powered electricity on the electricity market, most studies look at the effect on the level of electricity prices, ignoring how price variance is affected. Understanding the relation between VRE and electricity price variance is critical for the integration of VRE, as the price variance is one of the main decision criteria for investing in specific power generation technologies. Furthermore, in the context of a growing share of intermittent power generation from VRE, the variance of electricity prices is a central determinant for investment decisions regarding energy storage and balancing technologies. Also, existing studies usually take the form of a case study of a single country. Chapter 3 of this dissertation contributes to the existing literature in three ways: first, it is one of the few empirical studies to apply a GARCH model to understand the effect of VRE on price variance; second, it extends the geographical scope of existing studies by looking at ten European countries, with different VRE shares and different weather patterns; third, it uses very recent data on wind and solar power. Due to the upsurge of these technologies prior to and during the period under analysis, their contribution in meeting power demand has increased rapidly over the past few years. This rich dataset makes it possible to disentangle the individual effects of solar and wind power on the electricity price and its variance.

In Chapter 4, I look at the relation between the increasing share of electricity from VRE technologies and the process of integration of the different national power systems into a pan-European system. Over the past few decades, the European agenda of energy policy has been dominated by two main items: the integration of the electricity systems of individual countries into a pan-European electricity system, and the transition to a power system that is less reliant on fossil fuels and more intensive in cleaner, renewable energy resources. These two ambitions have historically been addressed individually, at both national and supra-national European levels - as is also reflected in two separate strands of literature - with different results. Indeed, the literature on the effect of VRE on electricity markets is unambiguous in its findings that an increase in VRE has a downward effect on electricity prices. On the other hand, the literature looking at power trade integration between different national power systems reports mixed results in terms of the effect of increased levels of power trade on electricity prices, finding both positive 
and negative relations between VRE and electricity price convergence. In Chapter 4, I argue that the two ambitions overlap in many respects and that a clear understanding of the relation between intermittent power generation from VRE and electricity market integration can reveal more efficient ways of pursuing this dual goal. As electricity markets become more integrated and electricity is freely traded among more countries, the price differential between these countries decreases. Therefore, in line with the existing literature, I use a measure of price dispersion, namely the coefficient of variation of the cross-sectional hourly electricity prices in a selection of European countries, to look at the process of integration of different electricity markets and how this process is affected by an increasing share of VRE. To this end, I develop a framework that looks at these two issues jointly and tackles the following question: what is the effect of intermittent power, generated by VRE, on the process of electricity price convergence? To answer this question, I look at eight European countries and find that there is an inverted Ushaped relation between VRE and electricity prices convergence, i.e. for very low and very high levels of VRE, the price differential is large, whereas for intermediate levels of VRE, prices tend to converge, thus reducing the price differential. This research is an important contribution to the existing literature, as it helps explain why the existing results are ambiguous with respect to the relation between VRE and power trade integration. The results point to the fact that an acceleration of interconnector capacity developments is required in order to benefit from the price-reduction effect of VRE, at the European level. ${ }^{6}$ Furthermore, increased policy coordination in different countries would mitigate the short-term negative effects of price divergence, e.g. the difference in consumer welfare in different countries, in the context of a pan-European energy system, following from unilateral decision making.

Finally, Chapter 5 summarizes the main findings of the research presented in this dissertation and offers several concluding remarks. It also highlights some limitations of the research and points to key areas for future research into the process of the transition towards a clean European power system.

\subsection{ABCs of electricity markets}

The previous section briefly introduced the content of each of the following chapters. Chapter 2 addresses the cost-optimal technology portfolio for a clean European power system, while Chapters 3 and 4 look exclusively at the effects of electricity from solar and wind power technologies on different aspects of the electricity market. In this section, we discuss four fundamental aspects of the electricity market that are relevant to Chapters 3

\footnotetext{
${ }^{6}$ The interconnector capacity refers to the power grid infrastructure that connects several different national power grids.
} 
and $4:{ }^{7}$ first, we discuss the time dimension of electricity markets; second, we focus on the determinants of electricity prices; third, we introduce the concept of "merit order effect", as part of understanding the effect of VRE on electricity prices; finally, we discuss the phenomenon of negative electricity prices and how it is handled in the research presented here.

\subsubsection{Consecutive electricity markets}

Until approximately three decades ago, the power sectors across Europe were organized as vertically integrated, highly regulated national monopolies. The same company that owned the power plants was in charge of the transmission of the generated electricity to distribution centers, and then of its supply to final consumers. The liberalization of the power sector introduced market competition at the power generation and distribution levels. $^{8}$ Currently, the electricity sector is no longer vertically integrated and different companies are in charge of power generation, transmission, distribution and supply. Different power generation companies compete to sell their output to large industrial consumers, as well as to suppliers for households, on what is referred to as the "wholesale electricity market". Since power supply and demand must match perfectly in any given moment, for the stability of the power grid, the hourly profiles of power demand and supply must be known well in advance of the actual power consumption. Therefore, the wholesale electricity market operates on several consecutive time dimensions, as shown in Figure 1.2.

The futures/forward market takes place up to several years in advance of the actual power consumption; the day-ahead market - sometimes referred to as the spot market - takes place on the day ahead of the actual power delivery and consumption, and the intra-day market has the role of making the final adjustments between power supply and demand, so that the two are in balance at all times.

The research presented in Chapters 3 and 4 looks exclusively at the day-ahead market. This is mainly due to the fact that the day-ahead prices are determined competitively and reflect the technology make-up of the particular power mix to deliver electricity at any given hour of the next day. This is because the market clearing price is determined by the power technology that provides the last (i.e. marginal) unit to meet power demand. ${ }^{9}$ In contrast, forward contracts are non-standardized, bilateral contracts and future contracts are more akin to financial instruments, as they can be traded further. With respect to

\footnotetext{
${ }^{7}$ For more information on the concepts discussed here and other concepts related to electricity markets, see KU Leuven Energy Institute (2020).

${ }^{8}$ The electricity transmission level has the characteristics of a natural monopoly and is operated by a single entity in each country, namely the transmission system operator (TSO).

${ }^{9}$ The following subsection discusses the particularities of the day-ahead market more in depth.
} 


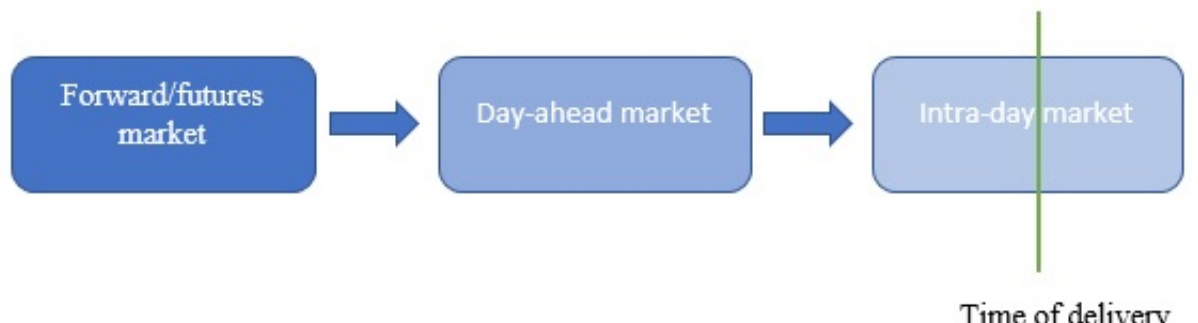

Time of delivery

Figure 1.2: The consecutive electricity markets

Source: KU Leuven Energy Institute (2020)

the intra-day market, it begins to operate after all trade on the day-ahead market is concluded and facilitates electricity trade of up to 30 minutes before the actual delivery (See Kraftwerke (2020)).

The intra-day market functions mainly as a correction market - i.e. it enables participants to adjust to unforeseen changes due to weather forecast errors, unexpected plant outages, etc. It is the final market mechanism to enable the equilibrium of power demand and supply. If there is a remaining supply-demand mismatch that cannot be taken care of on the intra-day market, it will be managed on the balancing market. ${ }^{10}$ As a result, the amount of electricity traded on the intra-day market is marginal, compared to the day-ahead market (KU Leuven Energy Institute (2020)). Furthermore, the data for the price, quantity and type of electricity by generation technology traded on the day-ahead market are made publicly available by the transmission system operators (TSOs), i.e. the entity responsible for the transmission of electricity from power generation plants to distribution centers. Therefore, the prices referred to in the following chapters are the prices determined on the day-ahead market, i.e. the day-ahead prices. These prices are determined by competitive bidding and reflect the interactions between the different power technologies. They are the prices faced by TSOs and charged by power generation companies. These prices will go through several modifications - including any adjustments of the intra-day and balancing markets, taxes and subsidies - before being transferred to the final consumers. As discussed above, the day-ahead market closes and the day ahead-price is determined - before the intra-day market opens. Therefore, any adjustments to the day-ahead forecasts for power supply and demand have no effect on the already determined day-ahead electricity price. The choice of the day-ahead elec-

\footnotetext{
${ }^{10}$ The balancing market consists of a procurement side and a settlements side. The procurement side, also referred to as the reserves market, is responsible for the activation of both replacement and frequency reserves. As a result, the procurement side can ensure grid stability of very high time resolution - of up to seconds in advance. On the other hand, the settlements side of the balancing market refers to the ex-post financial settlement of reserves providers (Kraftwerke (2020)).
} 
tricity market - and its corresponding data - is consistent with the standard electricity economics literature.

\subsubsection{Determinants of the day-ahead electricity price}

The day-ahead electricity market is operated by electricity exchanges - i.e. multilateral trading platforms - and functions based on a blind auction system. Buyers and sellers submit their quantity and price offers for each hour of the following day to the exchange, anonymously and in a one-off submission, between 24 and 36 hours in advance of the actual delivery. Once all bids for offer and demand are aggregated, the exchange operators calculate the electricity supply and demand curves, for each hour of the following day. The day-ahead electricity price for each hour is given by the market clearing price, i.e. the point of intersection of the supply and demand curves for any specific hour. The hourly market clearing price is the day-ahead electricity price charged to all buyers and sellers, indifferent of their initial bids. Once this price is determined, the buyers and sellers are informed and transactions can begin.

An important feature of the day-ahead electricity market is the fact that, once the market clearing price is known by buyers and sellers, these cannot re-adjust their bids (for more information on the operation of day-ahead electricity markets, see KU Leuven $(2020)) .{ }^{11}$ For this reason, the energy economics literature tacitly does away with any endogeneity concerns in power supply and demand on the day-ahead electricity market. With specific reference to the relation between wind and solar power supply on the dayahead electricity price, this is a reasonable assumption, given that wind and solar power output are by nature exogenous. However, the endogeneity assumption for the demand side is made explicit in several studies. For example, Forrest and MacGill (2013) argue that it "is considered to be a reasonable assumption since the majority of end consumers do not observe the spot market prices since retailers are the ones formally participating in the market" (p.124).

In line with the standard energy economics literature, the models presented in Chapters Three and Four are based on the assumption that any potential endogeneity issues stemming from day-ahead demand and day-ahead supply bids have limited, if any, impact on the model choices and results discussed in these chapters. ${ }^{12}$

\footnotetext{
${ }^{11}$ As discussed in the previous subsection, any adjustment between the forecasted level of demand or power generation submitted on the day-ahead market, on one hand, and the actual realizations, on the other, is dealt with on the intra-day market and the balancing market. These subsequent markets operate after the closure of the day-ahead market and their operation is based on different principles than those of the day-ahead market. As a result, any information provided on these markets has no effect on the already established information of the day-ahead market - be it price or forecasts of supply and demand.

${ }^{12}$ This issue is discussed in more detail in the Model sections of Chapters Three and Four, respectively.
} 


\subsubsection{Merit-order effect (MoE)}

Day-ahead electricity markets operate on the microeconomics principle of lowest marginal cost. ${ }^{13}$ The first power technology to meet demand is the one with the lowest marginal cost - which is usually associated with the cost of fuel. This results in a "merit order" of power technologies, i.e. the order in which power technologies provide power supply (Figure 1.3).
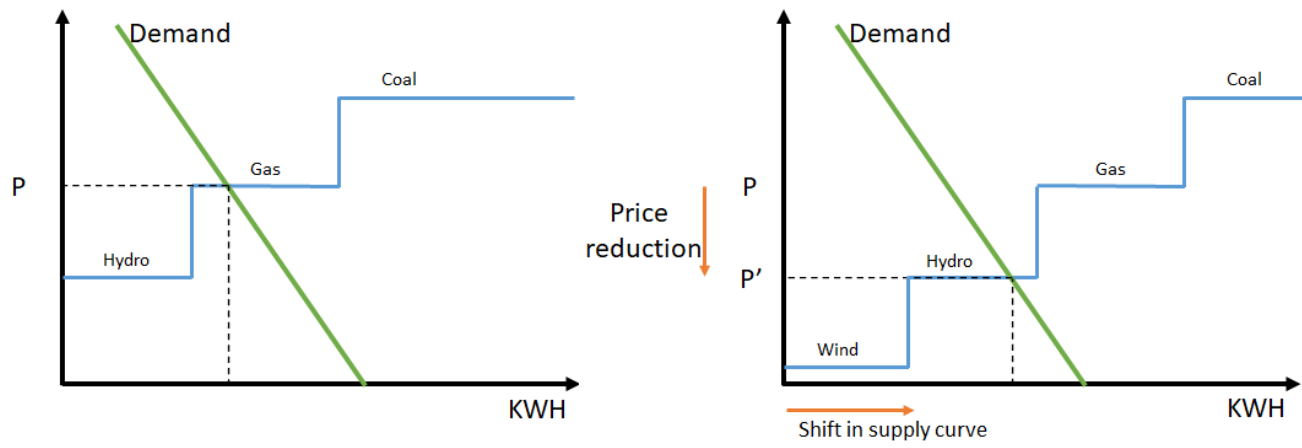

Figure 1.3: Merit order effect

Supply-demand curve before (left) and after (right) VRE

The marginal costs of electricity from wind and solar power plants are lower than those of more established power technologies, as these technologies have zero fuel costs. The introduction of these low marginal cost technologies pushes the supply curve to the right and determines a new, lower clearing price. This price reduction effect of VRE on the electricity price is known in the energy economics literature as the "merit order effect", henceforth abbreviated to MOE.

\footnotetext{
${ }^{13}$ This principle is consistent with profit maximisation under perfect competition. Under marginal cost pricing, lowest marginal cost units are cleared first. Via this merit-order, profit margins are sqeezed, but integral gross profits increase.
} 


\subsubsection{Negative day-ahead electricity prices}

Another way to categorise power generation technologies, apart from the type of fuel they use, is by how flexible they are, i.e. the technological and cost constraints that determine how rapidly and how often they can be turned off and back on, in order to meet a fluctuating demand. Electricity demand displays patterns of both daily and yearly seasonalities. Low levels of demand are met by baseload power plants, i.e. plants for which the technology makes it both difficult and costly to be switched on and off on a regular basis. This category includes mainly nuclear and coal-fired power plants. The regular but short periods of high levels of demand, i.e. the mid-day hours during the day, or, in particular, the early evening hours during winter days, are met by flexible, peakload power technologies, which are mainly gas-fired power plants.

During periods of low demand, an increasing share of intermittent power provided by VRE technologies drives the electricity prices further down, due to the MOE discussed before. When faced with the options of a costly and technically taxing, short-term shutdown, on one hand, and temporarily operating at a (lower) loss - by effectively paying buyers for the possibility to discharge surplus power - on the other hand, baseload power technologies opt for the latter. This can result in negative day-ahead electricity prices (Figure 1.4). ${ }^{14}$
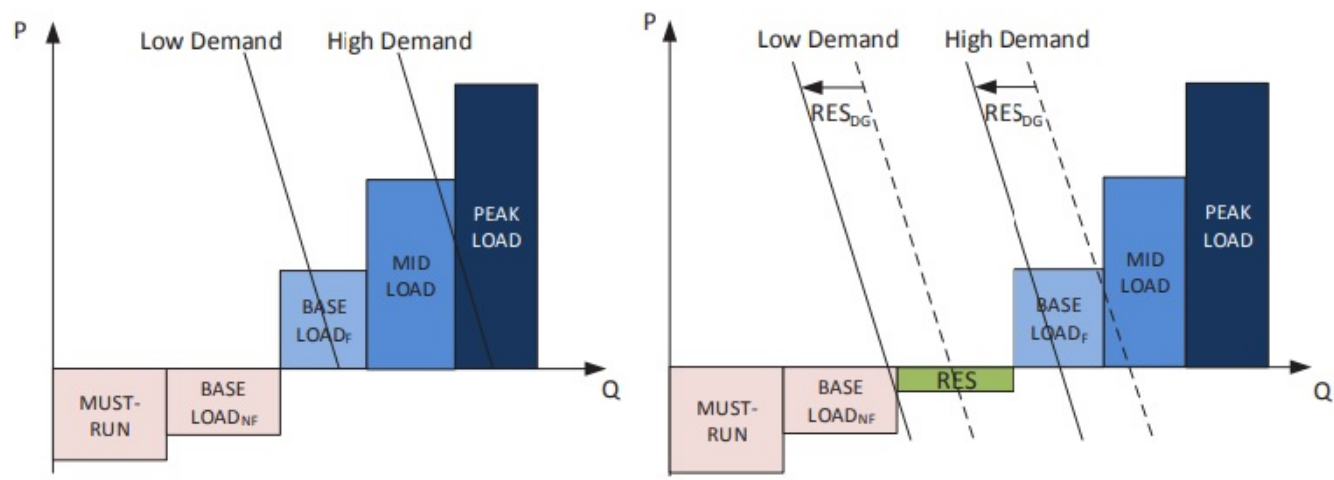

Figure 1.4: Merit order effect of wind power on the electricity price The subscripts $N F, F$ and $D G$ refer to non flexible, flexible and distributed generation, respectively. Source: KU Leuven Energy Institute (2020)

The research presented in Chapters 3 and 4 uses data on day-ahead hourly prices.

\footnotetext{
${ }^{14}$ In the case of the power sector, negative day-ahead prices are never transferred to consumers, due to additional taxes and subsidies, of which consumers are the ultimate payers. This phenomenon of negative prices has a parallel in the situation faced by the oil market during late April 2020. For a few days, the trading price of oil became negative due to a combination of events: low demand, high shutting-down cost of oil wells and low storage capacity. Despite the ubiquitous headline, there was no significant change in the price paid by the final consumer (Tobben (2020)).
} 
In chapter 3, data are aggregated at the daily level, thus all data at the unit level in our regression analysis are positive values. In chapter 4 , we use hourly prices for eight countries, over a period of three years. Of these over 35000 observations, six values are negative and close to zero. We thus decide to keep them in our analysis, but make the argument that they have a marginal, if any, effect. This issue is discussed in more detail in chapter 4 . 


\section{Chapter 2}

\section{What are the effects of power}

\section{trade integration on the energy mixes of different European} countries?

\subsection{Introduction}

The power sector is the largest $\mathrm{CO}_{2}$ emitter globally. Together with the heating sector, it accounts for $42 \%$ of worldwide emissions. ${ }^{1}$ At the same time, it has recorded the fastest progress towards decarbonization, as renewable power technologies have had sustained high annual growth for the past two decades and, more recently, are making up the lion's share of newly installed capacity (Fig. 2.1). IEA reports that, in 2016, renewable energy accounted for two thirds of global net capacity increase (IEA (2017b)). At the EU level, the current ambitions aim for a $32 \%$ share of electricity to be generated by renewable energy technologies by 2030, up from 17\%, in 2017 (European Comission (2017)).

This target brings about not only significant technical challenges, but also political and economic challenges, as discussed below. These challenges are highly interlinked and a solution to one of them is likely to impact the others. First, the technical challenge lies in meeting power demand from renewable energy sources at all times. Unlike traditional power plants, such as coal and gas-fired ones, wind and solar power plants

\footnotetext{
${ }^{1}$ Emissions of the electricity and heating sector are generally considered together, due to the high reliance on combined heat-and-power (CHP) plants in developing countries. For a detailed discussion on $\mathrm{CO}_{2}$ emissions accounting per sector, see IEA $(2017 a)$.
} 


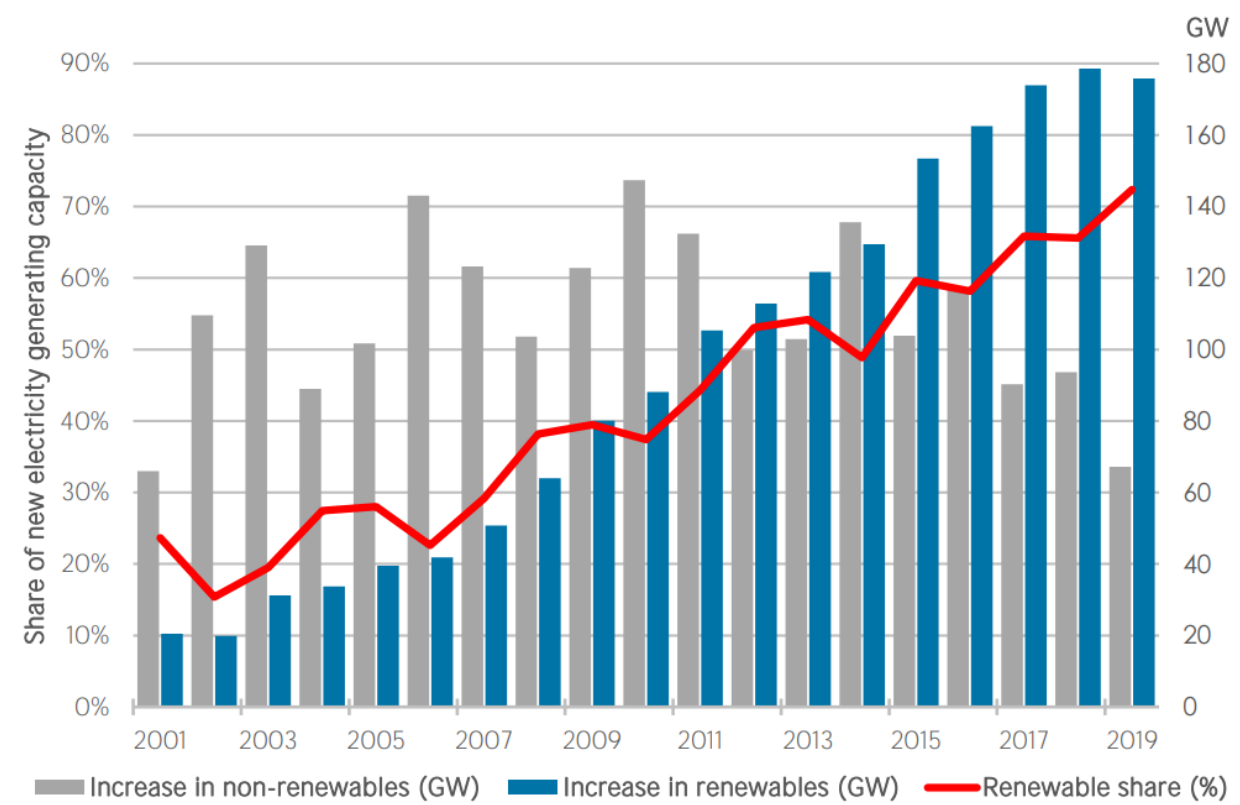

Figure 2.1: Transition towards wind and solar electricity

Growth in global installed capacity of power technologies, in gigawatts (GW) (bars) and share of renewable energy (RE) capacity in total energy mix (red line).

Source: IRENA (2020)

are not dispatchable - i.e. their output cannot be controlled by plant operators. Instead, power generation is weather-dependent and rarely completely synchronized with the power demand pattern ( this is referred to, in the energy economics literature, as the load curve). The technical challenge thus lies in saving excess power, i.e. the positive difference between the electricity produced and the electricity consumed in a given moment, and using it to meet residual demand, i.e. demand net of input from variable renewable energy (further called VRE), at a later time. The two main types of energy balancing technologies (further called EBT) address this challenge in the following ways: 1) by smoothing power generation across time - i.e. using energy storage technologies (hereinafter EST) to store excess power for use at a later time; and 2) by smoothing power generation across space - i.e. using cross-border power grid transmission (hereinafter CBT) to allow for excess power generation in a given region and time period to meet residual load in a different region, during the same time period.

Second, the economic challenge lies in meeting power demand at lowest cost. Power generation and balancing technologies can act either as complements or substitutes to each other. For example, photovoltaic (PV) panels generate most power during the sunny, mid-day hours, while wind power reaches its peak during evening and night hours. In 
this respect, PV panels and wind turbines have complementary power generation profiles. In other words, the power output of one technology complements the power output of the other in meeting power demand throughout the day. An increase in average demand during each hour of the day would require the output of both technologies to increase in similar proportions. One technology alone cannot substitute for a lack of the second one, given their hourly output profiles. At the same time, residual power generation i.e., excess power after demand is met - can be either used to charge EST or exported towards regions with excess power demand. In this case, EST and CBT act as substitutes to each other. In other words, one of these two technologies could substitute the other in absorbing the excess power generation. A clear and detailed understanding of the synergies between different energy technologies would support the design of a least-cost energy system.

Last, political challenges refer to the issue of energy security - more specifically, to the risks faced by energy supply continuity for any given country (Winzer (2012)). Increasing reliance on neighboring countries for a balanced power grid can lead to significant cost savings overall. However, historically, energy independence has been high on national political agendas. Addressing the question of how to equitably distribute among EU member states both the cost and the benefits stemming from a completely integrated pan-European power system is an important pre-requisite for the successful transition towards a single European energy market.

Understanding the interactions between the challenges discussed above and, more importantly, of those of their potential solutions, is critical to designing a clean, secure and cost-effective European power sector. This chapter aims to provide insights into these challenges and their respective potential solutions by addressing the following research questions: 1) What is the cost optimal energy technology configuration of a fully renewable European power system? 2) What are the country-level cost, technology and energy system independence implications of a fully integrated pan-European power system? And 3) How do these implications change for individual countries, for different levels of the integration of national energy systems into a single, pan-European one?

By examining these questions, this chapter aims to develop a framework to understand the trade-offs between the economic, technological and political challenges of the transition towards a fully renewable European power sector. ${ }^{2}$ To this end, I develop a portfolio optimization model that explicitly accounts for the uncertainty inherent in the supply of power generation from renewable energy technologies (further called RET), in order to investigate how different energy technologies can act as either complements

\footnotetext{
${ }^{2}$ The political challenge of energy security, in the sense discussed in this chapter, refers to a low reliance on energy trade. For this reason, the political challenge is operationalized in the model presented here as different levels of restrictions to power trade.
} 
or substitutes to each other. Unlike conventional power generation technologies, RET cannot supply power on demand - i.e., they are not dispatchable. Their output depends on the specific weather characteristic at any given moment. The uncertainty in power output of RET is determined by two factors: first, observed solar radiation and wind speed differ across daily and annual seasonal cycles; second, as the expected output of each power plant is scheduled before being generated, actual power from VRE is subject to forecast error. The uncertainty due to these two factors is ignored in deterministic models, such as models using observed data of previous years. The model developed in this chapter explicitly acknowledges this uncertainty by transforming the data in the following way: based on data for wind and solar hourly capacity factors over the 1985 2016 period, ${ }^{3}$ I construct a new dataset, corresponding to one year of hourly values of wind and solar capacity factors for each of the four countries considered in this chapter, namely Spain, Germany, Finland and Greece, the choice for which is discussed below. The new dataset thus covers 8760 hourly observations for each of the two variables wind and solar capacity factors - and for each of the four countries, for one year. Section 2.4 discusses the data sources and the transformation in more detail. I look at the energy mix and its corresponding investment requirements and country distribution across four scenarios: 1) the European energy mix is composed of only wind and solar power generation technologies; 2) EST are introduced in the energy mix; 3) instead of EST, countries can trade electricity via CBT and 4) both EST and CBT contribute to the energy mix. In Section 2.6 I discuss in detail the optimal energy-mix configuration under each of these scenarios.

I then explore how the technology mix - and its related investment requirements changes across a number of European power systems integration scenarios, ranging from complete country self-sufficiency to unconstrained trade of electric power. This gradual view of the European power system integration aims to reveal insights into the trade-off between the cost and technology aspects of the process of power system integration, on the one hand, and the political one, on the other, where the political aspect refers to the share of power trade a country is willing to rely on. As we shall see, the higher the share of power trade, the lower is the aggregate system cost. By looking at certain thresholds of power trade and their corresponding power system costs, the research presented here aims to provide numerical estimates of this relation. In turn, this discussion can inform the design of a mechanism for the distribution of costs and benefits across all countries.

This chapter is structured as follows: the next section discusses previous research on the three most frequently discussed solutions to balancing a fully renewable power

\footnotetext{
${ }^{3}$ The capacity factor of an energy technology is defined as the ratio between the actual output produced during a given period and the full potential of power generation of that technology during the same period.
} 
system, namely 1) hedging across different RET, 2) energy storage technologies, and 3) cross-border extension of the transmission network. Section 2.3 discusses previous applications of optimization in energy research. Section 2.4 and 2.5 discuss the data and the model, respectively. Results are presented in Section 2.6. Section 2.7 provides a detailed discussion of the results for different levels of power trade integration. Finally, Section 2.8 provides the concluding remarks.

\subsection{Overview of options to overcome fluctuating power supply}

The issue of integrating variable power generation into the electricity system - currently brought about by an increasing share of RET - is not new. Centralized power systems have dealt with fluctuating power output for over a century, mainly due to the seasonal pattern of generation from hydroelectric power plants. In general, this peaks during summer through autumn and reaches its lowest level in spring. This is due to winter precipitations - mainly snow - being accumulated, instead of flowing into the water stream. When snow begins to melt, in spring, rivers' debits increase. Depending on a country's climate and its reliance on hydropower, this seasonality can create significant strains on its electricity system. For example, in Norway, where hydropower accounts for over $95 \%$ of electricity, reservoirs levels can be up to four times higher during peak times, compared to their lowest levels (Wolfgang, Haugstad, Mo, Gjelsvik, Wangensteen and Doorman (2009)).

Increasing shares of power from wind and solar plants, together with an ongoing global trend towards liberalized electricity markets, adds several layers of complexity to the issue of power system stability. This research aims to provide an understanding of the challenges ahead of the European transition to a clean power system - and of potential answers to these challenges.

One main issue brought about by weather-dependent power generation technologies is to meet power demand at all times - including those of low solar radiation and low wind speed. The three most widely discussed solutions to this issue are: 1) hedging across power generation technologies, i.e. design an optimal configuration of wind and solar plants such that demand not met by one technology is met by the other, at any given time; 2) including energy storage technologies (EST) into the power mix, i.e. excess power generated during favorable weather conditions is stored for use at a later date, when poor weather conditions lead to less power generation than is needed to meet demand, and 3) hedging across countries, i.e. extending and reinforcing the cross-border power grid such that, at any given time, excess power generated in one country is exported to another 
country with less favorable weather conditions.

The following sub-sections discuss the previous research on each of the above three options.

\section{Hedging across RET}

Power output profiles of solar and wind technologies have a strong negative correlation, both at daily and seasonal levels: while the demand curve follows the daily solar radiation pattern and peaks in early afternoon, wind speed - and therefore, wind power - is generally higher during the night and in the early morning, when demand is lower. For seasonal fluctuations, the correlations with load are reversed: wind output is higher during winter, when power demand is higher, due to increased demand for heating, while solar output is higher during summer. Alongside daily and seasonal variations in power output from RET, there are also strong geographical variations across Europe, in terms of solar and wind power potential. Solar and wind power generation patterns are therefore complementary in meeting power demand throughout the day, in the sense that, during the hours when power generated by one of the power technologies decreases, the demand is met by the alternative RET. In other words, due to the negative correlation between solar and wind power output at both the hourly and the seasonal time resolution, one energy technology cannot substitute the second one, in meeting the bulk of power demand at the same time.

This fluctuating complementarity in power output across time and space between wind and solar power has motivated a diverse and increasing literature addressing the benefits of the energy technologies portfolio approach. Heide, Von Bremen, Greiner, Hoffmann, Speckmann and Bofinger (2010) find that, in the case of a fully renewable European power sector, an optimal mix of $55 \%$ wind and $45 \%$ solar power reduces the storage needs by a factor of two, compared with scenarios of either $100 \%$ solar or $100 \%$ wind. Thomaidis, Santos-Alamillos, Pozo-Vázquez and Usaola-García (2016) compare the performances of wind-only and wind-and-solar portfolios, in terms of the trade-off between two objectives, namely maximizing average power output and minimizing average variation in power output. Their assets universe consists of geographical sites across the Iberian Peninsula for onshore wind turbines and concentrated solar power (CSP) plants. They find that, for low levels of mean generating capacity, the mixed wind-and-solar portfolio has a much lower standard deviation than the wind-only alternative. However, the efficiency frontiers of the two portfolios overlap, for high levels of mean generating capacity - i.e. they can achieve similar values of maximum average power output, for similar values of high standard deviations. If, however, the portfolio manager is risk-averse - defined by Thomaidis, Santos-Alamillos, Pozo-Vázquez and 
Usaola-García (2016) as interested in reducing the hourly volatility of power output, together with maximizing average power output - wind-and-solar portfolios outperform significantly wind-only portfolios. Indeed, for a level of average power output of $20 \%$, the wind-and-solar portfolio yields $5 \%$ standard deviation - almost a third of the standard deviation of the wind-only portfolio, of $13 \%$.

\section{Energy storage technologies}

A balanced power grid requires power demand and supply to match perfectly at any given time. The main challenge brought about by an increased share of variable renewable energy (VRE) is meeting power demand in times of low wind speed and low solar radiation. As discussed earlier, power demand follows the daily pattern of solar radiation and is negatively correlated with it at the seasonal scale, while the opposite is true for wind power, which is negatively correlated with the daily pattern of power demand, and positively correlated with its seasonal variation. Ensuring that demand is met at any given time by an optimal combination of only wind and solar power would result in very high installed overcapacity of both technologies. Indeed, the fleet of wind turbines needed to meet peak demand during winter evenings would remain idle for most of the year. Similarly, the installed capacity of PV panels would need to be sufficiently large to meet day-time demand even during times of low solar radiation, thus making them idle during higher solar radiation. An alternative solution is given by EST, which can capture and store excess power generation during times of high solar radiation and strong wind speed - and release it during times of residual load.

EST have been increasingly addressed in the literature as an essential component in a fully renewable power system. Weitemeyer, Kleinhans, Vogt and Agert (2015) look at the role of EST in supporting the integration of renewable energy in Germany. They find that EST become increasingly important as the share of RET in Germany's energy mix increases beyond the 50\% threshold. Bussar, Moos, Alvarez, Wolf, Thien, Chen, Cai, Leuthold, Sauer and Moser (2014) develop an optimization model which minimises the cost of an energy system similar to the one presented here, i.e. consisting of wind turbines, PV panels, storage technologies and cross-border grid extension. Their model differs from the one developed in this chapter in two important ways: first, it covers the EUMENA region; ${ }^{4}$ second, they only look at one scenario alone, in which both EST and CBT are available and each country relies on self-supply to meet demand over three years - that is, countries can trade, as long as all power produced domestically by one country, over three years, is sufficient to meet the three-year average of demand. They look at the cost-optimal power system configuration over the EUMENA region, and at the cost

\footnotetext{
${ }^{4}$ EUMENA refers to the Europe, Middle East and North Africa.
} 
distribution of the components of the power system, and find that the cost associated with EST corresponds to a fifth of total system cost.

In a more recent study, Brown, Schlachtberger, Kies, Schramm and Greiner (2018) compare the total system cost for a low-carbon European system which relies on system coupling at the national level - i.e. the coupling of the power, transport and heating systems within each European country - with the total system cost of a pan-European power sector which relies on unrestricted power trade, but is isolated from both the transportation and the heating sectors. In the sector coupling scenario, technologies from the transportation and the heating sectors, such electric vehicles, synthetic electrofuels, heat pumps, district heating and long-term thermal energy storage effectively act as flexible energy storage units at different time scales. The authors find that, in this scenario, the total system cost is reduced by $28 \%$, compared with a scenario of inflexible sector coupling and no interconnection. This cost reduction is higher than that achieved in a scenario of unrestricted interconnection and lack of flexible sector coupling, of $25 \%$. However, Brown, Schlachtberger, Kies, Schramm and Greiner (2018) find that the optimal combination of both options - flexible sector coupling and interconnection - results in a cost reduction of $37 \%$, compared to a scenario where neither option is available. The following subsection discusses exclusively the literature regarding cross-border grid extension as an option to integrate VRE in the European power system, at an optimal cost.

\section{Cross-border power grids}

An increasing share of VRE in the energy mix of each European country is expected to bring about challenges in many parts of the current energy system and the functioning of the power market. For example, balancing power - needed to meet residual demand - should come from technologies that are reliable - i.e. provide power whenever needed; flexible - i.e. able to come into operation often and on short notice; and at low cost. One way to reduce the need for balancing power is to have overinstalled capacity of RET. However, since peak power demand occurs for only a few hours during the year, a large share of installed capacity would remain idle for most of the time.

A high share of VRE is expected to challenge the electricity market as well. Due to their low marginal cost, RET rank first in the merit-order of power technologies to meet demand, thus displacing traditional power technologies. This leads both to an overall reduction of electricity prices and to a redistribution of gains and losses of economic welfare among different power generation technologies (Schaber, Steinke, Mühlich and Hamacher (2012)).

An unconstrained and reliable pan-European power grid could help address all these 
challenges. Rodriguez, Becker, Andresen, Heide and Greiner (2014) look at the trade-off between transmission capacity and conventional power plants in balancing a European power system where VRE meet $100 \%$ of each country's average power demand. They find that European interconnectors could reduce balancing needs from conventional power by up to $37.8 \%$, compared to the case of no international transmission capacity. If interconnectors capacity remains at today's level, it would reduce balancing needs by $13 \%$, compared to the case of no-interconnectors, while a four-fold increase from today's level would reduce balancing needs by 33\% (Becker, Rodriguez, Andresen, Schramm and Greiner (2014)).

Schaber, Steinke, Mühlich and Hamacher (2012) examine the effects of grid extension on fundamental properties of the power system, such as backup capacity requirements and overproduction. They look at how these two characteristics change for different levels of VRE integration and when countries can trade power, compared to the situation when countries need to meet all demand domestically. They find that, in the no-trade scenario, the requirement of backup capacity is $100 \%$ of hourly peakload and this requirements drops to $60 \%$ of peakload, when countries can trade power. This is also due to the fact that hourly peakload does not occur at the same time across Europe. This significant drop corresponds to reducing overproduction from $10 \%$ of total demand, in the case of no inter-regional power grids, to less than $1 \%$, in the case of the pan-European power grid.

International power grid extension facilitates not only the technical, but also the economic integration of VRE. Schaber, Steinke and Hamacher (2012) develop a linear optimization model to examine how the power market - e.g. the level and volatility of electricity prices, as well as the welfare distribution among power market participants - is impacted by VRE, in the presence of grid extension. They find that power grid extension enables a geographical smoothing of these impacts: it reduces the differences in electricity prices between regions with different shares of VRE, ultimately contributing to lower electricity prices; it facilitates the economic integration of VRE by reducing the magnitude of the decline in revenue of conventional power plants - indeed, in the absence of CBT, excess RE power generation significantly lowers electricity prices, thus posing a challenge to conventional power plants; if, however, this excess power can be exported, the drop in electricity prices is lower and the decrease in revenue for conventional power plants is limited; at the same time, importing countries have access to lower-price electricity; furthermore, power grid extension reduces the overall system cost, by increasing capacity utilization of both conventional and RE power plants. These benefits are achieved at lowest cost when European power grid is extended by either $20 \%$ of 2011 capacity - if only underground cables are considered - or $60 \%$ - if only overhead lines are considered (Schaber, Steinke and Hamacher (2012)). 
While the cost-saving implications of a pan-European power grid are unanimously agreed upon in the literature, the same cannot be said about the political aspects. On a larger scale, while the cost and technical parameters of energy generation and balancing technologies are similar in different parts of the world, this is not the case for the political willingness for power trade integration, in different regions. Brinkerink, Ó Gallachóira and Deane (2019) provide a comprehensive review of modeling initiatives for globally connected power systems. They find that most challenges identified in the reviewed studies refer to political aspects, such as local resistance to interconnector development, concerns about disruption to energy supply, as the reliance on energy imports increases and others. Due to the difficulty in quantifying them, these issues are largely left out of optimal energy system modeling.

The research presented in this chapter aims to fill this gap by including the political dimension in the optimal design of a European power system. This is conceptualized as exogenous limits - ranging from $0 \%$ to $100 \%$ - of electricity imports on which individual EU countries may rely on. The resulting investment requirements and technology distribution associated with each limit to power trade provide a framework for the discussion on how to assess the challenges and opportunities brought about by an integrated European power system.

\subsection{Application of optimization in the energy eco- nomics literature}

Mathematical optimization is an established methodology for addressing a wide range of energy issues and has been increasingly applied to renewable energy topics in the past two decades. Banos, Manzano-Agugliaro, Montoya, Gil, Alcayde and Gómez (2011), Bazmi and Zahedi (2011) and Zeng, Cai, Huang and Dai (2011) review recent developments in energy modeling where optimization techniques are employed. These energy models can be grouped along several dimensions, among which: 1) the scale of the energy system ranging from building, to small island, to international level; 2) the objective function minimising greenhouse gas emissions, minimising cost, maximising profitability etc.; and 3) the technical complexity of the optimization model - e.g. multi-objective optimization, stochastic optimization etc.

Awerbuch (2006) argues that a portfolio optimization approach to energy system planning, as opposed to "traditional, least-cost stand-alone kWh cost measures" provides a more comprehensive picture of the effects of power technologies on energy systems (p:693). In the case of renewable energy, an optimization model approach reveals the positive impact of wind power on both energy security - in the form of mitigating the 
price volatility of imported fossil fuels - and the overall generating cost.

Østergaard (2009) reviews optimization criteria for models of energy systems with a high share of VRE and applies a selection of criteria to a Western Denmark energy system model. The objective function of the model is to identify the optimal capacity of heat pumps required to support the integration of wind power. The resulting energy systems vary significantly in the capacity of heat pumps, depending on the optimization criteria. One way to reconcile these conflicting objectives is by multi-criteria decision analysis, which incorporates several decision criteria into a framework for guiding decision making. However, this approach raises the issue of deciding upon weights for each criterion (Østergaard (2009)).

In their extensive review of the literature on optimization models of energy systems, Bazmi and Zahedi (2011) argue that the increasing application of this method came as a natural consequence of the increasing complexity of energy systems, over the past fifty years. Indeed, less than half a century ago, national energy systems were operated as state-owned, vertically integrated companies. Current energy systems, especially those in developed countries, have changed considerably, in many aspects. For example, the liberalization of power systems has led to competition at different levels - i.e. power generation, power supply, financing of energy projects etc. At the same time, the rapid development of alternative power technologies has led to increasing complexity for decision makers tasked with designing future energy systems, under financial and environmental limitations. Therefore, as energy systems have become increasingly sophisticated, so have the methods used for their analysis and to support decision making. Bazmi and Zahedi (2011) conclude their review study arguing that optimization models are "an effective and useful tool for problem solving in the power [generation] and supply sectors and especially for policymakers to establish policies based on detailed assessment of competing technologies and [large] amounts of scenario analyses" (p. 3495).

Hirth (2015) discusses three different classes of energy system optimization models with an explicit focus on how effective they are in addressing the inherent variability of power output from renewable energy technologies. He reviews the numerical modeling literature that is used to estimate optimal shares of energy technologies and argues that two of the three classes identified - namely integrated assessment models (IAM) and energy system models - generally have low resolutions that make it difficult to understand the effect of output variability on models results. A third type of numerical modeling category - power market models - do not suffer from low resolution, but in this technical subfield, the shares of power technologies are generally determined exogenously. Hirth (2015) argues that especially temporal variability can have a large impact on the welfareoptimal shares of renewable power generation technologies: "if winds were constant, the optimal share would triple" (p.179). Therefore, "[m] odels and analyses that cannot 
represent variability explicitly need to approximate the impact of variability carefully" (p.179).

In this chapter, I develop a linear optimization model that goes beyond the static techno-economic implications of an optimally designed energy system. The aim of this model is to help us understand the trade-offs between these implications, on the one hand, and the design of a fully renewable pan-European power grid, on the other. This research is a timely contribution to the existing literature due to its use of very recent data, its large geographical scope and particularly to its analysis of the trade-offs between the process of power trade integration and the aggregate power system cost.

\subsection{Data}

Research in renewable energy modeling faces the significant challenge of reliability of data for wind and solar power output potential. There are two main approaches to VRE data collection: bottom-up data collection from empirical observations of various power plants, and estimation from satellite and on-site meteorological data. Each of these options comes with important drawbacks: the former faces limitations in aggregation and extrapolation for larger geographical areas, as well as in comparison of power plants across different locations; the latter relies mainly on theoretical models and on the assumptions behind the transformation of meteorological data in power output potential, which often result in important departures from observed power output.

The research community of renewable energy systems is increasingly relying on datasets produced by reanalysis models, for simulating power output from renewable energy technologies (RET) (Staffell and Pfenninger (2016)). Reanalysis models originate in meteorology research and refer to the process of hindcast - i.e. developing a model that replicates historical weather observations. More exactly, "[r] eanalysis combines a system for assimilating historical weather observations with an atmospheric circulation model to infer the state of the global weather system. In essence, reanalysis takes difficult to use observations, apply automated quality control, and transforms them into a standardized dataset with uniform and complete spatial and temporal coverage" (p:1226).

Thus, reanalysis models have become a standard data source in renewable energy modeling. However, Staffell and Pfenninger (2016) and Pfenninger and Staffell (2016) argue that, despite their accessibility and affordability, reanalysis models should be used cautiously in energy system planning. When comparing NASA's MERRA reanalysis results against observed historic data on power output of wind turbines across Europe, they find low spatial correlation, with a correlation coefficient of 0.19 . They therefore suggest that data on power output of wind turbines and solar PV panels derived from reanalysis models need to be calibrated against observed data and adjusted accordingly. 
They then proceed to develop a bias-correction factor which, when applied to reanalysis models, yields results that are more in line with historic observations, where these are available. Indeed, taking reanalysis data at face value - with no validation and subsequent correction - would result in errors in estimated capacity factors for wind turbines ranging from a $30 \%$ underestimation, for Portugal and Romania, to a $60 \%$ overestimation, in the case of Germany and Denmark. Their resulting dataset of validated simulations for hourly capacity factors of wind turbines and solar PV panels is publicly available at renewables.ninja.com. ${ }^{5}$

I use a selection of this dataset on country-aggregated, hourly power output per unit of installed capacity of wind turbines and PV panels ( in other words, the hourly wind and solar capacity factors) over a period of 32 years. For simplicity, I limit my analysis to four European countries, namely Spain, Germany, Finland and Greece. This selection reflects the wide variation of weather regimes across Europe.

I also use hourly power demand data for the year 2017 for these countries, made available by the European Network of Transmission System Operators for Electricity (ENTSO-E). Data on total installed unit costs for wind power, solar power and EST come from the International Renewable Energy Agency (IRENA) ${ }^{6}$ I consider total installed unit cost of wind and PV power technologies due to the fact that they make up about $80 \%$ of the levelized cost of electricity (LCOE), i.e. the unit cost of electricity produced. This is the main indicator used in investment decisions for energy projects to compare the final cost of different energy technologies. ${ }^{7}$

The following subsection gives an overview of the input data to the model.

\subsubsection{Wind and solar capacity factor}

Wind turbines and solar panels never operate at $100 \%$ of their potential. The ratio of the actual electricity produced by a renewable power plant to its full potential - known as the capacity factor - is a number between 0 and $100 \%$. This section discusses in detail how capacity factors of the two technologies for the countries in my sample vary at different time resolutions.

I use data on the hourly wind and solar capacity factors of Spain, Finland, Greece and

\footnotetext{
5 "Renewables.ninja" is a data and research project developed by researchers at ETH Zurich and Imperial College London. The aim of the project is to provide open access to high-resolution worldwide data for wind and solar power plants to the scientific community. The resulting datasets and publications are available at www.renewables.ninja.

${ }^{6}$ Data on total installed unit cost of wind power and solar power are available from Renewable Power Generation Costs in 2017 (IRENA (2018)).

${ }^{7}$ Note that IRENA refers to "total installation cost" as including "all of the costs of developing a project [including] interest during construction (including on working capital needs), project development costs and any upfront financing costs" (IRENA (2018):27). Data on EST costs are available from Electricity Storage and Renewables: Costs and Markets to 2030 (IRENA (2017)).
} 
Germany from 1985 to 2016 . The hourly capacity factors vary considerably: while during the day the capacity factor of a solar panel might be as high as $90 \%$, at night it drops to zero. Figure 2.2 shows the average hourly capacity factors of each country over the years of my sample. As we can see in this figure, the average capacity factors are relatively constant over the years. In other words, there is no particular year which, on average, is significantly more windy or sunny. This figure also reveals general characteristics of the climate of these four countries. For example, according to panel (a), the capacity factor for wind is on average higher in Finland; this implies that a wind turbine will generate more electricity in this country than in Germany. However, as we can see in panel (b), Finland has the smallest solar capacity factor, as this country is the farthest of the four from the equator, where solar radiation is the strongest.

Finally by comparing panels (a) and (b) in Figure 2.2, one can clearly see that, for all countries considered in this research, wind power has a significantly higher capacity factor than solar power. In other words, one unit of installed wind capacity yields more power output than one unit of installed solar capacity, for equally favourable weather conditions. This distribution of power output potential has clear implications for the design of the optimal European power system, as we will see in section 2.6.

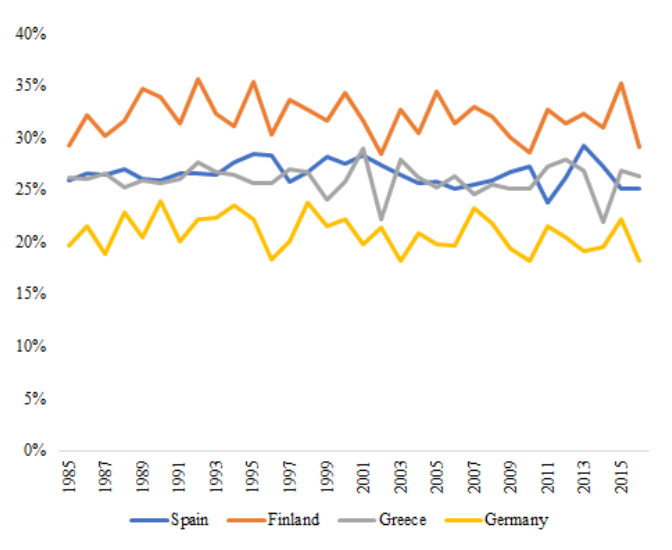

(a) Wind

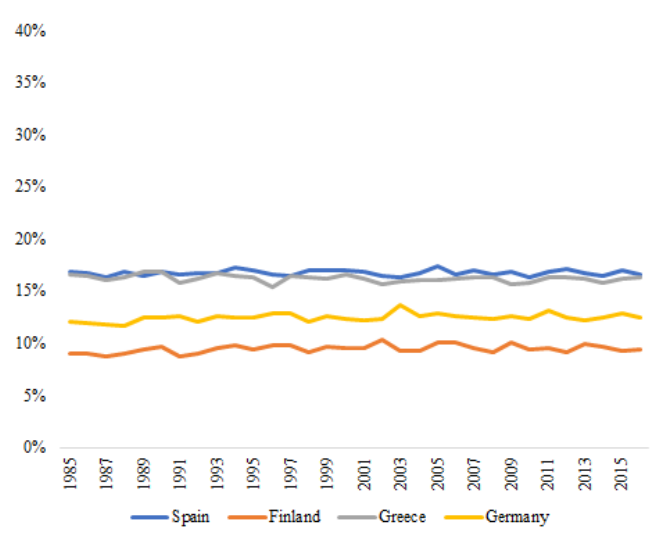

(b) Sun

Figure 2.2: Average of hourly capacity factors, per year

A second important observation is that the hourly capacity factors of wind and solar power plants are not constant throughout the year. Wind power plants are more efficient in winter and solar power plants have higher efficiency during the summer. Figure 2.3 depicts the average capacity factors of the four countries in each month during the entire sample from 1985 to 2016. The U-shaped and the reversed-U-shaped patterns shown in panel (a) and (b) of this figure, respectively, highlight the complementarity of power output of wind and solar power plant throughout a calendar year. As shown in panel 
(b), the capacity factor of solar power plants in Finland - the farthest country from the Equator, in our sample - drops to virtually zero during winter, while southern European countries such as Spain and Greece have relatively large solar capacity factors.

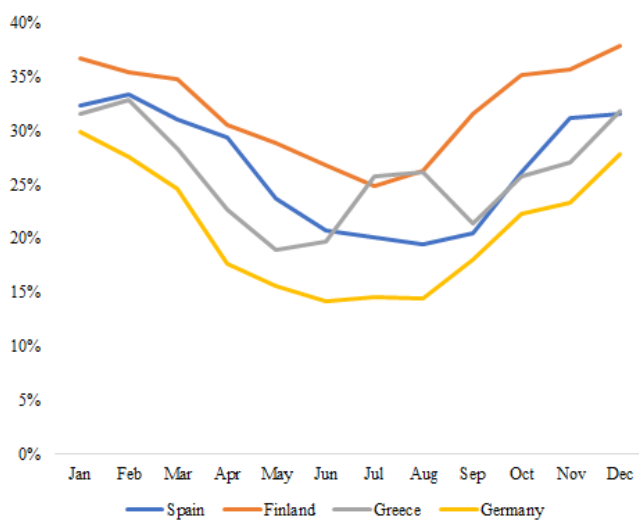

(a) Wind

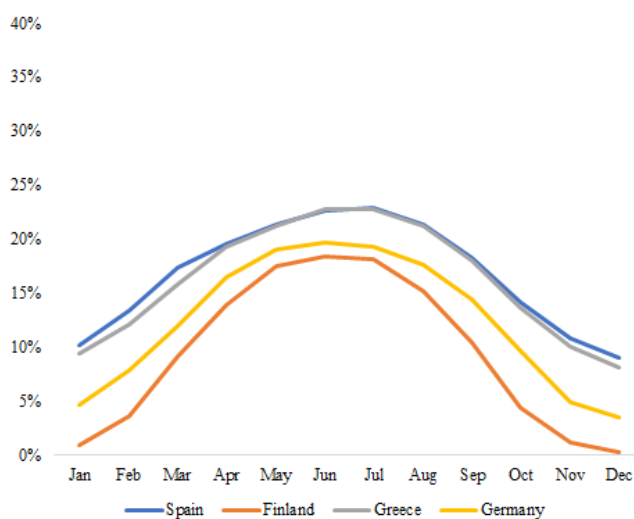

(b) Sun

Figure 2.3: Average of hourly capacity factors, per calendar month

Figure 2.4 shows the average capacity factors throughout a calendar month. Unlike the daily and yearly levels, capacity factors do not display seasonality across the days of a given month.

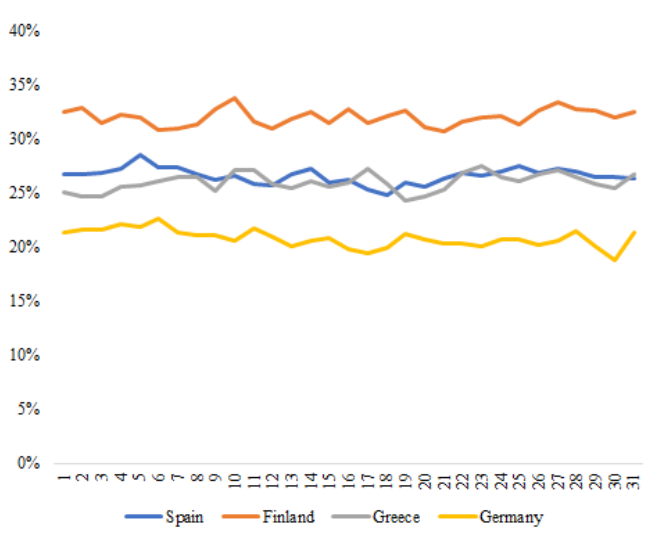

(a) Wind

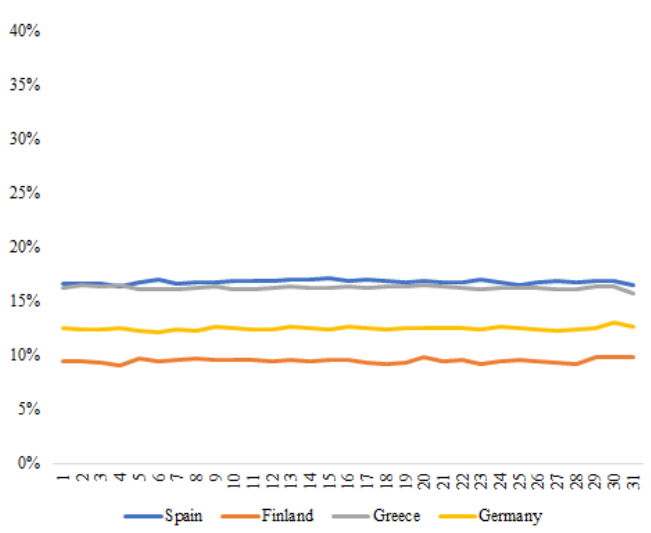

(b) Sun

Figure 2.4: Average of hourly capacity factors, per calendar day

Finally, Figure 2.5 shows the average capacity factors of wind and solar power over the entire sample from 1985 to 2016 for each hour of a day. As one would expect, the solar capacity factor in Greece, the easternmost country in our sample, peaks between 10AM 
to 11AM, while for Spain, the westernmost country in our sample, this number peaks between $12 \mathrm{PM}$ to $13 \mathrm{PM}$. As a general observation, the peaks in both power generation and demand occur at different times for different countries, due to the variations in the geographical coordinates across European countries. In other words, some countries experience peak demand at the same time as others experience surplus power generation. This observation has important implications for the geographical smoothing of power supply, in the context of an integrated European power grid.

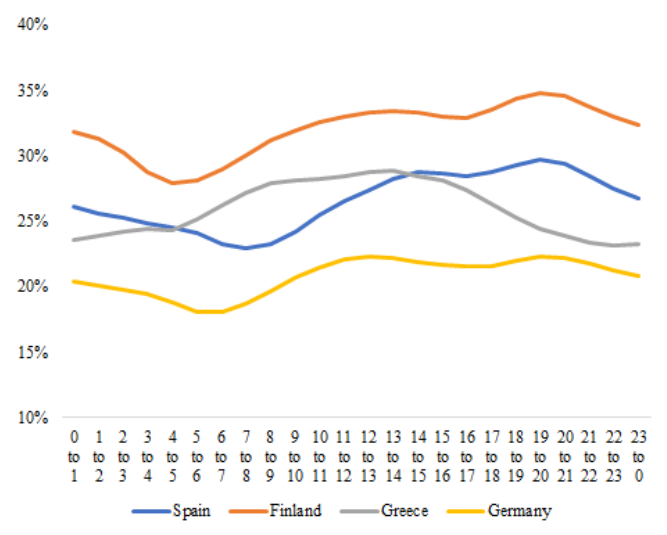

(a) Wind

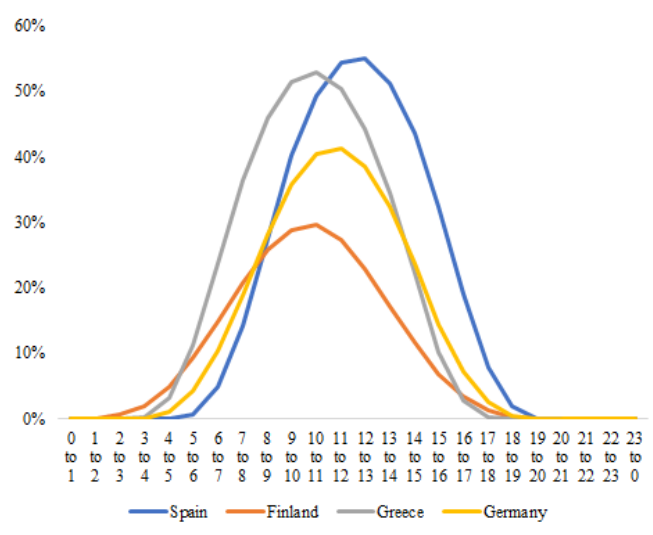

(b) Sun

Figure 2.5: Average of hourly capacity factors, per hour of a day

Table 2.1 provides a selection of summary statistics for the capacity factors time series. As we can see in panel (a), the minimum level of wind capacity factor is very small for all countries, yet non-zero. In other words, the efficiency of wind turbines never falls to absolute zero, and they can always produce electricity. This is not the case for solar power plants, as its capacity factor is zero during the night hours.

Furthermore, as the lower-right section of panel (b) shows, the correlation coefficients of solar capacity factors in different countries are relatively high, ranging from 0.69 to 0.88. This means that the maximum levels of solar power output occurs during similar time intervals for all countries. The opposite can be said about the countries' wind power output profiles. Indeed, as we can see in the upper-left section of panel (b), the correlation coefficients of wind capacity factors in different countries are very low, ranging from -0.03 to 0.14. Finally, as shown in the lower-left section of panel (b), the correlations between the capacity factors of wind and solar power plants are very small and often negative. This means that low values of wind power capacity factors occur at the same time as high values of solar power capacity factors. 
Table 2.1: Summary statistics of hourly capacity factors (1985-2016)

\begin{tabular}{|c|c|c|c|c|c|c|c|c|}
\hline & \multicolumn{4}{|c|}{ Wind Capacity Factor } & \multicolumn{4}{|c|}{ Solar Capacity Factor } \\
\hline & Spain & Finland & Greece & Germany & Spain & Finland & Greece & Germany \\
\hline \multicolumn{9}{|c|}{ Panel (a): Distribution } \\
\hline Ave. & $26.6 \%$ & $32.0 \%$ & $26.0 \%$ & $20.8 \%$ & $16.8 \%$ & $9.5 \%$ & $16.2 \%$ & $12.5 \%$ \\
\hline St. Dev. & $16.0 \%$ & $19.8 \%$ & $20.6 \%$ & $18.1 \%$ & $22.4 \%$ & $15.6 \%$ & $22.0 \%$ & $18.2 \%$ \\
\hline Min. & $0.69 \%$ & $0.07 \%$ & $0.0001 \%$ & $0.006 \%$ & $0.0 \%$ & $0.0 \%$ & $0.0 \%$ & $0.0 \%$ \\
\hline 5th Perc. & $7.6 \%$ & $6.1 \%$ & $2.9 \%$ & $2.1 \%$ & $0.0 \%$ & $0.0 \%$ & $0.0 \%$ & $0.0 \%$ \\
\hline 25th Perc. & $14.8 \%$ & $16.7 \%$ & $9.5 \%$ & $7.3 \%$ & $0.0 \%$ & $0.0 \%$ & $0.0 \%$ & $0.0 \%$ \\
\hline Median & $22.7 \%$ & $28.4 \%$ & $19.9 \%$ & $15.4 \%$ & $0.4 \%$ & $0.1 \%$ & $0.2 \%$ & $0.2 \%$ \\
\hline 75th Perc. & $34.6 \%$ & $43.7 \%$ & $38.1 \%$ & $28.9 \%$ & $33.9 \%$ & $13.6 \%$ & $32.3 \%$ & $21.9 \%$ \\
\hline 95th Perc. & $59.5 \%$ & $71.6 \%$ & $68.3 \%$ & $59.7 \%$ & $62.2 \%$ & $46.3 \%$ & $61.7 \%$ & $52.7 \%$ \\
\hline Max. & $94.9 \%$ & $96.8 \%$ & $96.5 \%$ & $96.5 \%$ & $76.3 \%$ & $72.1 \%$ & $76.5 \%$ & $73.6 \%$ \\
\hline
\end{tabular}

Panel (b): Correlation coefficients

\begin{tabular}{|c|c|c|c|c|c|c|c|c|}
\hline \multirow{4}{*}{$\begin{array}{l}\text { Wind } \\
\text { Capa- } \\
\text { city } \\
\text { Factor }\end{array}$} & Spain & & & & & & & \\
\hline & Finland & 0.03 & & & & & & \\
\hline & Greece & 0.02 & 0.08 & & & & & \\
\hline & Germany & 0.09 & 0.14 & -0.03 & & & & \\
\hline \multirow{4}{*}{$\begin{array}{l}\text { Solar } \\
\text { Capa- } \\
\text { city } \\
\text { Factor }\end{array}$} & Spain & -0.09 & -0.01 & 0.07 & -0.01 & & & \\
\hline & Finland & -0.17 & -0.13 & 0.00 & -0.15 & 0.69 & & \\
\hline & Greece & -0.13 & -0.05 & 0.03 & -0.04 & 0.80 & 0.82 & \\
\hline & Germany & -0.13 & -0.04 & 0.06 & -0.12 & 0.87 & 0.83 & 0.88 \\
\hline
\end{tabular}

Note: This table reports the summary statistics and correlation coefficients on hourly capacity factors from 1985 to 2016 for the four countries studied in this paper, namely Spain, Finland, Greece and Germany. 


\subsubsection{Power demand per country}

Figure 2.6 displays the average hourly electricity demand of all four countries in year 2017 (panel a), over each month of this year (panel b), over each day of the calendar month (panel c), and over the hours in each day (panel d). This figure reveals several interesting characteristics of electricity demand in Europe. As we can see in panel (a), for example, Germany and Spain are much bigger electricity consumers than Finland and Greece. This trivial observation has important implications for the country-wise technology distribution. Indeed, if cross-border power trade is restricted and countries need to meet demand by domestic power generation, the amount of installed capacity in each country is directly proportional with the national demand. This can result in very large installed capacity requirements, for countries with low capacity factors. Conversely, if power trade is unrestricted, the decision where to build power plants depends less on domestic demand and more on the capacity factors associated with the local weather patterns. In this case, countries with relatively low power demand and high capacity factors for one power technology could host the bulk of the respective power technology. Furthermore, according to Figure (b), the demand for electricity in 2017 peaked in winter and particularly in the month of January. According to Figure (c), there is no clear pattern between the electricity demand and the day of the month. And finally, as Figure (d) shows, the demand for electricity falls to its lowest levels between 3AM and 4AM, and it reaches its highest values between $11 \mathrm{AM}$ to $12 \mathrm{PM}$.

Table 2.2 provides summary statistics on the electricity demand data in 2017. As shown in panel (b), the correlation coefficients of the levels of electricity demand in the four countries are positive, ranging from 0.32 to a maximum of 0.80 . Therefore, even though their demand profiles partially overlap, the peak-load levels do not occur at the same time for all countries. If they did, the aggregate peak-demand would equal the sum of peak-demand levels in all countries, during the hour it would occur. This observation of peak-demand levels occurring at different times for different countries has important implications for the design of a pan-European power system. Indeed, at the European aggregate level, it corresponds to power demand smoothing over the hours in the day where peak-demand levels occur in all countries. However, the potential investmentrelated benefits arising from this phenomenon can only be achieved by an appropriate cross-border power grid infrastructure.

\subsection{Model design and calibration}

A European power sector relying entirely on wind and solar power generation technologies is expected to face significant challenges in ensuring a stable power supply. For this 


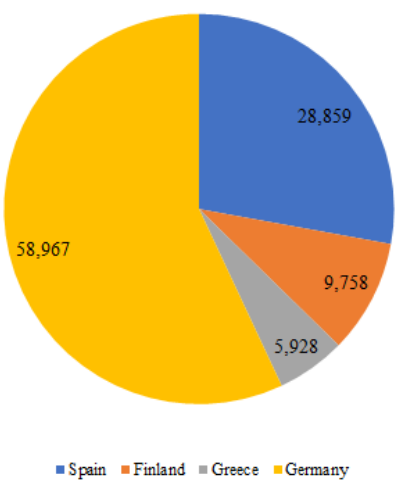

(a) Hourly average demand in year 2017 (MWh)

$$
120000
$$

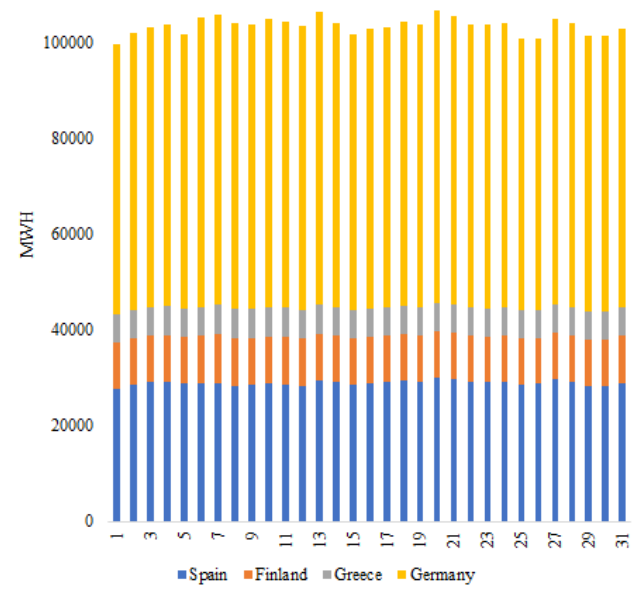

(c) Hourly average demand per calendar days (MWh)

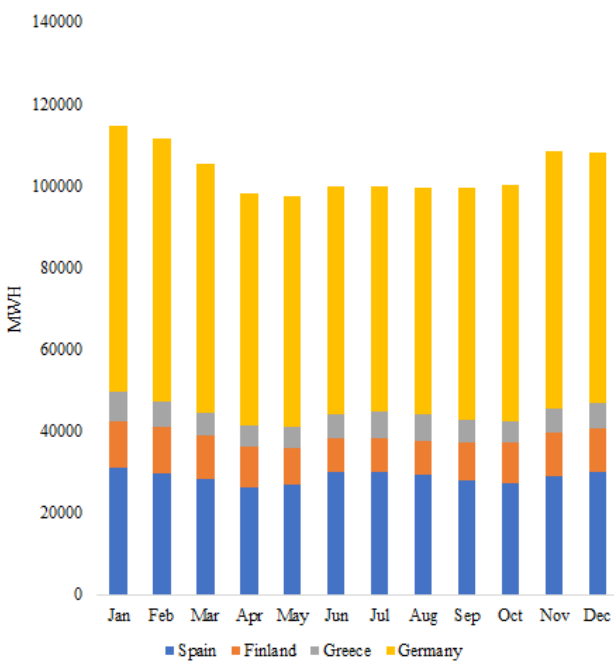

(b) Hourly average demand per calendar month (MWh) 140000

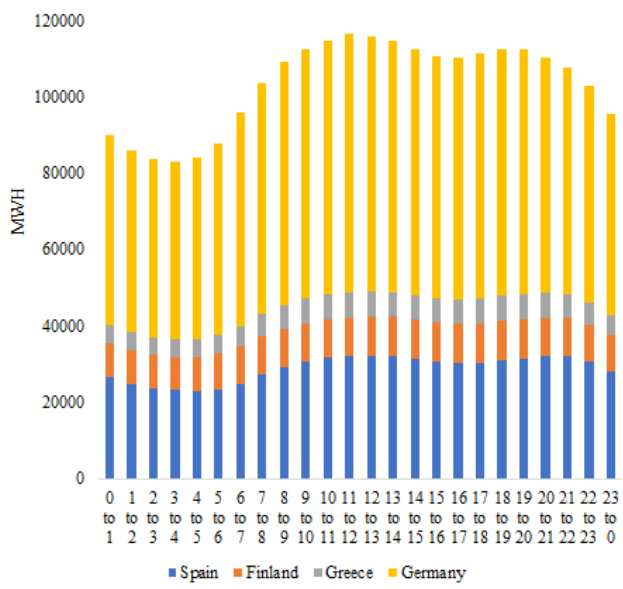

(d) Hourly average demand for each hour (MWh)

Figure 2.6: Electricity demand in Spain, Finland, Greece and Germany in year 2017 
Table 2.2: Summary statistics of hourly electricity demand in 2017 (MWh)

\begin{tabular}{|c|c|c|c|c|}
\hline & Spain & Finland & Greece & Germany \\
\hline \multicolumn{5}{|c|}{ Panel (a): Distribution } \\
\hline Average & 28859 & 9758 & 5928 & 58967 \\
\hline Standard Deviation & 4557 & 1451 & 1150 & 10417 \\
\hline Minimum & 18758 & 5916 & 3404 & 35801 \\
\hline 5th Percentile & 21879 & 7396 & 4222 & 42701 \\
\hline 25th Percentile & 24957 & 8674 & 5069 & 50159 \\
\hline Median & 29071 & 9722 & 5872 & 58809 \\
\hline 75th Percentile & 32270 & 10844 & 6644 & 67836 \\
\hline 95th Percentile & 36335 & 12042 & 8100 & 75411 \\
\hline Maximum & 41015 & 14374 & 9674 & 80316 \\
\hline \multicolumn{5}{|c|}{ Panel (b): Correlation coefficients } \\
\hline \multicolumn{5}{|l|}{ Spain } \\
\hline Finland & 0.36 & & & \\
\hline Greece & 0.75 & 0.32 & & \\
\hline Germany & 0.80 & 0.67 & 0.66 & \\
\hline
\end{tabular}

reason, energy balancing technologies are expected to make up a significant share in a cost-optimal energy portfolio. ${ }^{8}$ Therefore, the components of the energy portfolio considered in this model are: wind power technology, solar power technology, energy storage technology (EST) and cross-border grid extension (CBT), i.e. the power grid infrastructure needed for power trade. As VRE will make up a growing share of the energy mix, the two main options in ensuring the stability of the power system - EST and CBT - will become increasingly important. Therefore, a clear understanding of the relation between these two options is critical to informing an optimal design of a decarbonized European power system. The model developed in this section aims to provide such an understanding.

To this end, I develop a portfolio optimization model that explores how EST and CBT interact with each other in the context of a European power sector. In a first exercise, I look at four mutually exclusive configurations of the European power system: 1) Each country relies on domestic wind and solar power generation alone - i.e. no EST or CBT is allowed. This acts as a base scenario and helps us understand both the absolute and the relative contribution of each balancing technology; 2) each country

\footnotetext{
${ }^{8}$ As discussed in the Introduction Section of this chapter, the energy balancing technologies considered here are energy storage technologies and cross-border grid extension.
} 
introduces EST in their energy mix but cannot trade with other countries; 3) conversely, international power trade is allowed, but not EST; and 4) both EST and CBT contribute to a European power system. This framework will provide insights into the interactions between different energy technologies. For simplicity, I limit the analysis to the four European countries already mentioned, each representative of a different weather pattern. I thus disregard any interaction with other countries apart from these four. The model setting discussed above yields four mutually exclusive technological configurations which helps us understand the cost and technology implications of different energy mixes of a clean European power system. The results of this first exercise are discussed in subsection 2.6 .

In a second exercise, I move away from the static model of the optimal power system introduced above and address the process of integration of the different national power systems into a single, pan-European power system, as a gradual process. More specifically, I look at how both the aggregate cost and country-level energy mix change across six integration scenarios, corresponding to six different levels of power trade, namely:

1. Countries rely entirely on domestic power generation and storage capacity. This scenario is equivalent to the case of complete autarky in the second scenario discussed above.

2. Countries can access each other's storage capacities to store temporary excess power and meet temporary residual demand, but the total annual power generation in each country must be higher than or equal to annual power demand. This hypothetical scenario serves as an intermediate step between complete country isolation and a minimum level of power trade. It highlights the fact that important cost benefits arise with a minimum loss of energy security.

3. Countries can import stored and instantly generated power to meet up to $25 \%$ of their annual demand.

4. Countries can import stored and instantly generated power to meet up to $50 \%$ of their annual demand.

5. Countries can import stored and instantly generated power to meet up to $75 \%$ of their annual demand.

6. Power trade is completely unrestricted - i.e. international borders are non-existent, therefore countries can import power above the previous $75 \%$ limit.

These theoretical scenarios are intended as benchmarks against which to assess the cost and technology implications of an integrated European power system. I choose 
quartile-increments in the level of power trade due to the fact that they provide a sufficiently detailed level of analysis, as well as a compact framework for understanding the trade-offs between cost and energy security with which countries are faced, in the context of a pan-European energy system. This second contribution of the chapter is discussed in subsection 2.7.

\subsubsection{Model design}

The algorithm of the model is presented below:

Objective Function: The objective is to minimise the total cost of the power system, given by the sum of the costs of installed power plants and energy storage technology. The inputs of the model, i.e. the exogenous variables, are hourly demand, hourly capacity factors of solar and wind power technologies, and the costs for all technologies. In the different power trade scenarios, the levels of power trade are also given as inputs. The outputs of the model, i.e. the variables determined endogenously, are the cost-optimal time-invariant requirements of installed capacity of wind and solar power technologies, as well energy storage technologies. These requirements are calculated for individual countries and power trade levels. The results for each scenario are discussed at length in the next two sections.

$$
T S C=\operatorname{Cost}_{W} \times I C_{W}+\operatorname{Cost}_{S} \times I C_{S}+\operatorname{Cost}_{E S T} \times I C_{E S T} .
$$

In equation (2.1), $T S C$ stands for total system cost, $I C_{W / S}$ represents the total installed capacity of wind/solar power plants in $\mathrm{kW}$ and $I C_{E S T}$ denotes the total installed capacity of EST in kWh. Cost $_{W / S / E S T}$ are the total installation costs per unit for wind and solar power plants (in USD per kW) and of EST (in USD per kWh).

Constraints: The above objective function is subject to three constraints, detailed below. First, power demand $\left(D_{t}\right)$ is fully met in each time-step, i.e. hour. This is done by a combination of the wind and solar power generated at the same time step $\mathrm{t}$ (i.e. $\left.I C_{W} \times C F_{W, t}+I C_{S} \times C F_{S, t}\right)$ and the stored energy from previous periods $\left(E S_{t-1}\right)$, in the scenarios where this technology is available. Here, $C F_{W, t}$ and $C F_{S, t}$ are respectively the hourly wind and solar capacity factors.

$$
D_{t} \leq I C_{W} \times C F_{W, t}+I C_{S} \times C F_{S, t}+E S_{t-1}
$$

If generated power exceeds demand in any time-step t, i.e. $I C_{W} \times C F_{W, t}+I C_{S} \times$ $C F_{S, t}>D_{t}$, the excess power is stored, as long as there is available storage capacity 
$\left(I C_{E S T}\right)$. Conversely, if power generation at time $\mathrm{t}$ is less than demand at time $\mathrm{t}$, i.e. $I C_{W} \times C F_{W, t}+I C_{S} \times C F_{S, t}<D_{t}$, aggregated energy stored up until the previous time period $\left(E S_{t-1}\right)$ is used to meet residual load, as long as the storage capacity is not empty. The amount of stored energy $\left(E S_{t}\right)$ cannot become negative. In other words, there is no time period $t$ where power demand exceeds the sum of power generation and available stored energy. Indeed, the installed capacity requirements identified by the model are sufficient to cover demand and storage requirements in any time period. These two constraints are illustrated by equations 2.3 :

$$
\begin{aligned}
& I C_{W} \times C F_{W, t}+I C_{S} \times C F_{S, t}>D_{t} \rightarrow \\
& E S_{t}=\min \left(E S_{t-1}+(1-\alpha)\left(I C_{W} \times C F_{W, t}+I C_{S} \times C F_{S, t}-D_{t}\right), I C_{E S T}\right) \\
& I C_{W} \times C F_{W, t}+I C_{S} \times C F_{S, t}<D_{t} \rightarrow \\
& E S_{t}=\max \left(E S_{t-1}-\frac{1}{1-\alpha}\left(D_{t}-I C_{W} \times C F_{W, t}-I C_{S} \times C F_{S, t}\right), 0\right) .
\end{aligned}
$$

The round-trip efficiency of EST is less than $100 \%$ even for the most mature technologies. Hence, $\alpha$ represents the percentage of power loss during both the charge and discharge of EST.

Finally, for different self-sufficiency scenarios, I assume that countries must meet a minimum share $(\psi)$ of domestic load with domestically generated power, where $\psi$ takes five values between $100 \%$ and $0 \%$. The countries can meet residual demand by importing electricity.

$$
\sum_{t}\left(I C_{W, i} \times C F_{W, i, t}+I C_{S, i} \times C F_{S, i, t}\right) \geq \psi \times \sum_{t} D_{i, t} .
$$

In this restriction, $I C_{W, i}$ and $I C_{S, i}$ are the installed capacity of wind and solar power in country $i$, and $C F_{W, i, t}$ and $C F_{S, i, t}$ are the corresponding capacity factors in this country. Also, $D_{i, t}$ is electricity demand in country $i$ at time step $t$.

\subsubsection{Model calibration}

I optimise the problem outlined in equations 2.1 to 2.4 using hourly power demand data $\left(D_{t}\right)$ of all four countries in 2017 (see table 2.2) and randomly simulated samples of solar 
$\left(C F_{S, t}\right)$ and wind $\left(C F_{W, t}\right)$ capacity factors. All the expressions from equation 2.1 to 2.4 are linear. Therefore, I use a simplex algorithm with linear objective function and linear constraints for this optimization exercise to find the optimal installed capacity requirements for wind $\left(I C_{W}\right)$ and solar $\left(I C_{S}\right)$ power plants, as well as the optimal requirements for power storage capacity $\left(I C_{E S T}\right)$.

I run my optimization process 100 times. In other words, I simulate the wind and the solar capacity factors (i.e. $C F_{W, t}$ and $C F_{S, t}$ ) using random samples from the historical data of these time series from 1985 to 2016, for 100 times (see table 2.1). This simulation process is explained in detail in the following paragraph. In each optimization round by solving the optimization problem for the simulated wind and solar capacity factors to satisfy the hourly power demand of all four countries for 2017 - I obtain the optimal installed capacity for wind and solar power plants, as well as the optimal amount of power storage capacity. The results, reported in the following section, show the average optimal values over this 100 simulations. The appendix to this chapter reports the summary statistics of the results of all 100 simulations.

The random sampling of the hourly wind and solar capacity factors is conducted as follows: as discussed in the Data section, my historical data include hourly capacity factors for wind turbines and solar panels for 32 years from 1985 to 2016 . For each hour in each specific day of the year - e.g. 3 - 4pm on January 5 th - I randomly select a pair of wind and solar capacity factors from the 32 observations in the exact same hour and date in the previous 32 years. By repeating this procedure for each hour in each day of the year, I obtain a simulated time series of hourly capacity factors for wind and solar power for a fictitious year.

The unit investment costs for each energy technologies in the objective function (2.1) are the weighted average costs for each technology, as made available by IRENA (2017). These costs are identical for all four countries and are reported in table 2.5.2 below. ${ }^{9}$

\footnotetext{
${ }^{9}$ IRENA (2017) and IRENA (2018) only contain the figures for the historical evolutions of the costs of the energy technologies. In order to obtain the data behind these figures, I requested access to data and the technical documentation from IRENA. The unit cost for solar energy technologies is calculated as the average of the 2016 costs of all European countries for which data was provided, namely Italy, Germany, Spain and the United Kingdom. The unit cost for wind energy technology is calculated as the average between the minimum and maximum cost estimates for Europe, in 2016. The unit cost for energy storage technology corresponds to the unit cost for pumped-hydro storage in the reference scenario. The value for this cost estimate is the same in 2016 and 2030.
} 


\begin{tabular}{l|c}
\hline Energy technology & Installed unit cost (in ,000 US\$/ MW (MWH)) \\
\hline Wind & 1,550 \\
Solar & 1,220 \\
Storage & 21 \\
\hline \hline Note: This table shows the investment cost parameters for a \\
unit of installed capacity for each of the three energy technologies, \\
as calculated based on data from IRENA (2018) - for wind and \\
solar power technologies, and IRENA (2017), for energy storage \\
technologies.
\end{tabular}

Finally, I assume that the percentage of power loss during both the charge and discharge of EST (i.e. $\alpha$ in equation 2.3) is 5\%. This estimation is in line with IRENA (2017). For the scenarios where EST is available, I make the assumption than in the first hour of the year the installed storage technology is charged to $50 \%$ of its maximum capacity, i.e. $E S_{0}=50 \% \times I C_{E S T}$.

\subsection{Results}

The question under which conditions EST and CBT are either complements or substitutes has been addressed in previous research, albeit in different settings. For instance, Steinke, Wolfrum and Hoffmann (2013) look at the trade-off between CBT and EST in the context of a European power sector where yearly demand is met by an average of $100 \%$ of electricity from wind and solar power plants. They find that, in the absence of both CBT and EST, the required back-up capacity - in the form of biomass - for a $100 \%$ renewable European power system is $35 \%$ of yearly demand, which far exceeds the $10 \%$ limit of available resources. However, when countries can freely trade power, required back-up capacity drops to $20 \%$. If EST are also introduced in the power mix, the backup requirements further drop to $5 \%$ of annual demand - in the case of an EST capacity equivalent to storing energy up to one day - or to almost zero - in the case of an EST capacity that can store energy for up to one week. However, the levels of installed capacity of wind and solar power in Steinke, Wolfrum and Hoffmann (2013) are exogenous they are pre-determined, acting as an input to the model, rather than being determined endogenously, included in the technological portfolio to be optimized. Understanding how every component of the energy system - EST, CBT, as well as solar and wind power technologies - relates to each other is central to designing a cost-optimal decarbonized power system. This is because each power generation technology interacts differently with each of the power balancing technologies. For example, as the daily pattern of solar power generation follows the load curve, excess solar power could be exported to neighboring countries via CBT. In this case, solar power and CBT act as complements in 
meeting European power demand. Alternatively, if there is no CBT capacity, but there is available storage capacity, excess power can be used to charge the EST. EST can thus substitute CBT and vice-versa, in the case of excess power generation. On the other hand, wind power is mainly generated during hours of low power demand, thus there is no residual demand that any excess power generation could meet - at home or abroad. If EST capacity is available, however, excess power generation can be stored for use at a later time. In this case, also, wind power and EST act as complements in ensuring there is available power throughout the day. A model that determines the capacity requirements for each technology endogenously takes into account how each component of the power system relates to any other component, thus minimizing the aggregate cost of the power system - and not only the cost of a class of technologies, e.g. power balancing technologies. The framework put forward in this paper allows for the contribution of each power system component to be determined endogenously. While the model results of the cost variations between different energy technology portfolios are in line with previous research, the change of the overall energy technology mix across all scenarios of power trade presents a more intriguing picture.

This section is divided in two parts: sub-section 2.6.1 discusses how different energy technologies interact with each other in ensuring a stable power system, at the aggregate level across the four countries; subsection 2.6.2 zooms in on the experiences of individual countries.

\subsubsection{The cost-optimal energy technology portfolio at the ag- gregate level}

To understand how the two power balancing options (EST and CBT) can either complement or substitute each other in enabling a balanced power system, I look at the cost and energy technology mix over four scenarios: 1) neither of the two options is available - i.e. each country's power demand is met solely by instantly generated power from domestic over-installed capacity of wind and solar power, and, in the absence of EST and CBT, all excess power is curtailed; 2) only EST are available - i.e. domestic power demand is met both by instantly generated domestic power and from excess domestic power from previous periods, available in the storage capacity - but no power imports or exports are possible; 3 ) only CBT is possible - i.e. power demand is met by instantly generated power - both domestically and internationally - and excess power net of exports is curtailed, and 4) both EST and CBT are available. Each portfolio of energy technologies presented below meets the same level of power demand and is based on the same values for wind and solar power capacity factors. 
80000

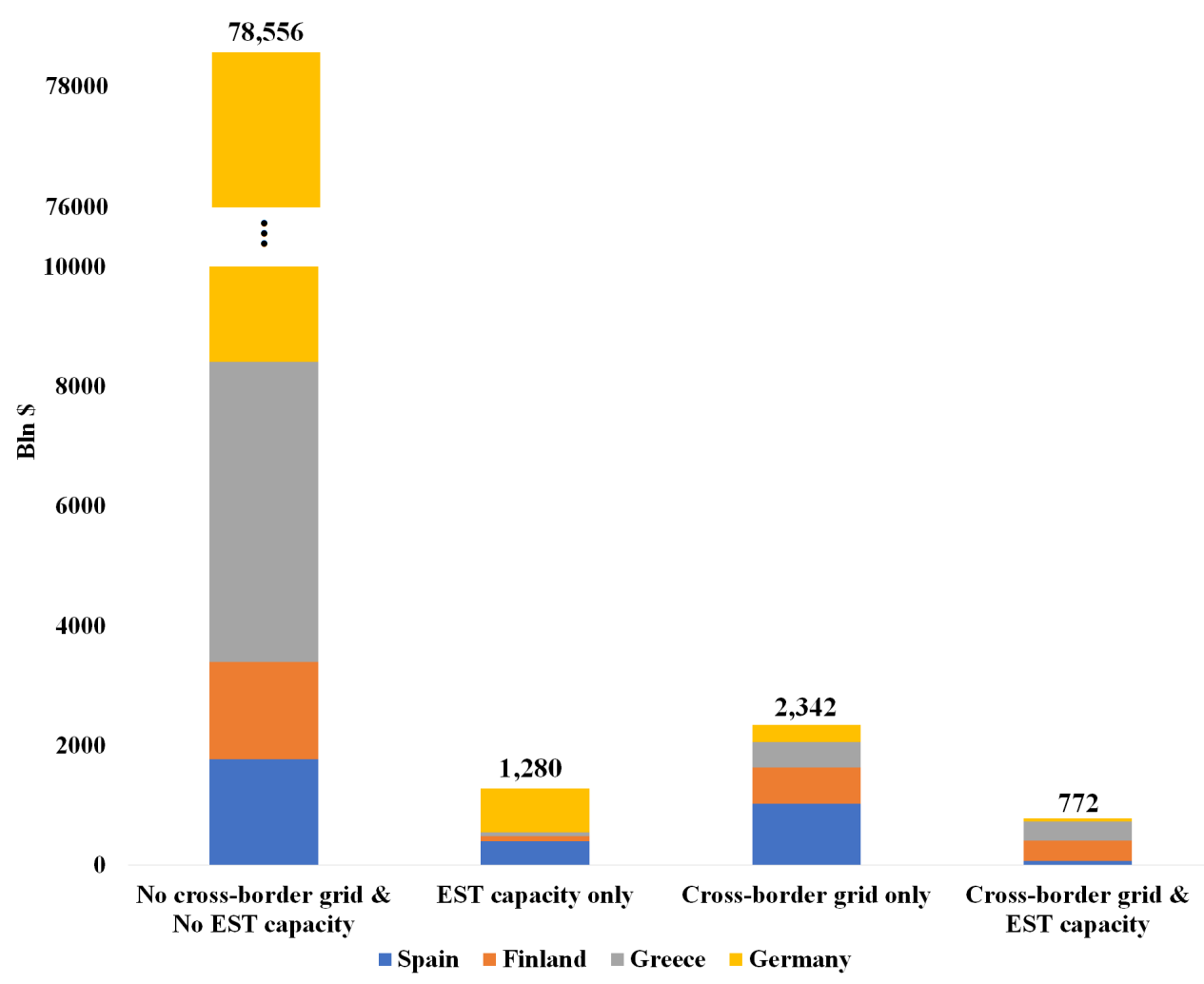

Figure 2.7: Cost of $100 \%$ renewable European power system 
Figure 2.7 shows how the total system cost changes across the four scenarios. A hypothetical power system, where neither EST nor CBT is allowed (scenario 1), would require a combined investment of 78.5 trillion USD for the four aforementioned countries. To put this number in perspective, it amounts to over 10 times the annual GDP of these countries combined. The reason behind this high number is the fact that, as countries cannot trade nor store the generated electricity surplus, the installed wind and solar power plants must generate enough power to meet the electricity demand instantly. As yearly peak demand only occurs for a few hours during the year, most of the installed capacity will remain idle for the rest of the time. This extreme hypothetical scenario acts as a basis to put into perspective the costs associated with the three scenarios discussed next. It helps highlight the role of even low levels of energy balancing technologies in achieving a least-cost, clean power system.

If energy storage is available (scenario 2), the resulting investment requirements decrease by over $98 \%$, down to 1.280 trillion USD. In this case, countries can store the excess power generated during low-demand periods for use during peak demand hours. This option significantly reduces the requirements for over-installed capacity for power generation. Indeed, in the previous scenario, the requirements for installed capacity are given by the highest level of hourly demand that occurs in a year. This generally happens for only a few hours of the year, during the winter months, and is several degrees of magnitude above average hourly demand. Therefore, the large requirements for installed capacity in the first scenario are used at full capacity for only several hours during the year.

When instead of storage capacity, cross-border grid capacity is available and countries can trade excess electricity (scenario 3), the level of required investment drops by $97 \%$, compared to the no CTB-no EST scenario, to 2.34 trillion USD. However, this number is $80 \%$ higher than that in the EST-only scenario. Each of the two options of energy balancing technologies, i.e. EST or CBT, can support a fully renewable European power system with no contribution from the other option - albeit at different costs. However, when both technologies are allowed in the energy mix (scenario 4), the overall investment requirements decrease to 772 billion dollar.

Figure 2.8 shows how the energy technology portfolio changes across the four scenarios of energy balancing technologies discussed above. In the absence of EST, installed capacity of wind and solar plants need to meet maximum load for each individual country - even if maximum load occurs for only several hours during the year. In other words, this scenario results in large installed overcapacity of power generation technologies.

As EST are introduced in each country's energy mix, excess power generation is stored for use at a later date. The correlation coefficient between the daily demand curve and solar output pattern is much higher than that of demand and wind power. Put differently, 
more excess power is generated during periods with high wind power generation. This means that, in the absence of export or storage possibility, oversupply of wind power is discarded. However, in the presence of EST, the excess power generated during times of low demand is stored for use at a later point in time. In other words, EST help smoothen power supply over time, reducing the need for over-installed capacity of wind power.

Indeed, as shown in Figure 2.8, introducing EST reduces the requirements for wind capacity more than the requirements for solar capacity. As discussed before, daily solar radiation follows the load curve and high wind speed occurs during the hours in the day when demand is lower. However, these relations reverse at the seasonal level: power demand increases during winter, when wind speed is higher and solar radiation is lower. Since a stable power system relies on the instant match between power generation and load, EST are used to store excess power generated during winter nights for later use, during day-time.

The contribution of each power technology to meeting demand changes both throughout the day and throughout the year. During warmer periods, the profile of sun power output matches the load during the day, while wind power output meets demand during evenings and early mornings. During colder periods, however, demand is significantly higher and less synchronized with the solar radiation pattern. In the absence of sufficient solar power generation, increased wind power output is used both to meet instant demand and to charge the storage capacity, for later use.
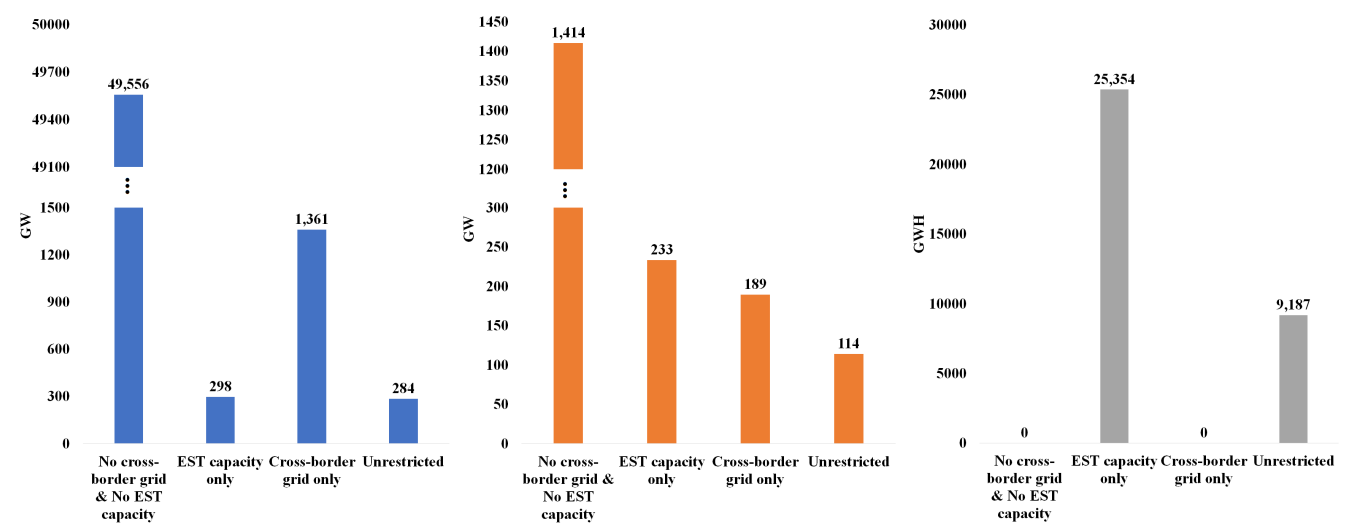

Figure 2.8: European energy technology mix

From left to right, the above figures show the optimal installed capacity for wind $(\mathrm{GW})$, solar $(\mathrm{GW})$ and storage technology $(\mathrm{GWH})$.

If CBT is introduced in the energy mix, instead of EST, both wind and solar installed capacity are reduced in comparison to the base case, where no EST nor CBT is allowed. Indeed, in the presence of CBT, country borders are virtually non-existent. Therefore, in the absence of storage possibilities, countries with excess wind or solar power generation 
can export residual power. In other words, CBT enables the geographical smoothing of power supply, reducing the need for over-installed capacity.

Finally, when both EST and CBT are included in the energy mix, solar and wind capacity are further reduced. Indeed, due to the availability of EST and CBT, the requirements for wind and solar power installed capacities drop to $284 \mathrm{GW}$ and $114 \mathrm{GW}$ respectively. This is equivalent to a distribution of $71.4 \%$ for wind and $28.6 \%$ for solar power capacity, in the optimal mix of power generation technologies.

The results discussed previously show that there are large gains stemming from power trade for the four countries under analysis - representative of the wider European power system - compared to an approach of isolated national power systems. These gains stem from the large variation in weather patterns across Europe. A completely integrated European power system virtually ignores national borders and considers all wind and solar resources pooled together to achieve a minimum-cost power system, with no consideration to the national distribution of embedded technology - i.e. the physical wind and solar power plants. Put differently, in the hypothetical case where the same country would have both the best solar and wind resources, it would be home to all power generation capacity needed for the entire EU, while all other countries would rely entirely on power imports. Conversely, in a scenario of complete self-reliance on national power systems, with no possibility of international power trade, each country must ensure sufficient installed capacity to meet domestic demand. The latter case would result in an important amount of over-installed capacity for each of the countries considered - with a correspondingly high cost.

The following subsection discusses how each country's energy technology portfolio changes between these two extreme scenarios of no possibility for trade and unrestricted trade.

\subsubsection{The energy technology portfolios for individual countries}

Solar and wind resources vary greatly across Europe. Some countries, such as Finland, are more endowed in wind resources, while others, e.g. Greece, enjoy more sun, on a yearly average (see Figure 2.2). If each country relied on its own resources alone and had no possibility to either import or export power, a high share of generated power would need to be discarded. If, however, an advanced power transmission network supported a fully integrated European energy system, the requirements for over-installed capacity would be much lower, due to a more efficient use of aggregate capacity. The improved aggregate capacity factor would result from wind and solar power capacities being installed disproportionately more - relative to domestic demand - in countries rich 
in wind and solar resources, respectively.

While an integrated approach yields significant cost reductions, it also brings about the politically sensitive issue of country-level energy security. Indeed, some countries would need to rely on a high share of power imports from net power exporting countries.

This situation raises the following conundrum: how can burden bearing and cost gains be shared equitably among all European countries? Since power demand curves vary less than potential power generation across countries, the status of either exporting or importing country is given by the exogenous endowment in wind and solar resources. ${ }^{10}$ On the other hand, the country-level distribution of the aggregate cost gains - the main rationale behind the power system integration - is a political question.

To better understand the implications of an integrated European power system for each of its member countries - that, in turn, would help inform an equitable mechanism for burden and cost sharing - Figure 2.9 and Figure 2.10 show the distribution of wind and solar installed capacity for each country and across each of the scenarios discussed in 2.6.1, respectively.

In the absence of storage possibility, installed wind power capacity needs to meet maximum load during dark hours, when solar power generation is zero. In the cold season, which is often more windy, the peak load is very high, compared to the rest of the year. If EST are not allowed, wind power plants operate at full capacity for a very limited number of hours during the year - the rest of the time, excess power generation is discarded. If EST are allowed in the national energy mix, wind power that would otherwise be discarded is stored and used to meet residual demand during peak time, thus resulting in a much lower installed capacity of wind power, as seen in the first two scenarios of Figure 2.9. ${ }^{11}$

As Figure 2.9 shows, with the availability of energy storage and cross border transmission, the requirements for wind power installed capacity decline sharply. However, these reductions are not homogeneous across countries. According to this figure, in the absence of storage and trade restrictions, Finland and Greece become the biggest producers of wind power in a fully integrated European power mix. This finding is intuitive, since these countries have the highest wind capacity factors (see Table 2.1).

Given the small surfaces of Finland and Greece, relative to Germany and Spain, the following questions arise: what is the upper limit of installed wind capacity that

\footnotetext{
${ }^{10}$ While the model considers energy storage and cross-border grid in the technology mix, their performance is similar for all countries, i.e. it does not depend on weather conditions.

${ }^{11}$ Interestingly, the relative position of each country, in terms of wind power requirements, in the EST capacity only-scenario, is very similar to their relative positions of actual installed capacity in reality: Germany has the highest installed wind power capacity - $61 \mathrm{GW}$, followed by Spain with $24.5 \mathrm{GW}$, While Finland and Greece have much lower installed capacities, of 2 and $3 \mathrm{GW}$, respectively (ENTSOE (2020)).
} 


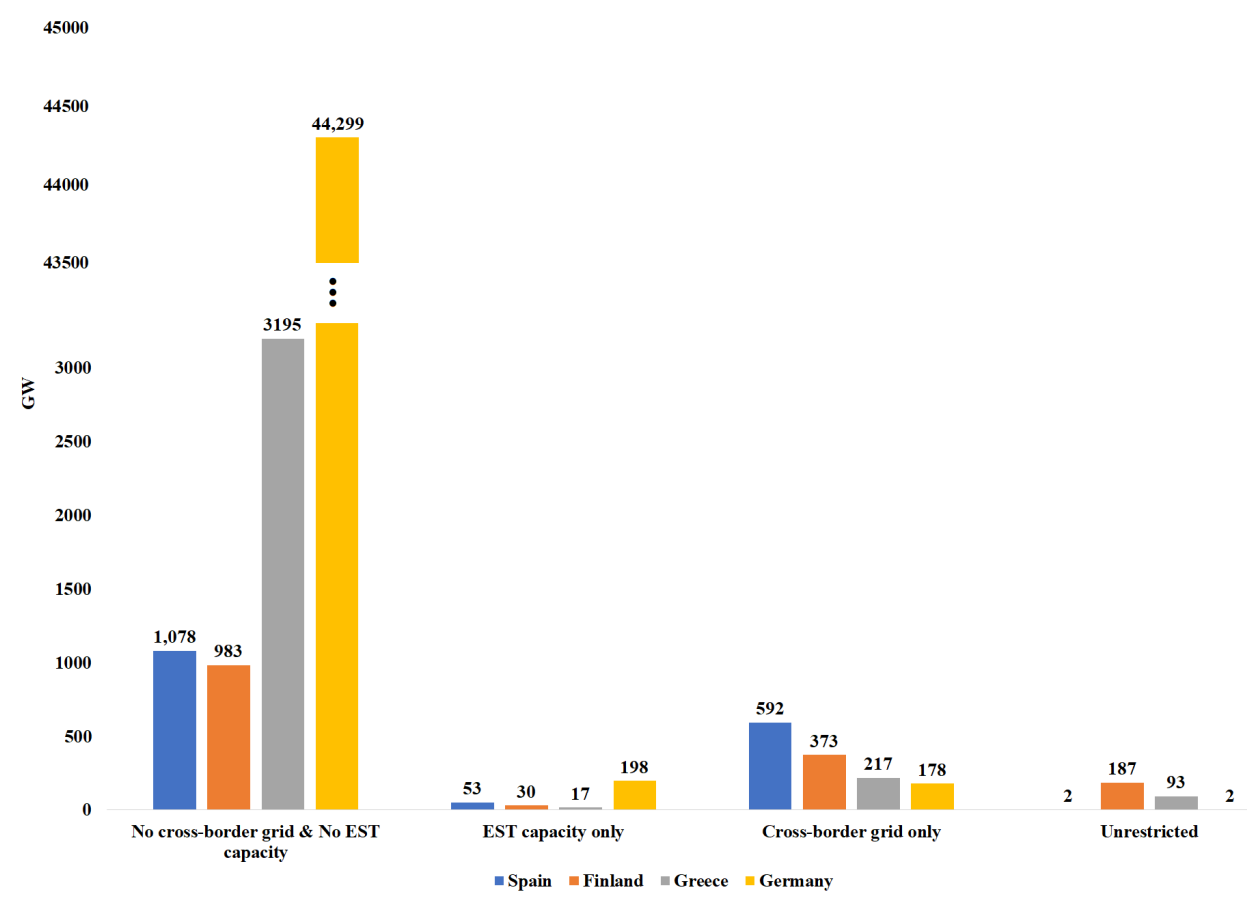

Figure 2.9: Wind installed capacity across countries

each of these countries could host? Are these limits in line with the results presented here? To answer this, it is useful to distinguish between the potentials for onshore and offshore wind installations. In terms of the potential for offshore wind power installations, both Finland and Greece have generous coastlines, which make for good locations for offshore wind turbines. At the EU level, the Offshore Renewable Energy Strategy, which was developed to support EU's climate ambitions to become the first carbon-neutral continent, sees an accelerated development for offshore wind power. Indeed, the targets for installed capacity for offshore wind are of $60 \mathrm{GW}$ and $300 \mathrm{GW}$ for 2030 and 2050, respectively, up from the current 12 GW (see European Comission (2020)).

In order to estimate the potential for onshore wind power installations in Finland and Greece, I use the estimations for land use of power technologies provided by the US National Renewable Energy Laboratory (NREL). According to these estimates, 1 GW of wind power requires $200 \mathrm{~km}^{2}$ of land. These estimates are in line with those found by IRENA (see IRENA (2019a) and US National Renewable Energy Laboratory (2020)). In Figure 2.9, Finland hosts $187 \mathrm{GW}$ of wind power and Greece hosts $93 \mathrm{GW}$. These numbers translate to $36.000 \mathrm{~km}^{2}$ and $20.000 \mathrm{~km}^{2}$ of land required for installed wind power plants in Finland and Greece, respectively. In turn, these estimates correspond to approximately $10 \%$ and $15 \%$ of the surfaces of Finland and Greece, respectively. 


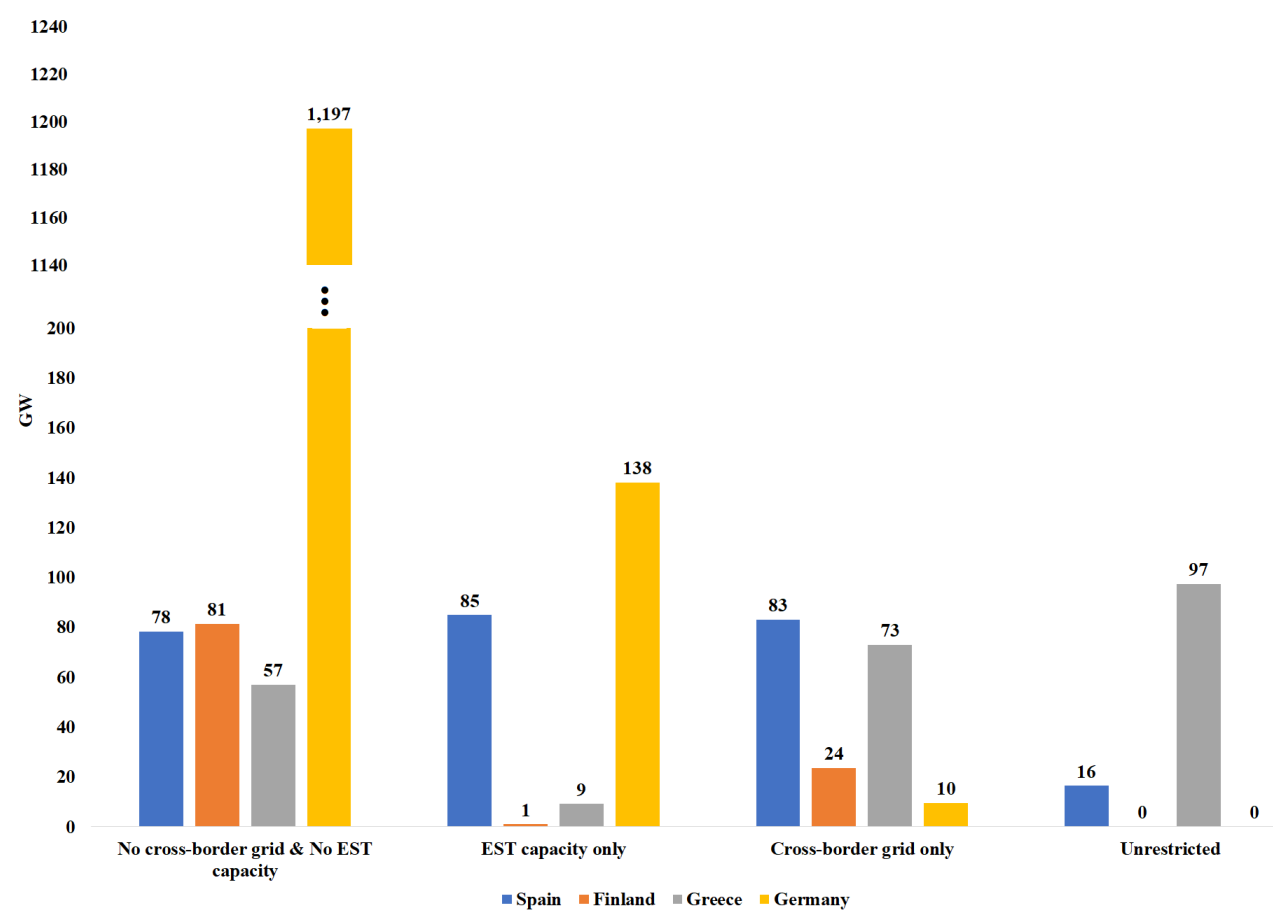

Figure 2.10: Solar installed capacity across countries

This conservative estimation ignores the considerable potential for offshore wind power, discussed above.

Figure 2.10 shows the evolution of the requirements for installed solar power capacity across the four scenarios. Similar to installed wind power capacity, solar capacity requirements are reduced significantly in a well-connected European power system in the EST-and-CBT case, compared to the other scenarios. Again, this reduction is not homogeneous across countries. Whether a country experiences a decrease or an increase in installed solar capacity is determined by the relative size of its solar capacity factor to the wind capacity factor. Indeed, when energy storage and cross border transmission are available, Spain and Greece become the only solar power producers in a fully integrated European energy mix, due to their higher capacity factors for solar power technology (see Table 2.1). ${ }^{12}$

As the aggregate capacity and its corresponding cost decrease in a well-connected

\footnotetext{
${ }^{12}$ According to IRENA (2019a) and US National Renewable Energy Laboratory (2020), the land requirement for $1 \mathrm{GW}$ of installed solar power is approximately $10 \%$ of that required for wind power. This implies that the $97 \mathrm{GW}$ of installed capacity of solar power in Greece, in the scenario where both EST and CBT are available (Figure 2.10), would require $10 \%$ of the land that the similar size of installed wind capacity would require, i.e. approximately $1.5 \%$ of the country's surface. This is a conservative estimate, considering that the existing build environment is a popular option for PV installation.
} 
European electricity system, the main challenge is to determine how to design an equitable mechanism for distributing this cost reduction across all member countries of a European power system. The reductions in required installed capacity are determined by both the importance of a country's wind and solar resources, relative to other countries, as well as by the relative importance of a country's wind resources, compared to its solar resources. Depending on these two levels of comparative advantages of capacity factors, a country is either a net electricity importer or an exporter, in a pan-European power system. Indeed, Greece - which displays the highest wind and solar capacity factors - becomes a net exporter of power, while Germany - with lower capacity factors - becomes a net importer.

To sum up, a completely integrated, pan-European power system is expected to bring about important shifts in the country-wise distribution of energy technologies. Some countries may experience an increasingly high reliance on power imports in exchange for significantly lower need for investments for their consequentially reduced requirements for solar and wind power technologies. Other countries would need to build up solar and wind capacities that would substantially exceed domestic requirements - in order to become a regional exporter of electricity. Nevertheless, simply allowing unrestricted power trade across all Europe does not imply that all barriers to a least-cost European power system disappear. On the contrary, the resulting country-wise redistribution of requirements for installed capacity brings about the challenges of cost burden and benefits redistribution, as well as that of the trade-off between economic gains and losses in energy security. While the design of a mechanism that would ensure such a redistribution is beyond the scope of the research presented here, it is important to note that it can benefit from previous experiences of international cooperation for environmental issues, as well as from related theoretical frameworks.

Indeed, there is no precedent for the integration of power systems of different countries, at the scale discussed in this chapter for the particular case of a pan-European power system. However, the challenge of designing a mechanism for determining the individual contributions for - and gains stemming from - a project that requires international cooperation is not new. A recent example is the 2015 Paris Agreement, whereby signatory countries pledged to limit global warming to "well below" 2 degrees Celsius above pre-industrial levels and closer to the 1.5 degrees Celsius limit (Rogelj, Den Elzen, Hohne, Fransen, Fekete, Winkler, Schaeffer, Sha, Riahi and Meinshausen (2016)). Similar to one of the questions addressed in this chapter, the Paris Agreement relies on individual countries agreeing to one common goal that would serve the interests of all of them. However, while the main objective of the Paris Agreement is broadly welcomed, the details underpinning its implementation are subject to reluctance and strong debate. Schacht (2020) suggests this can be improved by addressing the design of the agreement 
from a dynamic cooperative game-theoretical perspective. He provides an analysis of the cooperative game theory literature and finds that several characteristics identified in the literature as fundamental to the success of international cooperation are either missing from or only marginally considered in the design of the Paris Agreement. He concludes that more realistic modeling assumptions and representations of political processes could significantly improve the applicability of dynamic cooperative game theory to international climate agreements. This, in turn, could provide a common, scientifically grounded yardstick for all participants to assess the successful implementation of an international agreement. Kaul (2012) argues that the co-existence of both national and supranational levels in environmental decision making in the EU can accelerate the transition of individual member states to a low-carbon economy, and can help position the EU as a world leader in progress on climate issues. A detailed discussion of the political hurdles ahead of and the mechanisms for achieving a lowest-cost EU clean energy system is beyond the scope of the research presented in this chapter. However, as discussed here, this issue can be operationalized using findings from the cooperative game-theoretical literature and empirical analysis of instances of international cooperation on environmental issues.

The country-level gains stemming from a well-connected European energy system thus transcend the economic dimension and point towards a new paradigm of European energy policy-making. Some of the most important rationales underlying these new power relations are considerations of energy security - that is, how strongly reliant individual countries are willing to be on electricity imports from other European countries. The following section conceptualises the issue of energy security in terms of thresholds of power system inter-connection in order to gain some insights into the above-mentioned trade-off.

\subsection{Aggregate cost and country-level technology mix across integration thresholds}

In subsection 2.6 I discussed how each energy technology interacts with each of the other components of the power system, in the context of a fully renewable European power system. I found that the relation between any two technologies shifts not only across scenarios, but also with the level of seasonality within a certain scenario. Moreover, I discussed the implications of a completely integrated European electricity sector for each country - that is, whether it becomes either a net importer or exporter of electricity. The results emphasized that, in the absence of an appropriate cost-and-gains sharing mechanism, the cost savings resulting from reduced requirements for installed capacity 
are not distributed uniformly across European countries.

The results presented previously focused on economic and technical considerations and only marginally addressed the political aspect. The current section focuses on the political implications of the discussion of a clean European power system - conceptualized as thresholds of European power trade, or caps on electricity imports. ${ }^{13}$

The only change in the model setting is therefore an additional constraint on the level of domestically generated power (see equation 2.4). The model has the same output variables, i.e. it calculates the optimal levels of requirements of installed capacity for wind and solar power technologies, EST and the corresponding costs. I look at the following six scenarios of power trade integration:

1. countries are entirely isolated and self-sufficient - corresponding to the EST-only case in the previous section;

2. countries can access the international storage capacity, as long as annual domestic power generation is sufficient to meet annual demand. In this case, the storage capacity is accessible to all countries and excess power generated in one country can be used to meet demand in a different country, as long as annual power demand does not exceed annual power generation for any country. This hypothetical scenario serves as an intermediate step between complete country isolation and a minimum level of power trade. It highlights the fact that important cost benefits arise with a minimum loss of energy security;

3. countries meet at least $75 \%$ of their annual load by power generated domestically - i.e. power imports make up no more than $25 \%$ of a country's annual electricity consumption;

4. countries meet at least $50 \%$ of hourly load by domestic power generation;

5. they meet at least $25 \%$ of load by power generate domestically, i.e. they can import up to $75 \%$ of yearly electricity needs and

6. there is no cap on imports, thus no minimum required domestic generated power, i.e. power trade is unrestricted.

I first discuss how the overall investment requirements of a European power system behave across these scenarios. I then turn to the underlying dynamics of wind and solar installed capacities for each country and across all scenarios. Finally, I discuss the resulting requirements for EST capacity across the integration scenarios, at the aggregate European level.

\footnotetext{
${ }^{13}$ The model considers exclusively caps on imports as a domestic decision. External supply shocks are not discussed.
} 


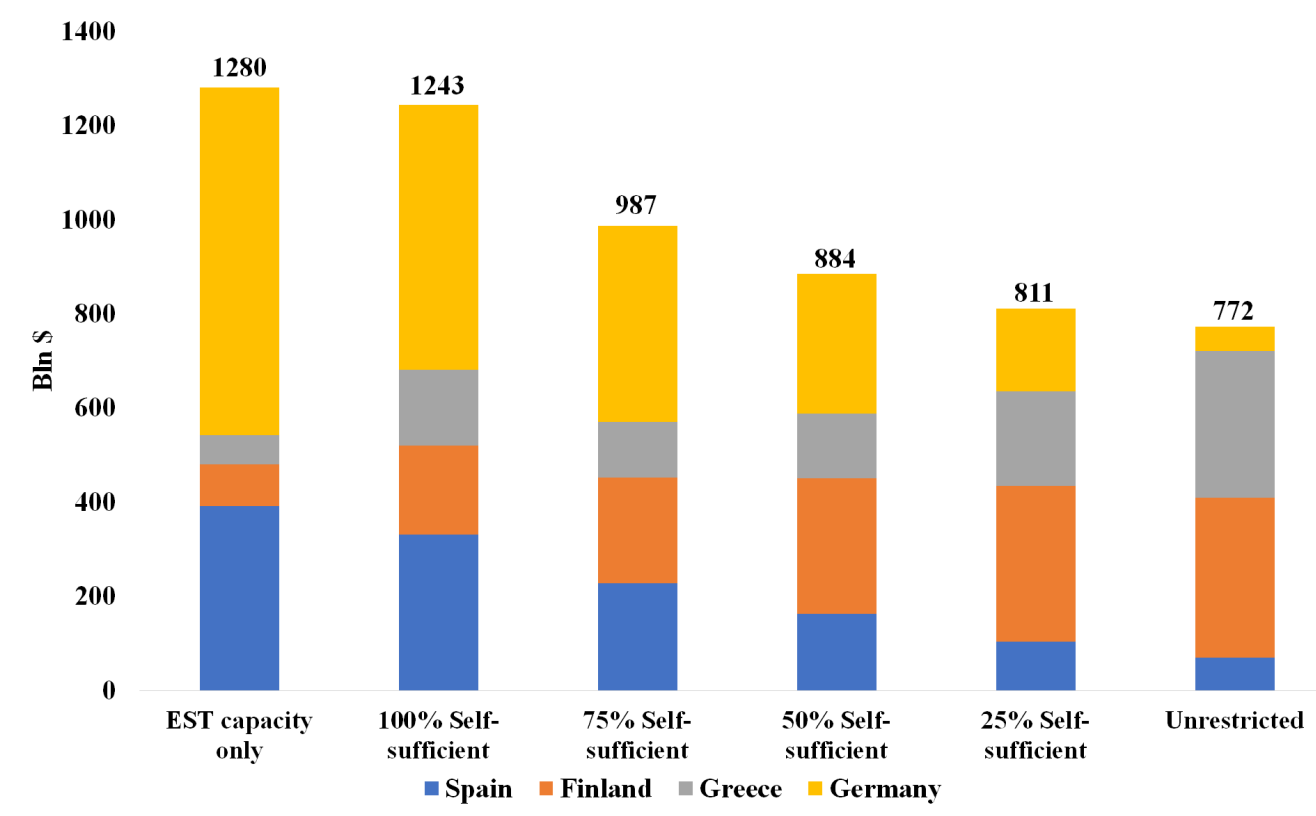

Figure 2.11: Cost of a fully renewable European power system for different trade integration levels

\subsubsection{The aggregate investment requirements for a European power system across integration thresholds}

Figure 2.11 shows the levels of investment requirements for all scenarios of power system integration considered here. As defined in the previous section, in the case of "EST capacity only" there is no possibility for power trade. As this restriction is relaxed, electricity trade increases gradually. A level of self-sufficiency of $\psi \%$ means that countries must meet at least $\psi \%$ of their annual electricity demand from domestic power generation (see equation 2.4). For simplicity, I consider that aggregate excess power generation is stored in a shared storage facility.

The overall cost reduction between the two extreme scenarios of entirely isolated and fully integrated power systems is $39.7 \%$, dropping from 1.280 trillion USD to 772 billion USD. This difference represents the upper limit of aggregate potential cost savings underlying a completely integrated, pan-European electricity system.

As Figure 2.11 shows, removing the trade restriction yet insisting on $100 \%$ annual self-sufficiency reduces the overall costs by 37 bln USD, or 2.9\%. Further relaxing the $100 \%$ self-sufficiency constraint results into much larger cost reductions. For example, if countries rely on power imports up to the level of $25 \%$ of demand ( which corresponds to $75 \%$ self-sufficiency), the overall cost of the pan-European electricity system drops to 987 


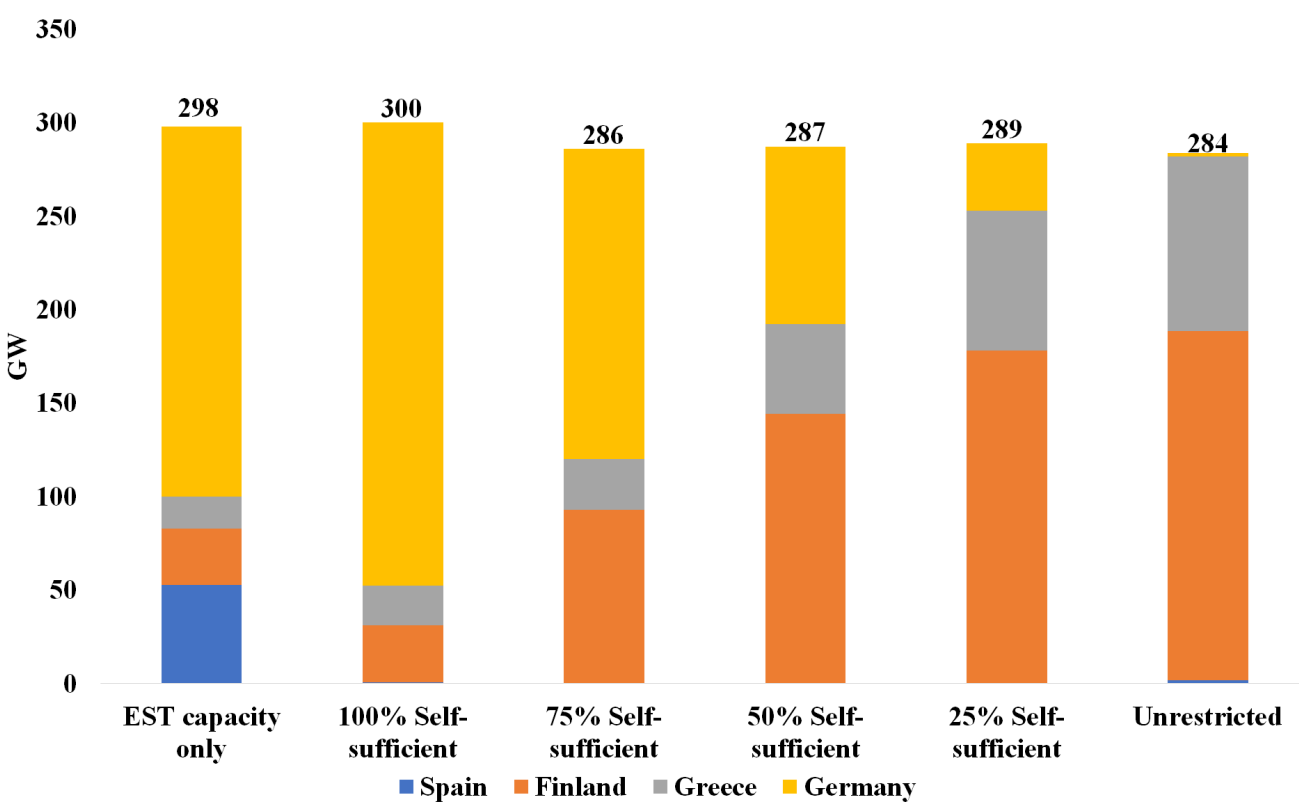

Figure 2.12: Country distribution of installed capacity of wind power for different trade integration levels

bln USD. These cost savings are due to the fact that wind and solar power technologies can be located in countries with higher capacity factors.

\subsubsection{Energy technologies across different integration thresholds}

Figures 2.12 and 2.13 show the evolution of installed capacity of wind and solar power, respectively, for each country and across all scenarios. I observe country-level shifts of installed capacity of both wind and solar power not only in absolute, but also in relative terms. In other words, some countries will experience an increase in their requirements for installed capacity, as power systems become more integrated.

\section{Installed wind capacity across countries and integration thresholds}

As we can see in Figure 2.12, with further integration of the power system in Europe, the overall investment requirements for wind power do not change considerably. As we saw before, hourly wind power generation is weakly correlated with hourly demand. When storage capacity is available - as is the case for all scenarios in Figure 2.12 - the excess wind power generation can be stored for use at a later time.

In the case of no cross border trade (EST capacity only), all countries have domestic storage capacity. As hourly solar power generation is strongly correlated with demand, 
the storage capacity is mainly used for electricity produced during times of high wind power generation. The requirements for wind power installed capacity are proportional with the demand level, for all countries.

However, as trade restrictions are relaxed, the optimal location for installing the wind turbines changes. When trade is possible, but countries must meet $100 \%$ of their annual electricity demand with national production, the requirements for installed capacity in Germany, the largest electricity consumer, increase significantly, while those for Spain vanish. As trade restriction are further relaxed, installed capacity in Greece and Finland increases significantly. This is due to their much higher average wind capacity factors. In a fully integrated European electricity system virtually all of the wind power plants are installed in these two countries. In other words, while the aggregate level of installed wind power capacity changes very little across the trade integration scenarios, the country-level distribution of these requirements changes substantially.

\section{Installed solar capacity across integration thresholds}

The change in aggregate solar power capacity is more pronounced in comparison to the reduction in wind power capacity, as trade barriers between countries are lifted. As shown in Figure 2.13, in the case where no trade is possible (first scenario), the optimal solar capacity is approximately $233 \mathrm{GW} .{ }^{14}$ However, as trade restrictions are lifted, this number declines to less than half, in the case of unrestricted trade.

Despite the difference in the aggregate levels, the changes in requirements for installed solar capacity across the power system integration thresholds resemble those of wind capacity, when we look at the individual countries. In the case of unrestricted trade, all solar capacity is installed in Greece and Spain, the countries with the highest solar capacity factors.

\section{EST capacity across integration thresholds}

Figure 2.14 shows the changes in EST capacity across the integration thresholds. As expected, the requirements for EST capacity are lower in the " $100 \%$ self-sufficient" scenario, compared to the "EST capacity only" scenario. When countries are allowed to access each other's storage capacities - both to charge them with excess generated power and to use them in meeting residual load - each country essentially has an additional source for meeting demand, thus reducing the individual requirements for EST. Indeed, peak production differs across countries (see Figure 2.5), therefore countries do not always compete for available storage capacity at the same hour. In addition, wind capacity

\footnotetext{
${ }^{14}$ This value is less than four times larger than the current combined installed capacity of solar power in the four countries, which is approximately $60 \mathrm{GW}$ (ENTSOE (2020)).
} 


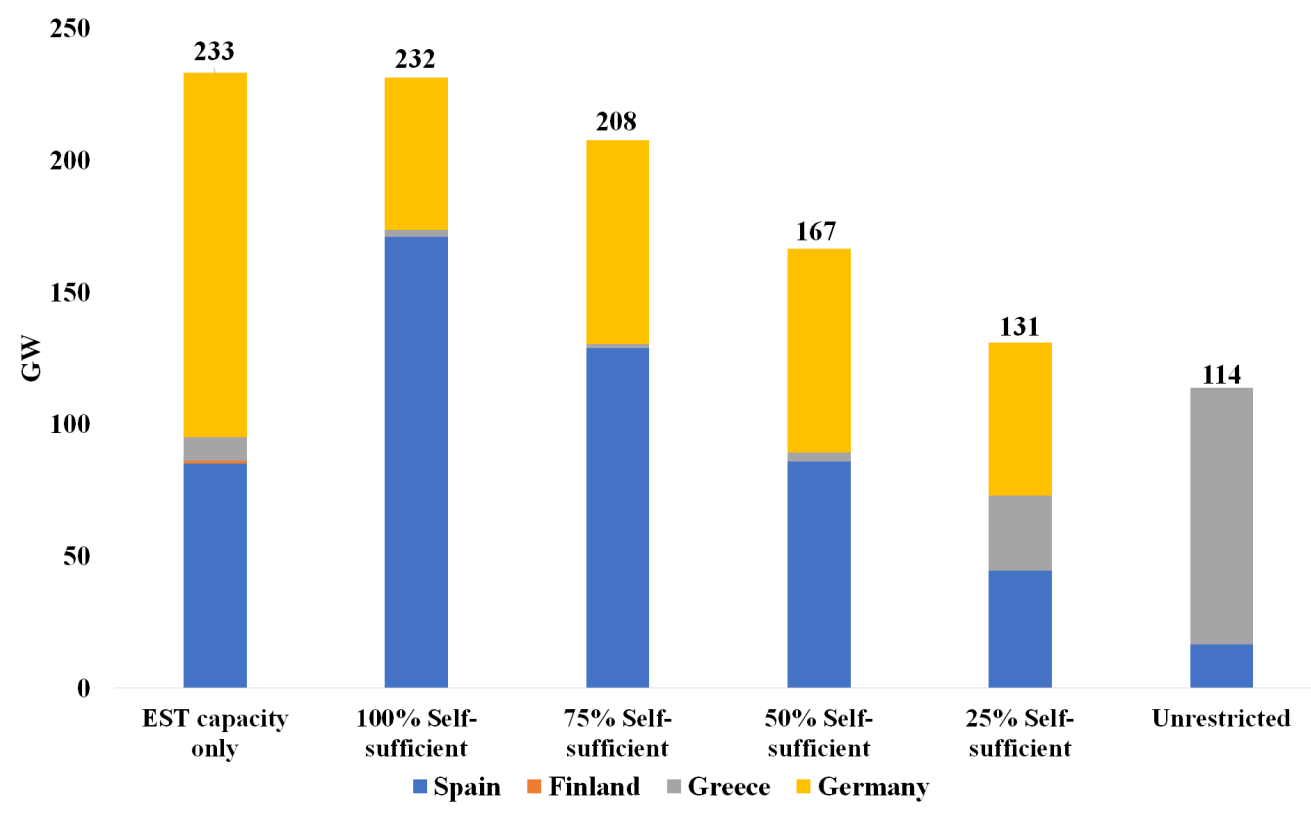

Figure 2.13: Country distribution of installed capacity of solar power for different trade integration levels

factors - and their patterns - differ across countries as well, which means that there is production of excess electricity during all hours, which can charge the storage capacity.

EST capacity requirements decline sharply as trade restriction are lifted. The requirements for storage capacity in the "unrestricted trade" scenario correspond to $36 \%$ of the requirements in the "no trade" scenario.

\subsection{Concluding remarks}

The ongoing European electricity system transition is a complex process with important technological, economic and political implications. This chapter attempts to present a framework for understanding the trade-offs between these dimensions.

In a first step, it looks at how different energy technologies interact with each other, with a focus on energy storage technologies and over-border grid extension and finds that these two energy balancing options can individually support a clean European system, alongside RET, but a cost-optimal system relies on both options. More importantly, it finds that the relations between each balancing option and each RET vary significantly - and even more so when we look at the experiences of individual countries.

In a second step, this chapter looks at intermediary scenarios between the two extreme cases of complete country isolation - corresponding to the EST-only scenario - and 


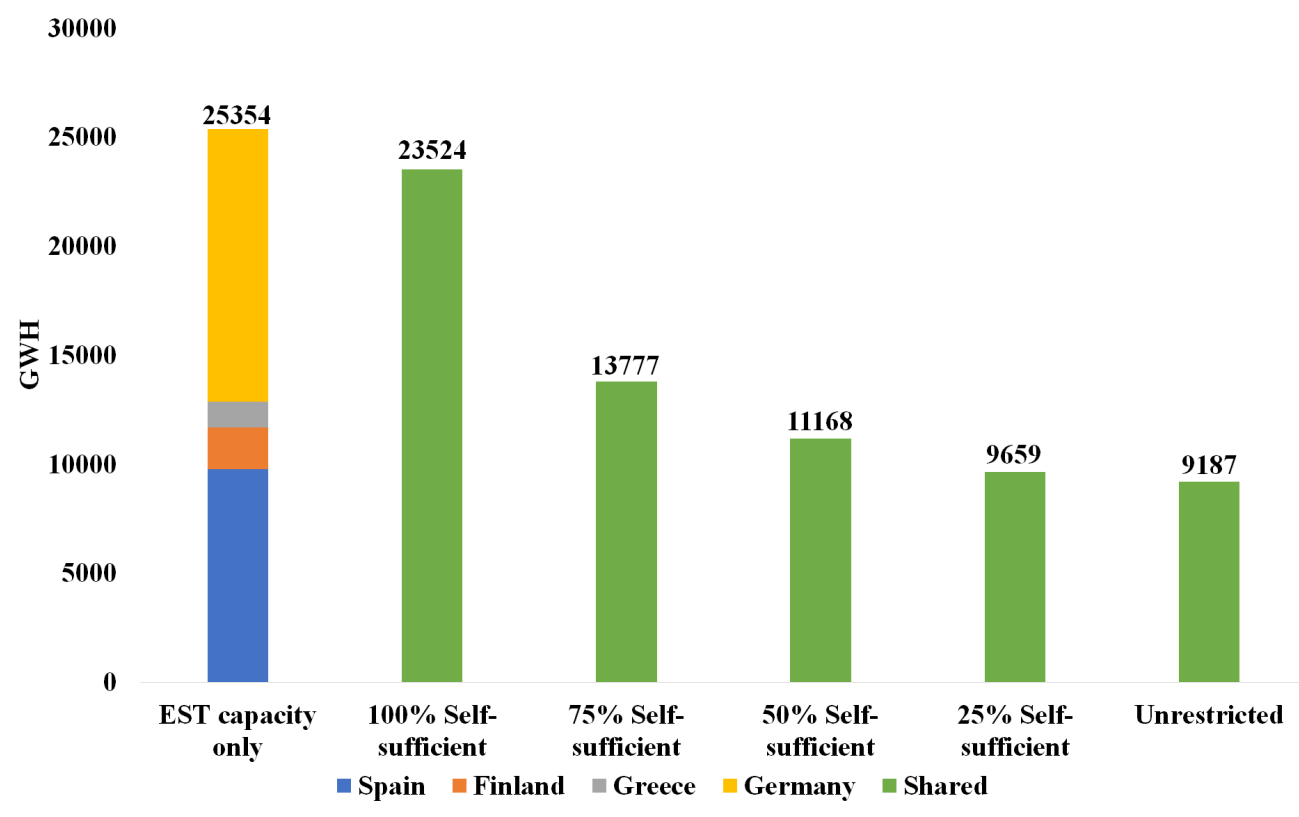

Figure 2.14: EST capacity requirements, in gigawatt-hours for different trade integration levels

unrestricted power trade - corresponding to the EST-and-CBT scenario. This analysis reveals important insights into the change of the requirements for each energy technology across integration thresholds and across countries. I find that access to international storage capacity alone, even when countries must meet $100 \%$ of annual demand from domestic power generation, has a large impact on the European energy mix - and its related cost. Indeed, it reduces the requirements of costly storage capacities - which, in the absence of CBT, remain idle for large periods of time.

Furthermore, I find that, as trade restrictions are relaxed, the required aggregate wind and solar capacity continuously fall. This aggregate decrease has different implications for different countries. Countries with relatively higher capacity factors for either wind or solar power experience significant increases in capacity requirements, thus becoming net electricity exporters, while countries with relatively lower capacity factors will increasingly rely on electricity imports. Therefore, there is a strong heterogeneity in how countries experience the changes in installed capacity of each technology across integration thresholds.

During the process of power trade integration, some countries are faced with the decision of further integration, at the cost of incurring additional installed capacity. Moreover, different countries are faced with this decision at different points in the power integration system. While the increased installed capacity seems, at first, a higher cost for 
an individual country, it can be covered by the aggregate cost savings. Since overall cost savings are significantly higher than the sum of the individual country-level cost increases, net cost savings would have to - at least partly - finance an incentive mechanism so that all countries agree on the desired level of power systems integration early on in this process.

However, while economic gains are relatively easy to determine and compare, the same does not hold for the political aspect of energy security. As discussed in Section 2.7, a clear understanding of the trade-off between economic and political considerations is key to achieving a cost-optimal European electricity system. One way of approaching this trade-off is to operationalize the issue of energy security as levels of power system integration.

These findings point to the importance of having clear targets for RET and European power system integration early-on in the integration process, as opposed to addressing this process as a linear scaling up/down of a determined energy mix of a country that becomes a net electricity exporter/importer. The results also show that the aggregate cost-optimum does not occur at the same point in the integration process, as all countrylevel cost-optima. Thus, an incentive mechanism is needed that would ensure a fair distribution of cost and benefits underlying a clean European power system, across all member countries. The framework advanced in this paper aims to be a first step in this direction. 


\section{Appendix 2.A Simulation results}

As explained in the Model Calibration section, I randomly sample pairs of hourly wind and solar capacity factors (i.e. $C F_{W, t}$ and $C F_{S, t}$ ) 100 times. I then run the optimization problem outlined in equations 2.1 to 2.4 for 100 times, using these randomized datasets of solar and wind capacity factors $\left(C F_{S, t}, C F_{W, t}\right)$. For each optimization, I obtain the results for the optimal requirements for install capacity of wind and solar power plants and the optimal values for the storage capacity. I therefore have 100 resulting values for each output variable. The analysis presented in this chapter is based on the average value of these model results. Table 2.3 in this appendix reports the average and the standard deviation of all 100 model results, for each scenario discussed in this chapter. 
Table 2.3: Summary statistics of the 100 simulations results

\begin{tabular}{|c|c|c|c|c|c|c|c|c|}
\hline & Spain & Finland & Greece & Germany & Spain & Finland & Greece & Germany \\
\hline $\begin{array}{c}\text { No cross-border grid \& } \\
\text { No EST capacity }\end{array}$ & 1767.6 & 1624.1 & 5023.2 & 70141.0 & 346.7 & 390.4 & 2373.2 & 39650.4 \\
\hline EST capacity only & 390.6 & 88.7 & 62.5 & 737.9 & 8.5 & 6.4 & 2.0 & 37.1 \\
\hline $75 \%$ Self-sufficient & 227.6 & 225.0 & 117.5 & 416.7 & 9.1 & 23.7 & 26.1 & 9.7 \\
\hline $50 \%$ Self-sufficient & 162.3 & 287.9 & 136.7 & 297.0 & 7.7 & 32.5 & 41.9 & 9.2 \\
\hline $25 \%$ Self-sufficient & 103.8 & 329.6 & 201.0 & 176.7 & 13.6 & 35.5 & 46.4 & 12.1 \\
\hline Unrestricted & 69.3 & 340.2 & 311.6 & 51.0 & 43.6 & 30.3 & 53.8 & 14.2 \\
\hline
\end{tabular}

\begin{tabular}{|c|c|c|c|c|c|c|c|c|}
\hline & Spain & Finland & Greece & Germany & Spain & Finland & Greece & Germany \\
\hline $\begin{array}{c}\text { No cross-border grid \& } \\
\text { No EST capacity }\end{array}$ & 1078.3 & 983.3 & 3195.2 & 44299.4 & 234.8 & 273.8 & 1538.4 & 25946.4 \\
\hline EST capacity only & 52.7 & 30.4 & 16.9 & 197.8 & 1.7 & 0.3 & 0.6 & 4.2 \\
\hline $75 \%$ Self-sufficient & 0.1 & 92.9 & 27.2 & 165.7 & 1.1 & 13.2 & 17.3 & 7.7 \\
\hline $50 \%$ Self-sufficient & 0.2 & 144.3 & 47.8 & 95.1 & 1.6 & 20.9 & 24.7 & 10.1 \\
\hline $25 \%$ Self-sufficient & 0.4 & 177.7 & 75.0 & 36.0 & 2.5 & 21.5 & 22.1 & 19.3 \\
\hline Unrestricted & 1.6 & 187.0 & 93.5 & 1.6 & 4.8 & 17.4 & 19.9 & 8.5 \\
\hline
\end{tabular}

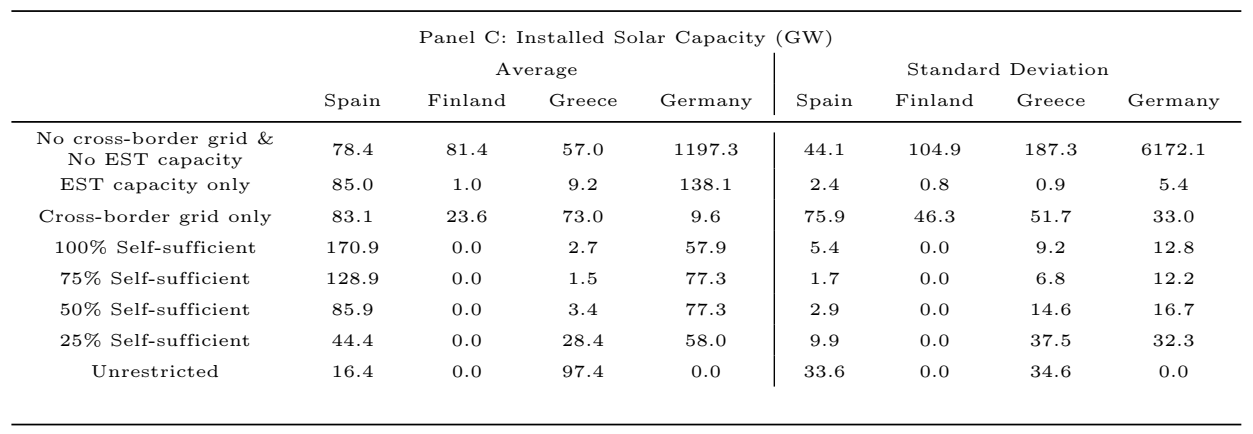

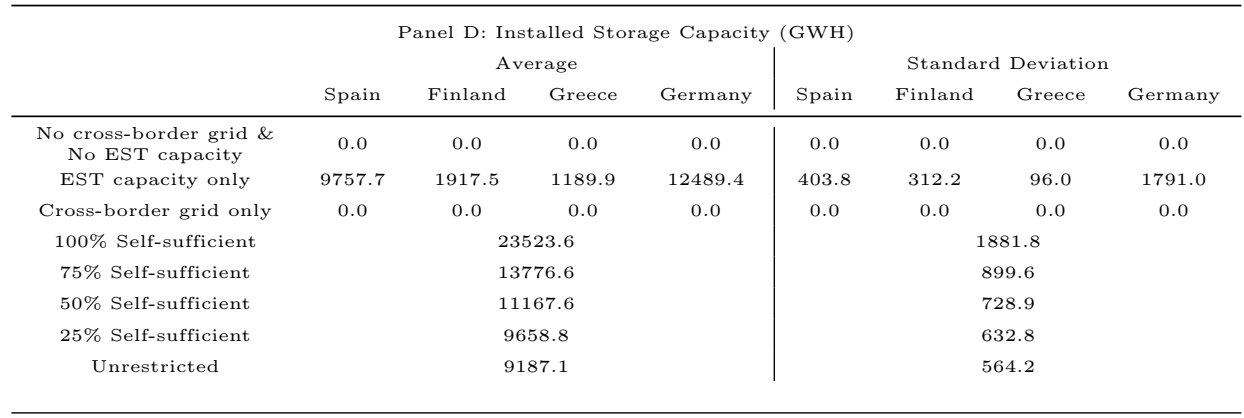

Note: This table reports the average and the standard deviation of the optimal values in the 100 simulations. 


\section{Chapter 3}

\section{Effects of renewable energy on electricity price level and \\ variance}

\subsection{Introduction}

The transition away from a fossil fuels-intensive power system is accelerating, globally, with variable renewable energy (VRE) - namely solar and wind power - making up the bulk of newly installed capacity. In 2019, solar and wind power technologies accounted for over $90 \%$ of newly installed capacity of renewable energy (Fig. 3.1), which, in turn, accounted for over $70 \%$ of newly installed capacity of all energy technologies (see Figure 2.1 in Chapter 2) (IRENA (2020)). In OECD countries, the share of renewable energy in the power mix increased from approximately $20 \%$ in 2010 , to more than $35 \%$, in 2018 (IEA (2020)).

This rapid increase brings about challenges for national power systems in general, and for the electricity markets, in particular. In case of the former, increased system flexibility - through more storage and interconnection capacity - is required, in order to accommodate a growing share of intermittent power from VRE. As for the electricity market, there are several short-term and long-term effects of VRE: the main short-term effect is that VRE puts a downward pressure on electricity prices, via two mechanisms: 1) by displacing flexible conventional technologies, with higher marginal cost (such as gas-fired power plants) and 2) by forcing less flexible conventional power technologies (such as coal-fired power plants) to operate at a loss, in order to avoid higher shutting 

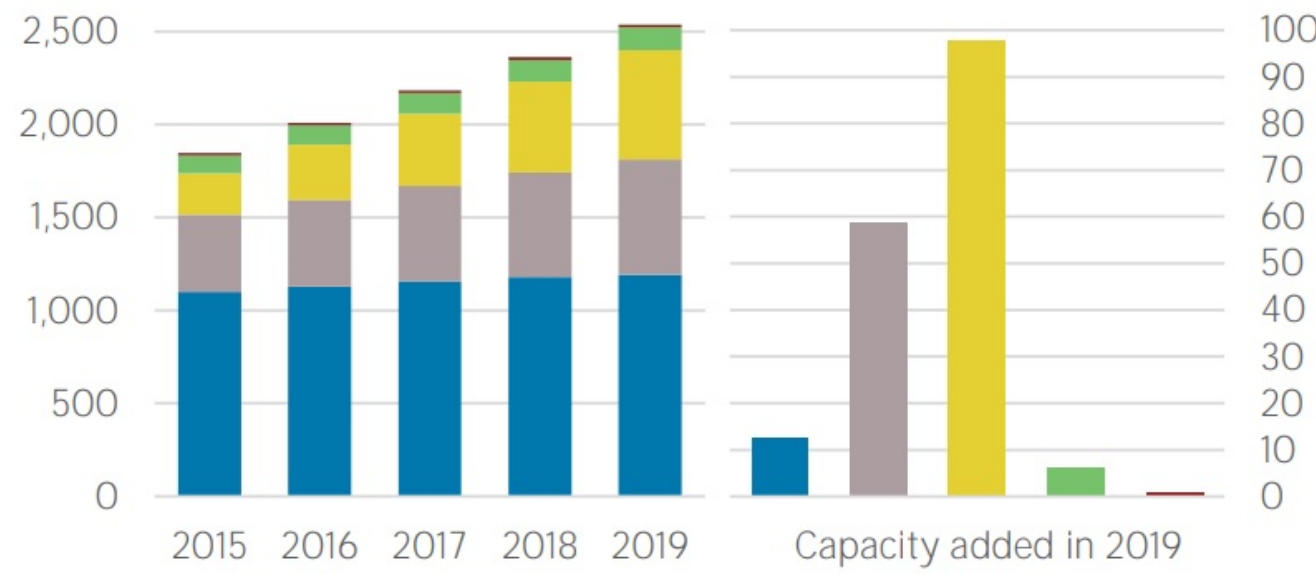

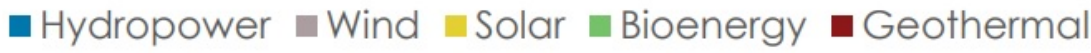

Figure 3.1: Global installed capacity of renewable power Source: IRENA (2020)

down/restart costs. The presence of these two mechanisms has been confirmed by an increasing number of theoretical and empirical studies, as discussed in the following section of this chapter.

A second short-term effect of VRE is that on the variance of the electricity price. Price variance is one of the main decision factors for investors in both VRE technologies and ancillary and arbitrage technologies - such as energy storage technologies. In a power system with a high reliance on VRE, energy storage technologies are essential in meeting power demand during times of low solar radiation or wind speed. This class of technologies can store cheap electricity, generated during periods with high wind speed and high solar radiation, for later use in times of excess power demand. Hence, storage technologies can act a vehicle to reduce electricity price volatility. The decision to invest in storage technologies is based on their expected potential revenue, given by the spread between low and high prices of electricity. Despite the important implications of the effect of VRE on the variance of electricity prices, empirical research on this topic has been limited, although it is currently attracting increasing interest. This chapter specifically addresses this gap in the empirical literature.

In terms of the long-term effects on the electricity market, VRE is expected to lead to lower electricity prices, together with a new technological configuration of the power system. Additionally, it is expected to drive significant changes in the operation of the 
electricity market - in terms of the relative volumes of power traded on the different time scales of the electricity market, as well as the remuneration mechanisms. More specifically, the electricity system currently operates based on an energy-only market, i.e. power plant operators are remunerated based on the amount of power they feed in to the transmission grid, according to contracts with varying maturity, that have been closed sometimes years in advance to actual real-time transmission. However, with a growing share of VRE, flexible reserve capacity - such as that provided by gas power plants becomes increasingly important. This is because power output of conventional plant can be forecasted more accurately than that of VRE, especially over long time horizons. Therefore, the reserve capacity, used to correct real-time differences between forecasted and actual power generation requirements, is expected to increase. These anticipated effects of VRE have motivated the discussion of transitioning towards a capacity market - whereby power plant operators are remunerated based on the (idle or not) flexible capacity, instead of only the electricity they generate. ${ }^{1}$

Therefore, a clear understanding of the effect of VRE on the electricity price and its variance is crucial when informing decision making both for investors in VRE and ancillary services, as well as for the redesign of the electricity market. Nonetheless, the literature regarding the effect of VRE on the volatility of electricity price is very limited, with the topic only very recently benefiting from academic interest. This chapter contributes to this limited literature by focusing on the short-term effects of VRE on the electricity market and addressing the following questions: 1) What are the effects of solar and wind power on electricity price and its variance? And 2) how do these effects change with an increasing contribution from VRE?

To answer this, I use recent data of solar and wind power generation (2015 - 2017) for ten European countries, thus covering the recent upsurge in VRE power as well as a wide geographical area. This is an important contribution to the existing literature, which uses earlier data - when the share of VRE was significantly lower - and which focuses on a single country. Indeed, most empirical research to date looks at the effect of VRE on the variance of German electricity prices, as discussed in the following section.

For these reasons, this chapter is an important contribution to the current empirical literature. I use a pooled panel GARCH model to address the questions stated above. This setting is appropriate for two reasons: 1) the pooled panel data setting allows us

\footnotetext{
${ }^{1}$ The term "energy-only market" is defined in the energy economics literature as being essentially an "electricity-only market", as opposed to "capacity markets." In the former case, power plant operators are remunerated for the actual electricity they generate - and sell. In the latter, they are remunerated based on the available capacity, both when it is generating power and when it is on stand-by. Therefore, in this case, there is a premium for providing back-up capacity and flexibility in power generation. The distinction between "energy-only" and "capacity" markets is discussed more at length in the following section. While these are not fundamental topics for the research presented here, it is useful to understand the distinction between them, in order to navigate certain parts of the literature discussion.
} 
to check the robustness of the VRE effects over a wide geographical area with different weather patterns, while controlling for individual country effects, and 2) the GARCH setting allows us to look at the effect of VRE on both price level and variance, while explicitly accounting for heteroskedastic error terms. This research contributes to the existing literature in several ways: 1) it is one of the first empirical studies looking at the effect of VRE on electricity price variance; 2) unlike existing studies that look at a single country at a time - usually Germany - I use data for ten European countries, covering diverse weather patterns; this allows us to understand how the VRE effect changes for different weather contexts; and 3) I use recent data on VRE generation, which is considerably higher than that of only a few years ago.

The remainder of this chapter is organised as follows: Section 3.2 discusses the theoretical and empirical literature on the effect of VRE on both the level and variance of electricity prices. The data and the model are discussed in detail in sections 3.3 and 3.4, respectively. In section 3.5, I discuss the results of the model and section 3.6 presents the concluding remarks and discusses the policy implications.

\subsection{The effects of VRE on the electricity market}

The recent growth in renewable energy in terms of both absolute contribution and share in the energy mix has brought about many challenges to the electricity system in general and to its market and technical structure, in particular (IRENA (2018), REN (2018)). The main technical challenge refers to the flexibility requirements of the power system, in order to accommodate an increasing share of intermittent power generation. As for the challenges to the incumbent market structure, an increase in VRE - in both absolute and relative terms - is underway, thus reshaping the traditional functioning of the electricity market. These challenges are documented by an expanding literature, discussed in the remainder of this section.

Deregulated electricity markets currently operate based on the microeconomics theoretical principle of lowest marginal cost. More specifically, the electricity price is given by the marginal cost - which is usually associated with the fuel cost - of the technology which meets the last unit of demand. An increase in VRE - with almost zero marginal cost - shifts the supply curve to the right, thus lowering the wholesale electricity price. This is known in the literature as the "merit order effect" of renewable energy on the electricity price (see Fig. 1.3 in the Introduction chapter).

There is a large theoretical literature that anticipated this effect, before VRE made up a significant share of the power mix. Subsequently, theoretical models were extended to include different aspects of the power system and the electricity market, such as the 
level of competition, availability of flexibility measures etc. ${ }^{2}$ This strand of literature is complemented by a growing empirical literature on an increasing number of countries that confirms the presence of the merit order effect, and more recently, addresses the effect on price variance as well. These two strands of literature are discussed below.

Martinez-Anido, Brinkman and Hodge (2016) use a production cost model of the New England Independent system operator to look at the effect of wind power on electricity prices, for different scenarios of wind power forecasts and the possibility of wind power curtailment. They find that, in the absence of adequate forecasting technology and possibility of curtailment, electricity prices drop significantly, due to the higher frequency of negative prices incurred by conventional power plants. ${ }^{3}$ Additionally, they find that wind power is associated with an increase in price variance and they suggest allowing for wind power curtailment, in order to reduce the price variance for higher levels of wind power.

Acemoglu, Kakhbod and Ozdaglar (2017) study the effect of portfolio diversification on the merit order effect, in an oligopoly where incumbent electricity producers operate a portfolio of both traditional and renewable power plants, while new market entrants operate only renewable energy plants. They find that this market setting allows incumbent utilities to shut down traditional power plants and only produce renewable power, during times of high power generation from renewable technologies. This reduces the magnitude of the merit order effect, since conventional power plants do not compete with renewable ones in the same time interval. In the extreme case where all renewable power plants are owned by incumbent producers, who continue to operate conventional plants as well - i.e. there is no competition with new, renewable energy-only producers -, the merit order effect disappears entirely. At the other extreme, the strongest merit order effect occurs when each technology is owned by a different producer. In other words, portfolio diversification within energy producers is associated with an lower decrease of electricity prices, compared to the case where one producer operates a single type of technology.

Hirth (2013) develops a mixed econometric and optimization analysis to look at the market value of wind and solar power. He defines the market value as "the revenues that generators can earn on markets, without income from subsidies" and finds that, for low levels of penetration of wind power in the energy mix, its market value is marginally higher than that of a power technology with constant generation. However, this value drops to $50 \%$ - $80 \%$ of that of a constant generation source, when the share of wind power increases to $30 \%$. For solar power, the same drop happens at lower levels of penetration,

\footnotetext{
${ }^{2}$ A flexible power system is a system that can respond quickly to changes in power demand or supply. Flexibility measures include power plants that can quickly ramp up power generation, available storage capacity and others.

${ }^{3}$ As discussed in the Introduction chapter, conventional power plants may choose to charge negative prices when the cost of temporarily shutting down is higher than the loss incurred by negative prices.
} 
of $15 \%$. Hirth (2013) argues that this drop in the market values of VRE technologies can be mitigated by measures that address the issue of power output variability, inherent in these power technologies. More specifically, he suggests integration measures such as investments in transmission capacity and increased flexibility of combined heat-andpower (CHP) plants points to a series of measures that could mitigate this drop in the market value of VRE technologies.

There are few recent theoretical studies that look explicitly at the effect of intermittent renewable energy on electricity price variation. Wozabal, Graf and Hirschmann (2016) develop a theoretical framework to understand this effect and apply it to German data. They construct a static market model with inelastic aggregate demand and a monotonically increasing convex supply curve. The fluctuations inherent in daily VRE supply are reflected in the daily residual demand, i.e. demand net of VRE. They find that daily price variation can either increase or decrease, as a result of a growing share of VRE. The direction of this effect depends on two factors which act in opposite directions. The first factor is the shape of the residual demand distribution with respect to price i.e. the density function - shown on the x-axis in Figure 3.2. The second factor is the slope of the supply function. In other words, if the introduction of (more) VRE does not change the shape of the residual demand distribution - i.e. demand net of VRE (as shown on the $\mathrm{x}$-axis of panel a in Figure 3.2) - then VRE will lead to lower price variance (as shown on the $\mathrm{y}$-axis of panel a in Figure 3.2). However, if the shape of the distribution is affected by an increase in VRE (as shown in panel b in Figure 3.2), the effect on price variance is ambiguous and depends on the slope of the supply function.

To further clarify the effect of VRE on price variance, the authors relax the assumption of supply curve convexity, in order to account for dynamic dispatch decisions, i.e. the inflexibility of conventional power plants in ramping up/down power generation. This setting is better suited when modeling instances of low demand and high VRE production feed-in (e.g. during evenings). In these cases, electricity prices can drop below zero, as base-load plant operators compete with almost-zero marginal cost VRE and find it more convenient to operate at a loss, rather than to shut down their plants.

The new assumption of plant inflexibility is modeled by a supply curve that consists of a concave part, followed by a convex part - known as an "inverse S-shape" (Fig. 3.3, panel a). In this theoretical setting, the authors find a U-shaped relation between residual demand and price variation: the price variation is high for both high and low values of residual demand, and lower for moderate values of residual load distribution (Fig. 3.3, panel b).

Wozabal, Graf and Hirschmann (2016) then use German data to empirically test the presence of this effect. They conclude that the effect of VRE on price variance depends on two factors, which act in opposite directions: the amount and variation of VRE are 


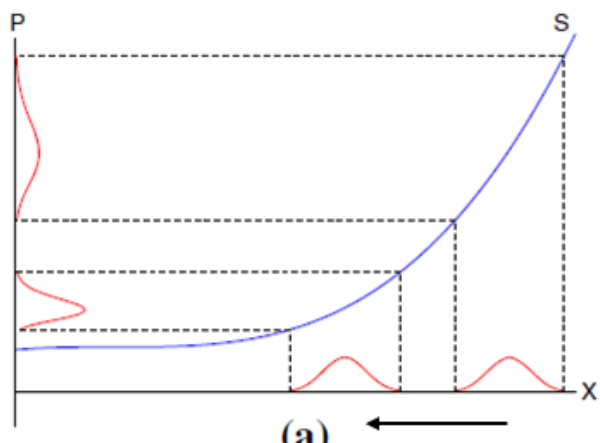

(a)

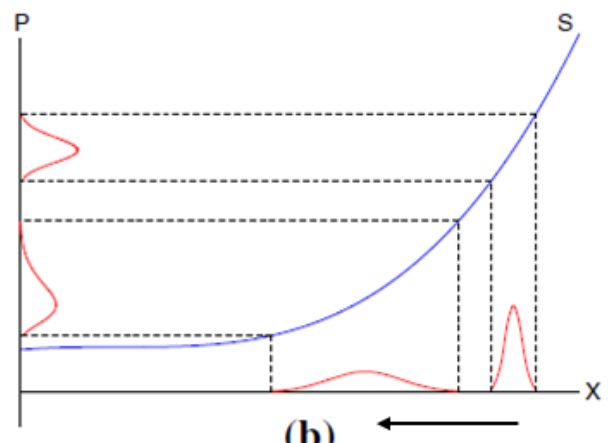

(b)

Figure 3.2: The effect of residual demand on electricity price variance: the case of a convex supply curve

Panel a: If an increase in VRE does not change the shape of the residual demand, price variance decreases. Panel b: If an increase in VRE changes the shape of the residual demand, the effect on price variance is ambiguous. The red curves represent the distributions of the residual demand (on the x-axis) and of the price (on the y-axis); the level of price variance is implicit in the kurtosis of the distributions.

Source: Wozabal, Graf and Hirschmann (2016), p:691.
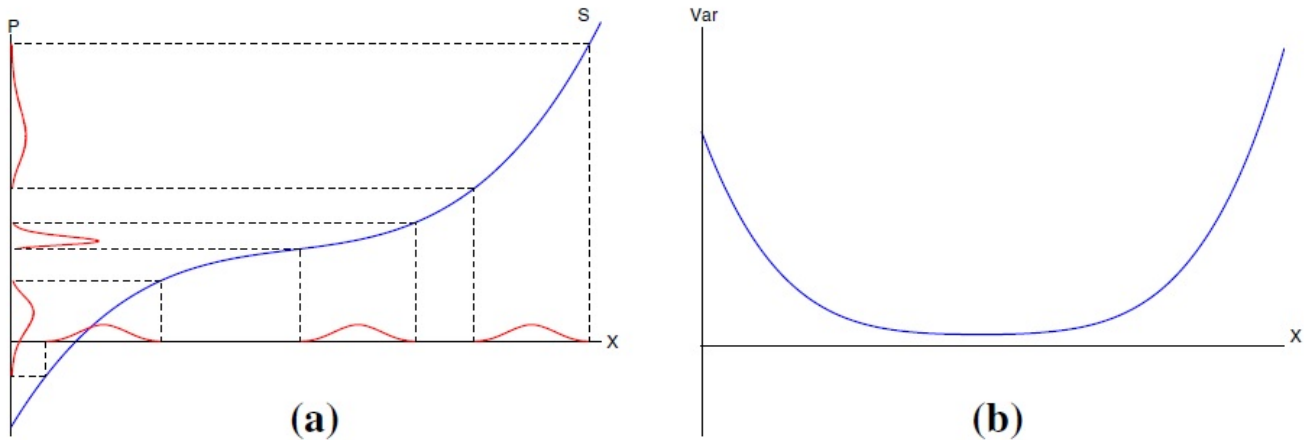

Figure 3.3: The effect of residual demand on electricity price variance: the case of a concave-convex supply curve

Panel a: price effects with a concave-convex supply function. Panel b: effects of a shift in the mean demand on the variance assuming a concave-convex supply function; the red curves represent the distributions of the residual demand (on the x-axis) and of the price (on the y-axis); the level of price variance is implicit in the kurtosis of the distributions. Source: Wozabal, Graf and Hirschmann (2016) p:693. 
positively associated with price variation, i.e. they move in the same direction. However, the higher the correlation between VRE feed-in and demand, the weaker this effect will be. Indeed, for correlations above a certain threshold, VRE has a negative effect on price variance - with solar power having a more pronounced negative effect than wind power. Solar power is stronger during the day, when demand is high, while wind power is stronger at night, when demand is low.

Sensfuß, Ragwitz and Genoese (2008) use a detailed electricity market agent-based model to quantify the merit order effect. They calibrate the model with hourly German data and find that the drop in electricity prices - i.e. the magnitude of the merit order effect - more than compensates the financial support schemes for renewable energy. Würzburg, Labandeira and Linares (2013) use daily data to develop an empirical model to understand the magnitude of the merit order effect across different levels of demand. They find that the effect is not significantly stronger during days of high demand. They argue that this may be due to the fact that gas-powered plants are still used to meet the bulk of this demand, for the period under consideration (2010-2012). However, as the installed PV capacity increases, it displaces gas-fired power plants, in particular during mid-day hours, when power demand peaks. This leads to an increased variation of the merit order effect for different hours of the day - which, in turn, are associated with specific VRE technologies (Paraschiv, Erni and Pietsch (2014)).

Cludius, Hermann, Matthes and Graichen (2014) use hourly time-series data to develop an empirical model and use their results to develop a forecasting model for the merit order effect. They find that the size of this effect increases considerably with the share of VRE. This leads to lower revenues for VRE plant operators. More importantly, as this support is unequally borne by different types of consumers - i.e. industrial and household consumers - the increasing merit order effect overcompensates industrial consumers. ${ }^{4}$ The authors therefore argue that this reduced revenue - and its implications for consumers - should be taken into account when (re)designing the financial support mechanisms for VRE.

Hildmann, Ulbig and Andersson (2015) also point to required changes in the current operation of the power system - and, more specifically, of the electricity market - motivated by the merit order effect. However, they argue that the challenges brought about by VRE can be accommodated through smaller changes to the system than previously thought. More specifically, they address the debate of energy-only versus capacity markets. As discussed in the introduction of this chapter, electricity markets are currently energy-only markets, meaning that power plant operators are remunerated depending

\footnotetext{
${ }^{4}$ This is due to the fact that the subsidies for VRE are indirectly financed by tax on households, while industrial consumers - i.e. "privileged consumers" - are excluded. As the merit order effect increases, wholesale electricity prices decrease, thus disproportionately benefiting industrial consumers.
} 
on the amount of electricity they produce, and not on the (potentially idle) installed capacity. More specifically, the electricity price is given by the marginal cost of the last power technology in use to meet demand - which, for conventional power plants, consists mainly of the fuel cost. As the contribution from VRE increases, it replaces conventional power, thus reducing the revenues for operators of conventional power plants. ${ }^{5}$ However, due to the intermittent nature of VRE, flexible back-up capacity becomes more important. The current electricity market design does not reflect the value of this flexibility. This has motivated the discussion of a transition from the current, energy-only market, to a capacity-market, in which plant owners are remunerated based on the installed capacity. Hildmann, Ulbig and Andersson (2015) argue that this transition is not necessary, as long as two adjustment are made: 1) increasing the share of power traded on the day-ahead market (and reducing the volume traded on the forward market), ${ }^{6}$ and 2 ) reflecting the true marginal cost of VRE in the price at which they are traded (in other words, accounting for the operation and maintenance costs, not only for the zero "fuel" cost).

Kyritsis, Andersson and Serletis (2017) provide one of the first empirical studies that uses a univariate GARCH model to address the effect of VRE on daily electricity price variance. They look at the effects of solar and wind power in Germany between 2010 and 2015 and find that solar power reduces price variance, while wind power increases it. This period was marked by profound changes in the German electricity market. One such change was the down-scale of nuclear power, announced in 2011, and a second important development was the surge in contribution of VRE-sourced electricity to total electricity supply from $16.6 \%$ in 2010, to 30.1\%, in 2015 (Kyritsis, Andersson and Serletis (2017)). This rapid development of VRE integration in the German power system raises the question of whether the effects of VRE on the electricity market are uniform across different levels of VRE integration, or they change, as VRE become more important in the energy mix.

A clear understanding of how the gradual uptake of VRE is expected to impact the status quo of electricity markets is necessary for the design of the policy framework required to support the transition to a VRE-intensive power system - in Germany and across the EU. The research presented in this chapter addresses this issue by looking at the effects of both solar and wind power on the level and volatility of electricity prices

\footnotetext{
${ }^{5}$ This situation is known in the literature as the "missing money problem" (Hildmann, Ulbig and Andersson (2015)). It refers to the fact that, despite the reduced revenues, conventional power plants are needed in the power system for their flexibility services.

${ }^{6}$ A central feature of the current design of European electricity markets is their time dimension. Sequential electricity markets are organized according to how far into the future the actual electricity delivery is agreed on to take place: the forward/futures markets operate from years up to the day before the actual delivery; the day-ahead market is active on the day before the delivery; on the intra-day market, electricity is traded during the delivery day itself.
} 
for different levels of VRE-intensity, for the 2015 - 2017 period across ten EU countries.

As mentioned above, most of the empirical literature on the effect of VRE on the electricity market focuses on Germany, due to its long history of promoting VRE. However, the geographical scope of these studies is rapidly diversifying. Gelabert, Labandeira and Linares (2011) use hourly data to look at wind, solar and co-generation (with mainly gas and biomass as fuels) power jointly - collectively termed "special regime" - in Spain and find that the magnitude of the merit order effect decreases, as the share of the "special regime" power technologies increases. However, this finding may be due to the gas-powered co-generation plants in the "special regime" portfolio, since they do not look at the individual effects of each power technology. Clò, Cataldi and Zoppoli (2015) use daily data to look at the effect of solar and wind power on electricity prices in Italy. In line with Gelabert, Labandeira and Linares (2011), they find that the magnitude of the merit order effect decreases as the share of VRE increases. Furthermore, they find that solar power has a stronger merit order effect - in other words, the reductions in electricity prices are larger for solar power than for wind power, mainly due to the larger prevalence of solar power, compared to wind power. However, the electricity cost reductions associated with solar power are lower than the cost of financial support schemes - indirectly borne out by the final consumer. The opposite is true for wind power, as the savings resulting from price reductions more than compensate the cost of support schemes. Forrest and MacGill (2013) look at the merit order effect of wind in Australia, and contrary to Gelabert, Labandeira and Linares (2011) and Clò, Cataldi and Zoppoli (2015), they find that this effect becomes stronger, as wind power capacity increases.

In a comparative study, Rintamäki, Siddiqui and Salo (2017) develop an empirical model to look at the effect of VRE on the variance of daily electricity prices in Germany and Denmark. They find mixed results: in Denmark, wind power is associated with a reduction of price variance, while in Germany, wind power increases variance and solar power is associated with a decrease in price variance. This is due to two main differences between the two countries: first, wind power in Denmark is more evenly distributed across all hours of the day, whereas wind power in Germany is more pronounced during off-peak hours, thus decreasing the already low prices in these hours; second, Denmark has higher cross-border transmission capacity, compared to the level of its domestic demand - it therefore has access to both the generous hydro-power reservoirs of its Scandinavian neighbors, during hours of peak domestic demand, and to foreign markets, where it can export the excess wind power generated during off-peak hours. The authors did not consider the effect of solar power in Denmark due to its small installed capacity.

Sapio (2019) develops a quantile regression model to analyse the effects of wind and solar power on the level and volatility of electricity prices in six Italian regions, over the 2006 - 2015 period. Their findings confirm the presence of the merit-order effects of 
both wind and solar power, with different characteristics: the merit-order effect of wind power is significant across all quantiles and all regions, but the magnitude of its effect on peak-time (i.e. higher) prices differs across regions; on the other hand, the merit-order effect of solar power is stronger for off-peak (i.e. lower) than for peak prices and loses its statistical significance, when year dummies are included. At the same time, solar power is found to increase price volatility, while the effect of wind power on volatility is ambiguous. The model choice of Sapio (2019) of six Italian regions and quantile-level analysis helps highlight the heterogenous effects of wind and solar power on electricity price and volatility across time and space.

The current chapter contributes to this growing literature in three main ways: first, it develops a multivariate GARCH model to look at the effect of solar and wind power on the level and variance of electricity prices. GARCH models are a standard method to study price volatility in the financial literature, but have only recently been used to look at the volatility of electricity prices, in the context of a growing share of VRE. This chapter presents the second GARCH model that addresse the relation between VRE and electricity price variance, after Kyritsis, Andersson and Serletis (2017), to the author's knowledge. A second contribution is the large geographical coverage of the study - ten countries, compared to the standard one-country analysis. This allows us to understand whether the sometimes contradicting findings in the literature - related to the effect of VRE on the volatility of electricity prices - are due to an individual country's weather pattern, or to the different shares of VRE. This brings us to the third contribution of this chapter - the use of recent data of solar and wind power to total power load, when these two technologies make up a significant share of power in all countries under analysis.

\subsection{Data}

To estimate the effect of variable renewable energy (VRE) supply on electricity price and price volatility, I use an $\mathrm{XAR}(7)-\mathrm{XGARCH}(1,1)$ model, which includes one equation for the level of electricity price and one equation for the variance of the residuals. ${ }^{7} \mathrm{I}$ therefore have two exogenous variables of interest: day-ahead forecasts of solar power generation and wind power generation. I also control for day-ahead forecasts of demand. ${ }^{8}$ The introduction of the demand variable is conditional on the assumption that there are no endogeneity concerns between demand and prices. In other words, the elasticity of forecasted day-ahead hourly demand with respect to day-ahead hourly prices is assumed to be negligible, if existent. This is a standard and implicit assumption in the empirical

\footnotetext{
${ }^{7}$ The choice of the model is discussed in the following section.

${ }^{8}$ Table 3.3 and Figures 3.5 to 3.8 in the appendix to this chapter give an overview of the control variables for each country.
} 
literature on the merit-order effect. This is because it "is considered to be a reasonable assumption since the majority of end consumers do not observe the spot market prices since retailers are the ones formally participating in the market." (Forrest and MacGill (2013):124). A similar standard and implicit assumption in the literature is that VRE output is exogenous, as it is determined essentially by exogenous weather patterns. All data comes from the ENTSO-E Transparency platform, a data platform operated by the association of European Transmission System Operators. For detailed information on the descriptive statistics and distributional properties of the data, see the appendix to this chapter.

The use of day-ahead forecasts of solar and wind power generation, instead of the actual values, is justified by the fact that day-ahead prices are determined based on these forecasts, not on the actual realizations (Huisman, Huurman and Mahieu (2007)). I use the share of solar and wind power in total load, instead of the absolute values, for several reasons: first, the same amount of wind generation in countries with different levels of consumption will impact electricity prices differently; secondly, even within the same country, the same amount of wind power will have different effects on spot electricity prices during times of high demand, compared to periods of low demand (Ketterer (2014); Jónsson, Pinson and Madsen (2010)).

The data covers the ten EU countries named below, grouped in eight bidding zones. A bidding zone is a geographical area where electricity can be traded freely for the same hourly price. Electricity prices can - and generally do - differ by hour and by bidding zone. The ten countries considered in this research are: Austria, Belgium, France, Germany, Greece, Lithuania, Luxembourg, Portugal, the Netherlands and Spain. Each country corresponds to a unique bidding zone - except for Germany, Austria and Luxembourg, which, for the period included in this research, make up a single bidding zone. ${ }^{9}$ These countries were selected for two main reasons: 1) there is available data for both wind and solar power generation forecasts, and 2) prices are reported in the same currency - Euro - thus making the results of the panel data model easier to interpret.

I calculate the daily average of hourly data for all variables from January 2015 until December 2017. The use of daily average, rather than the actual hourly data, is motivated by the fact that the latter do not display time-series characteristics. Indeed, quotes for all hours of a day are determined simultaneously, by 12 PM of the previous day. In other words, prices for all 24 hours of the following day are determined in the presence of identical relevant information. For example, the price for electricity at 1 PM does not contain new information for the price of electricity at 2 PM, since they are all determined

\footnotetext{
${ }^{9}$ As of 1st October 2018, the Austria-Germany-Luxembourg bidding zone is split between Austria, on one side, and Germany-Luxembourg, on the other (Politico (2018)).
} 
at the same time - i.e. before 12 PM (Huisman, Huurman and Mahieu (2007); Ketterer (2014)). An overview of the data is shown in Table 3.1.

I therefore have 8711 daily observations for each of the four time-series of interest - forecast of solar power, forecast of wind power, forecast of demand and actual dayahead prices in the eight bidding zones. There are 11 cases of negative daily prices (all of them occurring in the Germany-Austria-Luxembourg bidding zone, as shown in Table 3.4 in the appendix). I choose to analyse the entire dataset and not remove these observations, as they are important characteristics of a renewable-intensive power system (Kyritsis, Andersson and Serletis (2017)). This also means that I cannot log-transform the dependent variable (price). An alternative to log-transformation that takes into account the negative values of price is to take the first differences of the variables with respect to time. I use the changes in daily average between two consecutive days. The following section discusses this in more detail.

Table 3.1: Statistics based on daily data

\begin{tabular}{cccccccc}
\hline & Price & $\begin{array}{c}\text { Share of } \\
\text { Solar }\end{array}$ & $\begin{array}{c}\text { Share of } \\
\text { Wind }\end{array}$ & $\begin{array}{c}\text { Demand } \\
\text { (MWH) }\end{array}$ & $\begin{array}{c}\text { Daily } \\
\text { Change } \\
\text { of Price }\end{array}$ & $\begin{array}{c}\text { Daily } \\
\text { Change } \\
\text { of Sun }\end{array}$ & $\begin{array}{c}\text { Daily } \\
\text { Change } \\
\text { of Wind }\end{array}$ \\
\hline 1st Percentile & 13.1 & $0.0 \%$ & $0.3 \%$ & 1086 & -19.8 & $-4.1 \%$ & $-23.1 \%$ \\
25th Percentile & 32.7 & $1.0 \%$ & $3.9 \%$ & 5677 & -3.7 & $-0.4 \%$ & $-3.2 \%$ \\
Mean & 41.7 & $3.5 \%$ & $11.6 \%$ & 22870 & 0.0 & $0.0 \%$ & $0.0 \%$ \\
Median & 40.7 & $2.2 \%$ & $8.1 \%$ & 11369 & -0.4 & $0.0 \%$ & $0.0 \%$ \\
75th Percentile & 49.5 & $5.3 \%$ & $15.3 \%$ & 36790 & 3.1 & $0.4 \%$ & $3.1 \%$ \\
\hline 99th Percentile & 84.1 & $13.8 \%$ & $51.1 \%$ & 73969 & 21.6 & $3.9 \%$ & $23.5 \%$ \\
\hline
\end{tabular}

Note: This table reports certain summary statistics on the time series of electricity price, share of solar power, share of wind power and electricity demand, as well as the daily change in price and share of solar and wind power, across the ten countries (eight bidding zones) considered in this research. The percentiles refer to the distribution of the values of daily averages for the entire dataset. For example, $1 \%$ of all daily prices in the dataset are lower than 13.1 Euro/MWh and $1 \%$ are higher than 84.1 Euro/MWh.

\subsection{Model}

To understand the effect of renewable energy on electricity prices, I estimate the effects of wind and solar power on the changes of the day-ahead electricity price and the residuals variance, using a multivariate $(\mathrm{X})$ autoregressive (AR) process with GARCH residuals (Bollerslev (1986)). General autoregressive conditional heteroskedasticity (GARCH) models are commonly used in time series analysis in general and in the analysis of price volatility, in particular. This XAR-GARCH model includes two equations: [XAR] the mean equation, which explains day-to-day changes in the price level, and [GARCH] the variance equation, which corresponds to the variance of the residual terms. 
Figure 3.4 shows the partial autocorrelation of price changes in the entire sample. Daily lags are labeled horizontally and the size of the autocorrelation is given on the vertical axis. According to this figure, price changes show strong autocorrelation up to seven-day lags, due to the weekly seasonality of demand. Therefore, I choose to use seven lags for the autoregressive part of the mean equation $(\mathrm{XAR}(7))$. Following the standard literature, the order of the GARCH model in the variance equation is chosen to be $(1,1)$ (Ketterer (2014); Kyritsis, Andersson and Serletis (2017)).

\section{Price Return PACF}

$\begin{array}{lllllllllll}\text { L } 1 & \text { L } 3 & \text { L } 5 & \text { L } 7 & \text { L } 9 & \text { L } 11 & \text { L 13 } & \text { L 15 } & \text { L 17 } & \text { L 19 } & \text { L 21 }\end{array}$

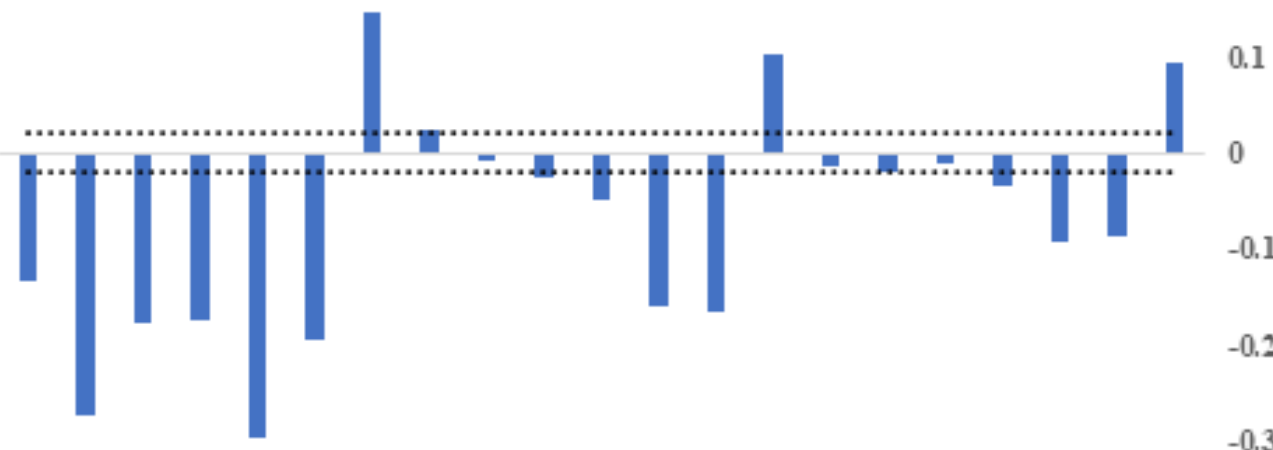

Figure 3.4: Partial autocorrelation of the electricity price return for different lags

I label this model XAR(7)-XGARCH(1,1), where X stands for the additional external regressors. This $\mathrm{XAR}(7)-\mathrm{XGARCH}(1,1)$ model can be illustrated as:

$$
R_{t}=\sum_{i=1}^{7} \phi_{i} R_{t-i}+\beta_{L} \Delta \text { Demand }_{t}+\beta_{S} \Delta R E_{t}+\text { DayDummy }+ \text { CountryDummy }+\epsilon_{t}
$$

where $R_{t}=P_{t}-P_{t-1}$ represents the change in the price from day $t-1$ to day $t$, and $\epsilon_{t}=\sqrt{h_{t}} z_{t}\left(z_{t}=N D(0,1)\right)$ is the residual term. ${ }^{10}$ Furthermore, $\Delta$ Demand $_{t}$ and $\Delta R E_{t}$ respectively correspond to the percentage change in demand and the change in the share of renewable energy between two consecutive days.

Table 3.4 in the appendix reports the total number of observations, as well as the number of negative price values. As we can observe in this table, the electricity price

\footnotetext{
${ }^{10}$ The choice of a change in price levels as dependent variable, as opposed to percentage change, is justified by the fact that the dataset contains 11 observations of negative price values, as discussed in the Data section.
} 
$P_{t}$ can have negative values. Therefore, I use the XAR-XGARCH model to explain the price variations measured as $R_{t}=P_{t}-P_{t-1}$, and not the return on price $R_{t}=\frac{P_{t}-P_{t-1}}{P_{t}}$.

The variance of the residuals $\left(h_{t}\right)$ itself also follows a XGARCH $(1,1)$ process:

$$
h_{t+1}=\omega+\alpha \epsilon_{t}^{2}+\beta h_{t}^{2}+\beta_{L} \Delta \operatorname{Demand}_{t}+\psi_{S} \Delta R E_{t}
$$

A large prediction for $h_{t+1}$, corresponding to expectation of higher variance for the residuals, means a higher conditional variability of the price and larger price variance at time $t+1$.

The main coefficients of interest are $\beta_{S}$ in equation 3.1 and $\psi_{S}$ in equation 3.2. These two coefficients estimate the effect of a change in the share of renewable energy $\left(\Delta R E_{t}\right)$ on the price level, in equation 3.1 and the effect of a change in the share of renewable energy on the volatility of price return, in equation 3.2, respectively.

I develop four model specifications which build on each other in the following way:

- Model 1: I first look at the time-series properties of electricity price.

- Model 2: I extend Model 1 by including the share of VRE.

- Model 3: I divide this share into four quartiles and look at how different levels of VRE intensity affect electricity price and its variance. Thus I have four brackets of VRE intensity with equal numbers of observations: for the $25 \%$ of observations with the lowest level of VRE integration, this level is lower than $\mathrm{Q} 1=6.66 \%$; for the following quartile, VRE integration is between $\mathrm{Q} 1=6.66 \%$ and $\mathrm{Q} 2=12.22 \%$; then, between $\mathrm{Q} 2=12.22 \%$ and $\mathrm{Q} 3=19.97 \%$; and for the top quartile, VRE integration is above above Q3 $=19.97 \%$. The aim of this model specification is to understand how an increasing share of VRE affects electricity price and its variance.

- Model 4: I differentiate between wind and solar power and look at the individual effects of each technology on electricity price and its residual variance. In this last model specification, I replace $\Delta R E_{t}$ with the change in share of solar $\left(\Delta S_{t}\right)$ and wind $\left(\Delta W_{t}\right)$ energy and investigate the individual impact of each of these variables on the electricity price and its variance.

In the price level equation, I include dummies for the days of the week, as well as country dummies for both the price level and variance equations. Each of the models and their results are discussed in detail in the following section. 


\subsection{Model results and discussion}

The results for all model specifications are summarized in Table 3.2 and discussed in detail in the following subsections. For this purpose, subsection 3.5.1 discusses the estimation results for electricity price and subsection 3.5.2 discusses the model results regarding the electricity price variance.

\subsubsection{Effects of solar and wind power on the level of electricity price}

Model 1 is an XAR(7)-GARCH(1,1) model of electricity price time series, with dummies for each day of the week, in order to control for weekly seasonality of prices, due to the weekly seasonality of demand. The results illustrate established properties of electricity prices in line with previous literature, namely: 1) the negative and significant coefficients of AR1 to AR6 suggests price mean-reversion. In other words, if the price in one day jumps due to an external shock, it tends to gradually revert back over the next few days; and 2) the positive and significant coefficient of the AR7 coefficient points to weekly seasonality, i.e. each day, the price moves in the same direction as the price movement of the same day of the previous week -for example, on Mondays, electricity prices increase from the low weekend levels and on Saturdays electricity price drops, relative to the Friday price level (Koopman, Ooms and Carnero (2007), Sensfuß, Ragwitz and Genoese (2008) and Kyritsis, Andersson and Serletis (2017)).

According to the estimation results of Model 2, an increase in electricity demand is associated with an increase in the electricity price. More importantly a larger share of VRE has a significant negative effect on the electricity price. These results therefore confirm the presence of the merit-order effect. If the contribution from VRE increases by 1 percentage point between two consecutive days, the price drops by 36.10 Eurocents/MWh. This effect is substantial, considering that daily electricity prices range between approximately 13 and 84 Euros/MWh, approximately (see column 1 of Table 3.1 for the $1^{\text {st }}$ and $99^{\text {th }}$ percentiles of the price level distribution).

In Model 3, I look at how the effect of VRE on the electricity price varies for different levels of VRE integration. The results in column 3 are interesting for two main reasons: first, all results are strongly significant for all levels of VRE; second, the negative effect of VRE on electricity increases in magnitude, as the share of VRE in total demand increases. Indeed, the price reduction associated with the highest VRE share (36.69 Eurocents/MWh) is over $20 \%$ higher than that associated with the lowest VRE share (30.26 Eurocents/MWh). In other words, the electricity price drops by 30.26 Euro- 


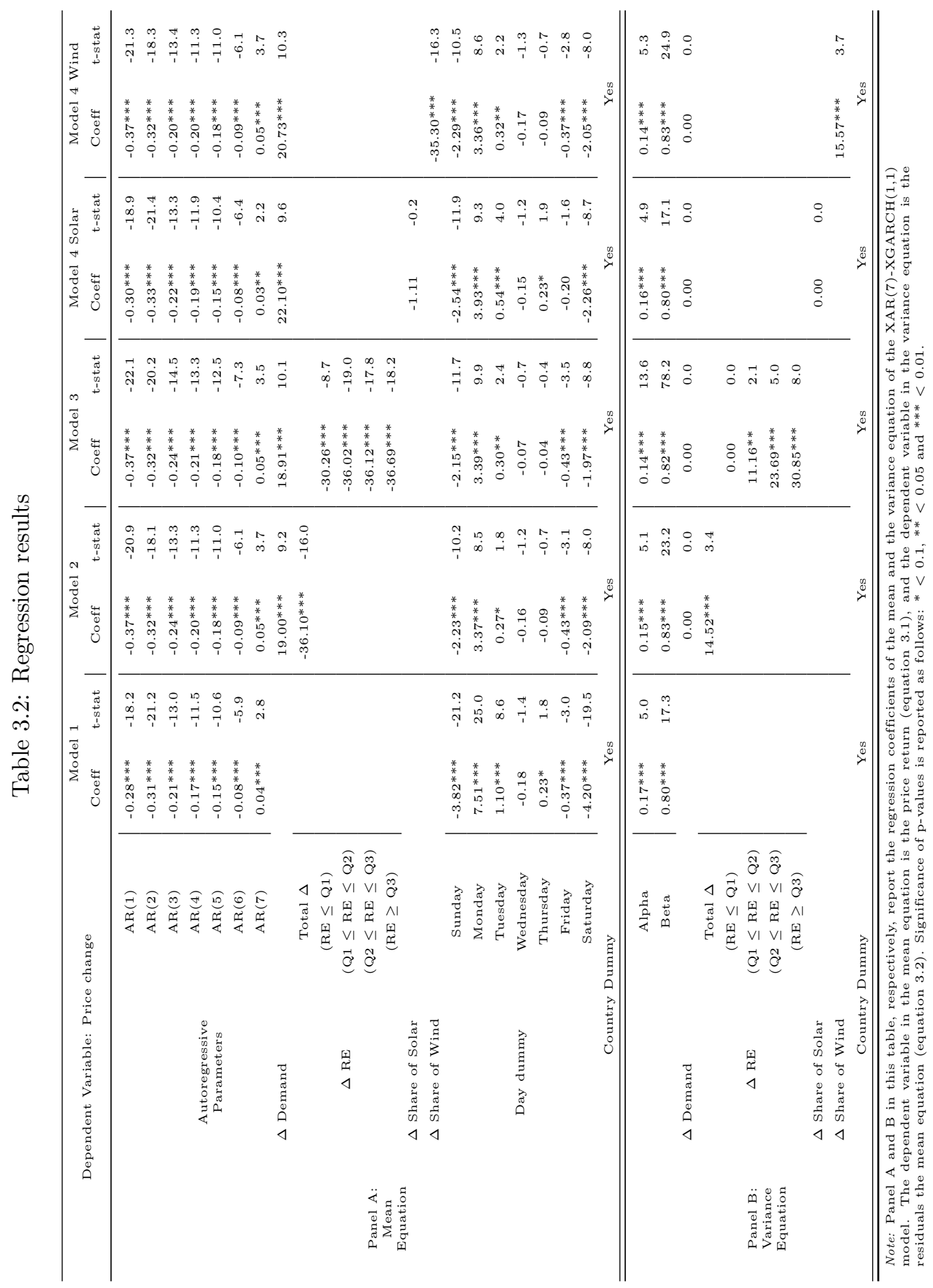


cents/MWh for every percentage point increase in VRE share when this share is below $\mathrm{Q} 1=6.66 \%$ of total load. If VRE make up over Q3 $=19.97 \%$ of demand, a percentage point increase between two consecutive days would reduce the electricity price by 36.69 Eurocents/MWh. A third important finding is that this increasing effect stabilizes, as the share of VRE increases beyond Q $1=6.66 \%$ of total load. More specifically, the price reduction effect increases from 30.26 to 36.02 Eurocents/MWh for every percentage point increase in the VRE power generation share, when this share is between the $\mathrm{Q} 1=6.66 \%$ and $\mathrm{Q} 2=12.22 \%$ thresholds. However, for higher shares of VRE, the price reduction effect only increases from 36.02 to 36.69 Eurocents/MWh, for a change in the VRE share from $\mathrm{Q} 1=12.22 \%$ to over $\mathrm{Q} 3=19.97 \%$. This is an important finding for the debate regarding the redesign of the electricity market, as it points to a potential level of VRE integration beyond which the impact of the merit-order effect stabilizes..

In fact, this result partially addresses the "missing money" problem. As discussed in section 3.2, this refers to a drop in revenues for conventional, flexible power plants, due to a continuous decrease in electricity prices, as the share of VRE increases. These lower revenues do not reflect the cost - and value, particularly in terms of providing system flexibility - of conventional power plants, thus making it unattractive for them to operate. However, system flexibility is crucial in a VRE-intensive power system, as quick access to back-up power is required for a proper functioning of the power system. In this regard, these findings suggest that the revenue drop for conventional power plants - due to lower electricity prices - declines, as the VRE share increases. In other words, there might be a lower bound below which revenues for conventional power plants are unlikely to fall, for a high enough level of VRE integration. ${ }^{11}$ As VRE deployment continues to increase, data in the near future will help confirm the presence and determine this specific level of VRE intensity and its implication for the electricity market redesign.

In Model 4, I look at the individual effects of solar and wind power on the electricity price. As shown in the last column, wind power has a strong negative effect on electricity prices: if the share of wind power increases by one percentage point between two consecutive days, the electricity price is expected to fall by 35.30 Eurocents/MWh. On the other hand, these results show that the effect of solar power on electricity prices is non-significant. This may be due to two main reasons: 1) solar power makes up a much smaller share of VRE than wind power (see Table 3.1). As shown in Table 3.3 in the appendix to this chapter, the average share of solar power for the countries in this sample is rather small, ranging between $0.5 \%$ and $6.9 \%$-the average share of wind power, on

\footnotetext{
${ }^{11}$ This high enough level of VRE is less that $100 \%$. In the situation discussed here, both VRE and conventional power meet a non-zero share of demand. If the share of VRE were 100\%, this would imply conventional plants are absent, therefore a discussion about their revenue is unnecessary.
} 
the other hand, varies between $4.3 \%$ and $22.7 \%$; 2) I aggregate hourly observations in daily averages. As discussed in the Data section, this is justified by the way that the day-ahead electricity market operates: prices for all hours in a day are determined at the same moment of time of the previous day. This means that the price of 1 AM contains no new information for the price of $2 \mathrm{AM}$ and therefore no relation between the prices of two consecutive hours can be inferred. As solar power is generated during only a limited number of hours during the day, its effect on the electricity price for those specific hours may be concealed by the aggregation of hourly data into a single observation for the daily average.

In summary, these results show that, for the data considered in this research, VRE has a strong negative effect on day-ahead electricity prices. This finding is in line with the merit order hypothesis of the theoretical literature, and contributes to the empirical studies that have investigated this effect previously. The negative effect of VRE on price decreases as the share of VRE in total demand increases. However, when I look at the individual effects of solar and wind power, I find that the drop in electricity prices is due to wind power alone. As solar power deployment is accelerating and its contribution in total demand is approaching that of wind power, a more pronounced effect of solar power on electricity prices is to be expected.

\subsubsection{Effects of solar and wind power on electricity price variance}

Panel B in Table 3.2 shows the effects of VRE on the variance of electricity prices. The effect of power demand on price volatility is non-significant in all model specifications. This is due to the fact that demand patterns are well established and predictable. For this reason, forecasting errors of demand are much smaller, compared to forecasting errors in VRE power generation. In other words, the expected effect of a variation in demand on a change in price is anticipated well in advance and already reflected in the price forecast. This contrasts to variations in VRE supply, which are more difficult to predict.

According to Model 2, VRE has a statistically significantly and positive effect on electricity price variance: for every percentage point increase in VRE share, the standard deviation of price (square-root of price variance) increases by 14.52 Eurocents/MWh.

When I look at the effects on price variance of different levels of VRE intensity in Model 3, I find that VRE only has a significant effect when it makes up a larger share of total power supply. Indeed, for levels below Q1 $=6.66 \%$, the effect of VRE on price variance is statistically non-significant. However, as the VRE share increases, its effect on price variance becomes statistically significant and its magnitude increases rapidly. 
For VRE shares of Q3 = 19.97\% or higher, one percentage point increase in VRE power generation increases the price variance by over 30.85 Eurocents/MWh.

In Model 4, I further disentangle the effect of VRE on price variance and look at how solar and wind power impact price variance individually. In line with subsection 3.5.1, these results show that the effect of solar power on price variance is insignificant. This may be due to several reasons: one reason may be the low share of solar power for the period under analysis; second, the aggregation of hourly data into one data point corresponding to the daily average may obscure heterogenous effects across different hours; and last, as solar power generation usually coincides with peak demand, a larger infeed of solar power may drive down peak prices, thus reducing the spread between low and high prices. Wind power, on the other hand, has a strongly positive effect: for every percentage point increase in the share of wind power in total demand, the variance of the electricity price increases by over 15.57 Eurocents/MWh. One possible explanation is that wind power generation is stronger during off-peak demand. A higher infeed of low-price wind electricity thus puts additional downward pressure on off-peak prices, therefore increasing the spread between peak and off-peak prices.

\subsection{Concluding remarks}

The increasing contribution of VRE in meeting power demand is reshaping the current electricity market. This chapter discusses the individual effects of solar and wind power on the electricity price and its variance, across a wide geographical area and for different levels of VRE integration. In line with established research, I find that an increasing share of VRE is associated with a drop in electricity prices. The results of the models developed in this chapter therefore confirm the presence of the merit order effect of VRE on electricity prices. However, when I look individually at the effects of solar and wind power on the electricity price, I find that the negative effect is due to wind power alone. Indeed, the effect of solar power on the electricity price is insignificant. This may be due to the still limited contribution of solar power to the energy mix, compared with wind power. As the intensity of solar power in the energy mixes of different European countries increases and new data become available, future research is needed to understand the effect of solar power on the electricity price.

More interestingly, I find that VRE has a strong positive effect on the variance of electricity price. In addition, the magnitude of this effect increases with the share of VRE. This effect is, again, only due to the contribution of wind power. However, this may also be explained by the fact that solar power capacity is lower than that of wind power, although this situation is rapidly changing. This finding is an important contribution to 
the limited empirical literature on the VRE effect on the variance of electricity prices. As discussed in section 3.2, this literature is divided between whether VRE is associated with an increase or decrease of the variance of electricity price. The research presented in this chapter has argued that the different results in the literature are due to 1) the use of limited data on the share of VRE and 2) the focus on single-country studies. In this chapter, I overcome these limitations by using the most recent data on the contribution of VRE to the energy mixes to date and extending the geographical focus to ten EU countries.

To my knowledge, this is the first empirical study yet on the effect of VRE on electricity price variance, on such a large geographical scale. These results have several policy implications: first, the effect of VRE on the variance of the electricity price becomes significant for higher levels of VRE. In other words, there is a lower bound of VRE intensity - around $12 \%$ - below which the current design and operation of the electricity market are not significantly affected. Second, the increasing share of VRE, coupled with an increasing price variance, is expected to lead to a growing role for power system flexibility - in the form of energy storage technologies and interconnection capacity. Third, as the price variance is expected to increase, this may create opportunities for market manipulation by producers who may withhold power for higher-price periods. The current debate on the electricity market transition needs to take this issue into account. Fourth, the discussion about an optimal energy mix needs to take into consideration the heterogeneity of the effects of different VRE technologies on the electricity market - namely the different effects that wind and solar power have on the variance of electricity prices, as well as design appropriate and individualized support schemes for each technology. The discussion of the necessary changes required by the current electricity market in order to accommodate the increasing share of VRE needs to take this issue into consideration, by looking at the individual effects of each energy technology on the electricity markets. 


\section{Appendix 3.A Summary statistics of the main vari- ables}

Table 3.3: Mean of all variables per bidding zone

\begin{tabular}{ccccc}
\hline & Price & Sun & Wind & Demand \\
& & & & \\
\hline BE & 42 & $3.4 \%$ & $5.7 \%$ & 9882 \\
DE, AU, LU & 31.7 & $6.9 \%$ & $16.9 \%$ & 62396.7 \\
ES & 47.4 & $5.1 \%$ & $19.1 \%$ & 28593.6 \\
FR & 40 & $1.8 \%$ & $4.3 \%$ & 54196.2 \\
GR & 49.8 & $7.1 \%$ & $8.2 \%$ & 5895.3 \\
LT & 37.9 & $0.5 \%$ & $8.9 \%$ & 1276.7 \\
NL & 37.2 & $1.3 \%$ & $6.7 \%$ & 14909.6 \\
PT & 47.5 & $1.7 \%$ & $22.7 \%$ & 5623.7 \\
\hline \hline
\end{tabular}

Note: This table shows the average daily values of the electricity price, share of solar power, share of wind power and electricity demand in the eight bidding zones considered in this research.

Table 3.4: Number of observations per bidding zone

\begin{tabular}{ccccccccccc}
\hline & BE & DE, AU, LU & ES & FR & GR & LT & NL & PT & Total \\
\hline nb Negative Prices & 0 & 11 & 0 & 0 & 0 & 0 & 0 & 0 & 11 \\
nb Observation & 1087 & 1087 & 1096 & 1090 & 1096 & 1071 & 1091 & 1093 & 8711 \\
\hline \hline
\end{tabular}

Note: This table shows the number of negative prices, as well as the total number of days for which I have data across the eight bidding zones considered in this research. 

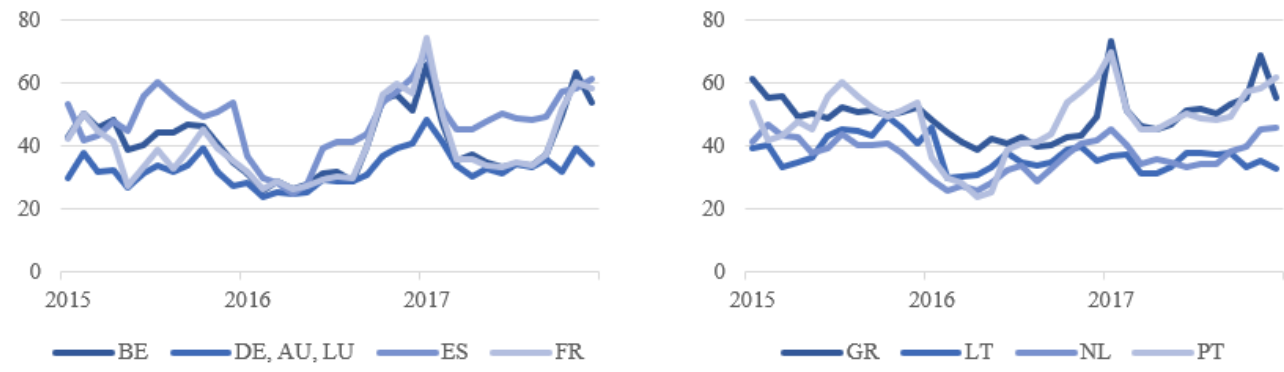

Figure 3.5: Average monthly price per bidding zone in Euros/MWh
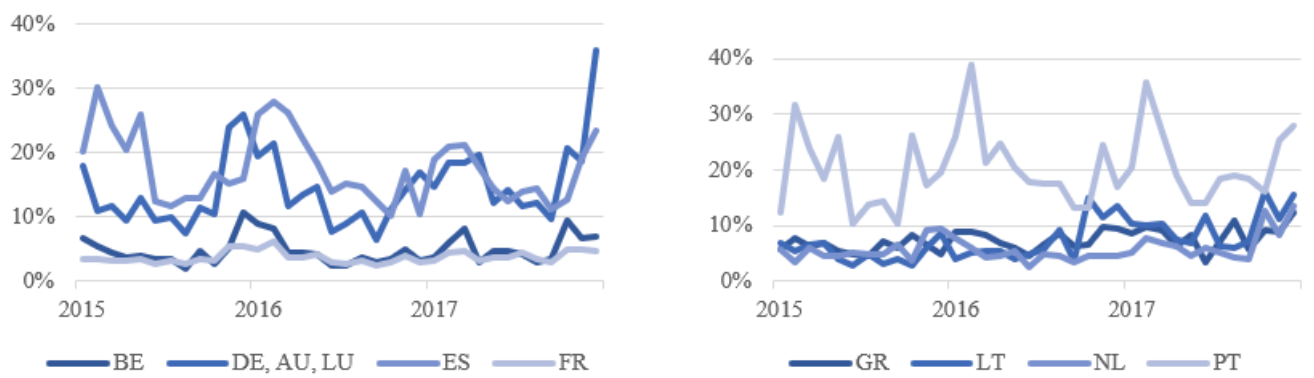

Figure 3.6: Average monthly share of electricity generated by wind per bidding zone 

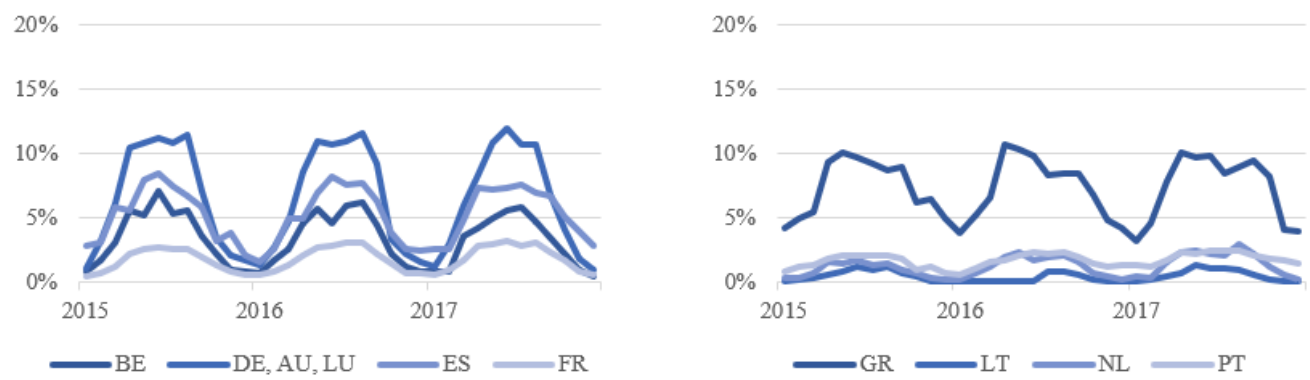

Figure 3.7: Average monthly share of electricity generated by solar per bidding zone
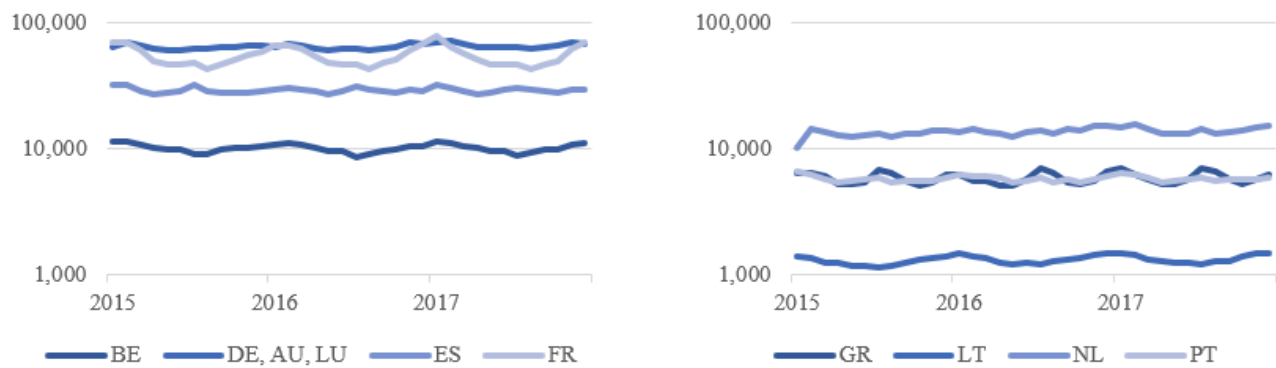

Figure 3.8: Average monthly demand for electricity per bidding zone in MW 


\section{Chapter 4}

\section{Understanding the relation between VRE and electricity price convergence}

\subsection{Introduction}

Electricity generated by intermittent variable renewable energy (VRE), namely solar and wind power, has experienced a sustained growth for the past two decades. This growth has been motivated by the need to reduce global greenhouse gas (GHG) emissions. Carbon dioxide accounts for more than $72 \%$ of GHG emissions and the energy sectorand particularly the heat and electricity sectors - is the largest $\mathrm{CO}_{2}$ emitter, since it is the main source of GHG emissions (Olivier and Peters (2020)). On this background, the combined global installed capacity of the wind and solar energy technologies increased significantly, from less than $20 \mathrm{GW}$ in 2000 to over $1000 \mathrm{GW}$, at the end of 2018 . In the EU, the combined installed capacity of solar and wind power is just under $300 \mathrm{GW}$, compared to just below $13 \mathrm{GW}$ in 2000 (Fig 4.1) (IRENA (2019b)). This evolution mirrors the ambitions of individual EU countries, driven at least partly by an EU-wide agenda to decarbonise the power sector, with the goal of reaching a $32 \%$ share by 2030 (European Commission (2019a)).

As the share of VRE in the energy mix continues to increase, displacing traditional power technologies, it raises significant challenges to the functioning of the traditional power system in general and to that of the electricity market in particular. With respect to the former, the increasing share of VRE has brought about the issues of power system stability and flexibility - which can be addressed by energy storage technologies and 
1200

1000

800

360

400

200

0

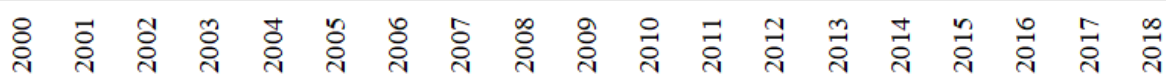

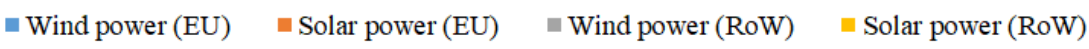

Figure 4.1: Cumulative global installed capacity of wind and solar power technologies. $R o W$ stands for "rest of the world".

Source: IRENA (2019b)

reinforcement of the power grid infrastructure. With respect to the electricity market, the growing share of VRE leads to a reduction of electricity prices, known in the energy economics literature as the "merit-order effect" of VRE on the electricity price. This effect has been anticipated by the theoretical literature on electricity markets and is confirmed by an increasing empirical literature, as discussed in the following section.

At the same time, increasing deployment of VRE in different national energy mixes across Europe means that the determinants of electricity prices in these countries become more similar. As the differences between national energy mixes narrow, differences in electricity prices are expected to narrow as well, since in a liberalized market the fuel is the most important determinant of the electricity price. In other words, as different national energy mixes move away from fossil fuels and towards a renewable-intensive energy mix, an increase in the share of VRE in different European countries is expected to enable the convergence of electricity prices of these countries, in the long run.

The convergence of electricity prices across the EU has been an explicit goal of European energy policy before that of VRE targets. More specifically, it was considered one of the main vehicles for the achievement of the Energy Union, first stated in the 
96/92/EC Directive in 1996 - while VRE targets are first mentioned in the 2001/77/EC Directive on Electricity Production from Renewable Energy Sources in 2001. The two ambitions of electricity price convergence and of increased VRE shares at the EU level have been addressed independently from one another not only politically, but also in the academic literature, as discussed in the following section.

In this chapter, I argue that the two topics are closely related, and that a clear understanding of the relation between them is necessary to help advance both ambitions of the Energy Union. I thus address the following research question: what is the effect of VRE on electricity price convergence, in Central and Western European countries? To answer this question, I bring together insights from the two strands of literature mentioned above - namely the literature on the effects of VRE on electricity prices and the literature on the phenomenon of convergence of electricity prices - in order to develop a conceptual framework that guides our understanding of the relation between VRE and electricity price convergence.

The remainder of the chapter is organized as follows: the next section discusses the two strands of literature mentioned above. In section 4.3, I develop an analytical framework to understand how VRE impacts the process of convergence of electricity prices. Sections 4.4 and 4.5 discuss the data and the empirical specification used to validate our analytical framework, respectively. The results of the empirical analysis are discussed in section 4.6. Finally, section 4.7 summarizes the findings and discusses the main policy implications.

\subsection{Literature review}

Following the liberalization of electricity markets across Europe, which began over three decades ago, the electricity price has been determined by the marginal cost of electricity production, itself determined largely by the fuel cost of conventional power plants. Increasing evidence confirms that the upsurge of VRE decreases electricity prices, due to its low marginal cost, and thus affects the profitability of conventional generators namely coal, gas and nuclear power plants.

Nevertheless, due to the unpredictability of power generated from VRE, the flexibility provided by dispatchable power technologies becomes increasingly important in maintaining the stability of the power grid. ${ }^{1}$ This has brought about the need to reconsider the

\footnotetext{
${ }^{1}$ Dispatchable power technologies refer to power technologies which generate power on demand, i.e. at a time decided by the plant operator. The term is used to differentiate between power technologies the output of which can be controlled, from those with power output out of the operator's control, namely wind and solar energy technologies. The term is used to refer mainly to gas power plants. This is due to the fact that coal and nuclear power plants are very costly to turn on and off, therefore gas power
} 
design of the electricity market, such that it reflects the flexibility value of conventional power plants ( Gelabert, Labandeira and Linares (2011), Cludius, Hermann, Matthes and Graichen (2014), Ketterer (2014), Clò, Cataldi and Zoppoli (2015), Martinez-Anido, Brinkman and Hodge (2016) and Kyritsis, Andersson and Serletis (2017)). What is more, an increasing number of recent studies have found that the downward effect of VRE on electricity prices is not limited to the national borders of the country experiencing an increase in VRE. Indeed, these price-reduction effects - stemming from the unilateral decisions of one country's VRE growth - spill over to neighboring countries (Phan and Roques (2015), Keppler, Phan, Le Pen et al. (2016)).

At the same time, the merits of regional integration of electricity markets are being increasingly recognized (Newbery, Strbac and Viehoff (2016), Abrell and Rausch (2016), Antweiler (2017) and Gianfreda, Parisio and Pelagatti (2016)). In the EU, the ambition of a single market for electricity precedes that of VRE targets. ${ }^{2}$ Similar to the Single Market for goods and services, the merits of an Energy Union would lie in reduced barriers to trade and convergence of electricity prices, which would translate into increased welfare for consumers. However, despite the overlap in terms of aspects they are touching upon, the two ambitions of increasing the contribution from VRE and integrating electricity markets have been historically addressed as separate objectives.

This historical sequence of interest in electricity market integration at the policymaking level, followed by, and independent from, interest in the effect of VRE on the electricity market, is reflected in the academic literature as well. Zachmann (2008) looks at the process of electricity price convergence for eleven EU countries and finds that, as of mid-2006, this process was only partially achieved. More specifically, he finds that there are wide variations between the degrees of price convergence of pairwise countries, as well as in convergence among peak and off-peak electricity prices. Bosco, Parisio, Pelagatti and Baldi (2010) confirm these results, in a study looking at six Central and Western European countries. They find that the process of price convergence is geographically clustered and argues that the price convergence among several pairs of countries is partially explained by the similarity in the marginal power technology in the countries concerned - namely gas. De Menezes, Houllier and Tamvakis (2016) find that the relative importance of electricity price determinants varies from one country to another: British electricity prices reflect fuel cost developments, while in the French and the Nord

plants are the most flexible source of power generation.

${ }^{2}$ The ambition of the Energy Union was first addressed in the Directive 96/92/EC, based in the treaty establishing the European Community, and in particular Article 47(2), Article 55 and Article 95. Since then, it has been replaced by Directive 2003/54/EC, itself replaced by Directive 2009/72/EC. On the other hand, renewable energy targets were first addressed by the Directive on Electricity Production from Renewable Energy Sources 2001/77/EC, replaced by Renewable Energy Directive 2009/28/EC, published on 23 April 2009. 
Pool market - which includes the Scandinavian and the Baltic countries - prices reflect electricity price developments on the markets of trading partners. Barteková and Ziesemer (2019) look at how the retail electricity prices faced by medium-sized industrial consumers differ across Europe. They look at bi-annual data between 2003 and 2013 and find that, for South-Western European countries, the price differential has remained constant, while for North-Eastern countries, it has increased.

Gugler, Haxhimusa and Liebensteiner (2016) is one of the first studies to consider VRE in the process of price convergence. It looks at twenty-five EU countries and finds that the markets became increasingly integrated during 2010-2012, but the process reverts after this date. It suggests this was potentially due to the growing share of VRE after this date, which led to increased electricity trade - and subsequently to more frequent congestion of the interconnector infrastructure - i.e. the connection of different national electricity networks. Gianfreda, Parisio and Pelagatti (2016) find similar evidence of a negative relation between VRE and price convergence, when looking at six EU countries. They argue that this is due to the fact that VRE has a strong effect on the electricity-fuel nexus, in the sense that it reduces the importance of fuel price as the main determinant of electricity prices. More specifically, they argue that prior to the high increase in VRE, the convergence of electricity prices was due to the fact that gas was the main determinant of prices. Therefore, any movement in the (international) gas price was reflected in a similar change in different national electricity prices. As the share of VRE increased, this weakened the relation between gas and electricity prices via two mechanisms: by displacing the costlier gas-powered plants, and by increasing the relative importance of coal, as a price determinant, as $\mathrm{CO}_{2}$ prices decreased. Therefore, these findings of a negative relation between VRE and the convergence of electricity prices in the statistical sense by which they tend to move in different directions - are robust over several European regions and methodological approaches, but the mechanisms which would explain how VRE leads to price divergence are not clearly understood.

In a more recent strand of literature, studies look at the effect of domestic VRE on electricity prices of neighboring countries. Phan and Roques (2015) provide one of the earliest studies to address this issue and find that this effect is identical to the one in the VRE-intensive country. In particular, they find that the steep increase in VRE deployment in Germany led to a drop in French electricity prices as well, and to an increase in their volatility during, the 2012 - 2014 period. However, the effect is much stronger for Germany than for France. The study uses simulations to look at the effect of potential extensions of interconnectors on the price differential and finds that, in the presence of additional interconnector capacity, the magnitudes of the effect of VRE on electricity prices are reversed: French electricity prices would drop more than German electricity 
prices. While the simultaneous drop in electricity prices in France and Germany - both in the case of the current infrastructure and with potential additions - would point to increased similarity between the two, the authors make no explicit claim with regards to the phenomenon of price convergence. This issue is addressed by Keppler, Phan, Le Pen et al. (2016), who find that VRE in Germany increases the price spread between Germany and France. The authors argue that this is due to the fact that excess VRE generation cannot be absorbed in Germany and is exported to France, thus leading to the congestion of interconnectors - which makes it impossible to further export excess power. This, in turn, reverses the process of price convergence, as illustrated by an increased spread between the French and German electricity prices.

However, this price divergence effect can be mitigated by improved trading conditions, in the form of market coupling. This is a term used to define a specific arrangement between two or more trading partners, in which they only place one single bid for electricity trade, instead of the traditional two bids - one to reserve the interconnector capacity that would allow the desired electricity trade, and the second, to buy the actual electricity to be traded. In this sense, market coupling effectively removes barriers to trade. Transactions between parties benefiting from market coupling are referred to as "implicit allocations", since the allocation of cross-border capacity is done implicitly, through the transactions of electricity trade. This is in contrast to "explicit allocations", whereby, in the absence of market coupling, allocations of interconnector capacity must be made explicitly and in a bid that occurs prior to bids for electricity trade. Market coupling thus leads to a more efficient use of the interconnector capacity (Meeus, Vandezande, Cole and Belmans (2009), Van den Bergh, Boury and Delarue (2016)).

The market coupling decision between the German and the French electricity markets came into effect in November 2010. To assess the effect of market coupling on the process of price convergence, Keppler, Phan, Le Pen et al. (2016) use a dummy to separate the before-and-after periods. They find that market coupling indeed reduced the spread between the two electricity prices. A similar effect was found by Sapio (2019) in different Italian markets, following the extension of the interconnector capacity between Sardinia and mainland Italy, in 2011. The study argues that this is due in large part to the fact that the new power cable helped to shave off high peak-time prices. By looking at the merit order effects of VRE both before and after the connection of the new power line, the author concludes that "robustness checks suggest that renewables and the cable mostly delivered their price reduction effects jointly or, in other words, the merit order and peak-shaving effects of renewables have been comparatively stronger in the postSAPEI [n.a. the new power cable] period" (p.467). In a follow-up study, Sapio and Spagnolo (2020) find that the power cable extension helped bridge the gap bewteen 
(higher) electricity prices in Sardinia and those in mainland Italy. This was mostly due to the possibility of Sardinian imports of peninsular renewable power generation. However, together with renewable power, the cable also made it possible for the higher volatility of peninsular prices to be exported in Sardinia. This phenomenon of higher price volatility was restricted to off-peak prices alone. The authors argue that this is because, during peak hours, the power congestion occuring on the new line limited the amount of export of VRE power generation.

Keles, Dehler-Holland, Densing, Panos and Hack (2020) look at the effects that the factors underlying developments of German, French and Italian electricity prices have on Swiss electricity prices. These four markets are strongly interconnected, i.e. the large amount of power trade is supported by a developed cross-border infrastructure. They find that Swiss electricity prices are correlated with electricity prices in Germany, France and Italy. This is due to both the demand and the energy mix in these countries having significant effects on Swiss electricity prices. However, the level of these pair-wise correlations - between Swiss prices, on the one hand, and prices in any one other country, on the other - varies monthly. For example, peak-demand levels in France are higher, relative to neighbouring countries, due to its high reliance on electrical heating. Therefore, the high power demand in France during the evening, in winter months, drives up electricity prices, which results in increased imports from Switzerland - thus an increase in Swiss electricity prices. On the other hand, the high level of renewable power generation in Germany, during summer months, leads to increased exports to Switzerland, thus driving down summer electricity prices. Their results are robust in both econometric and Nash-Cournot equilibrium models (see Keles, Dehler-Holland, Densing, Panos and Hack (2020)). Therefore, the literature on the effect of VRE on prices in neighboring countries finds a positive relation between VRE and the convergence of the electricity prices of the trading countries.

The two foci of research discussed above suggest that the current evidence on the relation between VRE and electricity price convergence is limited and ambiguous. More importantly, the mechanisms explaining this relation have only been marginally addressed and, to my knowledge, have not been investigated in an empirical framework.

This chapter argues that the inconsistencies regarding the effect of VRE on the process of price convergence between these two strands of literature - namely on electricity market integration and on the effect of VRE on the electricity market - stem from the shape of the relation between VRE and price. More specifically, I suggest that VRE has a positive effect on price convergence, however, this effect is limited by the existing interconnector capacity. I develop a conceptual framework - which I then validate empirically - with the aim to provide a clear understanding of this relation and of the mechanisms that explain 
it. I thus extend the current literature in two ways: 1. by providing a large geographical scale investigation of the relation between VRE and the process of price convergence and 2. by developing an analytical framework that brings together insights from the price convergence literature and the literature on the effect of VRE on electricity prices, with the goal to reconcile the findings of these two strands of literature.

\subsection{Theoretical model}

In this section, I develop a simple, two-country theoretical model, with the aim of understanding how VRE affects the process of price convergence in the context of international power trade. The process of price convergence is defined as the decrease in the electricity price differential of the two countries. The changing share of VRE in the energy mix has an indirect effect on the level of electricity trade, via its effect on electricity prices. This is discussed in more detail later in this section. As mentioned in the introduction of this chapter, the convergence of electricity prices of EU member states reflects the level of integration of different energy systems in a pan-European energy system, which is one of the explicit goals of the Energy Union. I first discuss the case of a single country in subsection 4.3.1, then I develop a two-country model, in subsection 4.3.2.

\subsubsection{Case one: single country}

Consider a country with two energy technologies: renewable and fossil fuel power plants. For simplicity, I consider gas power plants as the only fossil fuel technology, instead of a mix of coal and gas. This is because, while the two technologies are similar in terms of the cost structure (i.e. the cost of fuel makes up a significantly larger share than the fixed cost in the total cost), gas-fired power plants are more flexible in generating electricity. In other words, they can increase their output and be switched on/off much faster than coal-fired plants. This characteristic is central to compensate for the intermittent nature of the the output of VRE technologies, which can vary greatly over short periods. For this reason, the terms "conventional", "fossil fuels" and "gas" power plants are used interchangeably in this chapter.

The country has a domestic electricity demand $D$ and its net exports (i.e. net of imports) are denoted by $X$. I model trade restrictions - resulting from limited crossborder transmission infrastructure - by defining $X$ as exogenous and varying across the range $(-D, D)$. The electricity generated by the VRE technology, with installed capacity $I C_{V R E}$, is denoted by $q_{V R E}$. The residual power demand - i.e. demand net of $q_{V R E}-$ is met by $q_{F F}$, the power generated by the fossil fuels technology, with installed capacity $I C_{F F}$. 


$$
q_{F F}=D+X-q_{V R E}
$$

In line with the reality of the existing liberalized electricity markets, the first power technology to meet demand is the one with the lowest marginal cost. This ranking of power technologies in increasing order of their marginal costs is known in the energy economics literature as the "merit order". The electricity price is determined by two main factors: the cost of the last unit of electricity produced which is necessary to meet demand and the level of demand. Hence, the electricity price is given by:

$$
P\left(q_{F F}\right)=a+b \times q_{F F}=a+b \times\left(D+X-q_{V R E}\right)
$$

where $a$ is the fixed price of VRE electricity and $b$ is the variable cost of conventional electricity. ${ }^{3}$ Furthermore, $a>0$ and $b>0$. This inverse-demand (price) function can be plotted as shown in Figure $4.2 .^{4}$

Figure 4.2 shows the hypothetical inverse-demand (price) function. One simplifying assumption of this model is that there are only two energy technologies: conventional and VRE. In reality, each of these generic technologies consists of several power generation technologies, with different marginal costs. Therefore, a graphical representation of the price function that would be closer to reality would look more similar to a sequence of steps, as shown in the previous chapter, rather than a linear increase of the price. However, the focus of the model is on the long-term effect of a large increase in VRE on electricity prices, and not on short-term price effects driven by a temporary switch from one specific power technology to another. The linear price model presented here is therefore a simplified version of the merit-order effect discussed previously. It captures its main feature, i.e. the fact that, as power demand increases, technologies with increasingly higher marginal costs are brought online. This increase in the marginal cost of electricity is represented by a positive slope $(b>0)$. Furthermore, a negative demand for fossil fuels $\left(q_{F F}=D+X-q_{V R E}<0\right)$ can lead to a negative price of electricity. This phenomenon is discussed in Chapter 1.

In this one-country model, when VRE power generation exceeds domestic demand and exogenous export (i.e. when $q_{V R E}>D+X$ ), the demand for the fossil fuels technology will become negative $\left(q_{F F}<0\right)$. Although a negative excess demand for fossil fuel technology does not make intuitive sense, it can be considered as the amount of energy that can be stored. According to the price function in Figure 4.2, this negative excess demand for fossil fuels (i.e. positive excess demand for storage) can lead to a negative

\footnotetext{
${ }^{3}$ In the case of energy from fossil fuels, the variable cost is mainly given by the cost of fuel.

${ }^{4}$ The phrase "negative demand for fossil fuels" refers to the phenomenon where VRE supply exceeds demand.
} 


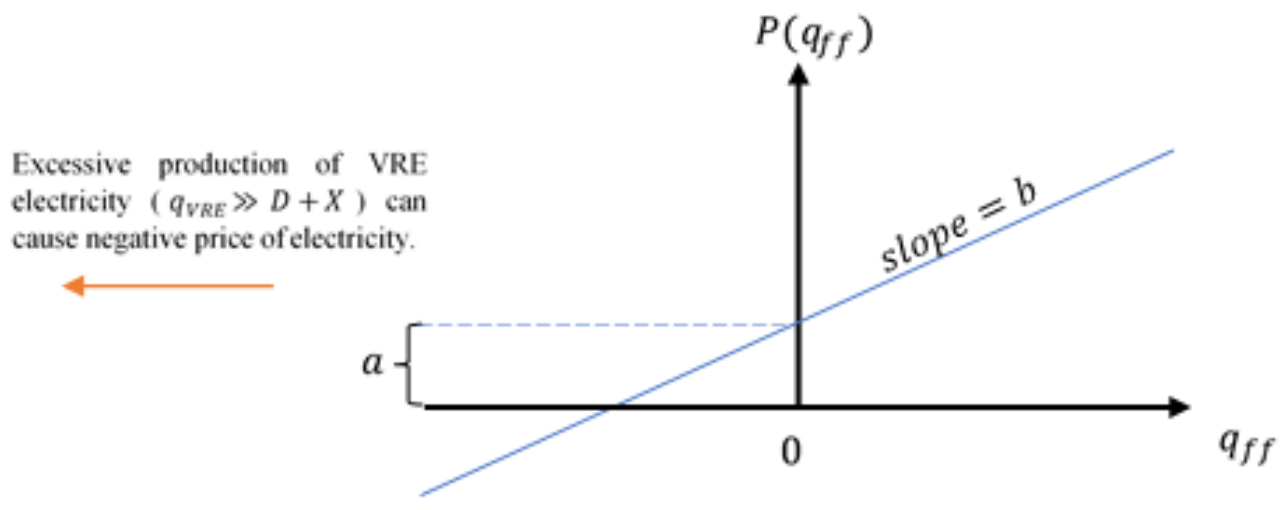

Figure 4.2: The price function

price of electricity. ${ }^{5}$ This negative price of electricity, which occurs in the days with significantly large VRE power generation, can be understood as the shadow (marginal) cost of storing one unit of excess VRE power. Indeed, when VRE power generation exceeds domestic demand and (exogenous) exports, the surplus electricity can be stored at this cost to the producer, in case there is available storage technology, or it can be sold at a negative price. The model developed in this chapter does not consider storage technologies, hence the use of the term "shadow cost of storing". Nevertheless, the discussion of extremely high VRE power generation is relevant for two main reasons: 1) in the presence of restricted trade (i.e. when trade is possible only up to a certain level due to an exogenous constraint, such as limited transmission capacity), this phenomenon is relevant to understand the effect of VRE on the convergence of electricity prices between trading countries, and 2) it highlights the importance of policy coordination between trading countries.

\subsubsection{Case Two: two countries}

Now let us consider two neighboring countries, country A and country B. Country A is larger than country B. For simplicity, let us make the following three assumptions:

1. Electricity demand in country $\mathrm{A}$ is twice as large as that in country B:

$$
D^{A}=2 D^{B}=2 d
$$

\footnotetext{
${ }^{5}$ In reality, negative electricity prices do occur on the wholesale electricity markets. This happens because, during unexpectedly high sun radiation and wind speed, less flexible power plants - such as nuclear or coal-fired ones - may find the cost of shutdown and restart to be higher than the cost incurred by a temporary negative price.
} 
2. Country A has twice as much installed capacity of VRE:

$$
I C_{V R E}^{A}=2 I C_{V R E}^{B}
$$

3. Due to their geographical proximity, both countries are exposed to the same amount of VRE resources, i.e. they are exposed to the same level of wind speed and solar radiations. From this and assumption 2 it follows that country A generates twice as much electricity from VRE.

$$
q_{V R E}^{A}=2 q_{V R E}^{B}=2 q_{V R E}
$$

The electricity exports of country B to country $\mathrm{A}$ is represented by $X^{B \rightarrow A}$. A negative value of $X^{B \rightarrow A}$ shows a reversed direction of trade, i.e. electricity exports from country A to country B. ${ }^{6}$

According to equations 4.2, 4.3 and 4.5, the prices in country A and country B are, respectively:

$$
P^{A}=a+b \times\left(2 d-X^{B \rightarrow A}-2 q_{V R E}\right)
$$

and

$$
P^{B}=a+b \times\left(d+X^{B \rightarrow A}-q_{V R E}\right) .
$$

For illustration purposes, I assume that $a=0, b=1$ and $d=1$. In the following figures, $q_{V R E}$ and $X^{B \rightarrow A}$ are expressed in units of demand of country B (i.e. $d$ ). For example, in Figure 4.3, $q_{V R E}$ varies between $0 d$ and $2 d$.

Panels A and B in Figure 4.3 show the electricity prices in countries A and B, respectively, as a function of the exogenous amount of the VRE electricity $\left(q_{V R E}\right)$ and the exogenous imports of country A (i.e. $X^{B \rightarrow A}$ ).

In the absence of electricity trade and VRE power generation, i.e. when $X^{B \rightarrow A}=0$ and $q_{V R E}=0$, power in both countries is met exclusively by domestic, gas-fired power generation. The electricity price in country A is higher, due to the higher level of demand. The prices in the two countries correspond to points $\overline{P^{A}}$ and $\overline{P^{B}}$ on panel $\mathrm{A}$ and $\mathrm{B}$ of Figure 4.3, respectively.

From equations 4.6 and 4.7 , the price difference between the two countries is

$$
\begin{array}{r}
|\Delta P|=\left|P^{A}-P^{B}\right|=\left|b \times\left(2 d-X^{B \rightarrow A}-2 q_{V R E}\right)-b \times\left(d+X^{B \rightarrow A}-q_{V R E}\right)\right| \\
=\left|b \times d-2 b \times X^{B \rightarrow A}-b \times q_{V R E}\right|
\end{array}
$$

\footnotetext{
${ }^{6}$ The default notation of the direction of electricity trade is justified by the higher demand of country A. However, as discussed later, $X^{B \rightarrow A}$ can also take negative values.
} 

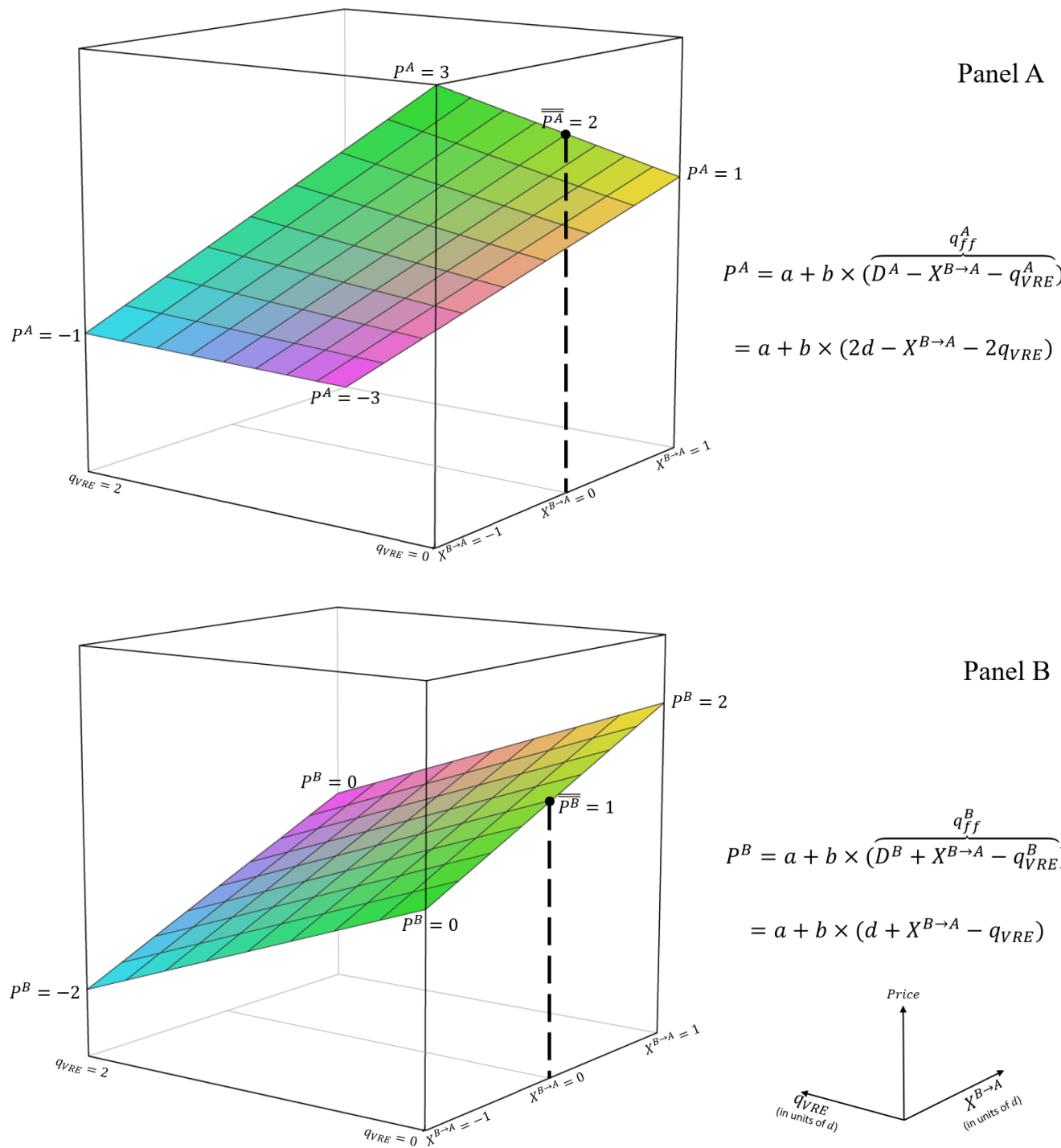

Panel B

$$
P^{B}=a+b \times\left(\frac{a_{f f}^{B}}{\left(D^{B}+X^{B \rightarrow A}-q_{V R E}^{B}\right.}\right)
$$$$
=a+b \times\left(d+X^{B \rightarrow A}-q_{V R E}\right)
$$

Figure 4.3: The electricity prices of countries A and B 


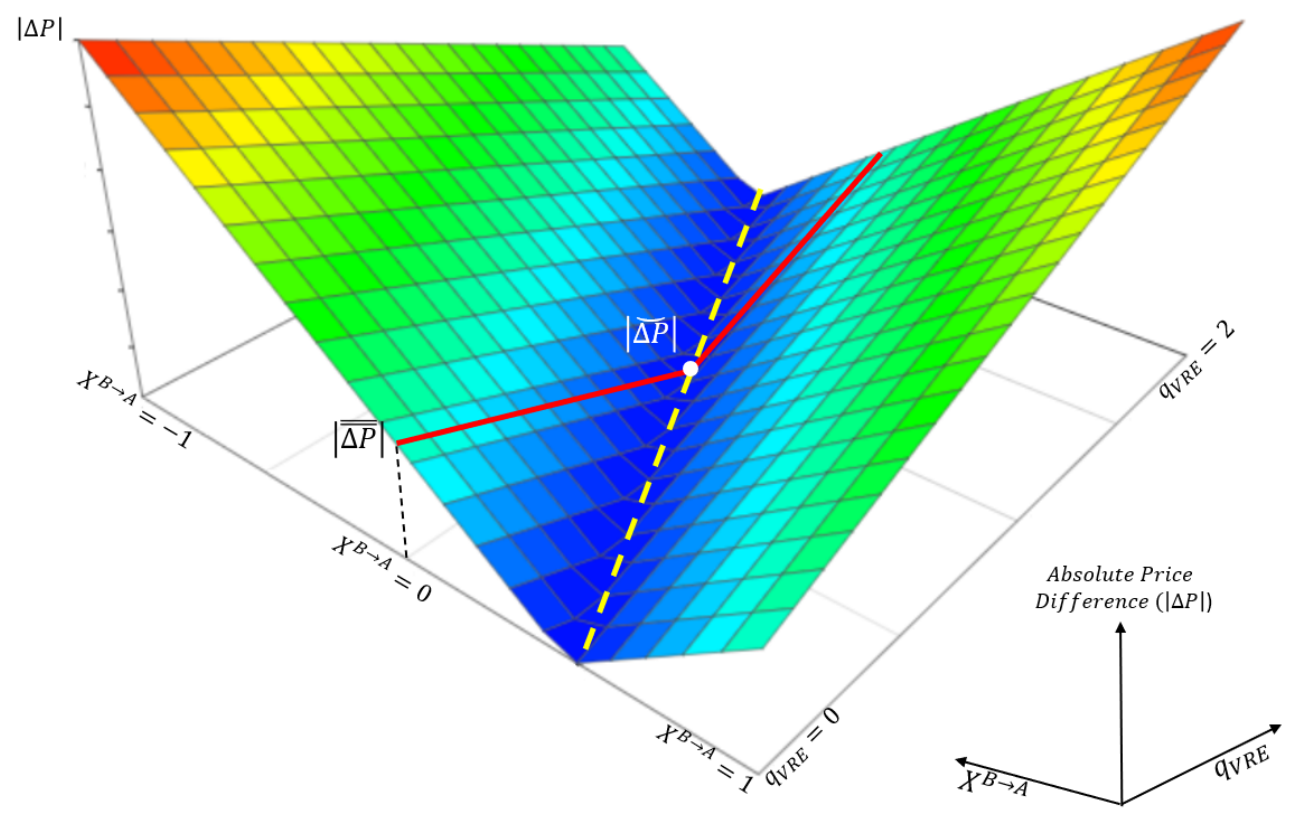

Figure 4.4: Price difference between countries A and B

This figure displays the absolute value of the difference between the price in country A and country $\mathrm{B}$, as function of the exogenous amount of the VRE electricity $\left(q_{V R E}\right)$ and the import of country $\mathrm{A}\left(X^{B \rightarrow A}\right)$.

Figure 4.4 shows the absolute value of the price difference between country A and B, as a function of $\operatorname{VRE}\left(q_{V R E}>0\right)$ and power trade $\left(X^{B \rightarrow A}\right)$. I choose the absolute value of the price difference as a measure of price dispersion due to the fact that I am interested in the general phenomenon of price convergence between the two countries. The price difference can increase due to changes in both countries, i.e. it can take both positive and negative values. However, the model discussed here aims to provide an understanding of the general effect of VRE on the process of price convergence, indifferent of which country displays the higher price. The special case of autarky $\left(X^{B \rightarrow A}=0\right)$ is shown by the red line.

\section{The isolated effect of trade on price convergence}

For simplicity, let us assume that there is no VRE, i.e. $q_{V R E}=0$. In this case the price differential of the two countries (from equation 4.8) can be rewritten as:

$$
|\Delta P|=\left|b \times d-2 b \times X^{B \rightarrow A}\right|
$$

In other words, as electricity exports from country B to country A increase from zero 
to $d / 2$, the prices in two countries converge. As VRE is not available, demand is met entirely by fossil fuels. Due to the availability of imports, demand for domestic fossil fuel in country A $\left(q_{F F}^{A}\right)$ drops, while the demand for fossil fuel electricity in country B $\left(q_{F F}^{B}\right)$ increases. This gives rise to a lower price of electricity in country A and a higher price of electricity in country B, compared to the autarky scenario. In other words, in line with the mainstream international trade literature, in the presence of free trade, the electricity sector experiences a convergence of international prices.

\section{The isolated effect of VRE on price convergence}

Now, let us assume that VRE becomes available in both countries, but there is no possibility for electricity trade, i.e. $X^{B \rightarrow A}=0$. In this case the price differential of the two countries (from equation 4.8) can be rewritten as:

$$
|\Delta P|=\left|b \times d-b \times q_{V R E}\right|
$$

In other words, as the amount of VRE increase - but is lower than $d$, i.e. $0 \leq q_{V R E} \leq d$ - the prices in the two countries converge. This is due to the fact that the higher price, in Country A, falls more rapidly than that of Country B, due to a higher level of VRE capacity displacing conventional power plants. However, as VRE power generation increases further in both countries, the price in country A will continue to drop at a faster rate than that of Country B, beyond the level of full price convergence. Put differently, if the amount of VRE exceeds a certain threshold $\left(q_{V R E} \geq d\right)$, the prices start to diverge again. This implies a U-shaped relationship between the VRE and the price differential: for low levels of VRE, the price differential is high. As the contribution from VRE in the energy mix increases, the price differential drops, only to increase again, once a certain level of VRE is surpassed. Since an increase in price convergence is defined as a decrease in the price differential, a U-shaped relationship between VRE and the price differential corresponds to a reverse U-shaped relationship between VRE and price convergence.

In the absence of both electricity trade and VRE, the price of electricity is higher in country A. The price difference, which is due to the higher demand in country A, is represented by $|\overline{\Delta P}|$ in Figure 4.4 .

As the amount of VRE electricity increases in both countries $\left(q_{V R E}>0\right)$, the prices of electricity are expected to decline, due to the "merit order effect" of VRE (Fig. 4.2). Since the VRE installed capacity in country A is twice as large as that of country B, more conventional power is crowded out by VRE in country A, thus leading to a faster price drop in this country with initial higher price and, consequently, to the convergence of the two electricity prices.

In the absence of electricity trade (i.e. $X^{B \rightarrow A}=0$ ), a small increase in the amount of 
VRE electricity in the two countries $\left(q_{V R E}>0\right)$ lowers the respective electricity prices. However, due to the higher VRE installed capacity in country A, the price reduction in this country is faster. Hence, as the exogenous amount of VRE electricity increases - as long as this increase is not too large - the price difference in the two countries is reduced. This corresponds to point $|\widetilde{\Delta P}|$ in Figure 4.4. If the amount of VRE electricity continues to grow, the price of electricity in both countries declines even further. Since the price in country A continues to drop faster, if VRE increases beyond the point of complete price convergence (i.e. the level of VRE that corresponds to $|\Delta P|=0$ ), the price difference will increase again.

Therefore, in the case of power generation autarky, the relation between VRE and price convergence is not monotonic. For lower levels of VRE, the price difference is reduced, however, if VRE increases beyond the point of full convergence, the price difference increases.

\section{The effects of both VRE and trade on price convergence}

Let us now see how removing barriers to trade affects the process of price convergence, in the presence of VRE. According to Figure 4.4, when electricity trade between the two countries is unrestricted, for any level of VRE electricity, there exists a corresponding level of trade for which the electricity prices of the two countries are identical. In other words, in the absence of trade restrictions, complete price convergence is possible, for any level of VRE. As the amount of VRE changes, the level and the direction of trade adjust and a new convergence price is reached. The paired levels of trade and VRE which correspond to complete price convergence, i.e. $|\Delta P|=0$, are shown in Figure 4.4 by the dashed yellow line.

However, if there are trade restrictions between the two countries, price differentials may persist. In other words, in the intermediary cases of possible-yet-restricted trade, price convergence only occurs up to a certain level of VRE power generation. If VRE continues to increase beyond the point of complete price convergence, electricity prices begin to diverge again.

Figure 4.5 displays the absolute value of the price difference between country $\mathrm{A}$ and $\mathrm{B}$, when trade is restricted to between -0.25 and 0.25 . As mentioned before, all variables are scaled by the level of demand d of country B. Therefore, in Fig. 4.5, power trade can only vary between -0.25 and 0.25 of the level of demand $d$. As we can see in this plot, for too small or too large values of VRE, the price differences persist. The model implications discussed here highlight the importance of coordination between power trade infrastructure and the decarbonization of different national power systems. In other words, different national-level decision-making about VRE targets need to be complemented by 


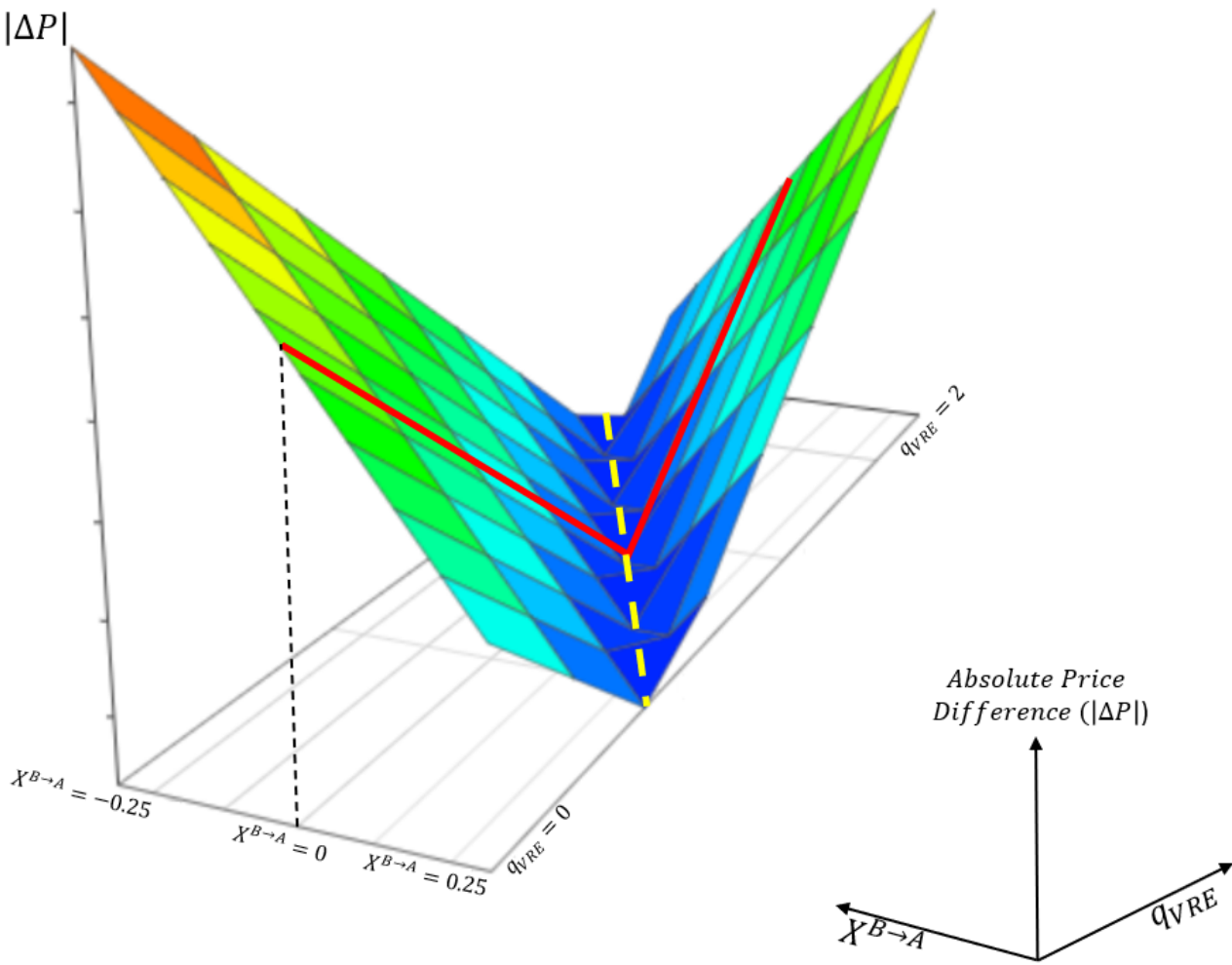

Figure 4.5: Price difference of country A and B when trade is restricted This figure displays the absolute value of the difference between the price in country A and country B, as function of the exogenous amount of the VRE electricity $\left(q_{V R E}\right)$ and the import of country $\mathrm{A}\left(X^{B \rightarrow A}\right)$. The special case when the two countries cannot trade electricity $\left(X^{B \rightarrow A}=0\right)$, is displayed with the red line. (Here I assume that $a=0$, $b=1$ and $d=1$. Furthermore, $q_{V R E}$ and $X^{B \rightarrow A}$ are scaled by $\left.d.\right)$

supra-national decision-making about targets for interconnector infrastructure. In the next section, I test the validity of this theoretical framework empirically.

\subsection{Data}

In order to understand the effect of VRE on the process of price convergence, I use hourly data for the period of 2015 to 2017 for the following variables: day-ahead electricity price, day-ahead forecast for electricity consumption (load), day-ahead forecast for electricity generation from variable renewable energy sources, namely - onshore and offshore - wind power and solar power and data on actual electricity trade between the countries under 
analysis, as well as trade between these countries and third-party countries. Data come from the European Network of Transmission System Operators for Electricity (ENTSOE) and will be discussed in detail in this section. To the best of my knowledge, this is the first study that uses hourly trade data instead of using trade proxies, such as the spread in consumption, as used in (Keppler, Phan, Le Pen et al. (2016)).

The countries under analysis are Portugal, Spain, France, Belgium, The Netherlands, Luxembourg, Germany and Austria. These eight countries form six bidding zones, as Luxembourg, Germany and Austria are grouped in a single bidding zone, while every other country corresponds to individual bidding zones. ${ }^{7}$ The choice of countries is motivated by three main reasons: first, many of these countries have very high absolute values of - as well as experiencing a rapid increase in the share of - VRE, for the period under investigation; second, this region is very active in terms of electricity trade, facilitated by ongoing projects for interconnector capacity extension. ${ }^{8}$ For these two reasons, this selection of countries provides an interesting case study of cross-border power trade increases, in parallel with increases in VRE generation. Third, the countries selected cover a large geographical area, a wide variety of national energy mixes and a common currency, thus lending the price convergence analysis to straight-forward interpretation.

The day-ahead electricity price is the price determined by trade on the day-ahead market, as distinct from both the future/forward market, which can take place up to years in advance of the actual trade, as well as intra-day and balancing markets, which take place on the day of the delivery. The day-ahead electricity price has historically reflected the marginal cost of electricity production. ${ }^{9}$ For these reasons, the day-ahead electricity price is the standard choice in the electricity economics literature (Keppler, Phan, Le Pen et al. (2016), De Menezes, Houllier and Tamvakis (2016), and Haxhimusa (2018)).

To model the process of price convergence, I look at the evolution of the cross-sectional coefficient of variation of hourly prices over the 2015-2017 period. For each hour, the coefficient of variation (denoted by $\mathrm{CoV}_{h}$ ) is defined as the standard deviation of electricity

\footnotetext{
${ }^{7}$ For the period under investigation, Luxembourg, Germany and Austria form a single bidding zone - i.e. a geographical area where interconnector capacity does not need to be explicitly scheduled, thus resulting in a homogeneous price. Usually, bidding zones and national borders overlap. In several cases, however, the fragmented geography of a country leads to several bidding zones within its borders, e.g. Italy, Sweden, Norway. The German-Luxembourg-Austria bidding zone was the only European example of a multi-national bidding zone. The Germany-Luxembourg-Austria bidding zone was created in 2002 in order to further the development of the Internal Energy Market. It formally split on the 1st of October 2018. The split followed official complaints from Czech and Polish grid operators that the unscheduled high flow of VRE from Germany towards Austria created congestions on the German grid, which spilled over on the neighboring grids, thus affecting both Polish and Czech power producers and consumers.

${ }^{8}$ For example, the INELFE project, commissioned in 2015 and aimed at promoting the integration of the Iberian Peninsula in the EU energy market, is set to double the interconnection capacity between France and Spain, from $1400 \mathrm{MW}$ to $2800 \mathrm{MW}$. (European Comission (2017))

${ }^{9}$ In contrast, as discussed in the Introduction Chapter, the intra-day market operates mainly as a correction market and supports a marginal share of the total electricity trade.
} 
prices of all countries, divided by their average over the same hour. Therefore, the values for the hourly electricity prices in the eight countries, for a specific hour, are aggregated in a single hourly value. A reduction of the $\mathrm{CoV}$ reflects convergence of electricity prices, and vice-versa. I make the following choices for notation: the term "price differential" is used throughout the remainder of this chapter to refer to the coefficient of variation. Therefore, a negative relation between the price differential and a given variable can be interpreted as a positive relation between price convergence and that same variable.

The day-ahead electricity price is determined by bids made on the day-ahead market based on information of expected (forecasted) demand and power generation. For this reason, I use data on day-ahead forecasts for - instead of actual realizations of - demand and power generation from VRE as the main explanatory variables. ${ }^{10}$

For data on power trade, I use the pair-wise total scheduled commercial exchanges between the countries under analysis, as well as between these countries and third-party countries. Total scheduled commercial exchanges are defined as the amount (in MW) of power trade that is scheduled to take place between two given countries for a specific hour, aggregated over bidding markets at all time horizons. This variable thus reflects the existing interconnector capacity for any given country and acts a a proxy for its upper limits to power trade.

Since all eight hourly price observations for all countries, for any given hour, are aggregated into one variable, namely the cross-sectional coefficient of variation of hourly prices, I proceed in a similar way with the remaining two variables of interest. Therefore, I calculate the share of VRE in power demand, at hourly resolution and for each country. I use the share of VRE in total load - instead of the absolute power - due to the large variation across the sizes of the different electricity markets considered. The final $V R E_{h}$ variable used in the model is calculated as the cross-sectional average of the hourly shares of VRE in total demand across the six bidding zones.

Trade $_{h}$ is the second exogenous variable of interest. Consistent with the definition of $V R E_{h}$, Trade $_{h}$ is computed as the cross-sectional average of the share of trade in total demand, across the six bidding zones. Thus, in order to compute Trade $_{h}$, I first compute the hourly ratio of utilized cross-border transmission to total load for individual countries. More specifically, I calculate the sum of imports and exports, at hourly resolution, for each country - both with each of the other countries considered, as well as with thirdparty countries. I then divide this aggregate trade by hourly domestic demand, for each country. As discussed above, electricity trade is both enabled and limited by the existing interconnector capacity - i.e. the electricity export potential of a country is not given by its excess power generation alone, but is conditioned by the presence of available

\footnotetext{
${ }^{10}$ As discussed in subsection 1.4.1 of the Introduction Chapter, this standard choice is due to the fact that day-ahead prices are determined based on these forecasts.
} 
interconnector capacity.

Occasionally the aformentioned time series have missing observations in a few hours over my three years of sample data. I remove these hours from my sample, and therefore, the final dataset has 25840 hourly observations for each of the time series mentioned above. An overview of descriptive statistics on the time series of demand, share of VRE and trade are displayed in appendix A to this chapter.

\subsection{Empirical model}

The research presented here addresses the following question: how does the increasing share of VRE affect the process of electricity price convergence? The current section develops an empirical specification to answer this question.

To guide our understanding of the relation between VRE and electricity prices, let us first discuss several stylized facts about electricity prices and electricity trade: 1) The main determinant of the electricity price is the fuel cost. Therefore, given the heterogeneity of energy mixes across the countries under analysis and their ambitions to significantly increase their reliance on solar and wind power, an increase in the contribution of VRE, with almost-zero fuel cost, would be expected to lower electricity prices across all considered countries, in the long run. 2) There is a wide variation in weather patterns - i.e. in wind speeds and solar radiation - across European countries. Also, countries differ substantially in terms of installed capacity of VRE. This points to a large scope for electricity trade. As electricity flows from a lower-price country to a higher-price country, trade reduces the price differential between the two countries. This mechanism enables the process of electricity price convergence between the trading countries. And 3) there is an upper limit to the amount of excess VRE power generation that a country can export, as electricity trade is only possible in the presence of available interconnector capacity. These three stylized facts are explicitly addressed in the theoretical model of section 4.3. Here I discuss the empirical specification of the mechanisms described in section 4.3 .

The empirical identification of the conceptual tool dicussed in section 4.3 is developed around four model specifications. With the exception of the first one, each specification builds on the previous one. In all model specifications, the dependent variable is the cross-sectional coefficient of variation of hourly electricity prices (across the bidding zones considered in this chapter). The main variables of interest are the share of electricity from VRE in hourly load and the share of power trade in hourly load. All hypotheses and the model specifications used to address them are discussed in the remainder of this section. 
Hypothesis 1: A growing contribution from low-cost VRE is associated with an increase of the price differential. Conversely, power trade is associated with a reduction of the price differential.

$$
\begin{aligned}
\operatorname{CoV}_{h}=\alpha+\beta_{1} V R E_{h} & +\beta_{2} \text { Trade }_{h} \\
& +\delta_{1} \operatorname{CoV}_{h-1}+\delta_{2} \operatorname{CoV}_{h-24}+\delta_{3} \operatorname{CoV}_{h-168}+
\end{aligned}
$$

$\delta_{4}$ TimeTrend $+\phi_{1}$ HourDummies $+\phi_{2}$ DayOfWeekDummies $+\phi_{3}$ MonthDummies $+\epsilon_{h}$

where $C_{o} V_{h}$ is the cross-sectional coefficient of variation of hourly prices between the eight countries, in hour $h$. It is calculated as $C o V_{h}=\frac{S_{h}}{\left|\overline{X_{h}}\right|}$, where $S_{h}$ is the cross-sectional standard deviation of hourly prices in the eight countries and $\left|\overline{X_{h}}\right|$ is the absolute value of the cross-sectional mean of the hourly prices of the eight countries. I chose the coefficient of variation over standard deviation, as a measure of variation, in order to account for any changes of the mean. In addition, I use the absolute value of the mean as the denominator - instead of the mean itself - due to the fact that the time series of $\left|\overline{X_{h}}\right|$ contains six observations with negative values for the cross-sectional mean hourly price. As the $C o V_{h}$ is a measure of dispersion, negative values do not make sense. Also, as the values of the negative prices are close to zero, this has no impact on my numerical results.

As defined in the previous section, $V R E_{h}$ is the main variable of interest and is calculated as the cross-sectional average of the hourly shares of VRE in the total demand across the six bidding zones. Similarly, Trade $_{h}$ is computed as the hourly cross-sectional average of the share of trade in total demand, across the six bidding zones.

$C o V_{h-1}, C_{o} V_{h-24}$ and $C o V_{h-168}$ are respectively the 1-hour, 1-day and 1-week lagged values of the cross-sectional $\mathrm{CoV}$ of hourly prices. This choice is in line with the established auto-regressive characteristic of electricity prices (Huisman, Huurman and Mahieu (2007)).

Furthermore, in this regression we have the following dummy variables: Hour Dummies refer to the 23 hour dummies, and DayOfWeekDummies refer to the 6 dummy variables for each day of the week. Similarly, MonthDummies represents 11 dummy variables to capture the month-specific effects. Finally, TimeTrend is a time series such that its $i^{\text {th }}$ element has a value of $\frac{i}{24 \times 365}$. In other words, the value corresponding to the 1 st hour of January 1st in 2015 is $\frac{1}{24 \times 365}$, and the values corresponding to the last hours of 2015, 2016 and 2017, are respectively one, two and three. Therefore, $\delta_{4}$ measures the average trend of price convergence across countries per hour between the first hour in 2015 to the last hour in 2017. 
In a second model specification, I aim to gain more insight regarding the shape of the relation between VRE and price convergence. More specifically, I investigate whether the data support the inverse- $U$ relation between the two variables, as displayed by the conceptual model presented in the previous section. This non-linear relation can be empirically tested by a polynomial model specification. My new hypothesis is:

Hypothesis 2: The relation between VRE and the price differential is U-shaped. As VRE increases, international prices converge - and their price differential decreases. However, as the level of VRE increases (starting from a low level) beyond a certain point, prices begin to diverge again.

$$
\begin{aligned}
\operatorname{CoV}_{h}=\alpha+\beta_{1} V R E_{h} & +\beta_{2} V R E_{h}^{2}+\beta_{3} \text { Trade }_{h} \\
& +\delta_{1} \operatorname{CoV}_{h-1}+\delta_{2} \operatorname{CoV}_{h-24}+\delta_{3} \operatorname{CoV}_{h-168}+
\end{aligned}
$$

$\delta_{4}$ TimeTrend $+\phi_{1}$ HourDummies $+\phi_{2}$ DayOfWeekDummies $+\phi_{3}$ MonthDummies $+\epsilon_{h}$

In order to analyze how the effect of VRE on price convergence is both enabled and limited by the insufficient interconnector infrastructure, ${ }^{11}$ I extend Model (2) by introducing the interaction term $V R E \times$ Trade in regression equation 4.10 . The rationale behind this model specification is the assumption that the effect of VRE on price convergence depends on the level of available interconnector capacity - as proxied by the share of power trade. In other words, the effect of VRE on price convergence is different in the presence of interconnector capacity, compared to a situation when trade is not possible. My new hypothesis is thus:

Hypothesis 3: The effect of VRE on price convergence depends on the level of power trade. The new model specification is given by:

$$
\begin{gathered}
C o V_{h}=\alpha+\beta_{1} V R E_{h}+\beta_{2} V R E_{h}^{2}+\beta_{3} \text { Trade }_{h}+\beta_{4} V R E_{h} \times \text { Trade }_{h} \\
+\delta_{1} C o V_{h-1}+\delta_{2} C_{o V} V_{h-24}+\delta_{3} C o V_{h-168}+
\end{gathered}
$$

$\delta_{4}$ TimeTrend $+\phi_{1}$ HourDummies $+\phi_{2}$ DayOfWeekDummies $+\phi_{3}$ MonthDummies $+\epsilon_{h}$

Finally, in the last empirical specification, I want to understand the shape of the relation between electricity trade and the process of price convergence. More specifically, my hypothesis is that there is a U-shaped relation between the two variables - as defined

\footnotetext{
${ }^{11}$ Insufficient relative to the trade potential, i.e. it sets an upper limit to the trade of excess VRE power generation.
} 
in the analysis - in line with the results from the conceptual framework. For low levels of power trade, the prices between countries converge, in line with the mainstream literature on international trade. However, as power trade goes beyond a certain level, prices begin to diverge again. This can be due to the fact that, when interconnector capacity becomes saturated and low-priced renewable electricity cannot be exported further, importing countries substitute relatively higher-priced domestic alternatives for imports. The last hypothesis is thus:

Hypothesis 4: The relation between power trade and the process of price convergence is non-linear. Low levels of power trade are associated with price convergence, however, as power trade goes beyond a certain threshold, prices begin to diverge again.

$$
\begin{gathered}
\operatorname{CoV}_{h}=\alpha+\beta_{1} \operatorname{VRE}_{h}+\beta_{2} \operatorname{VRE}_{h}^{2}+\beta_{3} \text { Trade }_{h}+\beta_{4} \operatorname{VRE}_{h} \times \text { Trade }_{h}+\beta_{5} \text { Trade }_{h}^{2} \\
+\delta_{1} \operatorname{CoV}_{h-1}+\delta_{2} \operatorname{CoV}_{h-24}+\delta_{3} \operatorname{CoV}_{h-168}+
\end{gathered}
$$

$\delta_{4}$ TimeTrend $+\phi_{1}$ HourDummies $+\phi_{2}$ DayOfWeekDummies $+\phi_{3}$ MonthDummies $+\epsilon_{h}$

To avoid spurious regression, before running any regression, one must ensure that the time series do not display unit-root, i.e. they are stationary. Table 4.1 reports the results values of the Granger-Engle Augmented Dickey Fuller test for stationarity (see Engle and Granger (1987); Dickey and Fuller (1979)). In this test, as a rule of thumb, the lag order is set to the greatest integer lower than $(N-1)^{1 / 3}$, where $\mathrm{N}$ is the number of observations. Since I have 25840 hourly observations for each time series, I choose 29 lags for this test. In this test, the null hypothesis is non-stationarity. As all the p-values are smaller than $1 \%$, the null-hypothesis, i.e. non-stationarity of the time series, is rejected. In other words, all three times series are stationary.

Table 4.1: Granger-Engle Augmented Dickey Fuller

\begin{tabular}{cccc}
\hline & $\mathrm{CoV}$ & VRE & Trade \\
\hline Statistic Value & -21.245 & -18.868 & -18.579 \\
P-Value & $<0.01$ & $<0.01$ & $<0.01$ \\
\hline \hline
\end{tabular}

As already mentioned, the main variables of interest are the share of electricity from VRE in hourly load and the share of power trade in hourly load. However, the Trade variable $\left(\right.$ Trade $\left._{h}\right)$ might be endogenous. In case of endogeneity, we can no longer use 
OLS as an estimation method, as in this case the estimated coefficient for trade is biased. To investigate the presence of endogeneity, I use a Durbin-Wu-Hausman endogeneity test. (For the detailed discussion, see Appendix $\mathrm{C}$ of this chapter.) Under the null hypothesis, the covariance of the regressor and the error term is zero. Therefore, in case of endogeneity, the null hypothesis is rejected. Table 4.2 reports the test results. Given the high p-value $(p-$ value $=0.125)$ of the last model specification, we fail to reject the null hypothesis. We conclude the model does not suffer from endogeneity, thus OLS can be used as an estimation method.

\subsection{Results}

In this section, I discuss the main findings of the four empirical models presented above. These findings are summarized in columns 1-4 of Table 4.2. I begin by discussing the lagged variables and the time trend. I then turn to the evidence that the data provides in support - or lack thereof - of the four hypotheses addressed in the previous section. Finally, I discuss potential mechanisms behind the models' results. Appendix B to this chapter reports the estimated coefficients for the dummy variables in this regression.

As expected, the one hour lag value of the coefficient of variation has a strongly significant and positive effect on its future values, thus confirming that the process of price convergence - as captured by the $\mathrm{CoV}$ - is auto-regressive. In other words, if prices converged in the previous hour, they tend do so in the current hour as well. Conversely, if the prices diverged in the past hour, they will diverge in the current hour as well. In addition, the fact that the coefficient of the one-hour lagged value is the largest in magnitude reflects the short-run persistence of weather patterns as well as the structural inertia of the electricity production and consumption curves. The Time Trend variable gives insights into how the dependent variable - the cross-sectional coefficient of variation of hourly electricity prices - has changed over the period under analysis. The strong statistical significance and negative sign of its coefficient point to the fact that the $\mathrm{CoV}$ has decreased between January 2015 and December 2017 - i.e. that there is a long-term price convergence tendency.

As shown in the first column of Table 4.2 - corresponding to the first model specification in the previous section (regression equation 4.9) - the share of VRE has a positive effect on the cross-sectional $\mathrm{CoV}$ of hourly electricity prices. In other words, according to the base-line specification, an increase in VRE is associated with an increase in the cross-sectional $\mathrm{CoV}$, i.e. the measure of price dispersion. This result is in line with the existing literature on the effect of VRE on the convergence of international prices, as discussed in the literature review section (Phan and Roques (2015); Keppler, Phan, Le Pen et al. (2016)). 
Table 4.2: Regressions results: cross-sectional coefficient of variation of price as dependent variable

\begin{tabular}{|c|c|c|c|c|c|}
\hline Dependant & $\begin{array}{l}\text { Variable: Cross-sectional Coefficient } \\
\text { of Variation of Price }\end{array}$ & $\begin{array}{l}\text { Model } 1 \\
\text { Coefficient } \\
\text { (St. Dev.) }\end{array}$ & $\begin{array}{l}\text { Model } 2 \\
\text { Coefficient } \\
\text { (St. Dev.) }\end{array}$ & $\begin{array}{l}\text { Model } 3 \\
\text { Coefficient } \\
\text { (St. Dev.) }\end{array}$ & $\begin{array}{l}\text { Model } 4 \\
\text { Coefficient } \\
\text { (St. Dev.) }\end{array}$ \\
\hline & Intercept & $\begin{array}{c}0.069 * * * \\
(0.007)\end{array}$ & $\begin{array}{c}0.169^{* * *} \\
(0.051)\end{array}$ & $\begin{array}{c}0.109 * * * \\
(0.028)\end{array}$ & $\begin{array}{c}0.167^{* * *} \\
(0.036)\end{array}$ \\
\hline & $V R E_{h}$ & $\begin{array}{c}0.204^{* * *} \\
(0.072)\end{array}$ & $\begin{array}{l}-1.061^{*} \\
(0.578)\end{array}$ & $\begin{array}{l}-0.686^{*} \\
(0.403)\end{array}$ & $\begin{array}{r}-0.697^{*} \\
(0.402)\end{array}$ \\
\hline & $V R E_{h}^{2}$ & & $\begin{array}{l}3.535^{* *} \\
(1.798)\end{array}$ & $\begin{array}{l}3.521^{* *} \\
(1.775)\end{array}$ & $\begin{array}{l}3.534^{* *} \\
(1.773)\end{array}$ \\
\hline & Trade $_{h}$ & $\begin{array}{c}-0.145^{* * *} \\
(0.039)\end{array}$ & $\begin{array}{c}-0.13^{* * *} \\
(0.034)\end{array}$ & $\begin{array}{c}0.107 \\
(0.126)\end{array}$ & $\begin{array}{c}-0.339^{* * *} \\
(0.102)\end{array}$ \\
\hline & Trade $_{h}^{2}$ & & & & $\begin{array}{c}0.811^{* * *} \\
(0.210)\end{array}$ \\
\hline & $V R E_{h} \times$ Trade $_{h}$ & & & $\begin{array}{r}-1.474^{*} \\
(0.860)\end{array}$ & $\begin{array}{l}-1.419^{*} \\
(0.861)\end{array}$ \\
\hline & CoV 1h-lag & $\begin{array}{c}0.798 * * * \\
(0.020)\end{array}$ & $\begin{array}{c}0.775^{* * *} \\
(0.032)\end{array}$ & $\begin{array}{c}0.773^{* * *} \\
(0.032)\end{array}$ & $\begin{array}{c}0.772^{* * *} \\
(0.032)\end{array}$ \\
\hline & CoV 24h-lag & $\begin{array}{c}0.018 \\
(0.011)\end{array}$ & $\begin{array}{l}0.018^{*} \\
(0.010)\end{array}$ & $\begin{array}{l}0.017^{*} \\
(0.010)\end{array}$ & $\begin{array}{l}0.017^{*} \\
(0.010)\end{array}$ \\
\hline & CoV 168h-lag & $\begin{array}{l}0.015^{*} \\
(0.008)\end{array}$ & $\begin{array}{l}0.014^{*} \\
(0.008)\end{array}$ & $\begin{array}{l}0.015^{*} \\
(0.008)\end{array}$ & $\begin{array}{c}0.014^{* *} \\
(0.007)\end{array}$ \\
\hline & Time Trend & $\begin{array}{c}-0.005^{* * *} \\
(0.001)\end{array}$ & $\begin{array}{c}-0.006^{* * *} \\
(0.002)\end{array}$ & $\begin{array}{c}-0.006^{* * *} \\
(0.002)\end{array}$ & $\begin{array}{c}-0.007^{* * *} \\
(0.002)\end{array}$ \\
\hline & Observations & 25840 & 25840 & 25840 & 25840 \\
\hline & Hour Dummies & Yes & Yes & Yes & Yes \\
\hline & Day-of-Week Dummies & Yes & Yes & Yes & Yes \\
\hline & Month Dummies & Yes & Yes & Yes & Yes \\
\hline & Adjusted R2 & 0.689 & 0.694 & 0.694 & 0.695 \\
\hline $\begin{array}{l}\text { p-value of } \mathrm{t} \\
\text { test (Null h} \\
\text { OLS and }\end{array}$ & $\begin{array}{l}\text { he Durbin-Wu-Hausman endogeneity } \\
\text { aypothesis: Null hypothesis: both the } \\
\text { d the IV estimators are unbiased.) }\end{array}$ & 0.948 & 0.808 & 0.287 & 0.125 \\
\hline
\end{tabular}

Note: This table reports the regression coefficients, when I regress the coefficient of variation of price on its own lagged values, the share of VRE, the share of Trade and their interactions, as well as several dummy variables. All reported standard deviations are robust to heteroskedasticity and autocorrelation based on the Newey-West technique (Newey and West (1987)). Significance of p-values is reported as follows: $*<$ $0.1, * *<0.05$ and $* * *<0.01$ 
Let us now address the second part of Hypothesis 1, namely the effect of power trade on the price difference between the countries in the sample. According to the results in Column 1, the effect of power trade on the cross-sectional $\mathrm{CoV}$ of prices is negative and statistically significant at the $1 \%$ significance level. Refering back to the first hypothesis stated in the previous section, namely:

Hypothesis 1: A growing contribution from low-cost VRE is associated with an increase of price differences. Conversely, power trade is associated with a reduction of the price differential.

- the base-line model specification provides sufficient evidence to support both the first and the second part of the hypothesis.

As we saw in the conceptual framework in Section 4.3, there are several factors that influence the relation between VRE and the convergence of electricity prices: first, the level of VRE - more specifically, how much demand is met by renewable power in each of the countries considered; second, the relative sizes of the countries; and finally, how power trade is both impacted by and itself influences the relation between VRE and the process of price convergence. The previous baseline specification cannot offer insights into these relation. Therefore, I extend the initial model specification in order to understand these relations.

In particular, I look at the shape of the relation between VRE and price convergence, as captured in the models by the CoV. Indeed, I investigate whether the effect of VRE on the cross-sectional CoV of electricity prices is the same for all levels of VRE, or it changes, with a varying share of VRE in overall demand. To do so, I extend the model in regression equation (4.9) by introducing the quadratic term of VRE, with the corresponding results displayed in Column 2. This will lead to regression equation (4.10).

How can we interpret the model results? First and foremost, the coefficient of VRE has the opposite sign, compared to the baseline specification. Second, the strong statistical significance of the coefficient of the new quadratic term confirms the presence of non-linearity in the relation between VRE and price convergence. These two main results confirm that this particular model specification is better suited to explain the relation between VRE and the process of price convergence. In other words, the positive sign of the VRE coefficient in Model 1 was obscuring a non-linear relation between VRE and price convergence. The results of Model 2 are in line with the predictions of the analytical framework, as well: low levels of VRE are associated with a decrease in price $\mathrm{CoV}$ - as depicted by the negative sign of the $V R E_{h}$ coefficient; however, as VRE levels increase above a certain threshold, international prices begin to diverge again, as confirmed by the statistically significant and positive coefficient of $V R E_{h}^{2}$.

Similar to the previous specification, the coefficient of the power trade variable i.e. 
Trade $_{h}$ has a negative sign and is strongly significant, at the $1 \%$ significance level.

Overall, the statistical significance of the coefficient of the quadratic term $V R E_{h}^{2}$, coupled with the increased explanatory power of this second model specification - as reflected in the increased value of the adjusted $R^{2}$ - confirm that this model specification is better suited to explain the shape of the relation between VRE and the process of price convergence. Going back to the second hypothesis stipulated in the Model section:

Hypothesis 2: The relation between VRE and price convergence is inverse U-shaped. For low levels of VRE international prices converge. However, as the level of VRE increases further, prices begin to diverge again.

The model specification finds sufficient evidence to support this hypothesis.

Therefore, the results of Model 2 show that the relation between VRE and the price differential is U-shaped. ${ }^{12}$ However, according to the conceptual framework, the effect of VRE on price convergence depends not only on the level of VRE, but also on the possibility to trade electricity.

The two models above have looked at these two variables separately and assumed they have independent effects on the process of electricity price convergence. In the following model specification, I look at whether power trade has any impact on the relation between VRE on price convergence. In other words, while the previous specifications confirmed the direct effect of VRE on price convergence, I test whether VRE also has an indirect effect, via power trade, on the convergence of international electricity prices. To do so, I extend the previous model by introducing an interaction term $V R E_{h} \times$ Trade $_{h}$ to get regression equation (4.11).

The estimation results for this model specification are shown in column 3 of Table 4.2 . The interaction term is negative and statistically significant. This confirms the indirect effect of VRE on price convergence, i.e. that the power trade infrastructure acts as a vehicle for the price convergence effect of VRE. In other words, the negative effect of VRE on the price differential is stronger in the presence of available interconnector capacity. When the interconnector infrastructure becomes saturated, the price convergence process slows down - and even reverses, when the VRE level goes above a certain threshold. This can be explained by the fact that, when countries can no longer import cheap VREgenerated electricity, due to the saturation of the interconnector capacity, they switch back to more expensive domestic fuels and thus experience an increase in electricity prices. At the same time, exporting countries continue to experience a decline in electricity prices, as excess VRE pushes domestic prices further down, due to the merit-order effect.

\footnotetext{
${ }^{12}$ Note that price convergence corresponds to lower price differential, i.e. $\Delta P$. Thus, an inverse Ushaped relation between price convergence and VRE corresponds to a U-shaped relation between the price differential and VRE.
} 
These simultaneous phenomena result in an increased spread between the electricity prices of the trading countries, as confirmed by the positive sign of the $V R E_{h}^{2}$ coefficient. The magnitude of the latter is virtually unchanged, compared to Model 2. Finally, the Trade $_{h}$ coefficient becomes non-significant, as its effect is captured by the interaction term.

This model specification confirms that the effect of VRE on the price differential is given by both the direct effect - corresponding to the coefficients of $V R E_{h}$ and $V R E_{h}^{2}-$ and the indirect effect, enabled by the possibility to trade, as captured by the interaction term. Therefore, going back to the third hypothesis:

Hypothesis 3: The effect of VRE on price convergence depends on the level of power trade.

The third model specification provides sufficient evidence to support it.

Finally, in the last model specification, I look further at non-linearities in the relation between power trade and price convergence. More specifically, I extend the previous model to include the quadratic term $\operatorname{Trade}_{h}^{2}$. The coefficients of $V R E_{h}, V R E_{h}^{2}$ and of the interaction term $V R E_{h} \times$ Trade $_{h}$ remain virtually unchanged in sign and magnitude. However, the coefficient of Trade $_{h}$ becomes negative again, similar to the specifications of Column 1 and 2 (regression equation 4.9 and 4.10), which excluded the interaction term. More importantly, the coefficient of the new quadratic term, Trade ${ }_{h}^{2}$, is statistically significant at the $1 \%$ significance level and has a positive sign.

How can we interpret these new results? First, the statistical significance of the new quadratic term confirms the presence of a non-linear relation between power trade and the chosen measure of price convergence, i.e. the cross-sectional coefficient of variation of electricity prices. Second, the negative sign of the Trade $_{h}$ coefficient, coupled with the positive sign of the $\operatorname{Trade}_{h}^{2}$ coefficient imply a U-shaped relation between power trade and the CoV. More specifically, for low levels of power trade, prices tend to converge - i.e. the $\mathrm{CoV}$ decreases - however, as the share of power trade in domestic demand increases, prices begin to diverge again. This is explained by the insufficient interconnector capacity: as long as cross-border transmission capacity is available, power trade contributes to the convergence of electricity prices, however, as this capacity becomes saturated, the price difference increases again. The final insight from this particular model specification is that the non-linear relation between VRE and price convergence, as captured previously by both the quadratic $V R E_{h}^{2}$ term as well as by the interaction term, is robust in the new specification. This, together with the strong statistical significance of the coefficient of the new quadratic term, as well as with the increase in the value of adjusted $R^{2}$, suggests that this new model specification is best suited to understand the relation between VRE and power trade, on the one hand, and the phenomenon of price convergence, on the other. Thus, in this model specification, the hypothesis: 
Hypothesis 4: The relation between power trade and the process of price convergence is non-linear. Low levels of power trade are associated with price convergence, however, as power trade goes beyond a certain threshold, prices begin to diverge again.

is validated.

One important question is whether the non-monotnic relationships suggested by the qudratic terms - between the Trade and VRE variables on one hand, and the price differential on the other hand - are observable in the domain of the observations in our sample data. In Appendix D of this chapter, we address this question at length and confirm that our data sample contains observations in the whole range of the predicted U-shaped relationships.

\subsection{Concluding remarks}

In this chapter, I developed a conceptual framework to gain insights into the relation between VRE and the process of convergence of electricity prices. The motivation behind this is two-fold: first, despite its large political relevance, especially in the EU context, the integrated approach has only recently started to receive attention in the academic literature. Most academic research addresses the topic in an isolated manner, in separate strands of literature, namely that of electricity market integration and that of the effect of VRE on electricity prices. Second, these studies find ambiguous and sometimes contradicting evidence on the effect of VRE on the process of price convergence. More specifically, studies looking at electricity market integration find that VRE leads to price divergence, while studies on the effect of VRE on electricity prices claim that VRE decreases prices, both domestically and abroad. The mechanisms of these effects have not been explicitly discussed. Therefore, the unifying framework put forward in this chapter reconciles these seemingly contradicting results. Indeed, the results of the theoretical exercise point to a U-shaped relation between VRE and the spread between different countries' electricity prices. This is explained by two main mechanisms: 1) in the long run, a simultaneous increase in VRE across different countries leads to overall lower prices, due to the merit-order effect and to more homogeneous energy mixes, hence to a similarity in price determinants; however, due to scale effects - i.e. the fact that, in higher-demand/higher VRE capacity, VRE energy displaces more traditional power electricity prices in these countries drop faster than in countries with lower demand and VRE capacity, thus reversing the price convergence process, for high enough VRE levels; and 2) in the presence of (limited) cross-border transmission capacity, the domestic downward pressure of VRE on electricity prices spills over to the trading partners; however, as VRE increases beyond the limited interconnection capacity and trade is no longer possible, the exporting country continues to experience a decrease in electricity prices, while 
the previously importing country switches to more expensive domestic power generation technologies.

Furthermore, I employed a number of empirical specifications to test the implications of the theoretical model. More specifically, I used hourly data for eight European countries grouped in six bidding zones. The findings confirm the presence of a non-linear, U-shaped relation between the increasing share of VRE in total load and the phenomenon of price convergence. In other words, prices tend to converge as the share of VRE in the energy mix increases, however, beyond a certain VRE threshold, this process is reversed. This is, however, due to bottlenecks in the inter-connector capacity, which reflects the importance of trans-national policy coordination.

These results thus point to the importance of policy coordination at different levels: first, individual countries need to anticipate the pressure that a unilateral increase in the share of VRE puts on its power trade needs and potential - and assess the requirements of interconnector capacity that would best accommodate its target VRE share. Second, as interconnector projects span several countries - and are generally subject to EU-level approval and funding - the results point to the need for increased policy coordination at the supra-national level. 


\section{Appendix 4.A Descriptive statistics of all variables of interest}

Table 4.3: Hourly electricity prices per bidding zone (in Euro/MWh)

\begin{tabular}{ccccccc}
\hline & Belgium & $\begin{array}{c}\text { Germany Austria } \\
\text { Luxembourg }\end{array}$ & Spain & France & Netherlands & Portugal \\
\hline Mean & 41.9 & 31.7 & 47.4 & 40 & 37.2 & 47.4 \\
St. Dev. & 22.7 & 14.6 & 14.4 & 20.2 & 12.2 & 14.3 \\
& & & & & & \\
\hline 5th Percentile & 18.9 & 10.9 & 21.1 & 16.9 & 20.8 & 21.8 \\
25th Percentile & 29.8 & 24.4 & 39.6 & 28.3 & 29.4 & 39.5 \\
Median & 38.5 & 31 & 48 & 37.3 & 35.3 & 48 \\
75th Percentile & 49.5 & 38.7 & 56.5 & 48.2 & 43.5 & 56.5 \\
95th Percentile & 74.8 & 53.9 & 69.2 & 72 & 58.6 & 69.2 \\
\hline \hline
\end{tabular}

Note: This table reports summary statistics on the price distribution in the different bidding zones and for the time period considered in this study. For example, the median Belgium electricity price is 38.5 Euro/MWh. $5 \%$ of Belgium hourly electricity prices are lower than 18.9 Euro/MWh, and $5 \%$ of Belgium hourly electricity prices are higher than 74.8 Euro/MWh.

Table 4.4: Hourly load distribution per bidding zone (in MW)

\begin{tabular}{ccccccc}
\hline & Belgium & $\begin{array}{c}\text { Germany Austria } \\
\text { Luxembourg }\end{array}$ & Spain & France & Netherlands & Portugal \\
\hline Mean & 9887 & 62414 & 28617 & 54296 & 14938 & 5628 \\
St. Dev. & 1377 & 10862 & 4574 & 11819 & 25523 & 967 \\
& & & & & & \\
\hline 5th Percentile & 7645 & 45213 & 21588 & 37400 & 9956 & 4223 \\
25th Percentile & 8799 & 53430 & 24701 & 45450 & 11414 & 4781 \\
Median & 9943 & 62443 & 28851 & 52650 & 13410 & 5617 \\
75th Percentile & 10923 & 71778 & 32101 & 62350 & 15250 & 6371 \\
95th Percentile & 12117 & 78825 & 36077 & 75750 & 17546 & 7218 \\
\hline \hline
\end{tabular}

Note: This table reports summary statistics on the power demand distribution in the different bidding zones and for the time period considered in this study. For example, the median Belgium hourly load is 9943 MW. $5 \%$ of Belgium hourly load values are lower than $7645 \mathrm{MW}$, and $5 \%$ of Belgium hourly load values are higher than $12117 \mathrm{MW}$. 
Table 4.5: Distribution of the share of wind power in hourly consumption (in \%)

\begin{tabular}{ccccccc}
\hline & Belgium & $\begin{array}{c}\text { Germany Austria } \\
\text { Luxembourg }\end{array}$ & Spain & France & Netherlands & Portugal \\
\hline Mean & 5.70 & 17.20 & 19.50 & 4.30 & 6.80 & 23.60 \\
St. Dev. & 4.90 & 13.20 & 11.70 & 2.90 & 5.70 & 18.90 \\
\hline 5th Percentile & 0.30 & 2.90 & 4.70 & 1.10 & 0.40 & 2.20 \\
25th Percentile & 1.70 & 7.20 & 10.40 & 2.20 & 2.50 & 8.70 \\
Median & 4.30 & 13.50 & 17.10 & 3.60 & 5.40 & 18.40 \\
75th Percentile & 8.70 & 23.80 & 26.40 & 5.60 & 9.60 & 34.50 \\
95th Percentile & 15.50 & 44.20 & 42.20 & 10.10 & 18.40 & 61.40 \\
\hline \hline
\end{tabular}

Note: This table reports summary statistics on the share of wind power in meeting the electricity demand in the various bidding zones and for the time period considered in this study. For example, the median Belgium share of wind power in hourly load is $4.3 \%$. $5 \%$ of Belgium values for the share of wind power in hourly load are lower than $0.3 \%$, and $5 \%$ of Belgium shares of the values of wind power in hourly load are higher than $15.5 \%$.

Table 4.6: Distribution of the share of solar power in hourly consumption (in \%)

\begin{tabular}{ccccccc}
\hline & Belgium & $\begin{array}{c}\text { Germany Austria } \\
\text { Luxembourg }\end{array}$ & Spain & France & Netherlands & Portugal \\
\hline Mean & 3.20 & 6.20 & 4.80 & 1.70 & 1.20 & 1.50 \\
St. Dev. & 5.00 & 9.60 & 5.50 & 2.50 & 2.00 & 2.00 \\
\hline 5th Percentile & 0.00 & 0.00 & 0.00 & 0.00 & 0.00 & 0.00 \\
25th Percentile & 0.00 & 0.00 & 0.30 & 0.00 & 0.00 & 0.00 \\
Median & 0.10 & 0.20 & 2.20 & 0.00 & 0.00 & 0.00 \\
75th Percentile & 5.10 & 9.80 & 8.70 & 3.10 & 1.70 & 3.20 \\
95th Percentile & 14.60 & 27.80 & 15.80 & 7.00 & 5.70 & 5.50 \\
\hline \hline
\end{tabular}

Note: This table reports summary statistics on the share of solar power in meeting the electricity demand in the various bidding zones and for the time period considered in this study. For example, the median Belgium share of solar power in hourly load is $0.1 \%$. $5 \%$ of Belgium values for the share of solar power in hourly load are lower than $0.0 \%$, and $5 \%$ of Belgium shares of the values of wind power in hourly load are higher than $14.6 \%$.

Table 4.7: Distribution of power trade, as a share in hourly load (in \%)

\begin{tabular}{ccccccc}
\hline & Belgium & $\begin{array}{c}\text { Germany Austria } \\
\text { Luxembourg }\end{array}$ & Spain & France & Netherlands & Portugal \\
\hline Mean & 23.90 & 6.40 & 10.20 & 24.70 & 7.00 & 77.20 \\
St. Dev. & 13.00 & 3.00 & 4.30 & 6.90 & 5.20 & 26.10 \\
\hline 5th Percentile & 5.80 & 2.30 & 3.90 & 14.30 & 0.50 & 39.60 \\
25th Percentile & 14.50 & 4.10 & 6.90 & 19.80 & 2.80 & 58.10 \\
Median & 22.30 & 6.00 & 9.90 & 24.20 & 6.00 & 74.20 \\
75th Percentile & 31.50 & 8.30 & 13.00 & 29.20 & 10.20 & 93.90 \\
95th Percentile & 46.50 & 12.10 & 17.80 & 36.70 & 16.80 & 123.80 \\
\hline \hline
\end{tabular}

Note: This table reports summary statistics on the share of trade in electricity demand in the different bidding zones and for the time period considered in this study. For example, the median Belgium share of power trade in hourly load is $22.3 \%$. $5 \%$ of Belgium values for the share of power trade in hourly load are lower than $5.8 \%$, and $5 \%$ of Belgium shares of the values of power trade in hourly load are higher than $46.5 \%$. 


\section{Appendix 4.B Results for hour, day-of-the week and month dummies}

According to Figure 1 from $11 \mathrm{am}$ to $9 \mathrm{pm}$ the prices tend to converge, with the exception of $6 \mathrm{pm}-7 \mathrm{pm}$.

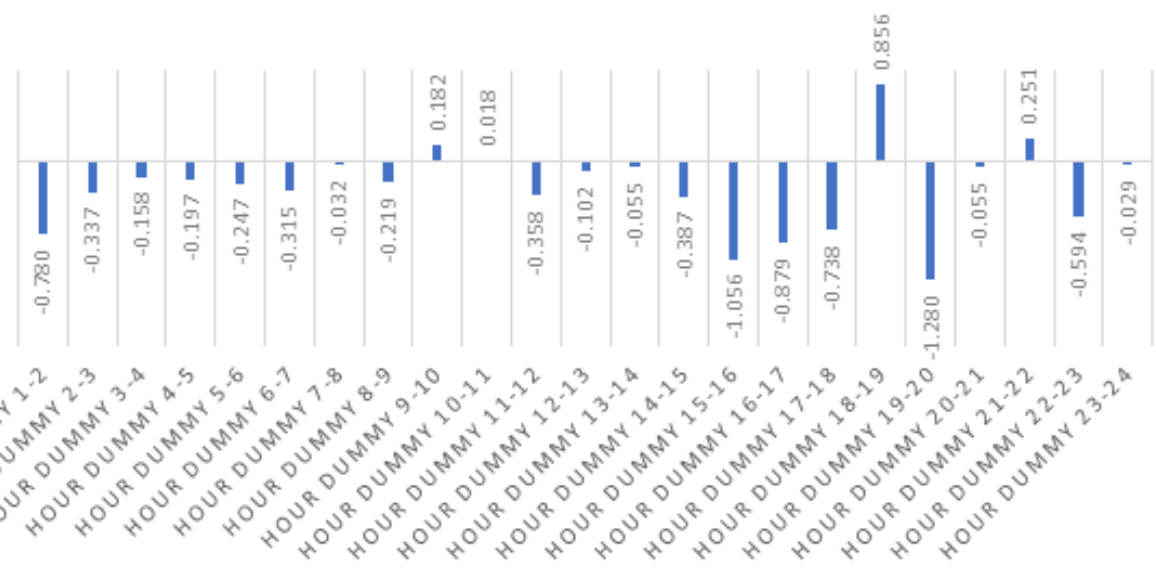

Figure 4.6: Estimated coefficients for hour dummies in regression 4 of table 4.2 .

The strongest price divergence is observed during weekends, when load and, consequently, electricity prices, record the lowest values.

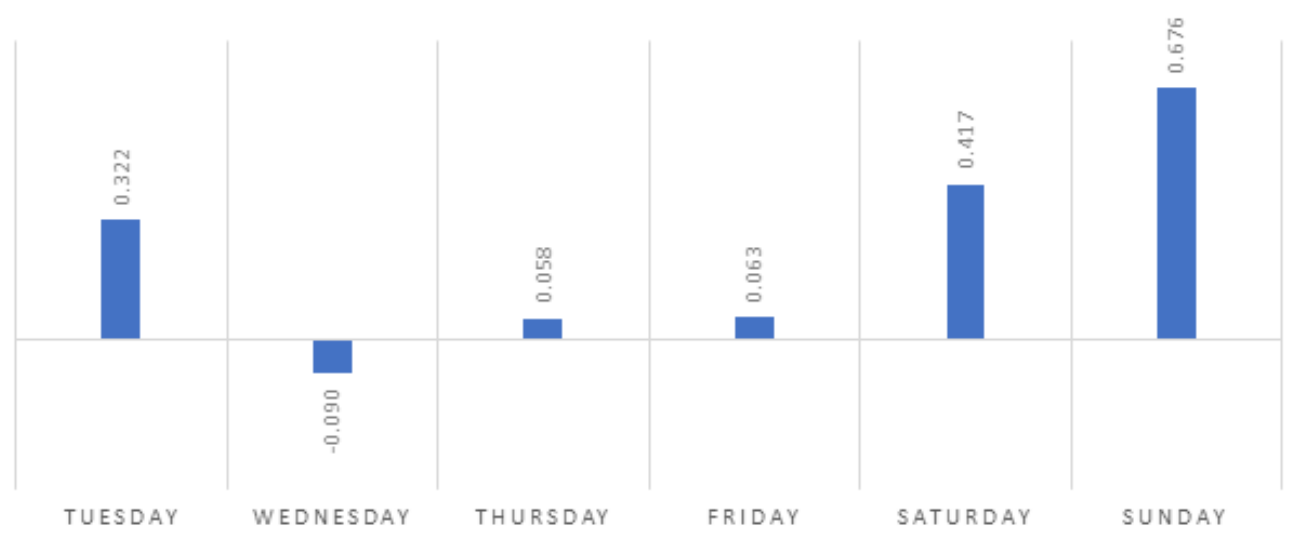

Figure 4.7: Estimated coefficients for day-of-week dummies in regression 4 of table 4.2.

Prices tend to converge in February and March, which are months with reduced hydroelectricity output and, consequently, increased electricity prices. 


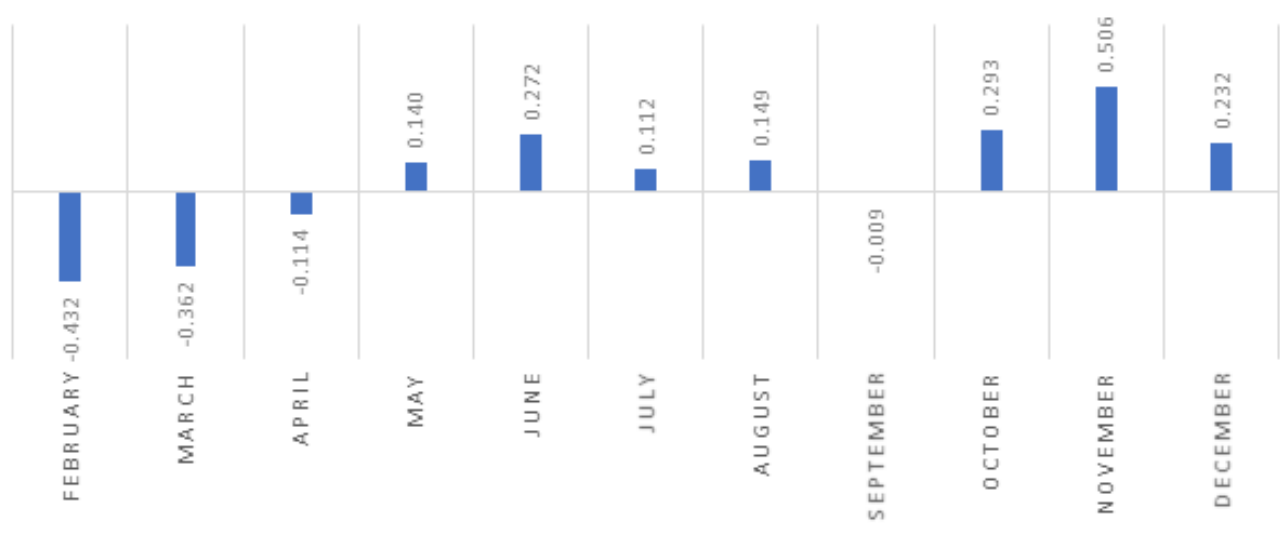

Figure 4.8: Estimated coefficients for month dummies in regression 4 of table 4.2. 


\section{Appendix 4.C Robustness test: Instrumental variable regression and Durbin-Wu-Hausman test for endogeneity}

The choice of OLS as an estimation method is based on the assumption that all independent variables are exogenous. In other words, in the presence of endogeneity, coefficients estimated using OLS are biased and an alternative estimation method should be used.

To verify whether OLS is a suitable estimation method for the model developed in this chapter, I use a Durbin-Wu-Hausman endogeneity test to check for the presence of endogeneity between the dependent variable, i.e. the coefficient of variation of price $\left(\mathrm{CoV}_{h}\right)$, and the trade $\left(\right.$ Trade $\left._{h}\right)$ variable. Essentially, this test compares the estimated coefficients of the initial independent variable (in this case, Trade $_{h}$ ) and the coefficient estimated using an instrumental variable, two-stage least square. Under the null hypothesis, both coefficients are unbiased, but the coefficient of the original variable (in this case, Trade $_{h}$ ) is efficient (i.e. it has a lower standard error). If the test fails to reject the null hypothesis, no endogeneity is detected and OLS can be used. Under the alternative hypothesis, endogeneity is detected and the estimated coefficient of the initial variable is not consistent. An instrumental variable method should be used instead.

I choose the one-week lag of Trade $_{h}$ as an instrument, since the share of the trade precisely 168 hours before a certain time has no impact on the price in that specific hour (and, therefore, on its coefficient of variation). Also, the one-week lag of Trade ${ }_{h}$ is correlated with Trade $_{h}$. Therefore, the two conditions that define a suitable instrumental variables are met.

Thus, I use the two-stage least squares technique to compute the coefficients in regression 4.9 to 4.12 . The low p-value $(p<0.01)$ of F-test statistics reported in the table below confirms that the one-week lag of Trade $_{h}$ is a strong instrument for Trade $_{h}$. More importantly, however, based on the high p-value $(p>0.1)$ of the Durbin-Wu-Hausman test in Model 4, we fail to reject the null hypothesis at all conventional confidence level ( $\mathrm{p}$ $=0.125)$. Therefore, no endogeneity is detected and using OLS as an estimation method yields consistent coefficients. 
Table 4.8: Robustness test: regression with two-stage least squares technique

\begin{tabular}{|c|c|c|c|c|}
\hline $\begin{array}{c}\text { Dependant Variable: Cross-sectional Coefficient } \\
\text { of Variation of Price }\end{array}$ & $\begin{array}{l}\text { Model } 1 \\
\text { Coefficient } \\
\text { (St. Dev.) }\end{array}$ & $\begin{array}{l}\text { Model } 2 \\
\text { Coefficient } \\
\text { (St. Dev.) }\end{array}$ & $\begin{array}{l}\text { Model } 3 \\
\text { Coefficient } \\
\text { (St. Dev.) }\end{array}$ & $\begin{array}{l}\text { Model } 4 \\
\text { Coefficient } \\
\text { (St. Dev.) }\end{array}$ \\
\hline Intercept & $\begin{array}{c}0.070^{* * *} \\
(0.007)\end{array}$ & $\begin{array}{c}0.173^{* * *} \\
(0.051)\end{array}$ & $\begin{array}{c}0.140^{* * *} \\
(0.028)\end{array}$ & $\begin{array}{c}0.324^{* * *} \\
(0.036)\end{array}$ \\
\hline$V R E_{h}$ & $\begin{array}{c}0.204^{* * *} \\
(0.072)\end{array}$ & $\begin{array}{c}-1.059^{*} \\
(0.578)\end{array}$ & $\begin{array}{c}-0.834^{* *} \\
(0.403)\end{array}$ & $\begin{array}{c}-0.905^{* *} \\
(0.402)\end{array}$ \\
\hline$V R E_{h}^{2}$ & & $\begin{array}{c}3.528^{* *} \\
(1.798)\end{array}$ & $\begin{array}{c}3.517^{* *} \\
(1.775)\end{array}$ & $\begin{array}{c}3.548^{* *} \\
(1.773)\end{array}$ \\
\hline Trade $_{h}$ & $\begin{array}{c}-0.151^{* * *} \\
(0.039)\end{array}$ & $\begin{array}{c}-0.151^{* * *} \\
(0.034)\end{array}$ & $\begin{array}{l}-0.020 \\
(0.126)\end{array}$ & $\begin{array}{c}-1.399^{* * *} \\
(0.102)\end{array}$ \\
\hline Trade $_{h}^{2}$ & & & & $\begin{array}{c}2.416^{* * *} \\
(0.210)\end{array}$ \\
\hline$V R E_{h} \times$ Trade $_{h}$ & & & $\begin{array}{l}-0.879 \\
(0.860)\end{array}$ & $\begin{array}{l}-0.554 \\
(0.861)\end{array}$ \\
\hline CoV 1h-lag & $\begin{array}{c}0.799^{* * *} \\
(0.020)\end{array}$ & $\begin{array}{c}0.774^{* * *} \\
(0.032)\end{array}$ & $\begin{array}{c}0.774^{* * *} \\
(0.032)\end{array}$ & $\begin{array}{c}0.771^{* * *} \\
(0.032)\end{array}$ \\
\hline CoV 24h-lag & $\begin{array}{l}0.018^{*} \\
(0.011)\end{array}$ & $\begin{array}{l}0.018^{*} \\
(0.010)\end{array}$ & $\begin{array}{l}0.018^{*} \\
(0.010)\end{array}$ & $\begin{array}{l}0.019^{*} \\
(0.010)\end{array}$ \\
\hline CoV 168h-lag & $\begin{array}{l}0.015^{*} \\
(0.008)\end{array}$ & $\begin{array}{l}0.014^{*} \\
(0.008)\end{array}$ & $\begin{array}{c}0.015^{* *} \\
(0.008)\end{array}$ & $\begin{array}{l}0.013^{*} \\
(0.007)\end{array}$ \\
\hline Time Trend & $\begin{array}{c}-0.005 * * * \\
(0.001)\end{array}$ & $\begin{array}{c}-0.007 * * * \\
(0.002)\end{array}$ & $\begin{array}{c}-0.007^{* * *} \\
(0.002)\end{array}$ & $\begin{array}{c}-0.010^{* * *} \\
(0.002)\end{array}$ \\
\hline Observations & 25840 & 25840 & 25840 & 25840 \\
\hline Hour Dummies & Yes & Yes & Yes & Yes \\
\hline Day-of-Week Dummies & Yes & Yes & Yes & Yes \\
\hline Month Dummies & Yes & Yes & Yes & Yes \\
\hline Adjusted R2 & 0.689 & 0.695 & 0.695 & 0.694 \\
\hline $\begin{array}{c}\text { p-value of F-test on first regression (Null } \\
\text { hypothesis: Instrumental variable is weak) }\end{array}$ & $<0.01$ & $<0.01$ & $<0.01$ & $<0.01$ \\
\hline $\begin{array}{l}\text { p-value of the Durbin-Wu-Hausman endogeneity } \\
\text { test (Null hypothesis: both the OLS and the IV } \\
\text { estimators are unbiased.) }\end{array}$ & 0.948 & 0.808 & 0.287 & 0.125 \\
\hline
\end{tabular}

Note: This table reports the results of the second stage of the two-stage least squares regression technique to compute the coefficients in regression 4.9 to 4.12, where one-week lag of Trade $_{h}$ is chosen as an instrument for Trade $_{h}$. The low p-value of the F-statistics confirms that one-week lag of Trade Th $_{h}$ is strong instrument. We fail to reject the null hypothesis of the Durbin-Wu-Hausman test (as $p>0.01$ ). OLS is therefore a consistent estimator. All reported standard deviations are robust to heteroskedasticity and autocorrelation based on Newey-West technique (Newey and West (1987)). Significance of p-values is reported as follows: $*<0.1, * *<0.05$ and $* * *<0.01$. 


\section{Appendix 4.D Data coverage in the whole range of the U-shaped relationships}

As mentioned in subsection 4.6, one important question is whether the non-monotnic relationships suggested by the qudratic terms - between the Trade and VRE variables on one hand, and the price differential on the other hand - are observable in the domain of the observations in our sample data. We address this question with two different approaches, namely a multivariate method and a univariate method.

1. Multivariate method: The estimated coefficients in the last column of Table 4.2 show the relationship between the coefficient of variation and VRE - after controlling for all other independent variables - as:

$$
C o V_{h} \simeq-0.697 V R E_{h}+3.534 V R E_{h}^{2}
$$

This relationship between the coefficient of variation and the share of VRE is shown in panel a of Figure 4.9. The range of VRE is chosen between 0 and 1 , as the share of VRE in meeting total demand can be between $0 \%$ to $100 \%$. As we can see in this plot, the curvature is the strongest between $0 \%$ and $30 \%$, where most of the VRE observations in our sample data are concentrated.

Similarly, according to the estimated coefficients in the last column of Table 4.2, the relationship between the coefficient of variation and the Trade variable - after controlling for all other independent variables - can be shown as:

$$
\operatorname{CoV}_{h} \simeq-0.339 \text { Trade }_{h}+0.811 \text { Trade }_{h}^{2}
$$

This relationship between the coefficient of variation and the share of Trade in total demand is displayed in in panel b of Figure 4.9. The range of Trade is chosen between 0 and 1, as the share of Trade can be between $0 \%$ to $100 \%$. As we can see in this plot, the the curvature is the strongest between $10 \%$ and $40 \%$, where most of the Trade observations in our sample data are concentrated.

2. Univariate method: Panle a of Figure 4.10 shows the scatter plot of the coefficient of variation and the VRE. The VRE and CoV observations are plotted in the $\mathrm{x}$ - and the $\mathrm{y}$-axis respectively. Each data point represents one observation (a few observations lie outside the range of $\mathrm{x}$ and $\mathrm{y}$, used for plotting.) Furthermore, this figure shows the fitted line when we regress the coefficient of variation on the VRE and the VRE-squared variables. As we can see in this picture, most observations are concentrated around the curvature point. 


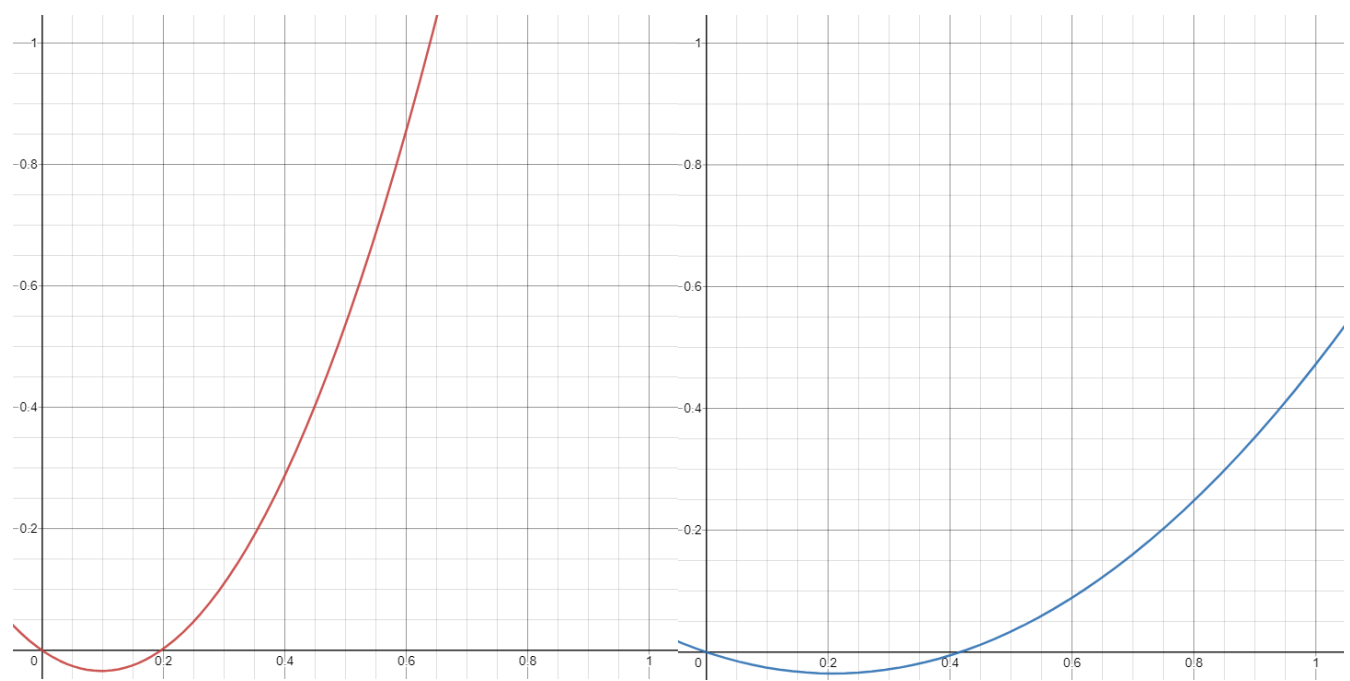

(a) VRE

(b) Trade

Figure 4.9: Fitted U-shaped relationships, with multivariate approach

Similarly, panle b of Figure 4.10 shows the scatter plot of the coefficient of variation and the Trade variables. The Trade and CoV observations are plotted in the $\mathrm{x}$ and the $y$-axis respectively. Each data point represents one observation (a few observations lie outside the range of $\mathrm{x}$ and $\mathrm{y}$, used for plotting.) This figure also shows the fitted line when we regress the coefficient of variation on the Trade and the Trade-squared variables. As we can see in this picture, most observations are concentrated around the curvature point.

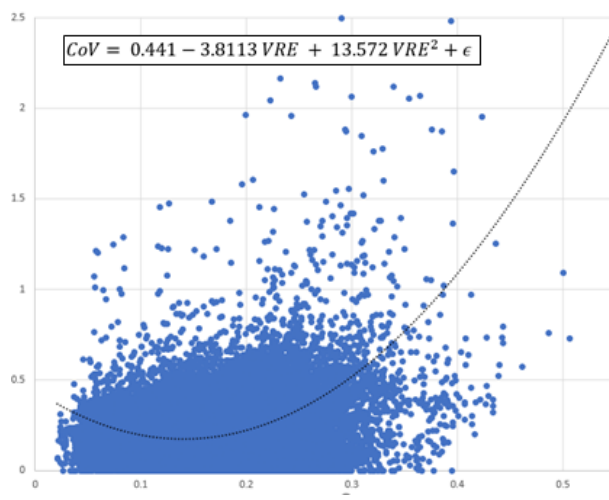

(a) VRE

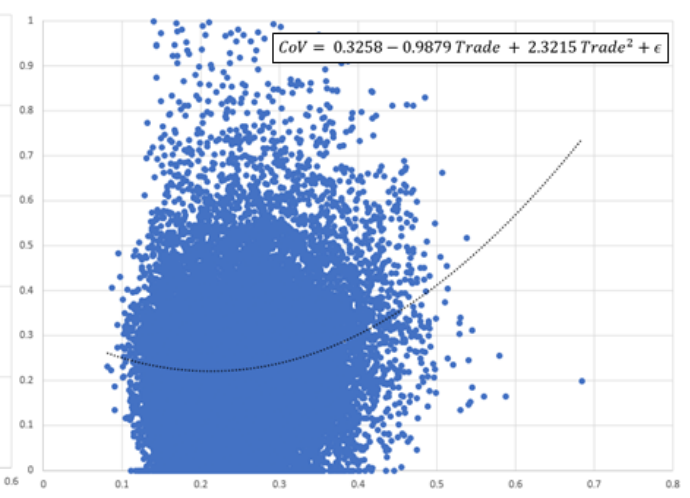

(b) Trade

Figure 4.10: Fitted U-shaped relationships, with univariate approach 


\section{Chapter 5}

\section{Conclusions}

\subsection{Key findings and concluding remarks}

The past years witnessed several milestones in the energy transition: in 2018, power generated by renewable energy sources outstripped that generated by burning coal, in the OECD bloc (Torkington (2019)). This is also the case for the US, where installed capacity of renewable energy surpassed that of coal-fired power plants, despite the less supportive political environment, at the federal level, during the Trump administration (Yale Environment 360 (2019)). In the UK, the cradle of industrialization, more power was generated by renewable energy than by the combined fossil fuels of coal, oil and gas, in the third quarter of 2019 (Evans (2019)). In 2019, the Netherlands organized the second auction worldwide for a subsidy-free offshore wind farm, due to be completed by 2023 (Government of the Netherlands (2019)); the first auction for unsubsidized off-shore wind farms was also organized in the Netherlands, in 2018 (Wind Europe (2018)). These encouraging developments have been possible against a background of sharply declining costs and increased public support for staying within the 2 degrees Celsius target emission threshold. While modest in the overall picture of a fully renewable energy system, these milestones would have raised some eyebrows a few decades back.

The research presented in this dissertation looked at the challenges facing the increasing shares of VRE in Europe, as well as at the effects that these shares have on the current power systems of different European countries, with implications for a panEuropean power system. The results of the research presented here can be summarized in several key findings:

Key finding 1: A cost-optimal, fully renewable European power system greatly benefits from the diversity of weather patterns across European countries. This is reflected in the fact that the investment requirements of a fully integrated clean European power 
system are less than half of those associated with a system where power trade is not possible.

Key finding 2: In a fully renewable, pan-European power system, some countries will become net power exporters, and some - net power importers. For this reason, the current, nationalistic approach to energy policy in EU countries is not in line with the long-term goal of achieving a reliable, lowest-cost, clean, European power system. At the same time, the extreme case scenario of entirely unrestricted power trade that would see all power generation capacity installed in a handful of countries faces not only political, but also technical constraints. Indeed, the current interconnection target of the European Commission is $15 \%$ of national installed capacity, by 2030 European Commission $(2019 b)$. The simplistic model developed in Chapter Two provides reference points for both completely isolated and completely integrated European power systems. The results discussed in Chapter Two point to a more nuanced transition between these two extreme scenarios, rather than a simplistic scale-up/down of the country-wise distribution of installed capacity of power generation technologies in the base scenario.

Key finding 3: While the cost associated with a fully renewable, integrated European power system drops as barriers to power trade are increasingly removed, this drop is not uniform for all thresholds of power integration. More importantly, the countrywise distribution of energy technologies can change significantly, as countries' reliance on power trade increases. For example, according to the results of the model developed in Chapter Two, the requirements for installed capacity of solar power in Greece drop, as power trade increases up to the $75 \%$ integration threshold. However, from this point until the complete integration of power systems, Greece experiences a sharp increase in its requirements of installed solar power.

Key finding 4: The well-documented negative effect of wind power on day-ahead electricity prices becomes stronger, with an increasing share of wind power in the overall power mix. For solar power, however, the effect is non-significant.

Key finding 5: An increasing share of VRE is associated with a sharp increase of the day-ahead price volatility.

Key finding 6: At low levels of VRE, an increase of the share of power from wind and solar plants is associated with a decrease in the spread of day-ahead electricity prices in different European countries. However, as the share of VRE increases beyond the level that the existing cross-border infrastructure can accommodate, this effect is reversed and prices begin to diverge. This finding points to the importance of coordination of policies regarding targets for VRE and targets for interconnection capacity.

Key finding 7: Similarly, low levels of power trade are associated with a reduced price differential, as measured by the coefficient of variation. However, as the power trade increases up to the level of the limited interconnector capacity, prices start to 
diverge again.

Key finding 8: The downward effects of VRE and power trade on the price differential reinforce each other, for low levels of both VRE and trade. As the contributions of both in the power mix increases, the relation between them becomes ambiguous. The higher shares of both VRE and power trade are individually associated with a divergence in electricity prices, but their interaction has a moderating effect on price divergence.

The outcome of the multi-method, quantitative research presented here contributes to a better understanding of some of the main issues faced by the transition towards a clean European power system. Given the transformations that the electricity systems of European countries are undergoing and given the ambitions of the Energy Union, this research aimed to provide useful insights that could inform the process of the European power system transition.

More specifically, the work developed here suggests several direct implications for the ongoing discussion on the energy system transition, at the policy-making level. First, despite the simplifying assumptions, the model presented in Chapter Two suggests that the cost savings resulting from a fully integrated European electricity systems are not proportional to the integration level. In other words, a disproportionately large part of cost savings occurs in the early stages of the integration of the different power systems. In turn, this finding has implications for the level of flexibility a country has in meeting its own power needs. The findings of Chapter Three are very relevant for the discussion of the optimal energy storage technology mix. With an increasing share of VRE, the volatility of electricity prices is expected to increase, which could benefit the business models of operators of energy storage technologies. Beyond the technical requirements, cost-optimal energy storage technologies would have to be flexible enough to integrate the changes in the volatility of electricity prices, at a high temporal resolution. So far, the optimal characteristics of energy storage technologies have focused on cost and capacity. However, the ongoing changes to electricity systems create opportunities for new markets and business models. A comprehensive approach to energy system design must discuss these new opportunities in detail. Last, the findings of Chapter Four can be connected to both the results of Chapters Two and Three: the share of VRE at national levels, the system-optimal level of cross-border power grid infrastructure and developments in the electricity prices and their volatility are strongly interdependent. Policy makers can benefit from a growing empirical literature that provides insights on the differences between integrated and fragmented approaches to clean energy policy making. 


\subsection{Future research}

This dissertation has highlighted and addressed in depth some of the challenges ahead presented by the 2 degrees Celsius target set in the Paris Agreement. Indeed, the overhauling of the current energy system is a complex process and relies on a clear understanding of how all GHG emitting sectors can interact for a more efficient path towards decarbonisation. The research presented here has looked at the power systems of several European countries, in isolation from other sectors. However, the distinctions between the main forms of energy - used for electricity, heating and transportation - are becoming increasingly blurry. One example is the advent of electric vehicles (EVs) worldwide. Indeed, instead of being curtailed, excess power from non-dispatchable solar and wind plants can be used to fuel EVs. Therefore, an over-arching view of all energy systems can reveal interesting interactions between the different power, transportation and heating systems.

A second important area for future research is that of energy storage technologies. The recent increase in storage requirements has driven up the market for mature storage technologies, the most established of which is represented by the decades-old lithiumion batteries. The value chain of this technology traces its roots in mines of rare earth and heavy metals, the exploitation of which has a considerable negative impact on the environment. Since the requirements for energy storage technologies are expected to parallel the absolute and relative increase in VRE, R\&D efforts would be required to target alternative, less mature energy storage technologies.

Finally, the transition towards a clean European power system could greatly benefit from a discussion of the political implications of the Energy Union. More specifically, given the changes to considerations of national energy security for country (partly addressed in Chapter Two), a clear understanding of how the resulting burden and benefits would be shared among member states could facilitate the success of the Energy Union. Previous experiences in different areas of the ongoing process of the integration of the member states into a European Union might hold some key lessons. In addition, previous experiences of international cooperation agreements in the area of climate change can offer valuable insights. As discussed in Chapter Two, the literature on dynamic cooperative game theory has been used in the past to address instances of international climate agreements (Schacht (2020)). It can thus offer applicable insights for the design and successful implementation of a mechanism to align individual countries' incentives with the EU-level ambition to become the world's first climate-neutral continent. 


\section{Bibliography}

Abrell, J. and Rausch, S. (2016), 'Cross-country electricity trade, renewable energy and European transmission infrastructure policy', Journal of Environmental Economics and Management 79, 87-113.

Acemoglu, D., Kakhbod, A. and Ozdaglar, A. (2017), 'Competition in electricity markets with renewable energy sources.', Energy Journal 38, 134-155.

Antweiler, W. (2017), 'A two-part feed-in-tariff for intermittent electricity generation', Energy Economics 65, 458-470.

Awerbuch, S. (2006), 'Portfolio-based electricity generation planning: policy implications for renewables and energy security', Mitigation and adaptation strategies for Global Change 11(3), 693-710.

Banos, R., Manzano-Agugliaro, F., Montoya, F., Gil, C., Alcayde, A. and Gómez, J. (2011), 'Optimization methods applied to renewable and sustainable energy: A review', Renewable and sustainable energy reviews 15(4), 1753-1766.

Barteková, E. and Ziesemer, T. H. W. (2019), 'The impact of electricity prices on foreign direct investment: evidence from the European Union', Applied Economics 51(11), 1183-1198.

Bazmi, A. A. and Zahedi, G. (2011), 'Sustainable energy systems: Role of optimization modeling techniques in power generation and supply — -A review', Renewable and sustainable energy reviews 15(8), 3480-3500.

Becker, S., Rodriguez, R. A., Andresen, G. B., Schramm, S. and Greiner, M. (2014), 'Transmission grid extensions during the build-up of a fully renewable pan-European electricity supply', Energy 64, 404-418.

Bollerslev, T. (1986), 'Generalized autoregressive conditional heteroskedasticity', Journal of econometrics $\mathbf{3 1}(3)$, 307-327. 
Bosco, B., Parisio, L., Pelagatti, M. and Baldi, F. (2010), 'Long-run relations in European electricity prices', Journal of applied econometrics 25(5), 805-832.

Brinkerink, M., Ó Gallachóira, B. and Deane, P. (2019), 'A comprehensive review of the benefits and challenges of global power grids and intercontinental interconnectors', Renewable and Sustainable Energy Reviews 107(10), 274-287.

Brown, T., Schlachtberger, D., Kies, A., Schramm, S. and Greiner, M. (2018), 'Synergies of sector coupling and transmission reinforcement in a cost-optimised, highly renewable european energy system', Energy 160, 720-739.

Bussar, C., Moos, M., Alvarez, R., Wolf, P., Thien, T., Chen, H., Cai, Z., Leuthold, M., Sauer, D. U. and Moser, A. (2014), 'Optimal allocation and capacity of energy storage systems in a future European power system with $100 \%$ renewable energy generation', Energy Procedia 46, 40-47.

Cherp, A., Vinichenko, V., Jewell, J., Brutschin, E. and Sovacool, B. (2018), 'Integrating techno-economic, socio-technical and political perspectives on national energy transitions: A meta-theoretical framework', Energy Research \& Social Science 37, 175-190.

Clò, S., Cataldi, A. and Zoppoli, P. (2015), 'The merit-order effect in the Italian power market: The impact of solar and wind generation on national wholesale electricity prices', Energy Policy 77, 79-88.

Cludius, J., Hermann, H., Matthes, F. C. and Graichen, V. (2014), 'The merit order effect of wind and photovoltaic electricity generation in Germany 2008-2016: Estimation and distributional implications', Energy Economics 44, 302-313.

De Menezes, L. M., Houllier, M. A. and Tamvakis, M. (2016), 'Time-varying convergence in European electricity spot markets and their association with carbon and fuel prices', Energy Policy 88, 613-627.

Dickey, D. A. and Fuller, W. A. (1979), 'Distribution of the estimators for autoregressive time series with a unit root', Journal of the American statistical association 74(366a), 427-431.

Energy and Climate Intelligence Unit (2020), 'Net zero tracker', available from:https: //eciu.net/netzerotracker.

Engle, R. F. and Granger, C. W. (1987), 'Co-integration and error correction: representation, estimation, and testing', Econometrica: Journal of the Econometric Society pp. 251-276. 
ENTSOE (2020), 'European network transmission system operators for electricity', available from:https://transparency.entsoe.eu/generation/r2/ installedGenerationCapacityAggregation/show.

European Comission (2017), 'Third Report on the State of the Energy Union', available from: https:https://ec.europa.eu/commission/sites/beta-political/files/ third-report-state-energy-union_en.pdf.

European Comission (2020), 'An EU Strategy to harness the potential of offshore renewable energy for a climate neutral future', available from: https://ec.europa.eu/energy/ sites/ener/files/offshore_renewable_energy_strategy.pdf.

European Commission (2019a), 'A European Green Deal', available from: https://ec. europa.eu/info/strategy/priorities-2019-2024/european-green-deal_en.

European Commission (2019b), 'Fourth report on the State of the Energy Union'.

European Commission (2019c), 'Fourth report on the state of the energy union', available from:https://ec.europa.eu/info/publications/4th-state-energy-union_en.

European Commission (2020), 'Committing to climate-neutrality by 2050: Commission proposes european climate law and consults on the european climate pact', available from:https://ec.europa.eu/commission/presscorner/detail/en/ip_20_335.

Eurostat (2010), 'Renewable energy statistics', available from: https: //ec.europa.eu/eurostat/documents/3433488/5565840/KS-SF-10-056-EN.PDF / 870344eb-ba2a-481c-aeea-19797238c8e2.

Evans, S. (2019), 'Analysis: UK renewables generate more power electricity than fossil fuels for first time', available from: https://www.carbonbrief.org/ analysis-uk-renewables-generate-more-electricity-than-fossil-fuels-for-first-time.

Forrest, S. and MacGill, I. (2013), 'Assessing the impact of wind generation on wholesale prices and generator dispatch in the Australian National Electricity Market', Energy Policy 59, 120-132.

Gelabert, L., Labandeira, X. and Linares, P. (2011), 'An ex-post analysis of the effect of renewables and cogeneration on Spanish electricity prices', Energy economics 33, S59S65.

Gianfreda, A., Parisio, L. and Pelagatti, M. (2016), 'Revisiting long-run relations in power markets with high RES penetration', Energy Policy 94, 432-445. 
Government of the Netherlands (2019), 'Vattenfall to build second unsubsidised Dutch offshore wind farm', available from: https://www.government.nl/latest/news/2019/ 07/10/vattenfall-to-build-second-unsubsidised-dutch-offshore-wind-farm.

Gugler, K., Haxhimusa, A. and Liebensteiner, M. (2016), 'Integration and efficiency of European electricity markets: Evidence from spot prices', Department of Economics Working Paper Series, Vienna University of Economics and Business 226.

Haxhimusa, A. (2018), 'The effects of german wind and solar electricity on french spot price volatility: An empirical investigation', Department of Economics Working Paper Series, Vienna University of Economics and Business .

Heide, D., Von Bremen, L., Greiner, M., Hoffmann, C., Speckmann, M. and Bofinger, S. (2010), 'Seasonal optimal mix of wind and solar power in a future, highly renewable Europe', Renewable Energy 35(11), 2483-2489.

Hildmann, M., Ulbig, A. and Andersson, G. (2015), 'Empirical analysis of the merit-order effect and the missing money problem in power markets with high RES shares', IEEE Transactions on Power Systems 30(3), 1560-1570.

Hirth, L. (2013), 'The market value of variable renewables: The effect of solar wind power variability on their relative price', Energy economics 38, 218-236.

Hirth, L. (2015), 'The optimal share of variable renewables: How the variability of wind and solar power affects their welfare-optimal deployment', The Energy Journal 36(1).

Huisman, R., Huurman, C. and Mahieu, R. (2007), 'Hourly electricity prices in day-ahead markets', Energy Economics 29(2), 240-248.

IEA (2017a), 'Co2 emissions from fuel combustion', available from: https://www.iea. org/reports/co2-emissions-from-fuel-combustion-overview.

IEA (2017b), 'Renewables 2017: Analysis and forecast to 2022', available from: https: //www.iea.org/reports/renewables-2017/.

IEA (2019), 'More efforts needed (international energy agency, 2019)', available from: https://www.iea.org/tcep/power/renewables/.

IEA (2020), 'Renewables information: Overview', available from: https://webstore.iea. org/renewables-information--2020-edition.

IRENA (2017), 'Electricity storage and renewables: Costs and markets to 2030', available from: https://www.irena.org/publications/2017/Oct/ Electricity-storage-and-renewables-costs-and-markets. 
IRENA (2018), 'Renewable power generation costs in 2017', available from: https:// www.irena.org/publications/2018/Jan/Renewable-power-generation-costs-in-2017.

IRENA (2019a), 'Future of wind: Deployment, investment, technology, grid integration and socio-economic aspects', available from: https://www.irena.org/publications/ 2019/Oct/Future-of-wind.

IRENA (2019b), 'Renewable capacity statistics 2019', available from:https://www.irena. org/publications/2019/Mar/Renewable-Capacity-Statistics-2019.

IRENA (2020), 'Renewable capacity highlights', available from:https://www.irena. org/-/media/Files/IRENA/Agency/Publication/2020/Mar/IRENA_RE_Capacity_ Highlights_2020.pdf.

Jónsson, T., Pinson, P. and Madsen, H. (2010), 'On the market impact of wind energy forecasts', Energy Economics 32(2), 313-320.

Kaul, I. (2012), 'Global public goods: explaining their underprovision', Journal of International Economic Law 15(3), 729-750.

Keles, D., Dehler-Holland, J., Densing, M., Panos, E. and Hack, F. (2020), 'Cross-border effects in interconnected electricity markets - an analysis of the Swiss electricity prices', Energy Economics 90, 104802.

Keppler, J. H., Phan, S., Le Pen, Y. et al. (2016), 'The impacts of variable renewable production and market coupling on the convergence of French and German electricity prices', The Energy Journal 37(3), 343-359.

Ketterer, J. C. (2014), 'The impact of wind power generation on the electricity price in germany', Energy Economics 44, 270-280.

Koopman, S. J., Ooms, M. and Carnero, M. A. (2007), 'Periodic seasonal Reg-ARFIMAGARCH models for daily electricity spot prices', Journal of the American Statistical Association 102(477), 16-27.

Kraftwerke, N. (2020), 'What does intraday trading mean?', available from: https:// www.next-kraftwerke.com/knowledge/intraday-trading.

KU Leuven Energy Institute (2020), 'Factsheets', available from: https://set.kuleuven. be/ei/factsheets.

Kyritsis, E., Andersson, J. and Serletis, A. (2017), 'Electricity prices, large-scale renewable integration, and policy implications', Energy Policy 101, 550-560. 
Martinez-Anido, C. B., Brinkman, G. and Hodge, B.-M. (2016), 'The impact of wind power on electricity prices', Renewable Energy 94, 474-487.

Meeus, L., Vandezande, L., Cole, S. and Belmans, R. (2009), 'Market coupling and the importance of price coordination between power exchanges', Energy 34(3), 228-234.

Newbery, D., Strbac, G. and Viehoff, I. (2016), 'The benefits of integrating European electricity markets', Energy Policy 94, 253-263.

Newey, W. K. and West, K. D. (1987), 'Hypothesis testing with efficient method of moments estimation', International Economic Review pp. 777-787.

Nobel Media (2007), 'The nobel peace prize, 2007', available from: https://www. nobelprize.org/prizes/peace/2007/summary.

Nobel Media (2019), 'The prize in economic sciences 2018', available from: https://www. nobelprize.org/prizes/economic-sciences/2018/summary/.

Olivier, J. and Peters, J. (2020), 'Trends in global CO2 and total greenhousegas emissions'.

Østergaard, P. A. (2009), 'Reviewing optimisation criteria for energy systems analyses of renewable energy integration', Energy 34(9), 1236-1245.

Paraschiv, F., Erni, D. and Pietsch, R. (2014), 'The impact of renewable energies on eex day-ahead electricity prices', Energy Policy 73, 196-210.

Pavarini, C. and Mattion, F. (2019), 'Tracking the decoupling of electricity demand and associated co2 emissions (international energy agency, 2019)', available from:https://www.iea.org/newsroom/news/2019/march/ tracking-the-decoupling-of-electricity-demand-and-associated-co2-emissions.html.

Pfenninger, S. and Staffell, I. (2016), 'Long-term patterns of European PV output using 30 years of validated hourly reanalysis and satellite data', Energy 114, 1251-1265.

Phan, S. and Roques, F. (2015), 'Is the depressive effect of renewables on power prices contagious? A cross border econometric analysis', Department of Economics Working Paper Series, Vienna University of Economics and Business, Faculty of Economis .

Politico (2018), 'Europe's power couple breakup', available from: https://www.politico. eu/article/germany-austria-energy-europe-power-couple-break-up.

REN (2018), 'Renewables 2018. global status report', available from: https://www.ren21. net/wp-content/uploads/2019/05/GSR2018_Full-Report_English.pdf. 
Rintamäki, T., Siddiqui, A. S. and Salo, A. (2017), 'Does renewable energy generation decrease the volatility of electricity prices? An analysis of Denmark and Germany', Energy Economics 62, 270-282.

Rodriguez, R. A., Becker, S., Andresen, G. B., Heide, D. and Greiner, M. (2014), 'Transmission needs across a fully renewable European power system', Renewable Energy 63, $467-476$.

Rogelj, J., Den Elzen, M., Hohne, N., Fransen, T., Fekete, H., Winkler, H., Schaeffer, R., Sha, F., Riahi, K. and Meinshausen, M. (2016), 'Paris Agreement climate proposals need a boost to keep warming well below 2 C', Nature 534(7609), 631-639.

Rogge, K. S., Kern, F. and Howlett, M. (2017), 'Conceptual and empirical advances in analysing policy mixes for energy transitions', Energy research $\&$ social science $\mathbf{3 3}, 1-$ 10 .

Sapio, A. (2019), 'Greener, more integrated, and less volatile? A quantile regression analysis of Italian wholesale electricity prices', Energy Policy 126, 452-469.

Sapio, A. and Spagnolo, N. (2020), 'The effect of a new power cable on energy prices volatility spillovers', Energy Policy 144, 111488.

Schaber, K., Steinke, F. and Hamacher, T. (2012), 'Transmission grid extensions for the integration of variable renewable energies in Europe: Who benefits where?', Energy Policy 43, 123-135.

Schaber, K., Steinke, F., Mühlich, P. and Hamacher, T. (2012), 'Parametric study of variable renewable energy integration in Europe: Advantages and costs of transmission grid extensions', Energy Policy 42, 498-508.

Schacht, P. (2020), 'The absence of cooperative game theory in the Paris Agreement - a comparative study of transfer payments', Master's Thesis, Maastricht University .

Sensfuß, F., Ragwitz, M. and Genoese, M. (2008), 'The merit-order effect: A detailed analysis of the price effect of renewable electricity generation on spot market prices in Germany', Energy policy 36(8), 3086-3094.

Staffell, I. and Pfenninger, S. (2016), 'Using bias-corrected reanalysis to simulate current and future wind power output', Energy 114, 1224-1239.

Steinke, F., Wolfrum, P. and Hoffmann, C. (2013), 'Grid vs. storage in a 100 percent renewable Europe', Renewable Energy 50, 826-832. 
Thomaidis, N. S., Santos-Alamillos, F. J., Pozo-Vázquez, D. and Usaola-García, J. (2016), 'Optimal management of wind and solar energy resources', Computers $\&$ Operations Research 66, 284-291.

Tobben, S. (2020), 'Oil for less than nothing? Here's how that happened', available from: https://www.bloomberg.com/news/articles/2020-04-20/ negative-prices-for-oil-here-s-what-that-means-quicktakes.

Torkington, S. (2019), '5 charts that show renewable energy's latest milestone', available from: https://www.weforum.org/agenda/2019/08/ renewables-energy-electricity-green-oecd/.

US National Renewable Energy Laboratory (2020), available from: https://www.nrel. gov/analysis/tech-size.html. Accessed: 2020-12-31.

Van den Bergh, K., Boury, J. and Delarue, E. (2016), 'The flow-based market coupling in Central Western Europe: Concepts and definitions', The Electricity Journal 29(1), 2429.

Weitemeyer, S., Kleinhans, D., Vogt, T. and Agert, C. (2015), 'Integration of renewable energy sources in future power systems: The role of storage', Renewable Energy 75, 1420.

Wind Europe (2018), 'World's first offshore wind farm without subsidies to be built in the Netherlands', available from: https://windeurope.org/newsroom/press-releases/ worlds-first-offshore-wind-farm-without-subsidies-to-be-built-in-the-netherlands/.

Winzer, C. (2012), 'Conceptualizing energy security', Energy policy 46, 36-48.

Wolfgang, O., Haugstad, A., Mo, B., Gjelsvik, A., Wangensteen, I. and Doorman, G. (2009), 'Hydro reservoir handling in Norway before and after deregulation', Energy 34(10), 1642-1651.

World Resources Institute (2020), '4 charts explain greenhouse gas emissions by countries and sectors', available from:https://www.wri.org/insights/ 4-charts-explain-greenhouse-gas-emissions-countries-and-sectors.

Wozabal, D., Graf, C. and Hirschmann, D. (2016), 'The effect of intermittent renewables on the electricity price variance', OR spectrum 38(3), 687-709.

Würzburg, K., Labandeira, X. and Linares, P. (2013), 'Renewable generation and electricity prices: Taking stock and new evidence for Germany and Austria', Energy Economics 40, S159-S171. 
Yale Environment 360 (2019), 'Renewable Energy Capacity Now Exceeds Coal in U.S.', available from: https://e360.yale.edu/digest/ renewable-energy-capacity-now-exceeds-coal-in-the-u-s.

Zachmann, G. (2008), 'Electricity wholesale market prices in Europe: Convergence?', Energy Economics 30(4), 1659-1671.

Zeng, Y., Cai, Y., Huang, G. and Dai, J. (2011), 'A review on optimization modeling of energy systems planning and GHG emission mitigation under uncertainty', Energies 4(10), 1624-1656. 


\section{Scientific and social impacts of the research results}

In accordance with Article 22 of the "Regulations for obtaining the doctoral degree at Maastricht University" adopted by decision of the Board of Deans and entered into force on 1st October 2020, this section provides a reflection on the scientific and social impacts of the research results presented within the doctoral dissertation.

For the past three decades, political action to tackle the climate change has significantly lagged behind the evidence-based impetus from the scientific community. Even despite the ubiquity in the media of the ambition of the 2015 Paris Agreement to ensure global warming remains within the 2 - and closer to the 1.5 - degrees Celsius limit by 2100, compared to pre-industrial levels, political action in this direction has been fragmented, globally. Six years later, only six countries enshrined their emissionreduction targets into law, and the EU and five countries have proposed legislation in this direction (see Energy and Climate Intelligence Unit (2020)). ${ }^{1}$ In March 2020, the European Commission presented the proposal of the European Climate Law - which sets the EU's ambition to become the world's first net-zero GHG emissions continent by 2050 (European Commission (2020)).

Approximately a third of global GHG emissions are produced by the electricity and heat sector (World Resources Institute (2020)). ${ }^{2}$ Therefore, in order to achieve their climate targets, countries need to decrease their reliance on conventional, fossil-fueled power plants and invest in cleaner alternatives at a much larger scale than until now. However, these cleaner alternatives - especially solar and wind energy technologies - differ from conventional technologies in several important aspects, two of which are: they can only generate power under specific weather conditions and they operate at virtually

\footnotetext{
${ }^{1}$ Bhutan and Surinam have already become net-zero GHG emitters (Energy and Climate Intelligence Unit (2020)).

${ }^{2}$ Sectors are considered together.
} 
zero fuel cost. Scaling up these technologies at the level required by a net-zero GHG emissions ambition will bring about significant changes in the operation of existing electricity system and the functioning of electricity markets. Also, the EU-wide geographical dimension of this ambition requires an integrated approach that goes beyond the traditional national-level energy system. This integrated approach to supra-national power systems would not only enable a less-costly transition towards a low-carbon European power system, but it is also critical in supporting the stability and flexibility of the power system, in general. Indeed, the data used for the research presented in this dissertation point to a systematic, extended period of time during late winter, when potential wind power decreases substantially, in the wider Central European region. What is particularly worth considering is that this is the period with highest power demand, due to the increased demand for heating. This demand is expected to increase considerably in the next few decades, in the context of an on-going transition towards the electrification of the heating sector. At the same time, during the identical time period of mid-late winter, both the Scandinavian and Mediterranean regions experience their highest wind power potential. An advanced cross-European power grid is therefore critical to the resilience of Central European countries, in the face of established weather patterns that result in low power production, during extended periods of high power demand. This fact is becoming increasingly recognized at the political level, as well. In fact, the goal of an Energy Union - whereby electricity would flow among member states without technical or regulatory constraints - was officially launched in 2015. As an intermediate step towards further integration, the European Commission aims to increase the interconnector capacity - that supports cross-border electricity trade - to $15 \%$ of installed capacity for electricity production, by 2030, up from 10\%, in 2020 (European Commission (2019c))

The research presented in this dissertation identifies and investigates the main challenges faced by the transition towards a low-carbon electricity system in the EU. More specifically, the research presented in Chapter 2 looks at how different European countries can cooperate in order to achieve lower-cost clean power systems. Due to the wide variation in weather patterns across the EU, an integrated approach to the design of a low-carbon European electricity system - as opposed to individual, national-level approaches - would result in significant cost savings. In Chapter Two, I develop a model that provides estimates for these cost savings, for a selection of EU countries.

A second important challenge raised by the large-scale deployment of wind and solar power technologies concerns the current operation of electricity markets. Due to its zero fuel cost, power generated by solar and wind plants puts a downward pressure on electricity prices. This makes it difficult for conventional power plants to remain competitive, even though they are necessary in ensuring the stability of the power grid. Therefore, an understanding of the type of challenges that a high share of these variable 
renewable energy sources would bring about for the current design of the electricity market is essential, in order to guarantee the smooth operation of the power grid. In Chapter Three and Four, I investigate the effects of power from solar and wind energy technologies on the electricity price and its variance, as well as on the convergence of electricity prices between different European countries.

The social impact of the research presented in this dissertation is therefore directly related to the global ambitions to lower the GHG emissions associated with the electricity sector.

The scientific impact of these research results adds to an increasing empirical literature that studies the effects of intermittent renewable energy on different aspects of the power system and on the electricity market. The research presented here uses recent electricity data at a high temporal resolution and for wide geographical coverage of the EU.

Ultimately, the research discussed in this dissertation aims to contribute to the understanding of the particular set of challenges that the EU faces in its transition away from a fossil-fuels intensive power system and towards a low-carbon one. 


\section{About the author}

Iulia Elena Falcan was born on the 19th of July 1988 in Târgovişte, Romania. She has a degree in International Economics from the Academy of Economics, Bucharest, including one year as an exchange student at Montpellier University. Iulia obtained her Master's Degree in Economic Analysis and Policy from Strasbourg University in 2012, after spending the second year of the program as an exchange student at SPRU, Sussex University. As a Masters student, Iulia worked as a research assistant at both Strasbourg University and SPRU.

Iulia joined the UNU-MERIT PhD program in 2013. During her time as a phd candidate, Iulia was involved in several teaching activities in the UNU-MERIT Masters Program of Public Policy and Human Development, in several courses: Public Economics, Innovation and Global Value Chains, Research Methods, Data Science, Econometrics and Advanced Econometrics. In addition, Iulia was involved in two science communication projects: the Jargon Buster and the SDG Indicators Guide.

Iulia's research interests lie in the broad area of environmental economics. As of July 2021, Iulia is part of the Natural Resources department of Ecorys, a research-based policy consultancy in Rotterdam. 


\section{UNU-MERIT/MGSoG Dissertation Series}

2021

\section{Iulia Falcan}

Transition towards a renewable European electricity system

What are the implications for the power technology mix, pan-European power trade and the electricity market?

UNU-MERIT/MGSoG Dissertation Series № 262

\section{Anne-Lore Fraikin}

The effect of financial retirement incentives originating from the social security system on the retirement behavior of older Belgian workers

UNU-MERIT/MGSoG Dissertation Series № 261

\section{Bart Kleine Deters}

A Quantitative approach to the right to education: Concept, Measurement, and Effects

UNU-MERIT/MGSoG Dissertation Series № 260

\section{Eliana Rubiano-Matulevich}

Essays on Conflict-Induced

Displacement and Gender in Colombia

UNU-MERIT/MGSoG Dissertation

Series № 259

\section{Njagi Purity Muthoni}

Financial Risk, Vulnerability and

Equity of Access to Healthcare Services in Kenya

UNU-MERIT/MGSoG Dissertation

Series № 258

\section{María José Espinosa-Romero}

The Shadow of Hierarchy in Marine

Fisheries Governance

UNU-MERIT/MGSoG Dissertation

Series № 257

\section{Lorena Rivera León}

Unveiling the Determinants of Scientific Productivity in Middle-Income Countries:

An Economics of Science Perspective UNU-MERIT/MGSoG Dissertation

Series № 256

\section{Racky Balde}

Essays on Informal versus formal Economy

Choices

UNU-MERIT/MGSoG Dissertation

Series № 255

\section{Caio Torres Mazzi}

Learning, Capabilities and Governance in Global Value Chains

UNU-MERIT/MGSoG Dissertation

Series № 254 


\section{Giulia Rossello}

Social Transformations and Labour Market Entry

An Investigation into University Systems in Emerging Economies

UNU-MERIT/MGSoG Dissertation

Series № 253

2020

\section{Rose Camille Vincent}

Essays in Public Economics

Multi-Layer Tax Structure and

Implications

UNU-MERIT/MGSoG Dissertation

Series № 252

\section{Emmanuel Mensah}

Structural change in developing countries:

patterns, causes, and consequences

UNU-MERIT/MGSoG Dissertation

Series № 251

\section{Ornsaran Manuamorn}

Governance of International Adaptation

Finance for Local Climate Change

Adaptation: An Analysis of Adaptation

Fund Projects

UNU-MERIT/MGSoG Dissertation

Series № 250

\section{Gillian McFarland}

Doing policy in Further Education

An exploration of the enactment of the

GCSE resits policy in Further Education

colleges in England

UNU-MERIT/MGSoG Dissertation

Series № 249

\section{Omar Rodriguez Torres}

Essays on Entrepreneurship in Colombia UNU-MERIT/MGSoG Dissertation Series № 248

\section{Elaine Lebon-McGregor}

International Organizations and Global

Migration Governance

UNU-MERIT/MGSoG Dissertation

Series № 247

\section{Janyl Moldalieva}

Playing the 'Game' of Transparency and

Accountability in Kyrgyzstan's Resource

Governance

UNU-MERIT/MGSoG Dissertation

Series № 246

\section{Kaleab Kebede Haile}

Essays on Rural Household Decision-

Making under Climate Risk

UNU-MERIT/MGSoG Dissertation

Series № 245

\section{Nora Jasmin Ragab}

Diaspora Mobilisation in a Conflict Setting

UNU-MERIT/MGSoG Dissertation

Series № 244

\section{Mary Kaltenberg}

From Micro to Macro: Essays on

Technological Change and Income

Divergence

UNU-MERIT/MGSoG Dissertation

Series № 243

\section{Ayla E. Bonfiglio}

Student migrant, refugee or both?

Exploring Refugee Agency and Mobility

through Tertiary Education in Kenya,

South Africa and Uganda

UNU-MERIT/MGSoG Dissertation

Series № 242 


\section{Danilo Sartorello Spinola}

Cycles, Economic Structures and External Constraints.

A Structuralist study on the causes of economic volatility in Latin America UNU-MERIT/MGSoG Dissertation

Series № 241

2019

\section{Jemal Adem}

Livelihood Vulnerability to Shocks,

Behaviour and Investment in Education:

Essays in Behavioural Development

Economics

UNU-MERIT/MGSoG Dissertation

Series № 240

\section{Davina Osei}

Corrupt or corrupted networks?

An empirical enquiry

UNU-MERIT/MGSoG Dissertation

Series № 239

\section{Patima Chongcharoentanawat}

Beyond Static Inequality

Public policies and economic mobility in

Thailand

UNU-MERIT/MGSoG Dissertation

Series № 238

\section{Charlotte Guillard}

Rethinking economic growth

and structural change.

The role of boundaries and linkages between industries

UNU-MERIT/MGSoG Dissertation

Series № 237

\section{Nicolas Echarti}

Employment Effects or Vocational

Rehabilitation in Germany:

A quantitative analysis

UNU-MERIT/MGSoG Dissertation

Series № 236

\section{Shellie E. Solomon}

Neighborhoods Matter:

Crime, collective efficacy and foreclosures in Miami

UNU-MERIT/MGSoG Dissertation

Series № 235

\section{Michał Kazimierczak}

Regional Innovation and Entrepreneurship

Patents, trade marks, entry and entrants' growth in European manufacturing

industries

UNU-MERIT/MGSoG Dissertation

Series № 234

\section{Fernanda Soares}

The Influence of Within School and Across Schools' Collaborative Practices on Student Learning and Teaching Outcomes in West Africa

UNU-MERIT/MGSoG Dissertation

Series № 233

\section{Mira Bierbaum}

New Mindsets to Innovate Activation UNU-MERIT/MGSoG Dissertation

Series № 232

\section{Norman Dytianquin}

Technology in the Asian Miracle and Crisis Debates: Applications of and Insights from the Field of Influence Approach to InputOutput Analysis

UNU-MERIT/MGSoG Dissertation

Series № 231

\section{Nga Le}

The implications of health insurance for the labour market and patient satisfaction with medical care in Vietnam

UNU-MERIT/MGSoG Dissertation

Series № 230 


\section{Jinhyuck Park}

Intellectual Property right protection and cross-border RED investments by multinational enterprises

UNU-MERIT/MGSoG Dissertation

Series № 229

\section{Richard de Groot}

Show me the Money:

Essays on the Impact of Cash Transfers on Child Nutrition and the Role of Intra-

Household Dynamics

UNU-MERIT/MGSoG Dissertation

Series № 228

\section{Catie Lott}

Diamonds are a Women's Best Friend Broadening Measures of Women's Access to Formal Political Decision-Making UNU-MERIT/MGSoG Dissertation Series № 227

\section{Ana Cristina Calderon Ramirez}

Public Management Reforms

Three stories about public procurement agencification in Latin America UNU-MERIT/MGSoG Dissertation Series № 226

\section{Camilo Nicanor Carrillo Purin}

Teachers' in-service training and student achievement:

The effect of in-service training of Peruvian teachers on student achievement UNU-MERIT/MGSoG Dissertation

Series № 225

\section{Hugo Confraria}

Developing scientific capacity in the Global South

UNU-MERIT/MGSoG Dissertation

Series № 224

\section{Alison Cathles}

Educational Pathways and Skills:

Past, Present, and Future

UNU-MERIT/MGSoG Dissertation

Series № 223

\section{Ibrahima Sory Kaba}

Aggregate Fluctuations and Development:

Essays on Macroeconomic Volatility and

Economic Growth

UNU-MERIT/MGSoG Dissertation

Series № 222

\section{Charlotte Keijser}

Firm Participation, Learning and

Innovation in Heterogenous Value Chains of IT-enabled Services

UNU-MERIT/MGSoG Dissertation

Series № 221

\section{Salih Çevikarslan}

Innovation Strategies and Their

Implications for Technological Change and Market Outcomes:

An Evolutionary Multi-Agent Based

Modelling Approach

UNU-MERIT/MGSoG Dissertation

Series № 220

\section{Wondimagegn Mesfin Tesfaye}

Essays on the Impacts of Climate-Smart

Agricultural Innovations on Household

Welfare

UNU-MERIT/MGSoG Dissertation

Series № 219

\section{Tatevik Poghosyan}

How Board Networks Affect Firm

Performance and Innovation Incentives in Transition Economies: The Case of

Armenia

UNU-MERIT/MGSoG Dissertation

Series № 218 


\section{Arip Muttaqien}

Essays on Inequality and Polarization:

Empirical Studies in Developing Asia

UNU-MERIT/MGSoG Dissertation

Series № 217

2018

\section{Katrin Marchand}

Essays on Forced Migration and Labour

Market Participation in Developing

Countries

UNU-MERIT/MGSoG Dissertation

Series № 216

\section{Ortrun Merkle}

The Myth of Gender Neutral Power:

Corruption and Gender Norms

UNU-MERIT/MGSoG Dissertation

Series № 215

\section{Biljana Meshkovska}

Life after Trafficking:

(re)integration processes of women that have been trafficked for the purpose of sexual exploitation in Europe

UNU-MERIT/MGSoG Dissertation

Series № 214

\section{Vincenzo Vinci}

The Relevance of Institutions and People's

Preferences for Social Protection

UNU-MERIT/MGSoG Dissertation

Series № 213

\section{Silke Heuser}

The Effectiveness of Environmental Policies on Reducing Deforestation in the Brazilian Amazon

UNU-MERIT/MGSoG Dissertation

Series № 212

\section{Jennifer Waidler}

Social Assistance and Remittances and

Their Role in the Fight Against Poverty

UNU-MERIT/MGSoG Dissertation

Series № 211

\section{Choolwe Muzyamba}

The role of community mobilization in the promotion of maternal health of women living with HIV in Zambia

UNU-MERIT/MGSoG Dissertation

Series № 210

\section{Juan Carlos A. Castillo Sánchez}

Assessing the Role of the Export Sector in Mexican Economic Development,1965-

2014

UNU-MERIT/MGSoG Dissertation

Series № 209

\section{Tareq Abuelhaj}

Food Security Policy Impact Analysis: The Econometrics of Cash and Food Assistance Cost Effectiveness

UNU-MERIT/MGSoG Dissertation

Series № 208

Marta Férnandez de Arroyabe Arranz Essays on MEAS and Innovation UNU-MERIT/MGSoG Dissertation

Series № 207

\section{Clotilde Mahé}

Essays on Migration and Occupational Choice

UNU-MERIT/MGSoG Dissertation

Series № 206

\section{Simone Sasso}

Talent on the move. Essays on Human Capital, Graduate Mobility and Economic Development

UNU-MERIT/MGSoG Dissertation

Series № 205 
Khaled Walid Rajab

Strategic Planning under Fragility

UNU-MERIT/MGSoG Dissertation

Series № 204

\section{Mutinta Hambayi Nseluke}

A Tall Order: Improving Child Linear

Growth

UNU-MERIT/MGSoG Dissertation

Series № 203

\section{Elvis Korku Avenyo}

Innovations and Firm Performance in sub-Saharan Africa: Empirical Analyses UNU-MERIT/MGSoG Dissertation

Series № 202

\section{Ni Zhen}

Employment Dynamics, Firm Performance and Innovation Persistence in the Context of Differentiated Innovation Types:

Evidence from Luxembourg

UNU-MERIT/MGSoG Dissertation

Series № 201

\section{Caroline Wehner}

Too Scared to Achieve: The Relation

Between Neuroticism, Conscientiousness

and Socioeconomic Outcomes

UNU-MERIT/MGSoG Dissertation

Series № 200

\section{Stefania Innocenti}

On Institutional Persistence

UNU-MERIT/MGSoG Dissertation

Series № 199

\section{Hassen Abda Wako}

Economic Globalization, Institutions and Development: Essays on Aid, Foreign

Direct Investment and Trade

UNU-MERIT/MGSoG Dissertation

Series № 198
2017

\section{Hans-Erik Edsand}

Winds of Change

UNU-MERIT/MGSoG Dissertation

Series № 197

\section{Ana Patricia Silva Vara}

Redressing the Gender Gap

UNU-MERIT/MGSoG Dissertation

Series № 196

\section{Andrés Iván Mideros Mora}

Essays on the Economic Effects of Noncontributory Social Protection UNU-MERIT/MGSoG Dissertation

Series № 195

\section{Tobias Broich}

New Actors in the Global Economy UNU-MERIT/MGSoG Dissertation

Series № 194

\section{Bernard Nikaj}

From No-government to E-government UNU-MERIT/MGSoG Dissertation

Series № 193

\section{Ali Safarnejad}

Prioritizing the HIV Response

UNU-MERIT/MGSoG Dissertation

Series № 192

\section{Clovis Freire}

Diversification and Structural Economic

Dynamics

UNU-MERIT/MGSoG Dissertation

Series № 191

\section{Michael Verba}

Innovation and Knowledge Dynamics:

Essays on the Knowledge Economy

UNU-MERIT/MGSoG Dissertation

Series № 190 


\section{Pui Hang Wong}

The Hearts and Minds in Conflict and

Peace: The Economics of

Counterinsurgency and the Psychology of

Reconstruction

UNU-MERIT/MGSoG Dissertation

Series № 189

\section{Brenda Yamba}

Schooling Despite All Odds: Evidence from Lesotho on Female Child Carers who Stayed in School

UNU-MERIT/MGSoG Dissertation

Series № 188

\section{Sheng Zhong}

Moving towards An Energy Efficient

Future: Essays on Energy Efficiency,

Technology and Development

UNU-MERIT/MGSoG Dissertation

Series № 187

\section{Julieta Marotta}

Access to Justice and Legal Empowerment of Victims of Domestic Violence through Legal Organizations in the City of Buenos Aires: A Qualitative Empirical Legal Study UNU-MERIT/MGSoG Dissertation

Series, № 186

\section{Andrea Franco-Correa}

On the Measurement of Multidimensional Poverty as a Policy Tool: Empirical Applications to Chile, Colombia, Ecuador and Peru

UNU-MERIT/MGSoG Dissertation Series, № 185

\section{6}

\section{Yesuf Awel}

Insurance for Growth: Empirical Essays on Insurance Demand and Impacts in Africa UNU-MERIT Dissertation Series, № 108
Tigist Mekonnen Melesse

Grow More Food using Fewer Resources: Agricultural Technology Adoption and Innovation Practices for Inclusive and Sustainable Development UNU-MERIT Dissertation Series, № 107

\section{Eleni Yitbarek}

Getting Ahead or left Behind? Essays on Poverty Dynamics and Social Mobility in Africa

UNU-MERIT Dissertation Series, № 106

\section{Thuy Dieu Nguyen}

Firm-Level Theory and Evidence of

Corruption

UNU-MERIT Dissertation Series, № 105

\section{Raquel Tsukada Lehman}

Essays on Household Production with Labor-Saving Technology UNU-MERIT Dissertation Series, № 104

\section{Eva Barteková}

Multi-Problem Challenges for a Renewable Future: Empirical Studies on Competitive Disadvantages from Electricity Price Differentials and Mineral Supply Risk in an Open Economy UNU-MERIT Dissertation Series, № 103

\section{Jocelyn Olivari}

Entrepreneurial Traits and Innovation:

Evidence from Chile

UNU-MERIT Dissertation Series, № 102 


\section{Muhammad Shafique}

Essays on the role of knowledge, RED, and Technology-based Firms in the Evolution of Socio-techno-economic System UNU-MERIT Dissertation Series, № 101

\section{Serdar Türkeli}

Governance of Innovation Policy:

Empirical Studies on Applied Political

Economy by Multi-Methods Analysis

UNU-MERIT Dissertation Series, № 100

\section{Ayokunu Adedokun}

Pathways to Sustainable Peace building in Divided Societies: Lessons and Experiences from Mozambique

MGSoG Dissertation Series, № 75

\section{Luiz Rothier Bautzer}

Organizing Concurrent Engineering

through ICT Platforms

Blueprinting Product Lifecycle

Management Platforms across Disciplinary Agencies

MGSoG Dissertation Series, № 74

\section{Natalia Popova}

Migration in the Periphery of the European Union:

Determinants of Successful and

Sustainable Labour Market Integration of

Return Migrants in Albania, Egypt,

Moldova and Tunisia

MGSoG Dissertations Series, № 73

\section{Richard A. Martina}

Uncertainty and Resource Constraint in the Small Island Developing States:

Essays in Entrepreneurial Cognition

MGSoG Dissertations Series, № 72

\section{Cécile Cherrier}

The Expansion of Basic Social Protection in Low-income Countries:

An Analysis of Foreign Aid Actors' Role in the Emergence of Social Transfers in SubSaharan Africa

MGSoG Dissertations series, № 71

\section{Paul Caldron}

The Tacit Bargain in Short-Term Medical Missions: Why U.S. physicians go and what it costs

MGSoG Dissertation Series, № 70

\section{Mahmut Kobal}

Customs \& Excellence: A Comparative Approach on Administrative and Regulatory Compliance Perspectives of the EU-Turkey Customs Union

MGSoG Dissertation Series, № 69

\section{Craig Loschmann}

Essays on Conflict-related Migration and Development in the Case of Afghanistan

MGSoG Dissertations Series, № 68

\section{Andrea Milan}

Rural Livelihoods, Location and Vulnerable Environments: Approaches to Migration in Mountain areas of Latin America MGSoG Dissertation Series, № 67

\section{Farida Lada}

On Guarding the Welfare of Clinical Trial Subjects While Promoting Novel Drug Innovation

A Game Theoretical Approach MGSoG Dissertation Series, № 66 
2015

\section{Hibret Belete Maemir}

Dissecting Aggregate Productivity:

International Integration and Growth with

Heterogeneous Firms

UNU-MERIT Dissertation Series, № 96

\section{Giorgio Triulzi}

Looking for the Right Path: Technology

Dynamics, Inventive Strategies and

Catching-up in the Semiconductor

Industry

UNU-MERIT Dissertation Series, № 95

\section{Abdul Baseer Qazi}

Knowledge flows and networks in the ICT sector: The case of Pakistan

UNU-MERIT Dissertation Series, № 94

\section{Ajay Thutupalli}

Technology Paradigm Shifts in

Agriculture: Drivers of Sustainability and Catch up

UNU-MERIT Dissertation Series, № 93

\section{Eduardo Urias}

Improving access to HIVIAIDS treatment in Brazil: When are Compulsory Licenses effective in Price Negotiations?

UNU-MERIT Dissertation Series, № 92

\section{Francesca Guadagno}

Why have so few Countries Industrialised? UNU-MERIT Dissertation Series, № 91

\section{Daniel Opolot}

The Evolution of Beliefs and Strategic

Behaviour

UNU-MERIT Dissertation Series, № 90

\section{Alejandro Lavopa}

Structural Transformation and Economic Development: Can Development Traps be Avoided

UNU-MERIT Dissertation Series, № 89

\section{Jinjin Zhao}

Urban water management reform: The Case of China

UNU-MERIT Dissertation Series, № 88

\section{Simona Vezzoli}

Borders, Independence and Post-colonial Ties: the Role of the State in Caribbean Migration

MGSoG Dissertation Series, № 65

\section{Silvia Consuelo Gómez Soler}

Civil Conflict and Education: How Does

Exposure to Civil Conflict Affect Human Capital Accumulation? Evidence from Standardized Exit Exams in Colombia MGSoG Dissertation Series, № 64

\section{Paula Nagler}

Occupational Choice in the Developing

World

MGSoG Dissertation Series, № 63

\section{Jasmin Kientzel}

Determinants of Professional Commitment to Environmental Sustainability

MGSoG Dissertation Series, № 62

\section{Mehmet Güney Celbiş}

Regional Policies: Convergence, Trade, and the Allocation of Public Capital MGSoG Dissertation Series, № 61

\section{Florian Henning}

Living Up to Standard: Interoperability Governance and Standards Adoption in Government Information Networks MGSoG Dissertation Series, № 60 
Niels P. Groen

The Never-Ending Project

Understanding E-Government Project

Escalation

MGSoG Dissertation Series, № 59

\section{Derek Copp}

Teacher-Based Reactivity to Provincial

Large-scale Assessment in Canada

MGSoG Dissertation Series, № 58

\section{Michaella Vanore}

Family-Member Migration and the

Psychosocial Health Outcomes of Children

in Moldova and Georgia

MGSoG Dissertation Series, № 57

\section{Sonja Fransen}

The Economic and Social Effects of Remittances and Return Migration in Conflict-Affected Areas: The Case of

Burundi

MGSoG Dissertation Series, № 56

\section{Ibrahim Khalil Conteh}

The Impact of Floods on Primary School

Education in Zambia

MGSoG Dissertation Series, № 55

\section{Richard Bluhm}

Growth Dynamics and Development

Essays in Applied Econometrics and

Political Economy

MGSoG Dissertation Series, № 54

\section{Nevena P. Zhelyazkova}

Work-Family Reconciliation and Use of Parental Leave in Luxembourg: Empirical Analysis of Administrative Records MGSoG Dissertation Series, № 53
2014

\section{Dirk Crass}

The Impact of Brands on Innovation and Firm Performance: Empirical Evidence from Germany

UNU-MERIT Dissertation Series, № 87

\section{Samyukta Bhupatiraju}

The Geographic Dimensions of Growth and Development

UNU-MERIT Dissertation Series, № 86

\section{François Lafond}

The Evolution of Knowledge Systems UNU-MERIT Dissertation Series, № 85

\section{Annalisa Primi \\ Promoting Innovation in Latin America: \\ What Countries Have Learned (and What They Have Not) in Designing and Implementing Innovation and Intellectual Property Policies \\ UNU-MERIT Dissertation Series, № 84}

\section{Fatoumata Lamarana Diallo}

Evaluation of Meal and Deworming Programs for Primary Schools in Rural Senegal

UNU-MERIT Dissertation Series, № 83

\section{Sachin Kumar Badkas}

Metachoice and Metadata: Innovating with Environmental Policy Analysis in Europe MGSoG Dissertation Series, № 52

\section{Irina S. Burlacu}

An Evaluation of Tax-Benefit Systems Impact on the Welfare of Frontier Worker: The Case of Luxembourg and Belgium MGSoG Dissertation Series, № 51 


\section{Özge Bilgili}

Simultaneity in Transnational Migration

Research: Links Between Migrants' Host and Home Country Orientation

MGSoG Dissertation Series, № 50

\section{Yulia Privalova Krieger}

Reshaping the Big Agenda: Transnational

Politics and Domestic Resistance Financial crisis and social protection reform in Bosnia and Herzegovina

MGSoG Dissertation Series, № 49

\section{Marieke van Houte}

Moving Back or Moving Forward? Return migration after Conflict

MGSoG Dissertation Series, № 48

\section{Oxana Slobozhan}

Global Governance in the Management of

Natural Resources: The Case of the

Extractive Industries Transparency

Initiative (EITI)

MGSoG Dissertation Series, № 47

\section{Luis Bernardo Mejia Guinand}

The Changing Role of the Central Planning

Offices in Latin America: A Comparative

Historical Analysis Perspective (1950-

2013)

MGSoG Dissertation Series, № 46

\section{Cheng Boon Ong}

Ethnic Segregation in Housing, Schools and Neighbourhoods in the Netherlands MGSoG Dissertation Series, № 45

\section{Luciana V. Cingolani}

Bureaucracies for Development: Oxymoron or Reality? Studies on State Capacity in Challenging Governance Contexts MGSoG Dissertation Series, № 44

\section{Carlos Cadena Gaitán}

Green Politics in Latin American Cities -

Sustainable Transport Agendas

MGSoG Dissertation Series, № 43

\section{Katie Kuschminder}

Female Return Migration and

Reintegration Strategies in Ethiopia

MGSoG Dissertation Series, № 42

\section{Metka Hercog}

Highly-Skilled Migration and New

Destination Countries

MGSoG Dissertation Series, № 41

\section{Margaret Agaba Rugadya}

Can Remittances Influence the Tenure and Quality of Housing in Uganda?

MGSoG Dissertation Series, № 40

\section{Ilire Agimi}

New Governance Under Limited Statehood: The Case of Local Government Reform in Kosovo

MGSoG Dissertation Series, № 39

\section{3}

\section{Anant Kamath}

Information Sharing through Informal Interaction in Low-Tech Clusters

UNU-MERIT Dissertation Series, № 82

\section{Flavia Pereira de Carvalho}

What we talk about when we talk about Brazilian Multinationals: An Investigation on Brazilian FDI, Economic Structure, Innovation and the Relationship between them

UNU-MERIT Dissertation Series, № 81 


\section{Jun Hou}

Complementarity in Innovation and

Development: A Cross-country

Comparison

UNU-MERIT Dissertation Series, № 80

\section{Rufin Baghana}

Impacts of Government Incentives to RED, Innovation and Productivity:

A Microeconometric Analysis of the

Québec Case

UNU-MERIT Dissertation Series, № 79

\section{Lilia I. Stubrin}

High-Tech Activities in Emerging

Countries: A Network perspective on the

Argentinean Biotech Activity

UNU-MERIT/MGSoG Dissertation

Series, № 78

\section{Kristine Farla}

Empirical Studies on Institutions, Policies and Economic Development

MGSoG Dissertation Series, № 38

\section{Marina Petrovic}

Social Assistance and Activation in the Pursuit of Happiness: Shedding New Light on Old Policy Solutions to Social Exclusion MGSoG Dissertation Series, № 37

\section{Laura Torvinen}

Assessing Governance Assessments: The Case of Mozambique: Governance Assessments in the Context of Aid Effectiveness Discourse

MGSoG Dissertation Series, № 36

\section{Biniam Egu Bedasso}

Institutional Change in the Long Shadow of Elite: Essays on Institutions, Human

Capital and Ethnicity in Developing Countries

MGSoG Dissertation Series, № 35
Sepideh Yousefzadeh Faal Deghati

Childhoods Embargoed: Constructing and

Reconstructing Multidimensional Child

Poverty in Iran 1984-2009

MGSoG Dissertation Series, № 34

\section{Robert Bauchmüller}

Investing in Early Childhood Care and

Education: The Impact of Quality on

Inequality

MGSoG Dissertation Series, № 33

\section{Martin Rehm}

Unified Yet Separated: Empirical Study on the Impact of Hierarchical Positions within Communities of Learning

MGSoG Dissertation Series, № 32

2012

Abdul Waheed
Innovation Determinants and Innovation
as a Determinant: Evidence from
Developing Countries
UNU-MERIT Dissertation Series, № 77

Bilal Mirza

Energy Poverty and Rural Energy Markets in Pakistan

UNU-MERIT Dissertation Series, № 76

\section{Benjamin Engelstätter}

Enterprise Software and Video Games: An

Empirical Analysis

UNU-MERIT Dissertation Series, № 75

\section{Fulvia Farinelli}

Natural Resources, Innovation and Export Growth: The Wine Industry in Chili and Argentina UNU-MERIT Dissertation Series 


\section{Rodolfo Lauterbach}

Innovation in Manufacturing: From

Product Variety and Labor Productivity

Growth to Economic Development in Chile

UNU-MERIT Dissertation Series

\section{Kirsten Wiebe}

Quantitative Assessment of Sustainable

Development and Growth in Sub-Saharan

Africa

UNU-MERIT Dissertation Series, № 74

\section{Julio Miguel Rosa}

Organizational Strategies, Firms'

Performance and Spatial Spillovers: The

Canadian Case in Research and

Development.

UNU-MERIT Dissertation Series, № 73

\section{Johannes Wilhelmus Marie Boels}

Joseph Schumpeter, Honderd Jaar

Economische Ontwikkeling: Een

Historisch-theoretische Beschouwing.

UNU-MERIT Dissertation Series

\section{Dorcas Mbuvi}

Utility Reforms and Performance of the

Urban Water Sector in Africa

MGSoG Dissertation Series, № 31

\section{Lina Salanauskaite}

Distributional Impacts of Public Policies:

Essays in Ex-Ante and Ex-Post Evaluation

MGSoG Dissertation Series, № 30

\section{Esther Schüring}

To Condition or not - is that the Question?

An Analysis of the Effectiveness of Ex-Ante and Ex-Post Conditionality in Social Cash

Transfer Programs

MGSoG Dissertation Series, № 29

\section{Joe Abah}

Strong Organisations in Weak States:

Atypical Public Sector Performance in

Dysfunctional Environments

MGSoG Dissertation Series, № 28

\section{Zina Samih Nimeh}

Social Citizenship Rights: Inequality and

Exclusion

MGSoG Dissertation Series, № 27

\section{1}

\section{Daniel Vertesy}

Interrupted Innovation: Emerging

Economies in the Structure of the Global

Aerospace Industry

UNU-MERIT Dissertation Series, № 72

\section{Tina Saebi}

Successfully Managing Alliance Portfolios:

An Alliance Capability View

UNU-MERIT Dissertation Series, № 71

\section{Nora Engel}

Tuberculosis in India: A Case of Innovation and Control

UNU-MERIT/MGSoG Dissertation

Series, № 70

\section{Evans Mupela}

Connectivity and growth in Sub-Saharan

Africa: The Role of Communication

Satellites

UNU-MERIT Dissertation Series, № 69

\section{Nantawan Kwanjai}

Cross Cultural Intelligence amid Intricate

Cultural Webs: A Tale of the

UnDutchables in the Land of 1002 Smiles

UNU-MERIT Dissertation Series, № 68 


\section{Lina Sonne}

Innovation in Finance to Finance

Innovation: Supporting Pro-poor

Entrepreneur-based Innovation

UNU-MERIT Dissertation Series, № 67

\section{Lenka Eisenhamerová}

Legitimacy of 'Humanitarian Military

Intervention'

MGSoG Dissertation Series, № 26

\section{Sonila Tomini}

Informal Payments for Health Care

Services in Albania

MGSoG Dissertation Series, № 25

\section{Jinjing Li}

Dynamic Microsimulation in Public Policy

Evaluation

MGSoG Dissertation Series, № 24

\section{Aziz Atamanov}

Rural Nonfarm Employment and International Migration as Alternatives to Agricultural Employment: The Case of

Kyrgyzstan

MGSoG Dissertation Series, № 23

\section{Frieda Vandeninden}

Poverty Alleviation: Aid and Social

Pensions

MGSoG Dissertation Series, № 22

\section{Juliana Nyasha Tirivayi}

The Welfare Effects of Integrating AIDS

Treatment with Food Transfers: Evidence from Zambia

MGSoG Dissertation Series, № 21

\section{Agnieska Ewa Sowa}

Who's Left Behind? Social Dimensions of

Health Transition and Utilization of

Medical Care in Poland

MGSoG Dissertation Series, № 20

\section{Emmanaouil Sfakianakis}

The Role of Private Actors in the Provision of Public Goods with Applications to Infrastructure and Financial Stability MGSoG Dissertation Series, № 19

\section{Siu Hing Lo}

White Collars Green Sleeves: An Interorganizational Comparison of

Determinants of Energy-Related Behaviors among Office Workers

MGSoG Dissertation Series, № 18

\section{Treena $\mathbf{W u}$}

Constraints to Human Capital Investment in Developing Countries:

Using the Asian Financial Crisis in Indonesia as a Natural Experiment MGSoG Dissertation Series, № 17

\section{Henry Espinoza Peña}

Impact Evaluation of a Job-Training

Programme for Disadvantaged Youths:

The Case of Projoven

MGSoG Dissertation Series, № 16

2010

\section{Fernando Santiago}

Human Resources Management Practices and Learning for Innovation in Developing Countries: Pharmaceutical Firms in Mexico

UNU-MERIT Dissertation Series, № 66

\section{Zakaria Babutsidze}

Essays on Economies with Heterogeneous Interacting Consumers

UNU-MERIT Dissertation Series, № 65

\section{Bertha Vallejo}

Learning and Innovation Under Changing Market Conditions: The Auto Parts Industry in Mexico UNU-MERIT Dissertation Series, № 64 


\section{Donatus Ayitey}

Technical Change, Competitiveness and

Poverty Reduction: A Study of the

Ghanaian Apparel Industry

UNU-MERIT Dissertation Series, № 63

\section{Sergey Filippov}

Multinational Subsidiary Evolution:

Corporate Change in New EU Member

States

UNU-MERIT Dissertation Series, № 62

\section{Asel Doranova}

Technology Transfer and Learning under the Kyoto Regime: Exploring the

Technological Impact of CDM Projects in

Developing Countries

UNU-MERIT Dissertation Series, № 61

\section{Florian Tomini}

Between Family and Friend:

Understanding the Interdependency of

Private Transfers

MGSoG Dissertation Series, № 15

\section{Michał Polalowski}

The Institutional Transformation of Social Policy in East Central Europe: Poland and Hungary in Comparative and Historical Perspective

MGSoG Dissertation Series, № 14

\section{Maha Ahmed}

Defining, Measuring and Addressing Vulnerability: The Case of Post Conflict Environments

MGSoG Dissertation Series, № 13

\section{Pascal Beckers}

Local Space and Economic Success: The Role of Spatial Segregation of Migrants in the Netherlands

MGSoG Dissertation Series, № 12

\section{Victor Cebotari}

Conflicting Demands in Ethnically Diverse Societies: Ethno political Contention and Identity Values in Europe

MGSoG Dissertation Series, № 11

\section{Dennis Gyllensporre}

Competing and Complementary

Perspectives on the EU as a Crisis

Management Actor:

An Examination of the Common Security and Defence Policy through the Lenses of Idealism and Realism

MGSoG Dissertation Series, № 10

\section{Judit Vall Castello}

Business Cycle and Policy Effects on Labour Market Transitions of Older and Disabled Workers in Spain

MGSoG Dissertation Series, № 9

\section{Keetie Roelen}

False Positives or Hidden Dimensions: The Definition and Measurement of Child Poverty

MGSoG Dissertation Series, № 8

\section{Denisa Maria Sologon}

Earning Dynamics in Europe

MGSoG Dissertation Series, № 7

\section{Melissa Siegel}

Money and Mobility: Migration and

Remittances

MGSoG Dissertation Series, № 6

\section{Jessica S. Hagen-Zanker}

Modest Expectations: Causes and Effects of Migration on Migrant Households inSource Countries

MGSoG Dissertation Series, № 5 
Alexis Habiyaremye

From Primary Commodity Dependence to

Diversification and Growth: Absorptive

Capacity and Technological Catch Up in

Botswana and Mauritius.

UNU-MERIT Dissertation Series, № 60

\section{Yoseph Getachew}

The Role of Public Capital in Economic

Development

UNU-MERIT Dissertation Series, № 59

\section{Sandra Leitner}

Embodied Technological Change and

Patterns of Investment in Austrian

Manufacturing

UNU-MERIT Dissertation Series, № 58

\section{Semih Akçomak}

The Impact of Social Capital on Economic and Social Outcomes

UNU-MERIT Dissertation Series, № 57

\section{Abraham Garcia}

The Role of Demand in Technical Change UNU-MERIT Dissertation Series, № 56

\section{Saurabh Arora}

Coherence in Socio-technical Systems: A

Network Perspective on the Innovation

Process

UNU-MERIT Dissertation Series, № 55

\section{Mirtha R. Muniz Castillo}

Human Development and Autonomy in

Project Aid: Experiences from four bilateral projects in Nicaragua and El Salvador

MGSoG Dissertation Series, № 4

\section{Christiane Arndt}

Governance Indicators

MGSoG Dissertation Series, № 3
Microfinance: Greater Good or Lesser Evil?

MGSoG Dissertation Series, № 2

2008

\section{Rutger Daems}

Medicines for the Developing World

UNU-MERIT Dissertation Series, № 54

\section{Johannes Hanel}

Assessing Induced Technology: Sombart's Understanding of Technical Change in the History of Economics

UNU-MERIT Dissertation Series, № 53

Rifka Weehuizen

Mental Capital: the Economic Significance of Mental Health

UNU-MERIT Dissertation Series, № 52

\section{Danielle Cloodt}

The Relationship between RED

Partnership Formation, Social

Embeddedness and Innovative Performance UNU-MERIT Dissertation Series, № 51

\section{Sabine Fuss}

Sustainable Energy Development under

Uncertainty

UNU-MERIT Dissertation Series, № 50

\section{Geranda Notten}

Measuring and Managing Poverty Risks

MGSoG Dissertation Series, № 1

2007

\section{Tobias Kronenberg}

Reconciling Environmental Conservation with Economic Prosperity: The Feasibility of Double Dividends in the Short and Long Run

UNU-MERIT Dissertation Series, № 49 


\section{Viktoria Kravtsova}

Assessing the Impact of Foreign Direct

Investment in Transition Economies

UNU-MERIT Dissertation Series, № 48

\section{Suhail Sultan}

The Competitive Advantage of Small and

Medium Sized Enterprises: The Case of

Jordan's Natural Stone Industry

UNU-MERIT Dissertation Series, № 47

2006

Bulat Sanditov

Essays on Social Learning and Imitation UNU-MERIT Dissertation Series, № 46

\section{Mamata Parhi}

Dynamics of New Technology Diffusion: A Study of the Indian Automotive Industry

UNU-MERIT Dissertation Series, № 45

\section{Andreas Reinstaller}

Social Structures and the Innovation

Process: Their Role in the Demand of Firms and Consumers

UNU-MERIT Dissertation Series, № 44

\section{Rose Kiggundu}

Innovation systems and Development: The Journey of a Beleaguered Nile Perch Fishery in Uganda

UNU-MERIT Dissertation Series, № 43

\section{Thomas Pogue}

The Evolution of Research Collaboration in South African Gold Mining: 1886-1933

UNU-MERIT Dissertation Series, № 42

\section{Önder Nomaler}

Technological Change, International Trade and Growth: An Evolutionary, Multi-

Agents-Based Modeling Approach

UNU-MERIT Dissertation Series, № 40

2005

\section{Samia Satti Osman Mohamed-Nour}

Change and Skill Development in the Arab Gulf Countries

UNU-MERIT Dissertation Series, № 39

\section{Elad Harison}

Intellectual Property Rights: Economics

and Policy Analysis

UNU-MERIT Dissertation Series, № 38

\section{Daniel Dalohoun}

Learning to innovate: agricultural innovation and entrepreneurship: the case of Songhai farmers in Benin

UNU-MERIT Dissertation Series, № 37

\section{Müge Ozman}

Networks, Organizations and Knowledge

UNU-MERIT Dissertation Series, № 36

\section{Bas Straathof}

Product Variety and Economic Growth:

The Counteracting Effects of Scale and Idiosyncrasy

UNU-MERIT Dissertation Series, № 35

\section{Wilfred Schoenmakers}

Knowledge Flows between Multinational Companies: A Patent Data Analysis UNU-MERIT Dissertation Series, № 34

\section{Geoffrey Gachino}

Foreign Direct Investment, Spillovers and Innovation: The Case of Kenyan

Manufacturing Industry

UNU-MERIT Dissertation Series, № 41 


\section{Myriam Cloodt}

Mergers and Acquisitions ( $M$ and $A s$ ) in

High-Tech Industries: Measuring the Post-

$M$ and $A$ Innovative Performance of

Companies

UNU-MERIT Dissertation Series, № 33

2004

\section{Paola Criscuolo}

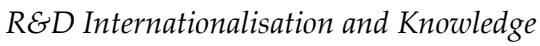

Transfer: Impact on MNEs and their Home

Countries

UNU-MERIT Dissertation Series, № 32

Maarten Verkerk

Trust and Power on the Shop Floor

UNU-MERIT Dissertation Series, № 31

\section{Gottfried Leibbrandt}

Adoption, Harmonization and Succession of Network Technologies across Countries UNU-MERIT Dissertation Series, № 30

\section{Mark Sanders}

Skill Biased Technical change: Its Origins, the Interaction with the Labour Market and Policy Implications

UNU-MERIT Dissertation Series, № 29

2003

\section{Nadine Roijakkers}

Inter-firm Cooperation in High-tech Industries: a Study of RED Partnerships in Pharmaceutical Biotechnology

UNU-MERIT Dissertation Series, № 28

\section{Viki Sonntag}

Speed, Scale and Sustainability

UNU-MERIT Dissertation Series, № 27

\section{Masaru Yarime}

From End-of-Pipe Technology to Clean

Technology

UNU-MERIT Dissertation Series, № 26

\section{Stéphane Malo}

The Combinatorial Chemistry Revolution:

Sustaining a Superior Performance

Position through Technological Learning

UNU-MERIT Dissertation Series, № 25

2002

\section{Annelies Hogenbirk}

Determinants of Inward Foreign Direct Investment: the Case of the Netherlands

UNU-MERIT Dissertation Series, № 24

\section{Bastiaan Johan terWeel}

The Computerization of the Labour Market UNU-MERIT Dissertation Series

2001

\section{John Adeoti}

Technology Investment in Pollution Control in Sub-Saharan Africa: The Case of the Nigerian Manufacturing Industry UNU-MERIT Dissertation Series, № 23

\section{Edward Huizenga}

Innovation Management: How

Frontrunners Stay Ahead: An Empirical

Study on Key Success Factors in the ICT sector

UNU-MERIT Dissertation Series, № 22

\section{0}

\section{Machiel van Dijk}

Technological Change and the Dynamics of Industries: Theoretical Issues and

Empirical evidence from Dutch

Manufacturing

UNU-MERIT Dissertation Series, № 21 
1999

\section{Jan Cobbenhagen}

Managing Innovation at the Company Level: A Study on Non-Sector-Specific

Success Factors

UNU-MERIT Dissertation Series, № 20

\section{Marjolein Caniëls}

Regional Growth Differentials: The Impact of Locally Bounded Knowledge Spillovers

UNU-MERIT Dissertation Series, № 19

1998

\section{Aldo Geuna}

Resource Allocation and Knowledge

production: Studies in the Economics of

University Research

UNU-MERIT Dissertation Series, № 18

1996

\section{Reinoud Joosten}

Dynamics, Equilibria, and Values

UNU-MERIT Dissertation Series, № 17

\section{Hugo Kruiniger}

Investment, $R \mathcal{E} D$, and the Financing

Decisions of the Firm

UNU-MERIT Dissertation Series, № 16

1995

\section{Hans van Meijl}

Endogenous Technological Change: The

Case of Information Technology,

Theoretical Considerations and Empirical Results

UNU-MERIT Dissertation Series, № 15

\section{René Kemp}

Environmental Policy and Technical

Change: A Comparison of the Technological Impact of Policy Instruments

UNU-MERIT Dissertation Series, № 14

\section{Rohini Acharya}

The Impact of New Technologies on

Economic Growth and Trade: A Case Study

of Biotechnology

UNU-MERIT Dissertation Series, № 13

\section{Geert Duysters}

The Evolution of Complex Industrial

Systems: The Dynamics of Major IT

Sectors

UNU-MERIT Dissertation Series, № 12

\section{Marjan Groen}

Technology, Work and Organisation: A

Study of the Nursing Process in Intensive

Care Units

UNU-MERIT Dissertation Series, № 11

1994

\section{Huub Meijers}

On the Diffusion of Technologies in a Vintage Framework: Theoretical Considerations and Empirical Results UNU-MERIT Dissertation Series, № 10

\section{Theon van Dijk}

The Limits of Patent Protection: Essays on the Economics of Intellectual Property

Rights

UNU-MERIT Dissertation Series, № 9

\section{Hans Voordijk}

Naar Integrale Logistiek in Bedrijfsketens: Ontwikkelingen in de Bouw

UNU-MERIT Dissertation Series, № 8 


\section{Paul Diederen}

Technological Progress in Enterprises and Diffusion of Innovation: Theoretical Reflections and Empirical Evidence UNU-MERIT Dissertation Series, № 7

\section{Ben Dankbaar}

Economic Crisis and Institutional Change: The Crisis of Fordism from the Perspective of the Automobile Industry

UNU-MERIT Dissertation Series, № 6

\section{Hanno Roberts}

Accountability and Responsibility: The Influence of Organisation Design on Management Accounting

UNU-MERIT Dissertation Series, № 5

\section{John Hagedoorn}

Evolutionary and Heterodox Innovation Analysis: A Study of Industrial and Technological Development in Process Control and Information Technology UNU-MERIT Dissertation Series, № 1

1992

\section{Bart Verspagen}

Uneven Growth between Interdependent Economies: An Evolutionary View on Technology Gaps, Trade and Growth UNU-MERIT Dissertation Series, № 4

\section{Sjoerd Romme}

A Self-organization Perspective on Strategy

Formation

UNU-MERIT Dissertation Series, № 3

1989

\section{John Spangenberg}

Economies of Scale, and Atmosphere in

Research Organisations

UNU-MERIT Dissertation Series, № 2 